\title{
BALANÇO DE ENERGIA E EVAPOTRANSPIRAÇÃO DE CAFEZAL ADENSADO EM CRESCIMENTO SOB IRRIGAÇÃO LOCALIZADA
}

\author{
EVANDRO ZANINI RighI
}

Tese apresentada à Escola Superior de Agricultura "Luiz de Queiroz", Universidade de São Paulo, para obtenção do título de Doutor em Agronomia, área de concentração: Física do Ambiente Agrícola.

P I R A C I C A B A

Estado de São Paulo - Brasil

Novembro - 2004 


\title{
BALANÇO DE ENERGIA E EVAPOTRANSPIRAÇÃO DE CAFEZAL ADENSADO EM CRESCIMENTO SOB IRRIGAÇÃO LOCALIZADA
}

\author{
EVANDRO ZANINI RIGHI
}

Engenheiro Agrônomo

Orientador: Prof. Dr. LUIZ ROBERTO ANGELOCCI

Tese apresentada à Escola Superior de Agricultura "Luiz de Queiroz", Universidade de São Paulo, para obtenção do título de Doutor em Agronomia, área de concentração: Física do Ambiente Agrícola.

P I R A C I C A B A

Estado de São Paulo - Brasil

Novembro - 2004 
Dados Internacionais de Catalogação na Publicação (CIP) DIVISÃO DE BIBLIOTECA E DOCUMENTAÇÃO - ESALQ/USP

\section{Righi, Evandro Zanini}

Balanço de energia e evapotranspiração de cafezal adensado em crescimento sob irrigação localizada / Evandro Zanini Righi. - - Piracicaba, 2004.

151 p. : il.

Tese (Doutorado) - - Escola Superior de Agricultura Luiz de Queiroz, 2004. Bibliografia.

1. Balanço de energia 2. Café 3. Evapotranspiração 4. Irrigação localizada 5. Micrometeorologia I. Título

CDD 633.73 
"Qual será o absurdo de hoje que será a verdade de amanhã?"

(Alfred North Whitehead)

\section{DEDICO}

Aos meus pais, Benjamin José Righi e Santina Zanini Righi.

À minha irmã Mariane e ao meu sobrinho João Victor. 


\section{AGRADECIMENTOS}

A Deus.

Aos meus pais, Benjamim J. Righi e Santina Z. Righi, que desde minha iniciação estudantil me deram liberdade e imensurável incentivo e apoio. Dedicação, honestidade, trabalho, respeito..., foi o que me ensinaram. Esse trabalho pertence a eles também. Muito obrigado.

Ao prof. Luiz R. Angelocci, pela orientação, pela amizade, pelos inestimáveis ensinamentos científicos e de conduta. Muito Obrigado.

Aos meus tios e primos, pelo apoio e por estarem sempre presentes em momentos de dificuldades. Em especial, à tia Maria L. Zanini e ao Geronimo, e a meu primo e amigo Everton Z. Rorato, que depositou uma grande confiança em mim e sempre me incentivou, sendo, para mim, uma referência.

Aos amigos e colegas de "republica" Alailson Santiago e Gustavo Lyra, que além do incentivo, em diversas situações foram conselheiros, e sempre estiveram presentes nos momentos de euforia e, principalmente, nos momentos de dificuldade. Especialmente ao Gustavo, pelas discussões "turbulentas" e valiosas opiniões que deixaram marcas qualitativas no trabalho.

Ao amigo Fabio Marin, pelas idéias e valiosas opiniões, principalmente no início do trabalho, com ajuda na instalação do experimento, contribuindo com seu conhecimento, experiência, ânimo e exemplar força de vontade. À sua esposa Michelle, pela amizade, e pela alegria do Andresinho e do Pedrinho. 
Ao amigo Jesus Ocariz, que sempre se pôs à disposição a contribuir e foi fundamental no experimento de campo, e com muito ânimo. À sua esposa Beatriz Lozada, que além da amizade, foi compreensiva com as ausências de Jesus e a roupa "vermelha" ao final dos dias de campo.

Aos amigos Rafael Ribeiro e Antonio Baptista, pelas horas de conversas descontraídas e exemplos de profissionalismo.

Aos amigos Rogério Cichota, Felipe Pilau e Reinaldo Bonnicarrere, pelas boas risadas em momentos de descontração e a ajuda na coleta e processamento dos dados.

Ao Ciro A. Righi, pela amizade e a ajuda em mutirões na coleta dos dados de campo.

Aos demais professores do Depto. de Ciências Exatas, em especial ao Nilson Villa Nova e ao Paulo Sentelhas, que muitas vezes contribuíram com sugestões a respeito do trabalho e com grande incentivo.

À UFSM, em especial aos professores do Depto. de Fitotecnia, por terem me lançado na Agrometeorologia e pela saudosa amizade.

A CAPES, por ser o órgão fomentador de minha bolsa.

À FAPESP, pelo apoio financeiro à realização dos experimentos.

Aos funcionários do Depto. de Ciências Exatas e do Depto. de Produção Vegetal, especialmente à Solange Sabadin, ao Edivaldo M. Abreu, ao Francisco B. Dias e ao Edson Teramoto, pelo apoio.

A todos os que tiveram participação na elaboração deste trabalho.

A todos os amigos, que mesmo à distância ou no passado contribuíram na minha formação pessoal.

MUITO OBRIGADO!! 


\section{SUMÁRIO}

Página

LISTA DE FIGURAS ................................................................................. viii

LISTA DE TABELAS ............................................................................. xii

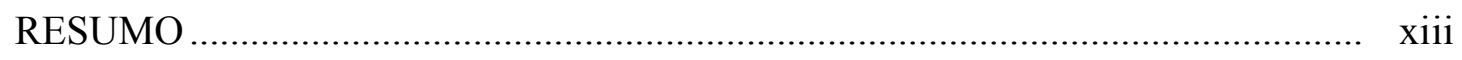

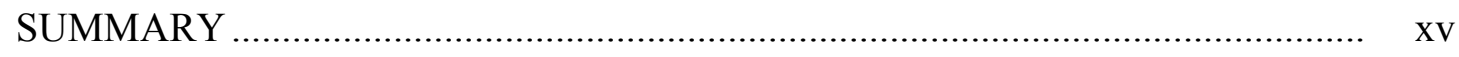

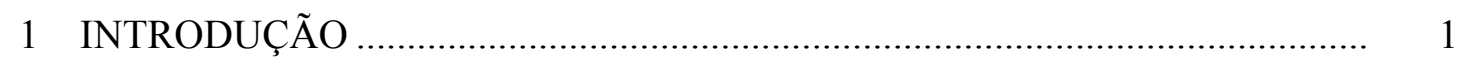

2 REVISÃO DE LITERATURA …............................................................... 3

2.1 Determinação dos fluxos verticais de energia em escala micrometeorológica... 3

2.1.1 Camada limite superficial ....................................................................... 3

2.1.2 Determinação dos fluxos de calor latente e sensível........................................ 6

2.1.2.1 Método aerodinâmico.................................................................................... 7

2.1.2.2 Método do balanço de energia - razão de Bowen......................................... 13

2.2 Determinação da transpiração pela medida do fluxo de seiva............................ 16

2.3 Determinação da evapotranspiração por lisimetria............................................. 19

2.4 Consumo de água da cultura do café.............................................................. 23

3 MATERIAL E MÉTODOS _...................................................................... 29

3.1 Descrição do cafezal ................................................................................ 29

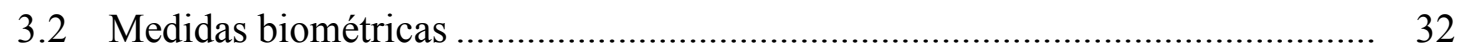

3.3 Determinação dos perfis de velocidade do vento, de temperatura e de umidade 34

3.4 Determinação do saldo de radiação da cobertura vegetal e do fluxo de calor no

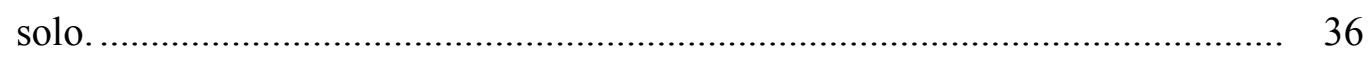

3.5 Determinação lisimétrica da evapotranspiração dos cafeeiros e das entrelinhas. 37

3.6 Determinação do fluxo de seiva (transpiração) dos cafeeiros............................ 42 
3.7 Armazenamento e processamento dos dados .................................................. 47

3.8 Determinação da evapotranspiração da cultura e de referência .......................... 47

4 RESULTADOS E DISCUSSÃO ................................................................... 55

4.1 Caracterização das condições ambientais durante o experimento ...................... 55

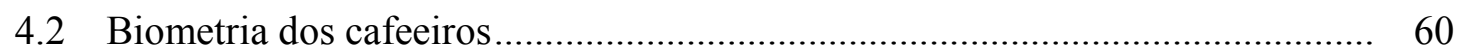

4.3 Evapotranspiração do cafezal..................................................................... 62

4.3.1 Efeito das condições de "bordadura" ......................................................... 62

4.3.2 Determinação do deslocamento do plano zero (d) e da altura de rugosidade

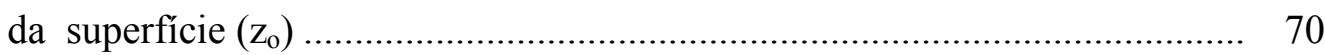

4.3.3 Análise da qualidade dos dados dos gradientes de temperatura e umidade.... 83

4.3.4 Comparação entre as estimativas de LE pelo MRB e pelo MA....................... 92

4.3.5 Partição da energia disponível na superfície................................................... 101

4.4 Partição da evapotranspiração ........................................................................ 109

4.4.1 Relações entre fluxo de seiva, evapotranspiração lisimétrica e variáveis ambientais; análise do desempenho dos lisímetros e dos sensores de fluxo de seiva

4.4.2 Componentes da evapotranspiração do cafezal.............................................. 117

4.4.3 Coeficientes de cultura .......................................................................... 121

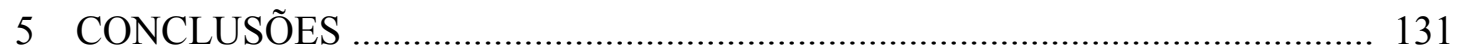

REFERÊNCIAS BIBLIOGRÁFICAS.............................................................. 133 


\section{LISTA DE FIGURAS}

Página

1 Representação da área experimental, juntamente com a evolução temporal da altura da cobertura da entrelinha.

2 Visualização do mastro micrometeorológico com os anemômetros, psicrômetros e os respectivos níveis de instalação, e o saldo radiômetro e da disposição dos mastros M1 e M2

3 Visualização dos lisímetros $L 1$ e $L 2$ em relação ao mastro M1 e o sistema de aquisição de dados e do sistema de pesagem e drenagem

4 Localização de quatro dos cinco minilisímetros e o sistema de suspensão para pesagem dos mesmos

5 Esquema dos sensores de fluxo de seiva

6 Seqüência de fotos mostrando as etapas de instalação dos sensores de fluxo de seiva

7 Extrato do balanço hídrico mensal normal $(1961$ - 1990) para Piracicaba e a temperatura normal 56

8 Balanço hídrico seqüencial qüinqüidial 57

9 Evolução dos valores médios diários do déficit de pressão de saturação de vapor no ar, da temperatura do ar, da velocidade do vento a $2 \mathrm{~m}$ do solo e do saldo de radiação acumulada diária $(R n)$ obtidos na estação meteorológica

10 Evolução biométrica média dos cafeeiros com o número de dias após o transplante

11 Relação entre a razão dos gradientes de temperatura e pressão de vapor no ar considerando-se os níveis $4-1$ e $3-1$. 
12 Relação entre a razão dos gradientes de temperatura e de pressão de vapor no ar considerando-se os níveis $4-1$ e $3-1$ : caso 1 , caso 2 e caso 3

13 Relação entre a razão dos gradientes de temperatura e da pressão de vapor no ar considerando-se os níveis $4-1$ e 3 - 1, no período de 17/05/03 a 22/07/03, referentes aos momentos com direção do vento dentro e fora dos limites de $40^{\circ}$ a $100^{\circ}$

14 Distribuição dos valores de velocidade do vento no nível 3 e do deslocamento do plano zero, determinado para os níveis $2-5$, de acordo com a direção do vento, antes da inversão dos anemômetros entre os níveis 1 e 2 e após a inversão.

15 Distribuição dos valores "utilizáveis" do deslocamento do plano zero e da altura de rugosidade nos períodos de maio - julho e agosto - setembro de 2003

16 Relação entre a velocidade do vento estimada no nível pela Equação 7 a partir dos valores da velocidade característica da cobertura, dos valores médios do deslocamento do plano zero e do comprimento de rugosidade com os valores medidos

17 Relação entre os fluxos de calor latente determinados pelo método do balanço de energia - razão de Bowen entre os níveis 4 e 1 e 3 e 1

18 Relação entre os fluxos de calor sensível determinados pelo método do balanço de energia - razão de Bowen entre os níveis 4 e 1, e 3 e 1

19 Perfis da temperatura potencial e da razão de mistura para um dia úmido (20/02/03), um dia seco no período úmido (01/03/03) e um dia seco no período $\operatorname{seco}(08 / 07 / 03)$

20 Perfis de temperatura potencial e da razão de mistura a partir das medidas nos mastros M1 e M2 ao longo dos dias 30/08/03 e 07/09/03

21 Relação entre os valores dos fluxos de calor latente e sensível determinados pelo método do balanço de energia - razão de Bowen com os dados dos mastros M1 e M2

22 Relação entre os fluxos de calor latente determinados pelo método aerodinâmico com aqueles determinados pelo método do balanço de energia - razão de Bowen e a energia disponível aos fluxos referente ao mesmo período do dia. 
23 Relação entre a razão do fluxo de calor latente determinados pelo método aerodinâmico com a energia disponível e o gradiente médio de pressão de vapor no ar

24 Variação dos gradientes de pressão de vapor, de temperatura do ar e de velocidade do vento entre os níveis 3 e 1, juntamente com o número de Richardson, com a precipitação e com a temperatura potencial medida no nível 3, no período de outubro - dezembro de 2002

25 Evolução diária das razões dos fluxos de calor latente e sensível determinados pelo método aerodinâmico com a energia disponível na superfície, da precipitação e dos valores médios entre 9:00 h e 16:00 h do número de Richardson e do gradiente de pressão de vapor entre os níveis 3 e 1

26 Variação dos gradientes de pressão de vapor, da temperatura do ar e da velocidade do vento entre os níveis 3 e 1, juntamente com o número de Richardson, a precipitação e a temperatura potencial medida no nível 3, no período de fevereiro - março de 2003

27 Variação da energia disponível no ambiente juntamente com as componentes fluxo de calor latente e calor sensível e a razão, no período entre os dias 50 $(19 / 02 / 03)$ e $59(28 / 02 / 03)$

28 Variação dos valores diários da energia disponível, dos fluxos de calor latente e sensível, da precipitação e da razão de Bowen

29 Relação entre os valores dos fluxos de calor latente entre os níveis 3 e 1 e a energia disponível

30 Valores das incertezas relativas do fluxo de calor latente médias do período entre 9:00 h e 16:00 h observadas nos dias "utilizáveis".

31 Evolução ao longo do dia 07/03/03 da energia disponível, do fluxo de calor latente e seus erros relativos e absolutos e do erro relativo na razão de Bowen...... 109

32 Relação entre os valores diários do fluxo de seiva normalizados pela área foliar e determinados concomitantemente em duas plantas em 2002 e fevereiro - março com sensores SGB16 e agosto - setembro de 2003 com sensores SGB25 
33 Evolução do fluxo de seiva normalizado pela área foliar nas plantas 1,2 , 3, e 4 em função do saldo de radiação e do déficit de saturação do ar no nível 3

34 Evolução do saldo de radiação, do déficit de pressão de saturação de vapor no ar e das determinações do fluxo de seiva nas plantas 5 e 6 e nas plantas 1 e 2, juntamente com a variação de peso lisimétrico

35 Variação diária da transpiração da planta e da evapotranspiração no lisímetro 2 e sua razão porcentual, juntamente com a precipitação e o saldo de radiação acumulado no período de 24 horas

36 Relação entre a evapotranspiração do renque normalizado pela área total disponível para cada cafeeiro e pela área do renque disponível para cada cafeeiro e a evapotranspiração da cultura

37 Flutuação dos valores do coeficiente de cultura, coeficiente de evapotranspiração do renque e da precipitação.

38 Relação entre os valores do coeficiente de cultura e a freqüência relativa de ocorrência de vento transversal aos renques de cafeeiros entre 9:00 h e 16:00 h nos períodos de maio - julho e agosto - setembro de 2003 


\section{LISTA DE TABELAS}

Página

1 Nível dos psicrômetros e anemômetros durante as campanhas de coleta de dados... 36

2 Diâmetro de copa, altura das plantas, número de folhas e área foliar do cafezal utilizados como referência para cada período.

3 Valores do deslocamento do plano zero, da altura de rugosidade, de seus respectivos desvio-padrão, da velocidade característica do escoamento e do número de dados considerados, para os períodos mensais, diferentes alturas da cobertura da entrelinha e para todos os dados, nos respectivos períodos de coleta de dados

4 Valores médios do deslocamento do plano zero, do comprimento de rugosidade da superfície, da velocidade característica do escoamento e da velocidade média do vento em faixas de direção do vento variando de $0^{\circ}$ a $30^{\circ}$, de 30 a $60^{\circ}$ e $60^{\circ}$ a $90^{\circ}$.

5 Relação do deslocamento do plano zero e da altura da rugosidade com a altura média dos cafeeiros

6 Valores médios por período da evapotranspiração do cafezal, do renque e de referência, dos coeficientes de cultura e do coeficiente de evapotranspiração do renque de cafeeiros, juntamente com o índice de área foliar médio do cafezal no respectivo período. 


\title{
BALANÇO DE ENERGIA E EVAPOTRANSPIRAÇÃO DE CAFEZAL ADENSADO EM CRESCIMENTO SOB IRRIGAÇÃO LOCALIZADA
}

\author{
Autor: EVANDRO ZANINI RIGHI \\ Orientador: Prof. Dr. LUIZ ROBERTO ANGELOCCI
}

\section{RESUMO}

Foram determinadas as taxas de evapotranspiração global $(E T c)$ e sua partição em evapotranspiração dos renques e das entrelinhas, bem como a partição da energia disponível em calores sensível e latente de um cafezal adensado (3,50m x 0,90m), irrigado por gotejamento, durante o período de 1 a 2 anos após sua implantação, em Piracicaba, SP. Foram utilizados os métodos do balanço de energia-razão de Bowen (MRB) e aerodinâmico (MA) para a determinação de ETc, o método lisimétrico para a evapotranspiração dos renques e o método do balanço de calor no caule para a transpiração a partir do fluxo de seiva. No uso do MA, foram verificados vários problemas. Um deles, é o aumento inicial pequeno do "deslocamento do plano zero" (d) normalizado pela altura da cultura, ter sido seguido por um decréscimo teoricamente inconsistente com o aumento da altura dos cafeeiros, além de uma grande variação do comprimento de rugosidade $\left(z_{o}\right)$, dependente das condições de cobertura das entrelinhas, da direção e da velocidade do vento, sendo evidenciado efeito dessas últimas duas variáveis também sobre $d$. Provavelmente, a maior fonte de erro para o MA foi terem os coeficientes de transporte turbulento, determinados com as funções empíricas do número de Richardson de estabilidade atmosférica, válidas para a subcamada atmosférica inercial e superfícies homogêneas, mostrado-se inadequados para as condições do 
estudo, resultando em valores irreais de ETc. As estimativas pelo MRB foram satisfatórias, por ter ocorrido boa similaridade entre os perfis de temperatura e de pressão de vapor do ar, indicando que a razão entre os coeficientes de difusão turbulenta para calor sensível e latente se manteve próxima de 1 . Durante o período seco, grande parte dos dias tiveram as determinações de ETc pelo MRB comprometidas, devido aos pequenos gradientes de pressão de vapor e aos erros causados pelos sensores dos psicrômetros. O fluxo de calor latente do cafezal correspondeu a mais de $80 \%$ da energia disponível no período úmido, diminuindo para valores da ordem de $64 \%$ no período seco. Os valores do coeficiente "global" de cultura (razão entre ETc e a evapotranspiração de referência (ETo)), variaram entre 1,04 e 1,30, sendo altamente dependentes das condições de umidade do solo. No último período de medida, o valor de aproximadamente 0,86 deve ser tomado com ressalvas devido a problemas de manejo da área. O "coeficiente de evapotranspiração do renque", sendo a razão entre a evapotranspiração do renque (evaporação do solo da área contínua sob as copas mais a transpiração dos cafeeiros) e ETo, variou entre 0,22 e 0,43, sendo influenciado pelas condições de umidade da superfície, especialmente pela área molhada na irrigação, e pelo aumento da área foliar dos cafeeiros. Os valores do coeficiente basal de cultura (razão entre transpiração dos cafeeiros e ETo) variaram de 0,03 a 0,20. Durante o período seco evidenciou-se efeito advectivo sobre as medidas, adotando-se critérios para selecionar dias com tal efeito nulo, ou mínimo, sobre os valores médios dos coeficientes acima. 


\title{
ENERGY BALANCE AND EVAPOTRANSPIRATION IN A HIGH DENSITY YOUNG COFFEE UNDER LOCATED IRRIGATION
}

\author{
Author: EVANDRO ZANINI RIGHI \\ Adviser: Prof. Dr. LUIZ ROBERTO ANGELOCCI
}

\section{SUMMARY}

The objectives of this study were to evaluate the magnitude of global evapotranspiration $(E T c)$ in a high density young coffee crop $(3.5 \mathrm{mx} 0.9 \mathrm{~m})$ under drip irrigation, the ETC partition considering hedgerows and interrows, and the partition of the available radiant energy between sensible and latent heat fluxes. The experiments were conducted from September 2002 to September 2003, in Piracicaba, SP, Brazil. ETc was determined by the Energy balance-Bowen ratio (BRM) and aerodynamic (AM) methods. Hedgerows evapotranspiration was measured by weighing lysimeters and coffee transpiration by the sap flow using the stem heat balance method. When AM was used, several problems were observed. One of them was the "zero plane displacement" (d) normalized by the crop height, which showed an earlier small increase, followed by an unexplained decrease when plant height increased, besides of a huge variation of the roughness length $\left(z_{o}\right)$, which depended on interrows cover conditions and wind direction and speed. Also, the effect of these former was noticed on $d$. Probably, the major source of error in AM was the use of turbulent transport coefficients determined with empirical functions, using the Richardson number, valid for homogeneous surfaces, and measurements taken on the inertial atmospheric sublayer. This procedure proved to be inadequate for the heterogeneous coffee crop surface, resulting in unrealistic ETc values. 
The BRM estimates of ETc were more appropriate, as a consequence of the good similarity between potential temperature and vapor pressure profiles, indicating that the ratio between the turbulent transport coefficients for sensible and latent heat was close to unity. During the dry season, in the majority of the days with measurements, ETc estimates were less effective due the small vapor pressure gradients and the errors caused by the psychrometer sensors. The ratio between global latent heat flux and available surface energy was higher than $80 \%$ in the wet season, decreasing to $64 \%$ when the interrows were drying. The "global" crop coefficient $(K c)$, representing the ratio between ETc and reference evapotranspiration (ETo) ranged from 1.04 to 1.30 , being highly dependent on soil moisture conditions. In the latest period of measurements, $K c$ was about 0.86 , which must be analyzed with care due problems in the coffee crop management. The "hedgerows evapotranspiration coefficient", which means the ratio between hedgerows evapotranspiration (evaporation of continuous soil area under hedgerows plus the crop transpiration) and ETo, ranged from 0.22 to 0.43 , being influenced by soil moisture, especially by the soil surface area wetted by the drip irrigation and by the increase of leaf area. The basal crop coefficient (ratio between transpiration and ETo) ranged from 0.03 to 0.20 . During the dry season, effect of advection on the measurements was observed; so, some criteria were used to select days in which this effect was considered to be null or having a minimum degree, in order to calculate the mean values of the above described coefficients. 


\section{INTRODUÇÃO}

O café é cultivado no Brasil há cerca de três séculos, ao longo dos quais houve uma intensa evolução nos sistemas de cultivo e no surgimento de novos cultivares. A bebida, muito apreciada pelos brasileiros e no mundo inteiro, ultimamente tem recebido atenção por suas qualidades medicinais. Isso torna o café um produto valorizado e de exportação, tendo importante função social, gerando riquezas e empregos, o que faz com que a história do país se confunda, em parte, com a do café e a de seus "barões".

Inicialmente, a produção de café se concentrou na região sudeste, estendendose posteriormente ao extremo norte da região sul, com vastos espaçamentos e cafeeiros com copas amplas. Atualmente, encontram-se lavouras cafeeiras desde o Paraná até o cerrado nordestino, em grande parte consistindo de cultivos adensados e em renques. A expansão para regiões com períodos secos mais intensos tem tornado a irrigação imprescindível para o sucesso da produção, tanto sob o ponto de vista quantitativo, como qualitativo. Mesmo na região sudeste, muitas vezes a produção fica comprometida pela ocorrência de veranicos durante o período úmido ou de floradas antes do período das chuvas se iniciar, tornando a irrigação necessária. Na atual tendência dos cultivos terem a configuração em renques, os produtores têm optado por utilizar sistemas de irrigação localizada, a qual tem maior eficiência de aplicação e disponibiliza a água somente na porção de solo realmente utilizada pela cultura.

Apesar da evidente importância da irrigação e passados praticamente três séculos de cultivo no País, existem poucos estudos sobre as relações hídricas em cafeeiros, tanto fisiológicos, como dos requerimentos hídricos, principalmente durante a fase de crescimento. Embora o desenvolvimento inicial compreenda somente uma pequena fração do período total viável de condução de um cafezal sem renovação, a 
irrigação proporciona um desenvolvimento mais homogêneo, com plantas mais vigorosas e com maior produtividade nas primeiras colheitas.

Nos estudos sobre as relações hídricas nas plantas em nível de campo, é fundamental a caracterização micrometeorológica, determinando-se os parâmetros aerodinâmicos da cobertura e a partição, tanto da utilização da energia, quanto da evapotranspiração, fatores importantes também para o manejo da cultura. As componentes do balanço de energia e da evapotranspiração total (dos renques e das entrelinhas) nesse tipo de cultivo são dependentes do estado da cobertura da entrelinha e do índice de área foliar dos cafeeiros. Especialmente na fase de desenvolvimento inicial, o sistema de irrigação empregado, a configuração de plantio e a cobertura da entrelinha têm relação direta com os valores do coeficiente de cultura e com o balanço de energia da superfície.

Portanto, dada a importância para o País e a carência de estudos sobre as relações hídricas em cafezais em crescimento e superfícies cultivadas com renques, mais a escassez de água anunciada e a busca pela redução de custos de produção, esse trabalho foi realizado a fim de subsidiar pesquisadores e produtores, com informações necessárias para futuras pesquisas e para o manejo da cultura. Desta forma, objetivou-se: 1. estudar os parâmetros aerodinâmicos do cafezal e verificar o desempenho dos métodos micrometeorológicos do balanço de energia - razão de Bowen e aerodinâmico na determinação da evapotranspiração do cafezal;

2. quantificar a partição do saldo de radiação ao longo de um ciclo de crescimento, dividido num período úmido e outro seco;

3. quantificar a partição da evapotranspiração do cafezal nas componentes referentes aos renques e às entrelinhas;

4. determinar os coeficientes de cultura ao longo dos períodos de estudo. 


\section{REVISÃO DE LITERATURA}

\subsection{Determinação dos fluxos verticais de energia em escala micrometeorológica}

\subsubsection{Camada limite superficial}

A superfície terrestre é composta por um mosaico de diferentes tipos e formas de cobertura, desde oceanos até florestas. Este mosaico acaba gerando ilhas de maior aquecimento, que associadas a sazonalidade da incidência de energia solar acabam por induzir o movimento do ar.

Uma parcela de ar tende a entrar em equilíbrio de condições com a superfície sobre a qual ela se desloca através das trocas de massa e energia. Dependendo da extensão da área na direção do vento e da altura na atmosfera, os fluxos são influenciados principalmente pelas condições locais, estabelecendo a camada limite superficial interna, ou, simplesmente, camada limite interna, que, devido a essas misturas, é composta por uma camada da atmosfera onde as taxas de fluxo das propriedades do ar são constantes com a altura e, acima desta, uma camada de transição, ou mista. É justamente na camada de fluxo constante, ou em suficiente equilíbrio com a superfície, onde se desenvolvem os estudos micrometeorológicos.

Dada a dinâmica atmosférica, a existência quase que constante de ventos e os movimentos de ascensão devido às forças térmicas, e aos processos de difusão, as propriedades de uma parcela de ar estão sempre com suas quantidades oscilantes. Como a superfície é a fonte ou o dreno de energia e momento, há a formação de gradientes verticais dessas propriedades, que são a base para os estudos micrometeorológicos baseados nas teorias da relação fluxogradiente. O fluxo de uma propriedade atmosférica $Y$ pode, então, ser descrito conforme a Equação 1: 


$$
Y=C \cdot \frac{\partial y}{\partial z}
$$

em que $C$ é um fator de proporcionalidade e $\partial y / \partial z$ é o gradiente vertical da propriedade em questão.

Devido à rugosidade superficial, a movimentação do ar nas camadas inferiores da atmosfera sofre uma força de atrito em sentido contrário ao movimento do vento, reduzindo sua velocidade e promovendo a formação de turbilhões. Os turbilhões deslocam as parcelas de ar horizontal e verticalmente, ascendendo propriedades que estão em maior concentração próximo à superfície e trazendo outras que são mais abundantes nos níveis superiores.

Normalmente, ao longo do período diurno, parte da energia radiante é absorvida e transformada na superfície, resultando no saldo de radiação $(R n)$, que se decompõe entre os processos de fluxo de calor no solo $(G)$, aquecimento superficial, evaporação, fotossíntese e armazenamento de energia no solo, na água e na biomassa vegetal. Assim, a superfície passa a ser fonte de calor sensível $(H)$ e de vapor d'água $(L E)$, os principais objetos de estudo neste trabalho. Durante a noite, o resfriamento radiativo da superfície pode resultar na inversão dos perfis na atmosfera, invertendo o sentido dos fluxos, como no caso da formação do orvalho.

A maior espessura da camada limite interna é dada pela camada de transição, onde as propriedades são referentes às superfícies a barlavento e à estudada. Abaixo da camada de transição, encontra-se a camada em equilíbrio com a superfície, onde os fluxos são constantes e particulares às condições locais. A espessura dessas camadas é dependente da velocidade do vento, da rugosidade da superfície estudada e do regime de turbulência a barlavento, e aumenta com a distância percorrida sobre uma superfície uniformemente rugosa numa determinada direção, definindo o termo "fetch" (Monteith \& Unsworth, 1990), o qual será referido no texto como "bordadura", expressando a distância percorrida na direção do vento por uma parcela de ar sobre a área de interesse. Essa nova camada de equilíbrio ainda pode ser dividida em uma subcamada inercial e, sob esta, uma rugosa, a qual é influenciada por fatores como estrutura e geometria dos elementos de rugosidade (plantas em coberturas vegetadas), espaçamento etc. 
Essa descrição geral das camadas atmosféricas superficiais foi obtida de Rosemberg et al. (1983), Brutsaert (1984), Oke (1987), Monteith \& Unsworth (1990), Stull (1994) e Pereira (1998), onde essas particularidades são exaustivamente discutidas.

Embora a falta de uma camada suficientemente equilibrada com a superfície possa ser contornada através de correções ou por medida dos gradientes horizontais da propriedade de interesse (Lang, 1973; Brakke et al., 1978; Verma et al., 1978; Angus \& Watts, 1984), as dificuldades operacionais, instrumentais e até mesmo teóricas desses procedimentos, tornam favorável a determinação dos fluxos dentro da camada de equilíbrio. Desta forma, o local e a disposição dos equipamentos de medida dentro da área experimental dependem do tipo da superfície e da "bordadura" e deve ser objeto de atenção na definição da altura de medida e do posicionamento do instrumental na área. A espessura da camada atmosférica em equilíbrio com a superfície aumenta lentamente na direção do vento a partir da transição entre duas diferentes áreas, sendo este aumento mais intenso em superfícies mais rugosas. Conforme a Equação 2 (Munro \& Oke, 1975), a altura da camada limite de equilíbrio, ou camada limite interna ajustada, $(\delta)$ é função da rugosidade da superfície $\left(z_{o}\right)$ e do tamanho da "bordadura" $(x)$, e corresponde a cerca de $10 \%$ da camada limite interna:

$$
\delta=0,1 \cdot z_{\mathrm{o}}^{0,2} \cdot x^{0,8}
$$

Conforme Munro \& Oke (1975), para superfícies com comprimento de rugosidade $z_{\mathrm{o}}$ entre $10^{-2} \mathrm{~m}$ e $10^{-1} \mathrm{~m}$ em condições de atmosfera próximas da neutralidade, a proporção $\delta: x$ pode ser estabelecida entre 1:60 e 1:40.

Pereira (1998) comenta que muitos autores têm utilizado a relação $\delta: x=1: 50$ como regra básica, salientando, porém, que quando o vento se desloca de uma superfície rugosa para uma mais lisa (menor $z_{o}$ ), ele sofre uma aceleração, sendo adequado considerar a relação 1:70. Ao contrário, quando o vento flui de uma superfície lisa para uma mais rugosa, a sua desaceleração faz com que $\delta$ aumente com maior intensidade com o aumento da "bordadura", sendo suficiente $\delta: x=1: 20$. Heilman et al. (1989) estudaram a transição de uma superfície rugosa para uma mais lisa (algodoal - gramado) e concluíram que pode ser considerado $\delta: x$ de 1:20 para a determinação da razão de 
Bowen, condição de "bordadura" consideravelmente inferior ao 1:70. Os autores justificam essa diferença em relação aos valores de "bordadura" comumente utilizados e aqueles baseados no trabalho de Munro \& Oke (1975) pelo efeito da instabilidade, a qual tende a aumentar a camada de equilíbrio. No entanto, Rosemberg et al. (1983) recomendam utilizar a razão 1:100 para se ter garantia que as áreas adjacentes não estão interferindo nas medidas quando se trabalha com culturas agrícolas $\left(10^{-2} \mathrm{~m}<z_{\mathrm{o}}<10^{0}\right.$ m). Entretanto, em cultivos irrigados contornados por áreas secas, tem-se mostrado que esses valores de "bordadura" são insuficientes, como no caso de McNaughton \& Laubach (1998), que identificaram advecção de calor sensível utilizando $\delta: x=1: 250$.

Na prática deve-se buscar "bordadura" tão grande quanto possível, mas diante das dificuldades normalmente encontradas em obter áreas suficientemente amplas, podese adotar uma relação de $\delta: x=1: 50$ (Pereira, 1998), desde que se evite a utilização de dados afetados pela advecção.

\subsubsection{Determinação dos fluxos de calor latente e sensivel}

Os métodos micrometeorológicos mais comuns para determinação dos fluxos de calor latente $L E$ e sensível $H$ são: o método da correlação de turbilhões, o método aerodinâmico e o método do balanço de energia - razão Bowen (Oke, 1987; Monteith \& Unsworth, 1990; Pereira et al., 1997). Desses, o método de correlação de turbilhões é o único capaz de medir diretamente os fluxos na atmosfera, enquanto que os outros dois produzem estimativas a partir dos gradientes verticais das propriedades. Porém, o método de correlação de turbilhões requer instrumentação específica, como anemômetro sônico, higrômetro e termômetro de rápida resposta e um sistema de aquisição de dados capaz de realizar medidas em altas freqüências. É evidente que a operacionalização do método em condições de campo é complicada e os sensores são caros, problemas de ordem prática são comuns em condições de campo, especialmente os relacionados à condensação de água sobre as partes sensoras e à ação de insetos (Redford et al., 1980; Dugas et al, 1991; Pereira, 1998; Rana \& Katerji, 2000). 
Por essas razões, o método do balanço de energia - razão de Bowen (MRB) e o método aerodinâmico (MA) são mais difundidos no meio científico e foram utilizados neste trabalho, sendo discutidos a seguir.

\subsubsection{Método aerodinâmico}

$\mathrm{Na}$ atmosfera turbulenta, o fluxo de momento é o mais importante a ser determinado, pois todos os outros fluxos são dependentes das características do escoamento (Pereira, 1998). Conforme Pereira (1998), como o transporte das propriedades atmosféricas é feito pelos turbilhões que se movem aleatoriamente na atmosfera, espera-se que todas as propriedades se desloquem igualmente, podendo-se estabelecer a igualdade entre os diferentes coeficientes de transporte, em que se fundamenta a hipótese da similaridade. Devido à dificuldade de se medir diretamente os fluxos verticais com precisão, sem a necessidade de instrumentos complexos, como ocorre no caso da correlação de turbilhões, no MA busca-se determinar os fluxos a partir de medidas da velocidade horizontal do vento.

Quando existe equilíbrio entre as forças térmicas e mecânicas, dado pelo número de Richardson $(R i)$ igual a zero, considera-se que a atmosfera encontra-se em condições de estabilidade neutra (Pereira, 1998). Assim, as flutuações instantâneas da velocidade do ar horizontal $u$ ' são iguais às verticais $w^{\prime}$, podendo-se estabelecer a relação $u^{*}=\left(u^{\prime} \cdot w^{\prime}\right)^{0,5}=u^{\prime}$, sendo $u^{*}$ a velocidade característica do escoamento (Monteith \& Unsworth, 1990). Sendo assim, a partir do perfil logarítmico do vento pode-se estabelecer a relação (Monteith \& Unsworth, 1990; Pereira, 1998):

$$
u=\left(\frac{u^{*}}{k}\right) \cdot \ln \left[\frac{(z-d)}{z_{o}}\right]
$$

em que $u$ é a velocidade média do vento num determinado período e na altura $z, k$ é a constante de von Kárman $(=0,41), d$ é o deslocamento do plano zero e $z_{o}$ é a altura da rugosidade.

No entanto, quando as forças térmicas são predominantes no turbilhonamento (atmosfera instável; $R i<0$ ) ou quando elas são suprimidas (atmosfera estável; $R i>0$ ), as 
velocidades $u^{\prime}$ e $w^{\prime}$ são diferentes, e $u^{*} \neq u^{\prime}$ (Monteith \& Unsworth, 1990). Nessas condições, o cálculo dos fluxos das propriedades não é mais diretamente relacionado a u', necessitando de correções de estabilidade para a validade das relações logarítmicas entre $u$ e $z$ (Monteith \& Unsworth, 1990):

$$
\begin{aligned}
\frac{\partial u}{\partial z} & =\frac{u^{*}}{k \cdot(z-d)} \cdot \phi_{m} \\
K_{m} & =k \cdot u^{*} \cdot(z-d) \cdot \phi_{m}{ }^{-1}
\end{aligned}
$$

sendo $\partial u / \partial z$ o gradiente de velocidade do vento, $K_{m}$ o coeficiente de transporte turbulento para momento e $\phi_{m}$ a função de estabilidade atmosférica. Similarmente, para o transporte de vapor e calor sensível, tem-se (Dyer, 1974):

$$
\begin{aligned}
\frac{\partial q}{\partial z} & =\frac{L E}{\rho \cdot L \cdot k \cdot u^{*} \cdot(z-d)} \cdot \phi_{w} \\
K_{w} & =k \cdot u^{*} \cdot(z-d) \cdot \phi_{w}{ }^{-1} \\
\frac{\partial \theta}{\partial z} & =\frac{H}{\rho \cdot c p \cdot k \cdot u^{*} \cdot(z-d)} \cdot \phi_{h} \\
K_{h} & =k \cdot u^{*} \cdot(z-d) \cdot \phi_{h}{ }^{-1}
\end{aligned}
$$

sendo, respectivamente: $\partial \theta / \partial z$ e $\partial q / \partial z$, os gradientes de temperatura potencial e umidade específica no ar; $K_{h}$ e $K_{w}$, os coeficientes de transporte turbulento para calor sensível e latente; $\phi_{h}$ e $\phi_{w}$, as funções de estabilidade atmosférica para os fluxos de calor sensível e latente. As demais variáveis são: $\rho$ a densidade do ar, $c p$ o calor específico do ar e $L$ o calor latente de evaporação. O sinal negativo é convencionado nas Equações 6 e 8 para resultar em $H$ e $L E$ positivos quando forem na direção superfície - atmosfera.

Businger et al. (1971), Dyer (1967; 1974), Dyer \& Hicks (1970) e Webb (1970) propuseram equações de correção $\phi$ para as condições de estabilidade atmosférica. Na neutralidade, pela hipótese da similaridade, esta função é igual a 1, sendo menor que 1 na instabilidade e maior na estabilidade. Dyer $(1967$; 1974) e Dyer \& Hicks (1970) verificaram que em condições de instabilidade atmosférica os coeficientes de transporte turbulento $K_{h}$ e $K_{w}$ são iguais, mas diferentes de $K_{m}$. Webb (1970) encontrou evidências que numa faixa próxima da neutralidade em direção da estabilidade $(-0,03<R i<1)$ 
pode-se considerar que todos os coeficientes são iguais, isto é, $K_{w}=K_{h}=K_{m}$. No entanto, as dificuldades teórica e prática para obtenção de dados confiáveis fazem com que este seja um assunto de discussão. Pruitt et al. (1973) propuseram uma relação em que $K_{w}$ foi $13 \%$ maior que $K_{m}$ em condição de neutralidade e estabilidade atmosférica. Porém, Lo \& McBean (1978) verificaram que as relações apresentadas por Dyer (1967; 1974); Dyer \& Hicks (1970) e Webb (1970) são mais confiáveis e fisicamente coerentes, recomendando sua utilização. Francey \& Garratt (1981) também encontraram maior consistência para as relações apresentadas por Dyer \& Hicks (1970), revisadas por Dyer (1974).

A teoria da similaridade requer a ausência de advecção, sendo que sob fortes condições advectivas de calor sensível regional (atmosfera estável), Blad \& Rosemberg (1974) verificaram subestimativas de cerca de $20 \%$ de $L E$ calculado pelo MRB, que, na sua forma simplificada $(\beta=\gamma . \partial T / \partial e)$, considera $K_{w}=K_{h}$, comparado aos valores medidos em lisímetros, sendo uma das hipóteses levantadas para as subestimativas o fato de ocorrer em tais condições $K_{h} / K_{w}>1$, posteriormente comprovada por Verma et al. (1978) e Motha et al. (1979), que encontraram valores de $K_{h} / K_{w}$ acima de 2 . Um resultado contraditório foi obtido por Bink (1996) sob advecção local, também sob condições de inversão dos gradientes de temperatura, que encontrou $K_{h} / K_{w}<1$ próximo da superfície. Angus \& Watts (1984) também verificaram subestimativa dos fluxos sob advecção considerando $K_{h} / K_{w}=1$. McNaughton \& Laubach (1998) e De Bruin et al. (1999) apresentam várias situações em que foram constatadas diferenças entre $K_{h}$ e $K_{w}$, que, além da advecção de calor, foram supostamente decorrentes do transporte vertical de parcelas de ar mais secas do topo, e acima dele, da camada limite planetária e da instabilidade do vento externo ao dossel, que causam variações instantâneas dos valores do déficit de saturação de vapor no ar próximo da superfície e até mesmo dentro do dossel, resultando em uma baixa correlação entre os gradientes de vapor e calor mediados no tempo. McNaughton \& Laubach (1998) demonstraram analiticamente que a maior fuga de 1 da relação $K_{h} / K_{w}$ ocorre na faixa de $\beta$ de $-0,2$ a 0,1 , que é característica de advecção de calor sensível, embora observaram os maiores erros nos cálculos de $H$ quando em forte condições de estabilidade $(\beta<-0,2)$. 
Devido a superfície ser um dreno de momento, a velocidade do vento é tanto maior quanto mais se afasta dela, estabelecendo-se um perfil logarítmico com a altura, que é válido para condições de neutralidade atmosférica (Villa Nova, 1973; Monteith \& Unsworth, 1990; Pereira, 1998). Em superfícies rugosas, como aquelas vegetadas, é necessário determinar-se o nível efetivo de absorção de momento, pois o mesmo não é absorvido totalmente no topo da cultura (Thom, 1971; Rosemberg et al., 1983; Oke, 1987; Monteith \& Unsworth, 1990; Pereira, 1998). Este nível corresponde à altura acima do solo em que ocorre a linearização da relação $\ln (z-d)$ versus $u$, sendo $d$ definido por Thom (1971) como a altura média de absorção de momento, chamada de deslocamento do plano zero. Thom (1971) encontrou uma relação de 0,76 entre $d$ e a altura dos elementos de rugosidade $h$ (relação $d / h$ ), a partir de cálculos do coeficiente de arrasto sobre cilindros em túnel de vento.

Em uma simulação numérica, Shaw \& Pereira (1982) verificaram que, conforme a densidade da vegetação aumenta e a concentração das folhas e ramos das plantas desloca-se para o topo do dossel, a relação $d / h$ aumenta. Conforme Monteith $\&$ Unsworth (1990), para valores representativos do coeficiente de arrasto e da estrutura do dossel, os valores de $d / h$ obtidos por Shaw \& Pereira (1982) foram consistentes com aqueles de experimentos de campo, entre 0,5 e 0,7. Raupach et al. (1980) em túnel de vento, consideraram valores coerentes de $d / h=0,66$ para $\lambda=0,09$ e de $d / h=0,83$ para $\lambda=0,18$, sendo $\lambda$ a concentração de rugosidade da superfície (igual ao produto da altura pela largura dos elementos de rugosidade, dividida pelo quadrado da distância média). Kustas et al. (1989b) encontraram $d / h=0,65$, sendo $h$ referente à altura das plantas de algodão cultivado sobre camalhões de solo, considerando o nível zero na base das valas. Diversos pesquisadores têm trabalhado com esse tipo de relação, sendo que Kustas et al. (1989a) considerou $d / h=2 / 3$ e Garrat (1978) utilizou $d / h=0,64$. Thom et al. (1975) citam alguns exemplos de trabalhos que obtiveram sucesso nas estimativas dos fluxos utilizando $d / h \leq 0,5$.

Outro parâmetro necessário para caracterizar a superfície e os fluxos sobre ela é a altura de rugosidade $z_{o}$. Este parâmetro também pode ser determinado empiricamente, correspondendo ao valor de $z-d$ na extrapolação do perfil logarítmico do vento para $u=$ 
0 (Monteith \& Unsworth, 1990; Pereira, 1998; Rosemberg et al., 1983; Oke, 1987; Villa Nova, 1973). Campbell \& Norman (1998) comentam que não existe um significado físico claro para $z_{o}$, mas que ele é uma medida da forma de arraste e do atrito superficial.

Conforme Munro \& Oke (1975), para a maioria das culturas agrícolas o valor de $z_{o}$ fica entre $10^{-3} \mathrm{~m}$ e $1,0 \mathrm{~m}$. Shaw \& Pereira (1982) demonstraram que a relação $z_{o} / \mathrm{h}$ aumenta com a densidade de elementos de rugosidade até um determinado patamar, que é dependente da altura no dossel em que se encontra a maior concentração de material. A partir deste ponto, o aumento na densidade de elementos de rugosidade resulta na diminuição de $z_{o} / h$, que se dá pelo selamento da superfície (o que a torna menos rugosa), mas é de certa forma compensada por um aumento adicional em $d / h$, devido sua interdependência (Pereira, 1998). Shaw \& Pereira (1982) concluíram também que em dosséis esparsos, quando a maior concentração de biomassa tende para o topo da vegetação, existe maior rugosidade, ocorrendo o contrário em dosséis densos. Hatfield (1989) confirmou os resultados de Shaw \& Pereira (1982) em medidas de campo, verificando um aumento praticamente linear de $d$ com o crescimento da cultura de algodão, enquanto que $z_{o}$ aumentou até um determinado período, permanecendo num patamar por um determinado tempo e diminuindo a partir de $70 \%$ de cobertura do solo. Esses resultados significam maior dificuldade em parametrizar $z_{o}$ somente com a altura da cultura.

Normalmente, determinam-se os valores de $d$ e $z_{o}$ a partir do perfil logarítmico do vento em condições próximas da neutralidade (Villa Nova, 1973), utilizando-se um valor fixo no cálculo dos fluxos. No entanto, como normalmente os dosséis são flexíveis, a variação do vento produz uma agitação dos elementos de rugosidade, podendo resultar na variação de $d$ e $z_{o}$ (Shaw \& Pereira, 1982; Pereira, 1998; Monteith \& Unsworth, 1990). Porém, Campbell \& Norman (1998) destacam que a dependência de $d$ e $z_{o}$ com a velocidade do vento é raramente levada em consideração por adicionar maior complicação e não ser bem entendida. McInnes et al. (1991) e Hatfield (1989) não encontraram efeito significante da direção do vento em relação à orientação das linhas de plantio sobre a variação de $d$ e $z_{o}$, embora McInnes et al. (1991) tenham evidenciado tal efeito. Sem considerar o efeito da estabilidade atmosférica, Righi et al. (2003) 
verificaram existir uma tendência de diminuição dos valores de $d$ e aumento de $z_{o}$ com a velocidade do vento, e quando na direção transversal aos renques de cafeeiros, a intensidade da resposta desses dois parâmetros ao vento foi menor.

A determinação destes parâmetros em estudos de campo é relativamente complicada. Na falta de "bordadura" suficientemente ampla, fazem-se as medidas próximas da superfície, na subcamada de rugosidade (Monteith \& Unsworth, 1990). Nesta camada da atmosfera, Thom et al. (1975), Garratt (1978, 1980), Raupach et al. (1980), Raupach \& Legg (1984), Cellier \& Brunet (1992) e Mölder et al. (1999) verificaram que ocorrem distorções nos perfis, principalmente de vapor e temperatura, devido à otimização do turbilhonamento causado pelos elementos de rugosidade e a uma conseqüente forte inflexão dos perfis no topo da cultura, com valores do produto $\left(\phi_{h, w} . \phi_{m}\right)^{-1}$ duas vezes maiores do preconizado para a sub-camada inercial (Dyer, 1967, 1974; Dyer \& Hicks, 1970; Webb, 1970). Nessas condições, existe tendência de subestimativa de $d$ (Garrat, 1980; Raupach et al., 1980) e, também, dos fluxos, se usados $\phi_{h, w, m}$ determinados na subcamada inercial (Garratt, 1978; Raupach et al., 1980; Raupach \& Legg, 1984; Cellier \& Brunet, 1992). Esses trabalhos apresentam controvérsias em relação à grandeza das modificações nessa subcamada, principalmente para momento, sendo que Raupach (1979), sobre floresta, e Raupach et al. (1980) e Raupach \& Legg (1984), em túnel de vento, não encontraram alterações significativas, enquanto que Garratt (1978, 1980), Raupach (1979), Mölder et al. (1996) e Cellier \& Brunet (1992) obtiveram valores dos coeficientes de difusão turbulenta, tanto para momento como para calor e vapor sobre coberturas naturais, acima de 1,5 vez maior do que na camada inercial. Um resultado contraditório foi obtido por Vogt \& Jaeger (1990), utilizando um método iterativo de modo a fechar o balanço de energia da superfície, que mesmo medindo os gradientes na subcamada rugosa, conseguiram boas estimativas de $L E$ com o MA, o que foi atribuído ao fato da floresta estudada ser bastante densa.

Apesar da complexidade do MA, tendo-se boas medidas dos perfis de vento, de temperatura e de umidade e, conseqüentemente, de $R i$, dentro da subcamada inercial, suas estimativas são de comprovada boa qualidade (Heikinheimo et al., 1999; Vogt \& Jaeger, 1990; Dugas et al., 1991; Pieri \& Fuchs, 1990; Pereira et al., 2003). Além disso, 
o MA fornece informações importantes sobre as propriedades aerodinâmicas da superfície, muitas vezes necessárias para a determinação dos fluxos superficiais através de outros métodos, como é o caso do método de Penman - Monteith (Monteith \& Unsworth, 1990).

\subsubsection{Método do balanço de energia - razão de Bowen.}

Segundo Lewis (1995), em 1915 Schimidt estimou pela primeira vez a evaporação usando o balanço de energia, introduzindo a relação simplificada:

$$
\beta=\frac{H}{L E}
$$

em que $\beta$ é assim conhecida como razão de Bowen após o desenvolvimento teórico realizado por I. S. Bowen em 1926.

Utilizando a expressão do balanço de energia numa cobertura vegetal, desconsiderando-se o armazenamento de energia no solo e/ou na biomassa e a quantidade de energia utilizada na fotossíntese ao longo do dia, pode-se estabelecer a Equação 11 (Pereira et al., 1997; Pereira, 1998):

$$
R n-G=H+L E \rightarrow L E=\frac{R n-G}{1+\beta}
$$

Seguindo Lewis (1995), Bowen considerou a transferência de calor de forma laminar, sem fazer referência ao transporte turbulento. Porém, como na atmosfera predomina a turbulência, utilizando-se as Equações 6-9 e considerando-se os coeficientes $K_{h}=K_{w}$ pela hipótese da similaridade, pode-se estabelecer:

$$
\beta=\frac{-\rho \cdot c p \cdot K_{h} \cdot \frac{\partial \theta}{\partial z}}{-\rho \cdot L \cdot K_{w} \cdot \frac{\partial q}{\partial z}}
$$

que simplificando e substituindo $q$ pela pressão de vapor do ar atmosférico $(e)$, sendo $e$ e $\theta$ determinados nos mesmos níveis, resulta em (Rosemberg et al., 1983; Monteith \& Unsworth, 1990; Pereira et al., 1997; Pereira, 1998):

$$
\beta=\gamma \cdot \frac{\partial \theta}{\partial e}
$$


em que $\gamma$ é o coeficiente psicrométrico $[=c p . P /(L .0,622)], P$ é a pressão atmosférica e $\partial e$ refere-se ao gradiente vertical de pressão de vapor no ar. Visto que $\beta$ também é baseado no transporte turbulento, toda a discussão apresentada para o MA é válida aqui.

A principal limitação para o uso do MRB é a existência de "bordadura" insuficiente, pois sob condições de advecção, têm-se $K_{h} \neq K_{w}$ (Blad \& Rosemberg, 1974; Verma et al., 1978; Motha et al., 1979; Bink, 1996; De Bruin et al., 1999; McNaughton \& Laubach, 1998). Em conseqüência disso, Blad \& Rosemberg (1974), Verma et al. (1978), Motha et al. (1979) e Angus \& Watts (1984) verificaram subestimativa de LE determinado pelo MRB com relação às medidas lisimétricas e pela correlação de turbilhões em vários tipos de cobertura vegetal.

Em relação ao MA, o MRB é consideravelmente mais simples, por admitir rigorosamente a igualdade nos coeficientes de transporte turbulento e não necessitar de um perfil de vento para a determinação de $u^{*}$, porém, exige as medidas de $R n$ e $G$, as quais são relativamente mais simples de serem realizadas.

O MRB pode ser considerado mais adequado para medidas dentro da subcamada rugosa. Conforme Garratt (1978) e Raupach \& Legg (1984) inferiram e, posteriormente verificado em estudo de campo por Cellier \& Brunet (1992) e Mölder et al. (1999), em função da similaridade para $K_{h}$ e $K_{w}$, as distorções observadas próximas da superfície tendem a serem iguais. Cellier \& Brunet (1992) verificaram que o uso de MA para a determinação de $L E$ e $H$ com medidas dentro dessa subcamada resultou em subestimativas quando comparadas àquelas da subcamada inercial, enquanto que o MRB produziu estimativas cuja razão com aquelas de uma altura de referência ficou sempre próxima de 1.

Quanto a $R n$, tendo-se um saldo-radiômetro instalado em local e altura apropriados para os fins desejados e com as constantes de calibração corretas, não ocorrem grandes erros nesta variável (Fuchs \& Tanner, 1970; Angus \& Watts, 1984; Pereira, 1998). Maior problema é a amostragem adequada de $G$, principalmente em coberturas heterogêneas, pois normalmente usam-se poucas placas de fluxo de calor para representar uma grande área (Fuchs \& Tanner, 1970; Angus \& Watts, 1984). Quanto à variação do armazenamento de calor no solo, esta é minimizada quando os fluxímetro 
são instalados próximos da superfície, especialmente em solo que possui condutividade térmica relativamente elevada, podendo seu efeito ser considerado pequeno e até insignificante na escala diária (Massman, 1992; Malek, 1993; Silans et al., 1997).

Na determinação dos fluxos por meio do MRB, deve-se observar a sua validade física em determinados valores de $\beta$. Perez et al. (1999) fazem uma análise de erro que mostra que para alguns valores de $\beta$, direção dos gradientes e energia disponível, os fluxos resultantes são fisicamente incoerentes. Normalmente, estes problemas ocorrem devido aos erros nos sensores e nos momentos de transição de $R n-G$ de negativo para positivo, e vice-versa, ou seja, normalmente no início e no final do dia, quando os gradientes tendem a zero, e quando $\beta \rightarrow-1$, tornando as relações indeterminadas. Os horários em que ocorrem tais condições devem ser descartados e, numa integração diária, seus valores podem ser interpolados a partir dos valores anterior e posterior, porém, desde que isso não ocorra em grande freqüência e por longos períodos, como realizado por Unland et al. (1996). Como normalmente isso ocorre no início e final dos dias (Angus \& Watts, 1984; Fuchs \& Tanner, 1970; Perez et al., 1999; Azevedo et al., 2003; Marin, 2000), quando os fluxos são baixos, esses erros não chegam a ser comprometedores na escala diária.

Comparativamente, o MRB tem vantagens práticas sobre o MA por não precisar da medida de perfil de vento, de temperatura e de umidade em mais do que dois níveis e não necessitar do valor de $d$ e $z_{o}$ nos cálculos. Sobre coberturas heterogêneas, as estimativas feitas a partir de medidas na subcamada rugosa parecem não sofrer as distorções observadas no MA pela similaridade entre o transporte de calor e de vapor (Aston, 1985; Cellier \& Brunet, 1992; Mölder et al., 1999). O desempenho do MRB quando comparado com o método da correlação de turbilhões e com lisímetros tem se mostrado muito bom (Spittlehouse \& Black, 1979, 1980; Malek \& Bingham, 1993; Prueger et al., 1997; Todd et al., 2000), principalmente em períodos úmidos (Angus \& Watts, 1984; Fuchs \& Tanner, 1970; Perez et al., 1999), levando alguns autores a utilizar suas estimativas de fluxo como referência para outros métodos (Dunin et al., 1989; Pieri \& Fuchs, 1990; Ortega-Farias et al., 1996; Vogt \& Jaeger, 1990; Cellier \& Brunet, 1992) e como estimativa da evapotranspiração e do balanço de energia de coberturas vegetais 
completas e incompletas (Villa Nova, 1973; Malek, 1992; Gutiérrez \& Meinzer, 1994a, b; Tyagi et al., 2000; Marin, 2000; Marin et al., 2001b; Cunha et al., 2001; Lopes et al., 2001; Hayashi et al., 2002; Teixeira et al., 2002; Inman-Bamber \& McGlynchei, 2003; Pereira et al., 2003; Azevedo et al., 2003).

\subsection{Determinação da transpiração pela medida do fluxo de seiva}

Atualmente, a determinação do fluxo de seiva de uma planta é feita pelo fornecimento de uma quantidade de calor ao caule, através de três métodos (Angelocci, 2002): o método do pulso de calor, introduzido por Hubber em 1932 (Slavik, 1974) e aperfeiçoado por Marshal (1958) e Swanson \& Whitfield (1981); o método da sonda de dissipação térmica, adequado para plantas lenhosas (Granier, 1985); e o método do balanço de calor (MBC), proposto inicialmente por Cěrmak et al. (1973) e modificado por Sakuratani (1981). Conforme Grime et al. (1995a, 1995b), Smith \& Allen (1996), Grime \& Sinclair (1999) e Angelocci (2001), o MBC tem como principais vantagens ser um método não destrutivo, não necessitar calibração e não ser necessariamente invasivo, o que o torna o mais utilizado atualmente. Neste trabalho, as atenções serão voltadas ao MBC por ter sido o utilizado na fase experimental.

O princípio do MBC é simples, consistindo no fornecimento de um fluxo de calor (expresso como uma potência elétrica dissipada) a um segmento do caule e na determinação de como ele é dissipado em fluxos condutivos axiais $(Q a)$ e radial $(Q r)$ de calor e em fluxo convectivo $(Q s)$ devido ao fluxo de seiva, além de se considerar uma possível variação do armazenamento (Arm).

Apesar da simplicidade do princípio empregado, o MBC tem várias fontes de erro que precisam ser conhecidas e minimizadas para que se tenham resultados confiáveis e precisos. Há muitos trabalhos na literatura envolvendo os aspectos teóricos e práticos do método, como os de Valancogne \& Nasr (1989), Baker \& Nieber (1989), Steinberg et al. (1989), Ham \& Heilman (1990), Ishida et al. (1991), Malek (1992), Groot \& King (1992), Gutiérrez et al. (1994), Grime et al. (1995a, b), Allen et al. (1995), 
Peressoti \& Ham (1996), Kjelgaard et al. (1997) e Grime \& Sinclair (1999), que discutem tais aspectos e analisam as fontes de erro.

Um dos problemas operacionais do MBC ao nível de campo é a carga radiante sobre o caule, pois o lado que recebe mais radiação tem temperaturas maiores do que o outro, que prejudica a representatividade das temperaturas medidas. Groot \& King (1992) aplicaram radiação de onda curta de $850 \mathrm{~W} \cdot \mathrm{m}^{-2}$ sobre um lado do caule exposto, que resultou numa temperatura aproximadamente $33 \%$ menor no lado não irradiado, que em altas taxas de fluxo de seiva $\left(90 \mathrm{~g} \cdot \mathrm{h}^{-1}\right)$ resultou em um erro equivalente, pois essa diferença de temperatura foi conduzida até os termopares. Esse problema foi evitado adicionando-se uma folha de alumínio com refletividade à onda curta de 0,8 , como também verificado por Gutiérrez et al. (1994).

Os fluxímetros comercializados pela Dynamax@ (Van Bavel, 1994) não levam em consideração o armazenamento de calor no caule, o que torna o método questionável em algumas situações. Grime et al. (1995b) compararam um modelo semelhante ao de Ishida et al. (1991) operando com potência variável, de modo a manter constante a diferença de temperatura entre o centro do aquecedor e uma determinada distância abaixo do mesmo, com um modelo de Baker \& Van Bavel (1987) operando com potência fixa, semelhante ao comercializado pela Dynamax $\bigodot$ (Van Bavel, 1994), sendo que encontraram melhor desempenho do modelo de Ishida et al. (1991). No entanto, os trabalhos de Grime et al. (1995a) e Grime \& Sinclair (1999) mostram que, ao se integrar os valores ao longo de $24 \mathrm{~h}$, os erros devidos ao armazenamento tendem a se anularem em caules pequenos, podendo-se esperar que as medidas fiquem dentro de menos de $15 \%$ de diferença em relação às medidas de transpiração, sendo um método eficiente na determinação do consumo d'água das plantas conduzidas sem restrição hídrica. Grime \& Sinclair (1999) verificaram que sob altas taxas de fluxo, os erros por se desconsiderar Arm são menores do que 5\%. Em dois cafeeiros com diâmetro do caule em torno de 16 $\mathrm{mm}$, Righi et al. ${ }^{1}$ verificaram diferenças menores do que $10 \%$ em dias sem nebulosidade entre os valores diários de $Q s$ calculados sem levar em consideração Arm em relação às

\footnotetext{
${ }^{1}$ RIGHI, E. Z.; RIBEIRO, R. V.; MARIN, F. R.; ANGELOCCI, L. R.; OLIVEIRA, R. F.; MACHADO, E. C. (ESALQ/USP) Estimative of sap flow in potted-plants by heat balance technique: I. methodological and practical aspects. (Em elaboração).
} 
determinações com o balanço de calor completo, mas que aumentaram para cerca de $30 \%$ quando o céu estava semi-encoberto, mostrando existir a possibilidade de se incorrer em erros elevados quando existe variação da nebulosidade ao longo do dia, ao se desconsiderar Arm. Marin et al. (2003b) também encontraram erros relativamente elevados comparando medidas de fluxo de seiva pelo MBC com medidas gravimétricas da transpiração, com superestimativa de $25 \%$ em uma muda de cafeeiro com diâmetro do caule de $10 \mathrm{~mm}$ e entre $2 \%$ e $30 \%$ em mudas de limoeiro com diâmetros de caule de $5 \mathrm{~mm}, 19 \mathrm{~mm}$ e $25 \mathrm{~mm}$, sendo que o menor erro correspondeu ao maior diâmetro em estudo, não sendo encontrada uma explicação para esses diferentes desempenhos.

A performance dos sensores de fluxo de seiva depende também das condições de instalação e operação no campo. Weibel \& De Vos (1994) destacam a necessidade de garantir-se um bom contato entre o sensor e o segmento de caule a fim de aquecer homogeneamente este último e de se medir os gradientes de temperatura corretamente. Van Bavel (1994) recomenda a utilização de uma pasta isolante elétrica, condutora térmica e repelente hídrica para corrigir as deficiências de contato devido às irregularidades dos caules. No entanto, em algumas espécies, esta pasta tem-se mostrado danificadora do tecido condutor das plantas (Wiltshire et al., 1995; Marin, 2003). Wiltshire et al. (1995) verificaram um anelamento em árvores jovens de Fraxinus excelsior L. quando a pasta foi aplicada, mesmo sem a instalação dos sensores de fluxo, tendo como possível causa as limitações às trocas gasosas no câmbio onde a pasta fora aplicada. Mesmo com o uso desta pasta, pode ocorrer condensação de água no sensor, sendo interessante enrolar sobre o caule um filme plástico fino antes de instalar o fluxímetro (Weibel \& De Vos, 1994).

Mesmo necessitando de estudos quanto à melhor configuração do sensor, à acurácia e à precisão do método, o seu uso tem-se expandido bastante, pois é uma ferramenta importante no estudo das relações hídricas das plantas e em problemas agronômicos, nas áreas de micrometeorologia de culturas, de irrigação, de ecofisiologia e de fitopatologia (relações entre disponibilidade hídrica e clorose variegada dos citros, por exemplo). No estudo das relações hídricas, principalmente nas situações com irrigação localizada, ter-se noção pelo menos da ordem de grandeza dos valores do fluxo 
de seiva $F S$, ou da transpiração $T$, é de fundamental importância para o auxílio da irrigação de uma lâmina d'água mais ajustada às necessidades reais da cultura, principalmente quando a espécie de interesse é arbórea, pelas dificuldades de uso de outras técnicas. Nesse sentido, o MBC tem sido usado para entendimento das respostas às variações ambientais e para conhecimento de valores da transpiração de espécies com cultivos descontínuos no terreno, como cafeeiros (Gutiérrez \& Meinzer, 1994a; b; Marin, 2003; Marin et al., 2003a; Marin et al., 2005), videiras (Silva et al., 2000), goiabeiras (Silva et al., 2002) e citros (Marin, 2000; Marin et al., 2001b; Coelho Filho, 2003), para citar as aplicações em café, motivo deste estudo, e seu uso por autores brasileiros em outras espécies.

\subsection{Determinação da evapotranspiração por lisimetria}

Existem basicamente três tipos de lisímetros para a determinação da evapotranspiração: de drenagem, de lençol freático constante e de pesagem (Pereira et al., 2002b). A utilização de lisímetros teve os primeiros registros no Século 17, sendo que o início da utilização de sistemas de pesagem ocorreu em 1951 (Howell et al., 1991). Os lisímetros de pesagem determinam a evapotranspiração a partir da variação do peso de um bloco de solo devida à entrada ou saída d'água, sendo uma medida direta da dinâmica da água num solo nu ou cultivado, com uso bastante difundido atualmente.

Nas últimas três décadas, passaram a predominar sistemas eletrônicos de pesagem, consistindo de células de carga que recebem uma excitação elétrica, sendo que a variação da voltagem de saída é proporcional à variação de uma resistência devido à maior ou menor deflexão da haste existente no interior da célula de carga, pela variação do peso sobre ela (interface@mpcnet.com.br). Como a sua resolução é infinita, então a resolução final das medidas é determinada pelo sistema de aquisição de dados ou transdutor de sinal utilizado, a qual pode ainda ser melhorada pelo aumento da área de evaporação, a qual, para Grebet (1991) deve ter no mínimo $2 \mathrm{~m}^{2}$, considerando um tamanho ótimo de $4 \mathrm{~m}^{2}$, para culturas que cobrem totalmente o terreno. 
A escolha do sistema de pesagem depende do objetivo pretendido para um determinado lisímetro, cuja sensibilidade é um fator importante na qualidade das medidas (Grebet, 1991). Na determinação da evapotranspiração, a sensibilidade desejada depende da escala temporal de trabalho, ou seja, se na escala horária, é necessário que ela seja maior do que na escala diária. As células de carga oferecem, normalmente, uma boa sensibilidade para as medidas em escalas maiores ou iguais à horária (Backer et al., 1991; Santiago, 2002). Pruitt et al. (1973) utilizaram células de carga na determinação da transferência de massa e momento na superfície, o que demonstra a potencialidade do seu uso em medidas que necessitam de alta acurácia, alta sensibilidade e alta resolução.

Porém, a alta sensibilidade pode levar a alguns problemas, principalmente no campo. Um problema comum é o efeito do vento, que produz oscilações instantâneas nas medidas, sendo mais comuns em lisímetros com plantas relativamente altas, devido à maior força de arraste recebida (Allen et al., 1991; Backer et al., 1991; Wright, 1991; Bergamaschi et al., 1997; Santiago, 2002). Bergamaschi et al. (1997) sugerem aumentar o período de integração para suavizar as variações instantâneas causadas pelo vento. Outro problema ao nível de campo é o efeito da variação da temperatura ambiental que resulta na contração e distensão das células, afetando o sinal de saída. Allen \& Fisher (1991) concluíram que quando as células foram posicionadas sob os tanques lisimétricos, onde a amplitude térmica é menor, o efeito da temperatura foi insignificante. Quando instaladas na superfície de uma área gramada, foi verificada uma forte influência da temperatura ambiental, mas que tendeu a se anular no período de $24 \mathrm{~h}$ devido ao efeito de resfriamento noturno.

Existem alguns cuidados levantados por Allen et al. (1991) a respeito das condições ambientais exigidas para o bom desempenho e boa representatividade dos lisímetros. Além de ter uma profundidade suficiente para um desenvolvimento normal do sistema radicular das plantas, deve-se evitar construir paredes da borda que circunscreve o tanque e do próprio tanque muito espessas, que aumentam a carga térmica nas plantas mais próximas da bordadura, e muito altas, que além do efeito térmico, podem sombrear algumas plantas do lado que os raios solares incidem e ter reflexão no lado oposto. Deve-se, também, trabalhar com "bordaduras" suficientemente 
grandes para se evitar o efeito "oásis" e buscar condições idênticas entre o interior e exterior do tanque lisimétrico, para que as plantas tenham o mesmo desenvolvimento. $\mathrm{O}$ efeito de borda é verificado também pelo surgimento de gradientes horizontais da temperatura do solo no lisímetro, tendo efeito na evapotranspiração (Martin et al., 2001).

Um dos momentos mais críticos da instalação é o preenchimento do tanque lisimétrico com solo, o qual deve ser completamente isolado para ter-se total controle das entradas e saídas de água do sistema. O preenchimento com solo removido é mais fácil e mais barato, no entanto tem as desvantagens de desestruturar e modificar as propriedades hidráulicas do mesmo e de misturar as diferentes camadas do perfil, originando condições diferenciadas daquelas do campo ao redor, pelo menos até que uma nova condição de equilíbrio biológico e físico seja atingida (Grebet \& Cuenca, 1991).

O solo a ser utilizado no lisímetro deve ser obtido de preferência no mesmo local a ser instalado, desde que sejam tomados cuidados para não compactar os arredores durante os serviços de escavação, se não, deve ser buscado em algum local próximo e com as propriedades físicas e químicas parecidas para que não haja diferença no desenvolvimento entre as plantas dentro e fora do tanque lisimétrico (Grebet \& Cuenca, 1991).

Conforme Ritchie (1972), logo após uma chuva a evaporação da superfície do solo ocorre em taxas próximas da potencial, permanecendo assim até acumular uma determinada lâmina, a partir de quando inicia-se uma segunda fase, em que a evaporação em taxas menores é controlada pelas propriedades físicas do solo. Além disso, conforme a cultura vai se desenvolvendo, existe tendência em diminuir a contribuição da participação da evaporação do solo ou evapotranspiração da entrelinha na evapotranspiração total da cobertura (Ritchie, 1972; Tanner \& Jury, 1976; Ham et al., 1990; Daamen, 1995). A sua determinação pode ser feita através do método de Ritchie (1972) ou através do método microlisimétrico, sendo este, conforme Daamen et al. (1993), o mais simples, direto e independente método para a determinação da evaporação do solo, embora trabalhoso. 
Desde a década de 70 tem-se utilizado microlisímetros para a determinação da evaporação ou evapotranspiração nos espaços sem cultura, principalmente nas entrelinhas. Conforme Daamen et al. (1993), os microlisímetros são pequenos volumes de solo nu, contidos em cilindros metálicos ou de PVC, normalmente com diâmetro menor que $20 \mathrm{~cm}$, amostrados no local de origem, sendo que a diferença de peso num determinado período equivale à evaporação. Desde que os microlisímetros instalados tenham seu volume de solo descartado em períodos curtos de tempo (1 ou 2 dias), suas medidas de variação de peso podem ser utilizadas para determinar a evapotranspiração das áreas sem cultura, mas com invasoras. Existem diversos trabalhos realizados com microlisímetros para determinar as componentes da evapotranspiração de uma cobertura, transpiração da cultura e evaporação ou evapotranspiração da entrelinha, (Ritchie \& Burnett, 1971; Yunusa et al., 1993a; 1993b; Daamen et al., 1995; Qiu et al., 1999; Liu et al., 2002), nos quais foram obtidos bons resultados, tanto na comparação com outros métodos de estimativa, como na calibração de modelos de evaporação do solo e evapotranspiração da cobertura.

É importante ressaltar que ao se isolar um bloco de solo, todos os fluxos laterais e verticais, tanto energéticos, quanto de massa, passam a ser limitados pelas paredes do tanque lisimétrico. Esta situação com certeza é mais grave quando se trabalha com deficiência hídrica, pois os fluxos verticais de água de horizontes profundos mais úmidos são impedidos. Além disso, as paredes impedem as plantas dos lisímetros emitirem suas raízes para fora do tanque, deixando-as com um volume limitado de solo para explorar. No entanto, quando se trabalha com irrigação, sem estresse para as plantas, e com um volume de solo adequado para um bom desenvolvimento radicular, esses problemas podem ser desconsiderados (Grebet \& Cuenca, 1991).

De qualquer forma, os valores de variação de peso fornecidos por lisímetros de pesagem podem ser considerados altamente acurados para a determinação da evapotranspiração da cobertura contido nele, desde que tomados os diversos cuidados a fim de evitar diferenças de condições com as áreas dos arredores. Nesse caso, de fato ele se torna uma referência em termos de evapotranspiração, tanto para avaliação de métodos como para a determinação da própria evapotranspiração da cobertura (Blad \& 
Rosemberg, 1974; Verma et al., 1978; Angus \& Watts, 1984; Prueger et al., 1997; Tyagi et al., 2000; Todd et al., 2000; Kashyap \& Panda, 2001; Liu et al., 2002; Inman-Bamber \& McGlinchey, 2003).

\subsection{Consumo de água da cultura do café}

Conforme Marin et al. (2005), desde 1727 é produzido café no Brasil, estimando-se que atualmente são comercialmente cultivados mais de $2,4.10^{6}$ ha, sendo uma cultura de grande importância econômica por ser uma grande geradora de divisas para o país. As áreas cultivadas com café se concentram na região sudeste do Brasil, mas se estendem até o norte do Paraná e ultimamente tem-se expandido para o nordeste brasileiro (Camargo, 1985).

O cafeeiro arábica (Coffea arábica L.) é uma espécie arbórea originária provavelmente dos sub-bosques úmidos e frios de altitudes elevadas da Etiópia, com temperaturas médias variando entre 15 e $20^{\circ} \mathrm{C}$ e chuvas bem distribuídas, acumulando 1600 a $2000 \mathrm{~mm}^{\mathrm{ano}}{ }^{-1}$, com uma estação seca variando de 3 a 4 meses (Ascanio Evanoff, 1994; Carr, 2001). Após sua grande disseminação realizada pelo homem, hoje é produzido desde o Havaí $\left(22^{\circ} \mathrm{N}\right)$ até o Estado do Paraná, no Brasil $\left(26^{\circ} \mathrm{S}\right)$ (Ascanio Evanoff, 1994; Carr, 2001; Barros et al., 1995), demonstrando sua grande capacidade de adaptação ambiental. Saída de um ambiente úmido, relativamente frio e de baixa radiação solar, hoje é em grande parte cultivado a pleno sol. Conforme Ascanio Evanoff (1994) e Barros et al. (1995), mesmo apresentando sintomas de estresse durante parte do dia devido ao excesso de radiação e/ou alta demanda atmosférica, existem evidências de as maiores produtividades ocorrerem a pleno sol nos sistemas de cultivo atuais.

O cafeeiro é uma planta com sistema radicular pivotante central, com até 4,5 m de profundidade, com raízes axiais se aprofundando no solo em até $3 \mathrm{~m}$ e raízes laterais superficiais e subsuperficiais que chegam a até $1,5 \mathrm{~m}$ do caule. Dessas raízes, surgem portadoras de raízes absorventes e as próprias absorventes, as quais são levemente mais concentradas nas camadas superficiais (Ascanio Evanoff, 1994). 
Conforme Ascanio Evanoff (1994), em plantas com 2 anos de idade a maior parte do sistema radicular não passa de $20 \mathrm{~cm}$ de profundidade, sendo que em plantas adultas $90 \%$ das raízes se concentram nos primeiros $30 \mathrm{~cm}$ de solo. No entanto, Carr (2001) cita resultados experimentais em café irrigado por gotejamento entre 7 e 36 meses após o transplante, em que a profundidade de solo explorada pelas raízes era de 0,45 m a 1,2 m. Em relação ao efeito do emprego da irrigação, Bull (1963) verificou em cafeeiro adulto considerável maior desenvolvimento radicular sob irrigação total, embora com tendência a se concentrar em camadas mais superficiais.

A parte aérea do cafeeiro tem desenvolvimento ereto, com uma haste principal e ramificações laterais (Carr, 2001), resultando em uma copa em forma aproximada de um cone nos estratos superiores e verticalizando-se nas camadas inferiores (Marin et al., 2003a). Esse tipo de forma da copa resulta em maior interceptação de radiação solar nas camadas superiores, sendo que Marin et al. (2003a) observaram uma extinção de 79\% da radiação fotossinteticamente ativa na camada superior da copa com $10 \%$ da área foliar total da planta. No mesmo experimento foi verificado que a taxa de transpiração por unidade de área foliar foi praticamente a mesma nas três camadas do dossel consideradas, mostrando a capacidade dos estômatos em controlar as trocas de vapor com a atmosfera (Marin, 2003). Esses resultados corroboraram com aqueles de Da Matta et al. (1993) que inferiram ser o cafeeiro um "poupador de água" e não uma espécie tolerante à desidratação.

Embora ainda exista carência de estudos sobre as relações hídricas do cafeeiro (Carr, 2001), é evidente na literatura que a deficiência hídrica no sistema radicular ou a elevada demanda atmosférica, atuando isoladamente ou associada com cargas radiativas elevadas, causam o fechamento estomático, restringindo a transpiração em taxas suportáveis pela cultura ou permissíveis pelas condições hídricas do solo, que em casos extremos podem causar sérios prejuízos ao desenvolvimento e à produtividade final (Vieira, 1979; Da Matta et al., 1993; Camargo \& Pereira, 1994; Gutiérrez \& Meinzer, 1994a, b; Carr, 2001; Barros et al., 1997; Brunini \& Angelocci, 1998; Gervasio \& Lima, 1998; Marin, 2003; Marin et al., 2003a). 
As observações experimentais e a busca de melhores produtividades, associadas à expansão do cultivo dos cafezais para as regiões de cerrado do Brasil (Camargo, 1985; Marin, 2003), têm levado os produtores a investir em irrigação e, conseqüentemente, os pesquisadores têm voltado sua atenção às relações hídricas do cafeeiro e a quantificação correta das lâminas a serem aplicadas.

Nas regiões produtoras de café, o ciclo de chuvas pode ser divido em bimodal e unimodal (Carr, 2001). Portanto, antes de tudo, o ciclo das chuvas é que determina quando e como irrigar o cafezal. Juntamente com o regime pluvial, deve-se considerar o ciclo anual do cafeeiro, o qual está associado com a temperatura do ar (Camargo \& Pereira, 1994; Ascanio Evanoff, 1994).

Especialmente na região sudeste, predomina o ciclo de chuvas unimodal, com um período úmido no verão e seco no inverno. Em cafezais em plena produção, a indução floral é feita justamente durante o inverno pela deficiência hídrica e pelas temperaturas baixas, quando o desenvolvimento da cultura é restrito (Garriz \& Sanchez, 1986; Soto \& Morales, 1993, 1996; Camargo \& Pereira, 1994; Ascanio Evanoff, 1994; Drinman \& Menzel, 1995; Barros, 1997). Durante esse período a irrigação pode ser importante de modo a evitar estresse hídrico no solo excessivamente alto (Carr, 2001), mas sua importância maior é evidente quando as chuvas param antes de se completar o ciclo produtivo anual e, principalmente, no período de floração no início da primavera, pois a irrigação causa a quebra de dormência e induz ao florescimento de forma homogênea (Magalhães \& Angelocci, 1976; Ascanio Evanoff, 1994; Camargo \& Pereira, 1994; Carr, 2001). Além disso, com certa freqüência, ocorre quebra da dormência dos botões florais por algum evento de chuva com posterior estiagem, resultando no aborto dessas flores, além de veranicos durante o período de produção, problemas que podem ser contornados ao dispor-se de irrigação para manter condições adequadas ao desenvolvimento dos frutos com qualidade (Vieira, 1979; Carr, 2001; Santinato \& Fernandes, 2000).

Durante o período de crescimento, além da maior facilidade para o pegamento das mudas após o transplante, que, pelo pequeno sistema radicular, explora um limitado volume de solo, consegue-se maior homogeneidade do stand e o período produtivo pode 
ser atingido com plantas mais vigorosas com o uso de irrigação corretamente manejada, conseguindo-se maiores rendimentos nas primeiras produções (Gervasio \& Lima, 1998).

De acordo com as características fisiológicas do cafeeiro, é evidente a importância da irrigação no desenvolvimento da cultura nas principais regiões produtoras de café no Brasil. Portanto, na escassez de água anunciada, torna-se importante no manejo do cultivo determinar corretamente a lâmina de irrigação de modo a não desperdiçar recursos ou ter prejuízos na produção devido à deficiência hídrica.

Nutman (1937a, b, 1941), na África, e Franco \& Inforzato (1950, 1951), no Brasil, foram, possivelmente, os primeiros pesquisadores que buscaram quantificar as necessidades hídricas do cafeeiro, com as primeiras determinações de coeficientes de cultura feitas por Pereira (1957) e Wallis (1962). Atualmente, têm-se desenvolvido novos trabalhos, utilizando-se de técnicas modernas, como a determinação do fluxo de seiva e métodos que utilizam variáveis meteorológicas para a determinação da evapotranspiração (Gutiérrez \& Meinzer, 1994a, b; Marin, 2003).

O avanço tecnológico ocorrido ao longo dos anos na irrigação de cafezais mostra uma tendência na preferência dos produtores em utilizar sistemas localizados, como micro-aspersão e gotejamento (Vieira, 1979; Santinato \& Fernandes, 2000), que são mais eficientes na aplicação de água do que a aspersão total. Contudo, nesses sistemas de irrigação localizados, que aplicam a água sobre o volume de solo onde se concentra o sistema radicular das plantas de interesse, a lâmina de água a ser reposta é aquela correspondente à depleção do armazenamento no volume de solo explorado pela cultura, necessitando-se, portanto, separar-se a evapotranspiração do renque da total (ou de cultura), pois aquela da entrelinha não necessita ser reposta.

Uma variável prática para o manejo da irrigação é o coeficiente de cultura $(K c)$, que é definido de acordo com Allen et al. (1998) como:

$$
K c=\frac{E T c}{E T o}=\frac{E T c b+E T s}{E T o}=K c b+K s
$$

em que ETc, ETcb, ETs e ETo são, respectivamente, a evapotranspiração da cultura, basal, do solo e de referência; $K c b$ e $K s$ são as componentes de $K c$ respectivas à transpiração da cultura (coeficiente basal de cultura) e à evaporação do solo. Havendo 
determinado o coeficiente de cultura, é possível, a partir de ETo, determinar a evapotranspiração da cultura e, conhecendo-se a quantidade de água disponível no solo, pode-se estabelecer a freqüência de rega.

Os valores de $K c b$ e $K c$ recomendados para cafezal adulto no boletim FAO 56 (Allen et al., 1998) são, respectivamente, de 1,0 a 1,05 e de 1,05 a 1,10, quando cultivado com invasoras na entrelinha. Em cafezal adulto com 5 anos de idade e densidade de 4000 plantas por hectare, Marin et al. (2005) encontraram Kcb médio igual a 0,78 e $K c$ variando de 0,6 a 1,0. Esses autores verificaram também que quando ETo foi maior do que 4 mm.dia ${ }^{-1}, T$ tendeu a estabilizar num determinado patamar em função dos cafeeiros estarem respondendo com o fechamento estomático aos elevados valores da demanda hídrica atmosférica. Esses resultados são de elevada relevância, pois demonstram ser possível a diminuição de $K c b$ a partir de determinados valores de ETo, o que representaria o fechamento estomático.

Gutiérrez \& Meinzer (1994b) estudaram as necessidades hídricas de cafezais com idades entre 1,5 e 5,3 anos e densidade de 4000 plantas por hectare, verificando valores de $K c$ variando de 0,42 a 0,82 . Seus resultados foram dependentes do índice de área foliar $(I A F)$, e, conseqüentemente, da fração de área de solo coberta pela cultura, e das condições meteorológicas diferentes em anos distintos. Villa Nova et al. (2002), trabalhando no mesmo cafezal usado por Marin (2003) e Marin et al. (2005), porém com idade entre 15 e 40 meses, encontraram valores de $K c$ entre 0,092 e 1,184 e de $K c b$ entre 0,076 e 1,036, para valores de área foliar $A F$ variando entre $0,665 \mathrm{~m}^{2}$ e $8,53 \mathrm{~m}^{2}$, a partir do balanço de água "in situ", de ETo calculada pelo método do tanque classe A e considerando a evapotranspiração da entrelinha equivalente a ETo.

Esses resultados mostram que os valores de $K c$ para cafezais adultos parecem ficar entre 0,7 e 1,2, enquanto que $K c b$ entre 0,7 e 0,8 , valores relativamente próximos daqueles propostos por Allen et al. (1998). No entanto, existem carências de estudos em cafezais em crescimento, acompanhando a evolução das condições micrometeorológicas e dos próprios coeficientes de cultura. De acordo com Allen et al. (1998), Kc representa a altura da cultura e seu efeito sobre a resistência aerodinâmica da cobertura; o albedo e seu efeito sobre a radiação líquida; a resistência do dossel para trocas gasosas, 
integrando $A F$, idade e condições foliares, grau de controle estomático; e a evaporação do solo. Portanto, como verificado nos trabalhos de Gutiérrez \& Meinzer (1994a, b), Villa Nova et al. (2002), Marin (2003) e Marin et al. (2005), as condições micrometeorológicas e da cultura variam ao longo do ano de cultivo, devido às condições macroclimáticas, de cobertura na entrelinha, manejo etc., repercutindo na partição dos fluxos de calor e na contribuição relativa de suas componentes, e, conseqüentemente, nos coeficientes de cultura. 


\section{MATERIAL E MÉTODOS}

\subsection{Descrição do cafezal}

O experimento foi conduzido em um cafezal cultivado a pleno sol, com plantas de Coffea arábica L., cultivar Obatã IAC 1669-20, pé franco, 12 a 24 meses após o transplante, compreendendo o período de outubro de 2002 a setembro de 2003. As plantas foram dispostas em renques espaçados de 3,5 $\mathrm{m}$ e com distância entre plantas de $0,9 \mathrm{~m}(\approx 3180$ plantas por hectare). O cafezal situa-se em áreas dos Departamentos de Ciências Exatas e de Produção Vegetal, no campus “Luiz de Queiroz”, ESALQ/USP, em Piracicaba, SP (2242’30’'S; 47³0’00”W; 546 m), em solo classificado como Nitossolo Vermelho, sendo que o clima local é subtropical úmido de acordo com a classificação de Köppen, com verão chuvoso e inverno seco e temperaturas normais variando entre 17,9 ${ }^{\circ} \mathrm{C}$ em julho e $24,5{ }^{\circ} \mathrm{C}$ em fevereiro, sendo o valor médio anual de $21,6{ }^{\circ} \mathrm{C}$. A Figura 1 mostra uma representação esquemática da área.

Com área de aproximadamente 3,5 ha, tendo dimensões de $290 \mathrm{~m}$ de comprimento, $120 \mathrm{~m}$ na extremidade norte e cerca de $100 \mathrm{~m}$ na extremidade sul, $\mathrm{o}$ cafezal era contornado pelo aeroporto local ao sul, por uma área de pastagem e 10 renques de cafezal adulto a leste, pelo posto meteorológico a norte e por um seringal consorciado com café e uma lavoura de pupunha a oeste (Figura 1). Nas áreas onde estão situados o posto meteorológico e o aeroporto, a vegetação era de porte rasteiro, com altura inferior a $1 \mathrm{~m}$. As plantas de seringueira tinham entre 10 e $15 \mathrm{~m}$, a pupunha aproximadamente 8 a $10 \mathrm{~m}$ e os cafeeiros adultos cerca de $2,5 \mathrm{~m}$ de altura. No local do aeroporto, além de $50 \mathrm{~m}$ afastado da borda sul do cafezal, existiam cerca de 5 árvores 
isoladas e algumas edificações. Em parte da coleta de dados, a borda sul ficou coberta com plantas com cerca de $2 \mathrm{~m}$ de altura.
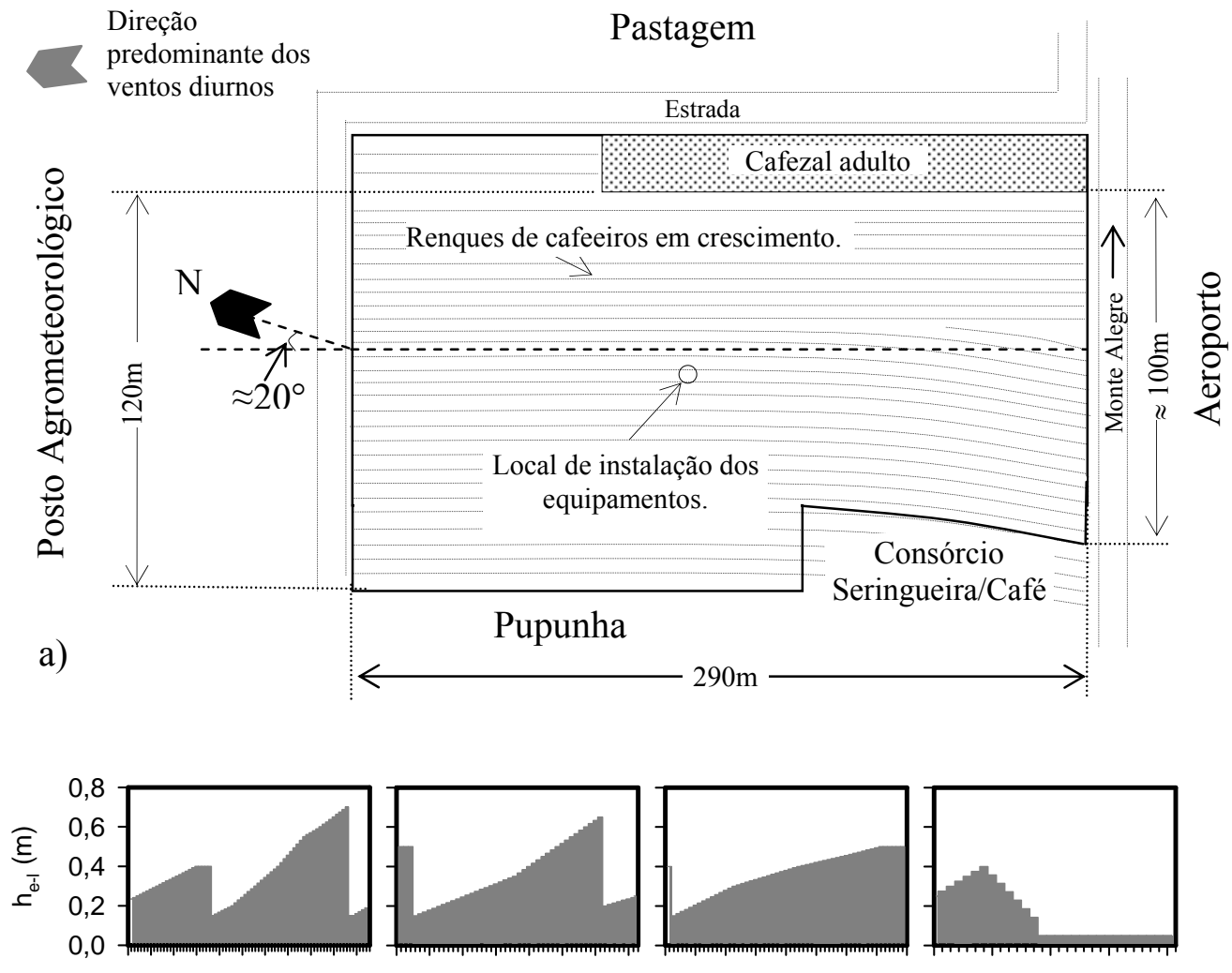

b)

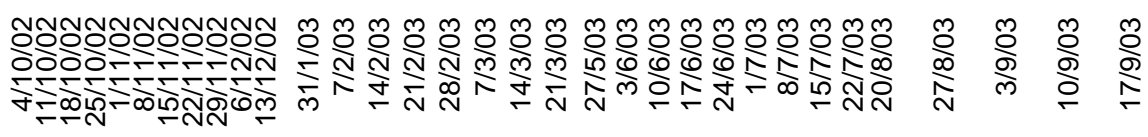

Outubro-Dezembro/2002 Fevereiro-Março/2003 Maio-Julho/03 Agosto-Setembro/03

Figura 1 - Representação da área experimental (a), fora de escala, juntamente com a evolução temporal da altura da cobertura da entrelinha $\left(h_{e-l}\right)$ durante os períodos de coleta de dados (b). No período de agosto - setembro de 2003, até o dia 02/09/03, a cobertura da entrelinha representada na Figura refere-se à somente $50 \%$ da área do experimento, sendo que o restante estava com solo nu. A porcentagem de cobertura da entrelinha variou entre 80 e $100 \%$, da qual menos de $20 \%$ era seca, em outubro - dezembro de 2002 e fevereiro - março de 2003, sendo que na primeira semana após cada roçada, cerca de $40 \%$ do material de cobertura era seca. Em maio - julho de 2003, a cobertura total ficou entre 70 e $100 \%$, sendo 55 a $70 \%$ seca 
O transplante das mudas para o campo foi realizado em outubro de 2001, quando a altura das plantas era de aproximadamente 20 a $30 \mathrm{~cm}$. No mesmo período, foi instalado o sistema de irrigação com gotejadores espaçados cerca de $0,9 \mathrm{~m}$ e vazão entre 2,5 e 2,8 litros por hora. A irrigação foi manejada de maneira a garantir que as plantas não sofressem estresse hídrico, principalmente durante o estabelecimento das mudas. $\mathrm{O}$ sistema de irrigação foi dimensionado para irrigar $1 / 4$ da área por vez, sendo acionado por cerca de 12 horas em cada talhão, duas vezes por semana, totalizando entre 30 e 34 litros por planta em cada aplicação. É provável que o manejo de irrigação adotado tenha superado as necessidades hídricas dos cafeeiros, mas o solo local apresenta boas condições de drenagem e durante o período de setembro de 2002 a maio de 2003, as chuvas ocorreram com boa freqüência, sendo que em grande parte do período não foi necessário irrigar. A partir de março de 2003, a irrigação passou a ser realizada durante aproximadamente 16 horas (totalizando entre 40 e 45 litros por planta) uma vez por semana, de modo a estimular o desenvolvimento radicular.

No dia 31 de outubro de 2002, cerca de 12 meses após o transplante, as raízes de 4 plantas tinham cerca de $0,45 \mathrm{~m}$ de profundidade por $0,40 \mathrm{~m}$ de raio horizontal, equivalendo a $0,23 \mathrm{~m}^{3}$ de volume de solo explorado. Tendo esse solo cerca de $15 \%$ do volume ocupado por água entre a capacidade de campo e o ponto de murcha permanente (Pauletto, 1986), tem-se uma capacidade de água disponível para cada planta $(C A D)$ de aproximadamente 34 litros. Como os maiores valores de evapotranspiração do lisímetro com uma planta de porte médio em novembro de 2002 eram equivalentes a 2,6 L.dia ${ }^{-1}$, a evapotranspiração acumulada num período de 4 dias com alta demanda hídrica atmosférica era de aproximadamente $10 \mathrm{~L}$, ou seja, 30\% da água armazenada no volume disponível para as plantas, quantidade inferior ao fator médio de depleção máxima para o cafeeiro não sofrer estresse hídrico [40\% de acordo com Allen et al. (1998)]. Nas situações em que toda a área superficial dos lisímetros estava úmida devido à ocorrência de chuvas, a evaporação ocorrendo em taxas potenciais também na fração da superfície do solo que normalmente não é molhada pelo gotejador do sistema de irrigação resultou em valores de evapotranspiração de até 4,0 L.dia' ${ }^{-1}$, os quais, portanto, não são 
representativos das condições observadas durante o período de irrigação. Desta maneira, evidencia-se que as plantas não sofreram estresse no turno de rega utilizado.

Com a nova freqüência de irrigações realizada a partir de março de 2003 (17 meses após o transplante), não é possível fazer-se a mesma análise, pois não foi determinado o volume de solo explorado pelas plantas. Mas, considerando-se uma profundidade seguramente conservadora de $0,55 \mathrm{~m}$ (Carr, 2001) e um raio de 0,50 m, estima-se que cada planta dispunha de $65 \mathrm{~L}$ de água na capacidade de campo. Com os valores de máxima evapotranspiração dos lisímetros no mês de março equivalentes a 3,1 L.dia ${ }^{-1}$ e com o turno de rega de 7 dias, calcula-se que a depleção máxima de armazenamento de água do solo foi de $35 \%$, indicativo que os cafeeiros transpiraram em taxa máxima durante a realização das medidas.

$\mathrm{Na}$ implantação do cafezal, a adubação foi realizada conforme resultado de análise do solo, com aplicação de $441 \mathrm{~kg} \cdot \mathrm{ha}^{-1}$ de adubo fosfatado super simples, $47 \mathrm{~kg}^{-1} \mathrm{a}^{-1}$ de cloreto de potássio, $206 \mathrm{~kg} \cdot \mathrm{ha}^{-1}$ de FTE, composto de micronutrientes (B, Zn, Fe, Mn e Mo), e $206 \mathrm{~kg} \cdot \mathrm{ha}^{-1}$ de calcário.

O cafezal foi manejado de acordo com o cultivo padrão de lavouras comerciais, normalmente sem invasoras numa faixa entre aproximadamente $0,9 \mathrm{~m}$ e $1,5 \mathrm{~m}$ rente ao renque e com invasoras nas entrelinhas, as quais periodicamente foram roçadas, sendo que a altura média dos elementos mais altos, predominantemente gramíneos, chegou a um máximo de 0,7 m, observados em dezembro de 2002. Em geral, a altura das plantas da entrelinha variou entre $0,15 \mathrm{~m}$, logo após a roçada, a aproximadamente $0,5 \mathrm{~m}$. Na Figura 1 é mostrada uma evolução aproximada das condições de cobertura da entrelinha ao longo do experimento. As adubações de manutenção foram realizadas nos meses de outubro, novembro e dezembro, constando de $100 \mathrm{~kg} \cdot \mathrm{ha}^{-1}$ de $\mathrm{N}$ e $100 \mathrm{~kg} \cdot \mathrm{ha}^{-1}$ de $\mathrm{K}_{2} \mathrm{O}$.

\subsection{Medidas biométricas}

Para caracterizar o crescimento das plantas, determinou-se a área foliar média, a altura e o diâmetro das copas. Foram realizadas quatro determinações: setembro e dezembro de 2002, e fevereiro e setembro de 2003. 
Em setembro de 2002, foram selecionadas visualmente 50 plantas de porte médio, representativas do cafezal. A partir de dezembro de 2002, as determinações foram feitas em plantas selecionadas aleatoriamente, com início no segundo renque após o cafezal adulto no lado leste da área até cerca de 4 linhas antes da plantação de pupunha, buscando assim evitar a amostragem de plantas da bordadura afetadas pelo sombreamento do pupunhal. As plantas dos dois renques próximos ao consórcio seringal/cafezal foram desconsideradas. Em cada linha foi escolhida uma primeira planta aleatoriamente, considerando-se aquela mais próxima de um objeto lançado às costas, e a partir desta, eram amostradas outras três plantas na mesma linha separadas por $45 \mathrm{~m}$ (50 plantas), desconsiderando-se as falhas. No mês de fevereiro de 2003, novas plantas foram selecionadas pelo mesmo método, as quais foram marcadas para as novas medições em setembro de 2003.

Nessas plantas, contou-se o número de folhas, mediu-se a altura e o diâmetro das copas ao longo e transversalmente ao renque. Em setembro de 2002, selecionou-se visualmente uma folha representativa do tamanho médio das folhas em cada planta amostrada, e mediu-se o comprimento e a largura da mesma, para obter-se uma média representativa dessas variáveis no cafezal para posteriormente calcular-se a área foliar. Nas medidas feitas em fevereiro e setembro de 2003, a cada 5 plantas amostradas foi selecionado um ramo representativo e foram medidos o comprimento e a largura das folhas do mesmo. A área foliar de cada planta $i$ foi determinada multiplicando-se a média do produto entre o comprimento e a largura (C.L) pelo número de folhas $\left(N_{f}\right)$ e um fator de conversão para a área da folha $(f)$, de maneira a obter-se a área foliar de cada planta $i\left(A F_{i}=\right.$ C.L.f. $\left.N_{f}\right)$. O fator $f$ foi determinado para o mesmo cafezal, relacionandose a área foliar individual de cada folha medida com auxílio de um "scanner" de mesa (Area Meter LI-3000, Li-Cor) e o produto entre o comprimento e a largura de cada folha, obtendo-se um valor médio de 0,6862 , com um coeficiente de determinação igual 0,98 (Righi, C. A. ${ }^{2}$ ). Este valor é bem próximo daquele determinado para cafezal adulto (Marin et al., 2003a), aproximadamente 0,7. A área foliar representativa do cafezal foi

\footnotetext{
${ }^{2}$ RIGHI, C.A. Comunicação pessoal, 2003.
} 
considerada equivalente à média das plantas amostradas $\left(A F=\Sigma_{i}^{N} A F_{i} / N\right.$, em que $N$ é o número de plantas amostradas).

\subsection{Determinação dos perfis de velocidade do vento, de temperatura e de pressão de vapor do ar}

A escolha do local de instalação dos equipamentos de medidas micrometeorológicas foi feita respeitando-se os requerimentos mínimos e possíveis de "bordadura", a partir das dimensões da área e da direção predominante dos ventos. Os ventos predominantes no local são de direção sudeste, aproximadamente no sentido aeroporto-posto meteorológico, com algumas variações ao longo do ano durante o período diurno: nos meses de setembro a dezembro, predominam ventos de sul a leste; em fevereiro, de norte a leste; em março, de sudeste a leste; em abril, de sul a leste; em maio e em junho, de leste; e em agosto, de sul a leste; sendo que durante o período noturno predomina quase que constantemente ventos de sudeste (Pereira et al., 2002a). Por isso, conforme pode ser visto na Figura 1, o local dos equipamentos está deslocado um pouco a noroeste em relação ao centro geométrico da área, aproximadamente a 170 $\mathrm{m}$ do extremo sul, cerca de $60 \mathrm{~m}$ afastado do cafezal adulto e cerca de $40 \mathrm{~m}$ do seringal. Na posição adotada, tinha-se uma "bordadura" de aproximadamente $170 \mathrm{~m}$ na direção predominante dos ventos.

As medidas dos gradientes de temperatura e de pressão de vapor do ar e de vento foram realizadas em um mastro de $5 \mathrm{~m}$ de altura (M1) localizado entre o centro de uma entrelinha e um renque (Figura 2a), sendo instalados seis anemômetros de canecas (cinco MET ONE 014A e um MET ONE 034B-L Wind Set, Met One Instruments, Grants Pass, EUA). Até o dia 08/07/2003, o anemômetro 034B-L estava instalado no nível $2\left(z_{u, 2}\right)$, quando foi passado para o nível $1\left(z_{u, 1}\right)$. Os gradientes de temperatura e pressão de vapor foram determinados com psicrômetros projetados por Marin et al. (2001a). 

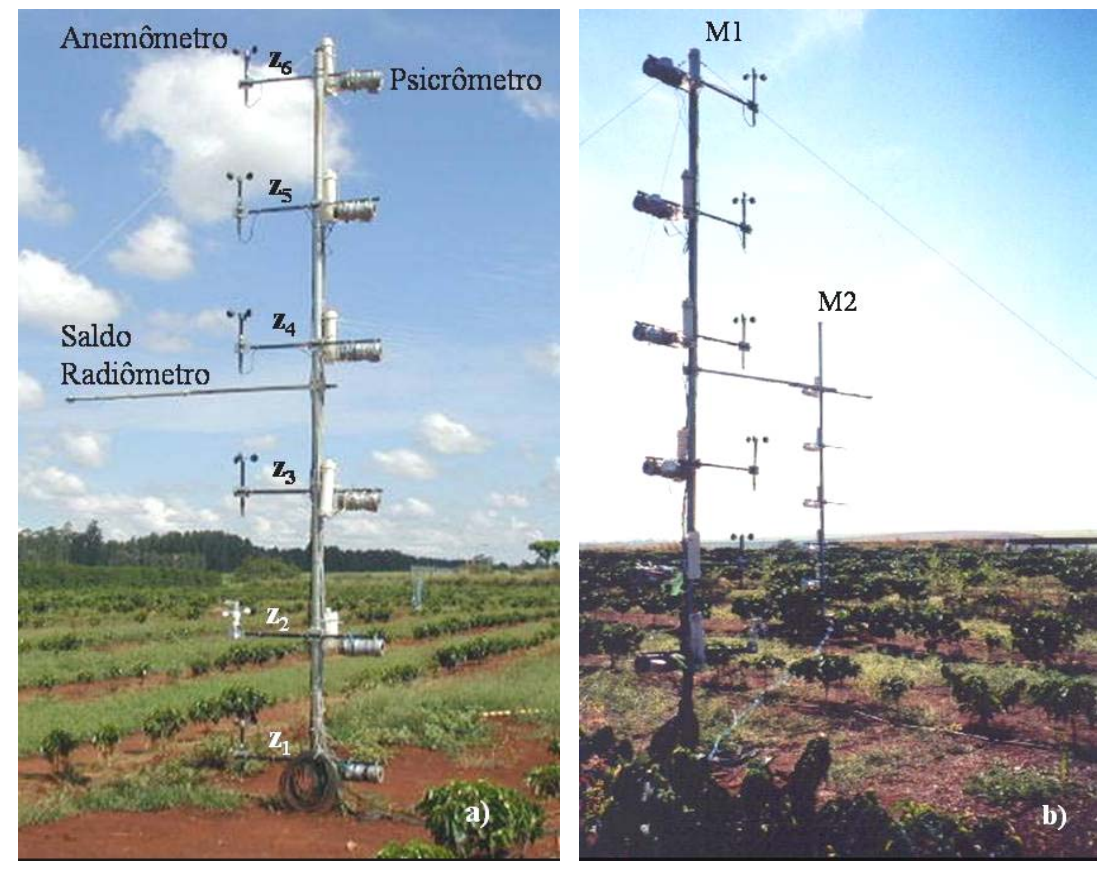

Figura 2 - Visualização do mastro micrometeorológico M1 com os anemômetros, psicrômetros e os respectivos níveis de instalação $\left(z_{i}\right)$, e o saldo radiômetro (a) e da disposição dos mastros M1 e M2

Em julho de 2003 instalou-se um segundo mastro (M2) afastado $15 \mathrm{~m}$ de M1, com os novos psicrômetros nos mesmos níveis do M1, com exceção do mais alto (Figura 2b), com a finalidade de melhorar a amostragem, devido ter-se observado algumas distorções nos perfis de temperatura e umidade em M1 durante as medidas anteriores. $\mathrm{Na}$ Tabela 1 são apresentadas as alturas acima do solo dos instrumentos durante os períodos experimentais. Essas alturas foram determinadas a partir das condições de "bordadura" e das diferenças nas respostas psicrométricas às condições ambientais, buscando por diferenças verticais de temperatura não muito pequenas, a fim de diluir os erros de medida (Fuchs \& Tanner, 1970; Rosemberg \& Brown, 1974; Spittlehouse \& Black, 1979, 1980; Redford et al., 1980; Munro, 1980; McCaughey \& Brintnell, 1984; Aston; 1985). Em função do crescimento das plantas e de algumas trocas ou inversões de equipamentos, feitas para verificar se existiam erros sistemáticos por deficiência de operação dos sensores, os níveis de medida foram mudados ao longo do experimento. $\mathrm{O}$ 
fornecimento de água para o reservatório do psicrômetro foi feito a partir de um tubo de Mariotte, para diminuir a freqüência da presença de um operador na área.

A determinação correta de gradientes de temperatura e umidade a campo é bastante difícil. A deposição diferenciada de sujeira sobre os bulbos com a altura, especialmente o úmido, modifica o coeficiente psicrométrico não uniformemente e por isso, as gazes feitas de cadarço de algodão foram substituídas em intervalos de no máximo 4 dias, fervendo-as previamente para retirada da goma (Fevrot, 1977; McCaughey \& Britnell, 1984; Monteith \& Unsworth, 1990; Allen et al., 1994; Visscher, 1995; Marin et al., 2001a).

Tabela 1. Nível dos psicrômetros e anemômetros (em metros) durante as campanhas de coleta de dados. Os símbolos $\left(T_{i}\right)$ denotam os níveis $i$ de instalação dos psicrômetros e $\left(u_{i}\right)$ denotam os níveis $i$ de instalação dos anemômetros, em metros acima da superfície do solo

\begin{tabular}{lllllllllllll}
\hline Período & $u_{1}$ & $T_{1}$ & $u_{2}$ & $T_{2}$ & $u_{3}$ & $T_{3}$ & $u_{4}$ & $T_{4}$ & $u_{5}$ & $T_{5}$ & $u_{6}$ & $T_{6}$ \\
\hline $04 / 10-17 / 12 / 02$ & 0,55 & 0,24 & 1,27 & 1,04 & 2,31 & 1,96 & 3,23 & 2,88 & 4,15 & 3,80 & 5,07 & 4,72 \\
$31 / 01-13 / 03 / 03$ & 0,55 & 0,24 & 1,27 & 1,04 & 2,31 & 1,96 & 3,23 & 2,88 & 4,15 & 3,80 & 5,07 & 4,72 \\
$13 / 03-23 / 03 / 03$ & 0,98 & 0,68 & 1,49 & 1,28 & 2,29 & 1,99 & 3,21 & 2,91 & 4,13 & 3,83 & 5,05 & 4,75 \\
$27 / 05-02 / 07 / 03$ & 0,97 & 0,68 & 1,52 & 1,27 & 2,32 & 1,98 & 3,24 & 2,93 & 4,17 & 3,87 & 5,11 & 4,80 \\
$02 / 05-08 / 07 / 03$ & 0,93 & 0,71 & 1,44 & 1,29 & 2,23 & 2,00 & 3,17 & 2,93 & 4,11 & 3,85 & 5,05 & 4,78 \\
$08 / 07-22 / 07 / 03$ & 0,86 & 0,71 & 1,53 & 1,29 & 2,25 & 2,00 & 3,19 & 2,93 & 4,13 & 3,85 & 5,07 & 4,78 \\
$20 / 08-18 / 09 / 03$ & 0,85 & 0,72 & 1,52 & 1,29 & 2,25 & 2,01 & 3,20 & 2,95 & 4,12 & 3,86 & 5,02 & 4,78 \\
\hline
\end{tabular}

\subsection{Determinação do saldo de radiação da cobertura vegetal e do fluxo de calor no solo.}

O saldo de radiação $(R n)$ foi medido com um saldo-radiômetro modelo $Q^{* 7.1}$ (Rebs Inc., Seattle, EUA.) instalado a 3,5 $\mathrm{m}$ do solo, sobre um braço com comprimento de 2,5 m em M1. O fluxo de calor no solo $(G)$ foi obtido por três placas modelo HTF 3.1 (Rebs Inc., Seattle, EUA) enterradas a aproximadamente $2 \mathrm{~cm}$ de profundidade. Para obter maior representatividade da área, uma placa foi instalada sob a copa de um 
cafeeiro, outra entre duas plantas e a terceira no centro de uma entrelinha, consideradas representativas, respectivamente, da área coberta pela copa dos cafeeiros, da área descoberta pelas plantas na faixa do renque equivalente ao diâmetro médio das copas $\left(D_{c}\right.$ $=\left(\sum_{i}^{N} D_{c, i}\right) / N$, sendo $D_{c, i}$ o diâmetro médio da planta $\left.i\right)$ e da faixa da entrelinha livre das copas $\left(3,5-D_{c}\right)$. A ponderação dos valores obtidos pelas três placas foi realizada conforme as Equações 15 e 16, a partir de uma área $A_{G}=1 \mathrm{~m}^{2}$ :

$$
\begin{aligned}
& G=\frac{1}{A_{G}}\left[G_{p} \cdot A_{C}+G_{e-p} \cdot\left(A_{r}-A_{C}\right)+G_{e-l} \cdot\left(1-A_{r}\right)\right] \\
& 1=\frac{1}{A_{G}}\left\{A_{\text {copa }} \cdot n+\left(D_{c} \cdot 0,2857-A_{\text {copa }} \cdot n\right)+\left[0,2857 \cdot\left(3,5-D_{c}\right)\right]\right\}
\end{aligned}
$$

em que $G_{p}, G_{e-p}$ e $G_{e-l}$ são, respectivamente, os valores de fluxo de calor no solo sob uma planta, entre duas plantas e na entrelinha $\left(\mathrm{W} . \mathrm{m}^{-2}\right) ; A_{\text {copa }}$ é a área referente à projeção horizontal da copa média calculada a partir do diâmetro médio das copas $\left[A_{\text {copa }}=\right.$ $\left.\pi \cdot\left(D_{c} / 2\right)^{2}\right] ; A_{r}, A_{e-l}$ e $A_{C}$ são, respectivamente, as áreas superficiais referentes à faixa ocupada pelo renque (considerada equivalente $D_{c} .0,2857 \mathrm{~m}^{2}$ ), à área da entrelinha e à área total ocupada pelas copas das plantas; $n$ é o número de plantas no segmento do renque de 0,2857 m compondo um lado do retângulo de $1 \mathrm{~m}^{2}$, cujo lado ortogonal mede $3,5 \mathrm{~m}$ (espaçamento entre os renques).

\subsection{Determinação lisimétrica da evapotranspiração dos cafeeiros e das entrelinhas.}

Cerca de $2 \mathrm{~m}$ e $4 \mathrm{~m}$ afastados de M1 foram instalados dois lisímetros de pesagem de $0,9 \mathrm{~m}$ de diâmetro e $0,7 \mathrm{~m}$ de profundidade (Figura 3). $\mathrm{O}$ tanque lisimétrico de aço carbono, com parede de espessura de $5 \mathrm{~mm}$, foi instalado interna e concentricamente a uma parede externa de mesma espessura e material, com um espaço de $50 \mathrm{~mm}$ entre eles, sendo que o poço escavado no solo (cerca de 2,0 $\mathrm{m}$ de profundidade) permitia o acesso por meio de uma abertura lateral ao sistema de drenagem por gravidade e às células de carga, para sua manutenção. Três células de carga, modelo GL, com capacidade nominal de 5 a $250 \mathrm{~kg}$ (Interface Ltda, Campinas - 
SP), foram instaladas em cada lisímetro sobre colunas de concreto, estando o tanque lisimétrico interno apoiado sobre elas.
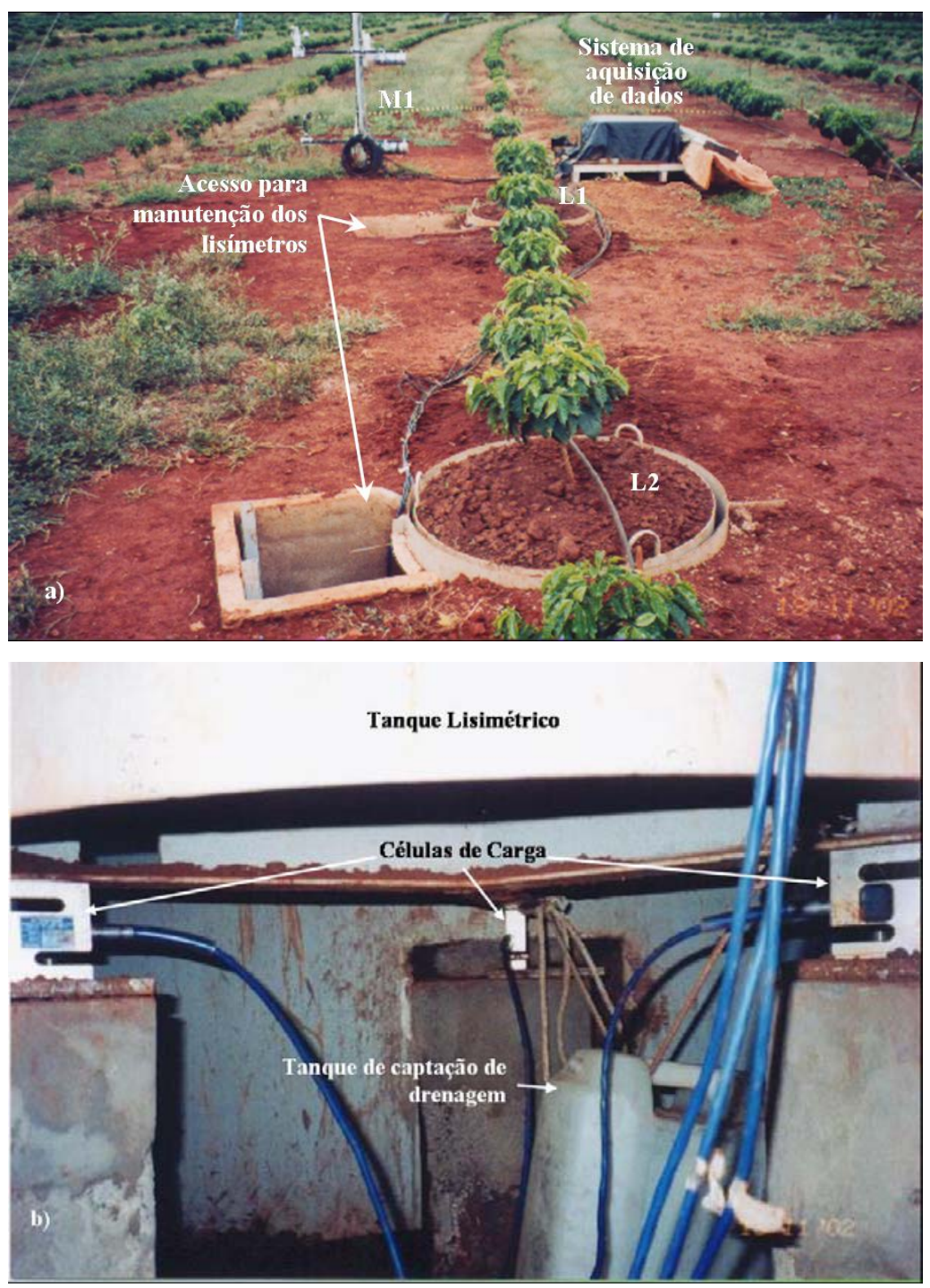

Figura 3 - Visualização dos lisímetros $L 1$ e $L 2$ em relação ao mastro M1 e o sistema de aquisição de dados (a) e do sistema de pesagem e drenagem (b)

O lisímetro foi preenchido com um monolito de solo retirado em local próximo para preservar as propriedades físicas e químicas naturais. Após cerca de 20 dias do preenchimento, duas plantas periféricas no cafezal foram removidas com um torrão de 
aproximadamente $0,30 \mathrm{~m}$ de altura por $0,30 \mathrm{~m}$ de diâmetro para minimizar os danos ao sistema radicular, as quais foram re-implantadas uma em cada lisímetro.

A calibração das células de carga foi realizada individualmente com auxílio de uma máquina de tração e compressão universal (Instron 4466) no laboratório de Mecânica e Máquinas Motoras da ESALQ. Conforme o fabricante, na carga máxima $(250 \mathrm{~kg})$, as células de carga deveriam ter um sinal elétrico de aproximadamente $2( \pm 0,2)$ $\mathrm{mV} . \mathrm{V}^{-1}$ de excitação. Isso corresponde a aproximadamente $125 \mathrm{~kg} \cdot \mathrm{mV}^{-1}$ de saída. Os valores obtidos na calibração com passos de aproximadamente $50 \mathrm{~kg}$ variaram entre $125,07 \mathrm{~kg} \cdot \mathrm{mV}^{-1}$ e $125,89 \mathrm{~kg} \cdot \mathrm{mV}^{-1}$, com coeficientes lineares entre $0,06 \mathrm{~kg}$ e $2,24 \mathrm{~kg}$. O efeito da variação da temperatura sobre as propriedades elétricas das células de carga foi minimizado pela manutenção da temperatura constante durante a realização dos ensaios de aferição, já que o laboratório dispunha de sistema condicionador de ar. No campo, conforme resultados de Allen \& Fisher (1991), o efeito térmico pode ser considerado como insignificante devido ter-se trabalhado na escala diária e, principalmente, pelo fato das células terem sido instaladas cerca de 1,00 $\mathrm{m}$ de profundidade, protegidas das altas amplitudes térmicas presentes na superfície, e por estarem todas submetidas às mesmas condições ambientais.

Até o dia 12/11/02, as células de carga foram excitadas com uma tensão fixa de $1 \mathrm{~V}$ aplicada pelo sistema de aquisição de dados (“datalogger" CR7, Campbel Scientific Inc., Logan, EUA). A partir de então, passou-se a excitar as células com uma fonte externa, aplicando-se aproximadamente $4,5 \mathrm{~V}$, a qual era medida também pelo “datalogger”. Devido à grande oscilação na tensão na rede elétrica, a partir da campanha de maio - julho de 2003, voltou-se a excitar as células de carga com o "datalogger", agora com $5 \mathrm{~V}$, por fornecer uma tensão estável e, portanto, reduzir o "ruído" de saída das células de carga.

Para facilitar o controle de entrada e saída de água, instalou-se um galão plástico de $20 \mathrm{~L}$ suspenso no tanque de cada lisímetro, permitindo que a variação de peso fosse somente referente à evapotranspiração, mesmo durante a ocorrência de drenagem. Em alguns casos, especialmente quando a irrigação passou a ser feita durante 16 h, ocorria transbordamento dos galões, sendo estes dias identificados e descartados. 
Os dias com chuva durante o período diurno (entre 7:00 h e 18:00 h) e irrigação ou drenagem, foram desconsiderados. Para evitar erros devido à elevada flutuação dos sinais de saída observada mesmo à noite, a evapotranspiração lisimétrica foi obtida pela subtração de um dia para o outro do peso médio medido entre 22:00 h e 2:00 h.

A componente evapotranspiração da entrelinha foi obtida utilizando-se 5 minilisímetros de pesagem, instalados três no centro da segunda entrelinha a leste de M1 e os outros dois entre o centro da entrelinha e o renque de cafeeiros (Figura 4a). Para a montagem, foram utilizados tanques de PVC de 0,43 $\mathrm{m}$ de diâmetro na base superior, $0,35 \mathrm{~m}$ de diâmetro na base inferior e $0,40 \mathrm{~m}$ de altura, sendo um volume amostrado de $0,048 \mathrm{~m}^{3}$. Os tanques foram preenchidos com o solo retirado do local de sua instalação, sendo que os $10 \mathrm{~cm}$ superiores consistiram de um bloco de solo retirado próximo do local, conservando a cobertura representativa da entrelinha. Após sua instalação foi realizada uma intensa irrigação até o encharcamento completo, para favorecer o restabelecimento das invasoras e re-agregar o solo. Sete dias depois se realizou nova irrigação. A partir de então, aguardaram-se 20 dias para que os minilisímetros tivessem uma situação semelhante ao exterior para iniciarem-se as medidas no dia 01/07/03.

A variação de peso dos minilisímetros foi determinada com uma célula de carga de tração com capacidade de $100 \mathrm{~kg}$, calibrada da mesma forma daquelas dos lisímetros grandes, porém com passos de $10 \mathrm{~kg}$ (peso $=43,6004 \mathrm{~kg} \cdot \mathrm{mV}^{-1}-0,1884 \mathrm{~kg}$ ). A célula foi excitada com aproximadamente $10 \mathrm{~V}$ por uma fonte de corrente contínua. As medidas da voltagem de excitação e de saída foram feitas com um multímetro digital (ET-2702, Heavy Duty Digital Multimeter), com resolução máxima de 0,01 mV. Desta forma, a resolução das medidas obtidas foi de aproximadamente $0,05 \mathrm{~kg}$, o que não foi suficientemente alta para medidas diárias. Uma evapotranspiração na entrelinha de 0,5 mm equivale a $0,07 \mathrm{~kg}$ por minilisímetro, valor muito próximo da resolução do sistema de medida. Portanto, com as medidas iniciadas no dia 01/07/2003, foram realizadas diariamente até o dia 04/07/2003 e subseqüentemente, com intervalos de 3 a 4 dias. Quando da ocorrência de chuvas, o período foi descartado, iniciando-se uma nova seqüência de medidas após o fim da drenagem. Devido à oscilação da energia na rede 
elétrica principal, que repercutia na saída da fonte, cada medida consistiu da média de 4 leituras, tanto na voltagem de excitação como na de saída, feitas num intervalo de $30 \mathrm{~s}$.

Para a realização das pesagens e facilitar o levantamento de aproximadamente $50 \mathrm{~kg}$, construiu-se um cavalete de 2,0 $\mathrm{m}$ de altura e 0,7 $\mathrm{m}$ de largura, onde era suspensa a célula de carga e, nela, o minilisímetro, com o auxílio de um moitão de duas roldanas. Os tanques minilisimétricos foram suspensos por correntes fixadas a duas barras metálicas soldadas em cruz sob os mesmos. Antes das leituras, foi retirado o solo impregnado externamente às paredes lisimétricas e depositado sobre as barras de ferro para não haver variações errôneas entre as medidas. Assim, a evapotranspiração da entrelinha foi determinada pela diferença entre as leituras anterior e atual referentes à área da base superior dos tanques, dividida pelo número de dias do período entre as duas medidas, considerando-se a densidade da água equivalente a $1 \mathrm{~kg} . \mathrm{L}^{-1}$.
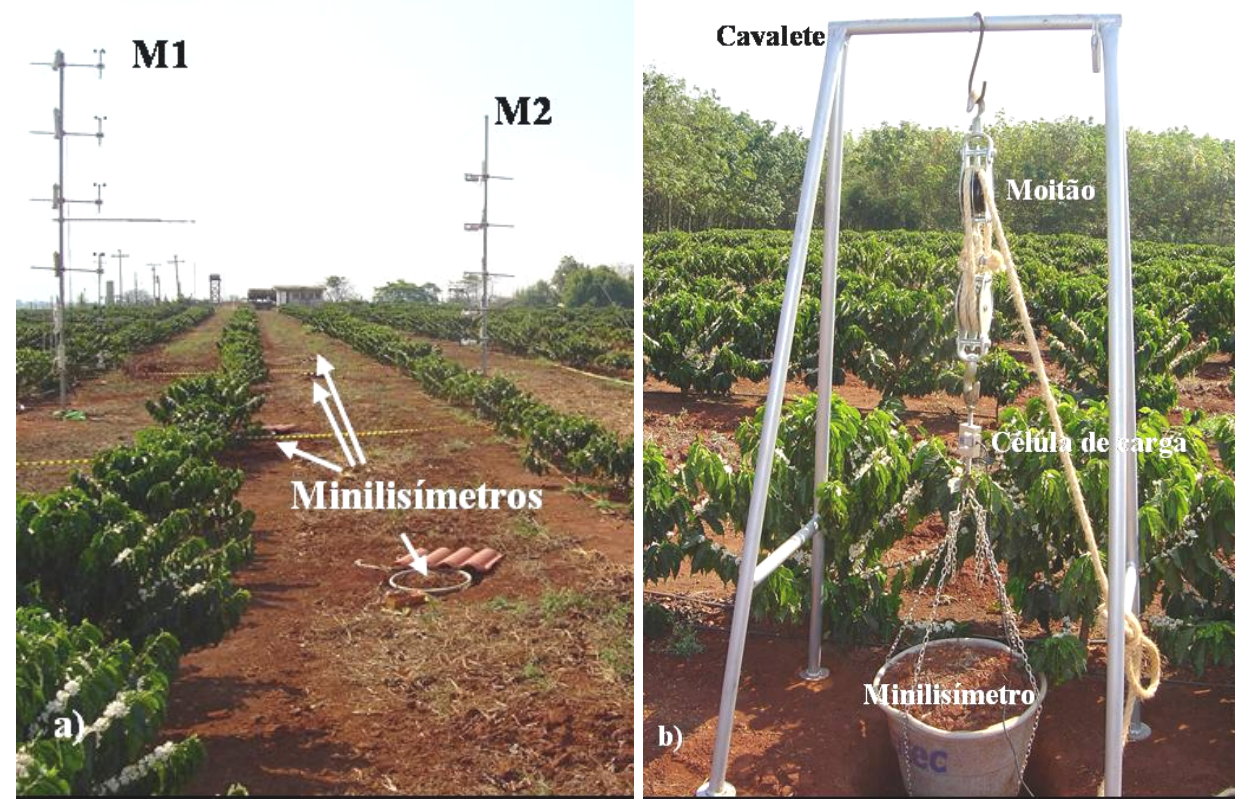

Figura 4 - Localização de quatro dos cinco minilisímetros (a) e o sistema de suspensão para pesagem dos mesmos (b) 


\subsection{Determinação do fluxo de seiva (transpiração) dos cafeeiros}

As determinações do fluxo de seiva foram realizadas pelo método do balanço de calor no caule (MBC) com o uso de sensores comercializados pela Dynamax@ inc. (Houston, Texas, EUA) (Van Bavel, 1994) modelo SGB16 (diâmetro nominal entre 15 e $19 \mathrm{~mm}$ ) e modelo SGB25 (diâmetro nominal entre 24 e $32 \mathrm{~mm}$ ).

Com a finalidade de maior detalhamento sobre os cálculos de fluxo de seiva, apresenta-se a seguir as equações usadas no MBC, propostas por Sakuratani (1984) e Baker \& Van Bavel (1987). Para facilidade de entendimento, a Figura 5 mostra um esquema da montagem do sensor, com seus elementos componentes (aquecedor, fluxímetro, termopilha, termopares e placa de neopreno atuando como isolante).

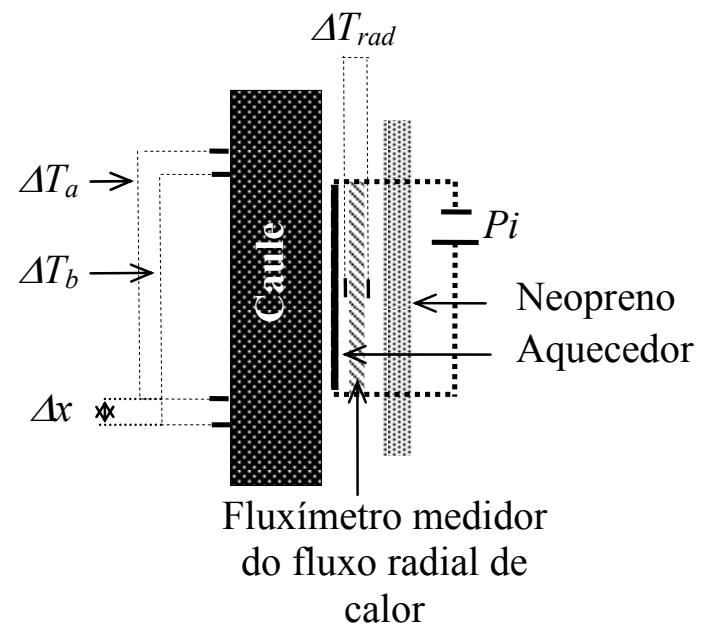

Figura 5 - Esquema dos sensores de fluxo de seiva comercializados pela Dynamax ( (Van Bavel, 1994), utilizados no experimento. O aquecedor, em contato com o caule, dissipa uma potência $P i$ na forma de calor. Os fluxos axiais são calculados a partir das diferenças de temperatura $\Delta T_{a}$ e $\Delta T_{b}$, medidos por termopares à distância $\Delta x$ nas extremidades superior e inferior do segmento. O fluxo radial é determinado a partir da diferença de temperatura radial $\Delta T_{\text {rad }}$ medido por um fluxímetro de termopilha consistindo de uma placa de cortiça com conjuntos de termopares em série em cada lado da placa 
A equação geral do balanço de calor no caule, em intervalos de tempo estabelecidos (15 min), é assim descrita:

$$
A r m=P i-(Q s+Q a+Q r)
$$

em que Arm é o armazenamento de calor, $P i$ é uma taxa de calor (potência dissipada) fixa fornecida continuamente, $Q a$ e $Q r$ são, respectivamente, os fluxos condutivos axiais e radial e $Q s$ é o fluxo de calor transportado convectivamente pela seiva.

O valor de Arm foi considerado igual zero devido ao pequeno diâmetro do caule, conforme sugerido por Van Bavel (1994), Grime et al. (1995a, b) e Grime \& Sinclair, 1999). Os fluxos axiais (a montante e a jusante do sensor) foram calculados na forma integrada, conforme a Equação 18:

$$
Q a=K s t . A_{c} \cdot \frac{\left(\Delta T_{b}-\Delta T_{a}\right)}{\Delta x}
$$

em que Kst é a condutividade térmica do lenho úmido, considerada igual a $0,42 \mathrm{~W} \cdot \mathrm{m}^{-1} \cdot{ }^{\circ} \mathrm{C}^{-1}$ (Steinberg et al., 1989) e $A_{c}$ é a área da seção transversal do caule.

Qr foi obtido de acordo com a Equação 19:

$$
Q r=K r \cdot \Delta T_{r a d}
$$

em que $K r$ é a condutividade térmica do fluxímetro de calor radial e pode ser obtida em condições de fluxo de seiva nulo ou desprezível para cada instalação do sensor, com a Equação 20:

$$
K r=\frac{(P i-Q a)}{\Delta T_{r a d}}
$$

Obtidos os valores de $Q a$ e $Q r$, assumindo-se $A r m=0$ e conhecendo-se $P i, Q s$ pode ser calculado como o termo residual do balanço. O grande problema no cálculo de $Q s$ é a correta determinação de $Q r$, que por sua vez depende da acurácia de $K r$, pois em cada instalação do sensor, seu formato final é diferente, resultando em dissipação de calor diferenciada. Para facilitar o uso do método, Sakuratani (1984) e Baker \& Van Bavel (1987) propuseram a determinação de $K r$ em caules cortados, ou plantas cobertas por sacos plásticos, ou no final da madrugada em plantas cultivadas sem restrição hídrica nas raízes, de modo a garantir-se fluxo de seiva zero ou desprezível (Equação 
20). No caso presente, a determinação de $K r$ foi feita na madrugada e, embora Righi et al. ${ }^{1}$ tenham verificado transpiração noturna dos cafeeiros, o que acaba superestimando o seu valor (Ishida et al, 1991; Grime et al., 1995a), desde que o fluxo seja próximo de zero, os erros em $K r$ não chegam a ser limitantes à utilização do método (Grime et al., 1995a). Sendo assim, os valores de $K r$ foram determinados a cada instalação e para cada sensor nas noites em que se realizava irrigação e/ou até três noites após uma irrigação ou chuva, buscando-se o menor valor médio entre 3:00 h e 5:00 h, o qual representa a condição com menor influência dos erros decorrentes da desconsideração de Arm e de assumir-se $Q s=0$ (Righi et al. ${ }^{2}$ ). Nos períodos em que se identificaram problemas nos sinais de saída devido ao acúmulo de água no interior dos sensores, os dados foram desconsiderados, sendo alguns dias completos descartados.

Obtido o valor de $Q s$, sua transformação em fluxo volumétrico de seiva foi realizada de acordo com a Equação 21:

$$
F S=\frac{Q s}{C p \cdot\left[\frac{\left(\Delta T_{a}+\Delta T_{b}\right)}{2}\right]}
$$

em que $C p$ é o calor específico volumétrico da seiva, considerado igual ao da água (4186 $\left.\mathrm{J} \cdot \mathrm{L}^{-1} \cdot{ }^{\circ} \mathrm{C}^{-1}\right)$.

O aquecedor foi energizado com uma voltagem próxima da faixa média recomendada pelo fabricante, suficiente para manter $T_{\text {sup }}-T_{\text {inf }}=\left(\Delta T_{a}+\Delta T_{b}\right) / 2<8^{\circ} \mathrm{C}$ a noite e $T_{\text {sup }}-T_{\text {inf }}>0,30{ }^{\circ} \mathrm{C}$ durante os períodos de alta taxa de fluxo, conforme recomendado pelo fabricante (Van Bavel, 1994) e avaliado por Grime \& Sinclair (1999). A alimentação elétrica dos sensores foi feita com uma fonte de corrente contínua (AVR3/6, Dynamx Inc., Houston, EUA), cuja voltagem foi mantida entre $4 \mathrm{~V}$ e 4,5 V (típica recomendada é 4,5 V) no SGB16 e entre 3,5 V e $4 \mathrm{~V}$ (típica recomendada é $4 \mathrm{~V}$ ) no modelo SGB25. A potência foi calculada a partir dos valores da tensão $(V)$ aplicada sobre o aquecedor e medida pela "datalogger", e da resistência $(R)$ do aquecedor,

\footnotetext{
${ }^{1}$ RIGHI, E. Z.; RIBEIRO, R. V.; MARIN, F. R.; ANGELOCCI, L. R.; OLIVEIRA, R. F.; MACHADO, E. C. (ESALQ/USP) Estimative of sap flow in potted-plants by heat balance technique: I. methodological and practical aspects. (Em elaboração).
} 
fornecida pelo fabricante $\left(P i=V^{2} / R\right)$, resultando em valores de $P i$ variando em torno de 0,18 W nos sensores modelo SGB16 e 0,30 W nos sensores modelo SGB25. Para o cálculo de $Q a$, foi medido o diâmetro do caule em três posições onde o sensor seria instalado, tomando-se a média para determinar $A_{c}$.

As medidas foram realizadas em duas plantas com o SGB16 em dezembro de 2002 e, como as plantas utilizadas durante essas medidas haviam morrido, no período de fevereiro - março de 2003 foram realizadas em seis plantas, sendo amostradas duas em cada seqüência de dias de medida, a fim de reduzir o tempo de aquecimento constante do mesmo caule como tentativa de reduzir os danos causados pelo calor e pela pasta aplicada sobre o caule, conforme discutido por Wiltshire et al. (1995), o que não se mostrou efetivo. Assim, em agosto - setembro de 2003 as medidas foram feitas somente em 4 plantas. Em todas as coletas de dados, os sensores foram operados continuamente na mesma planta por no máximo 5 dias.

Antes de instalar-se o sensor de fluxo de seiva, foram removidas a sujeira e a casca morta na superfície do caule, passando-se suavemente uma lixa e, posteriormente, um pano seco. Então, foi aplicada a pasta condutora térmica Dow Corning Compound 4 (Dow Corning Corporation, Medland, EUA), a qual também é isolante elétrica e repelente hídrica e, sobre ela, aproximadamente 1,5 volta de um filme plástico de PVC fino para evitar o contato direto do aquecedor e dos termopares com a pasta e qualquer fonte de umidade, minimizando possíveis problemas de curto-circuito ou danos ao próprio sistema aquecedor/sensor (Weibel \& De Vos, 1994). Finalmente, foi instalado o sensor, apertando-o bem contra o caule para se ter bom contato. Sobre o mesmo, foram enroladas 6 a 7 camadas de folha de alumínio com o lado mais refletivo voltado para fora, desde a superfície do solo até cerca de $10 \mathrm{~cm}$ acima do sensor. Na extremidade superior dessa proteção, foi aplicada borracha de silicone a fim de evitar a entrada da água da chuva escorrida através do caule. Posteriormente, foi colocada mais uma camada de folha de alumínio em forma de cone, sendo este fechado na extremidade superior contra o caule e abrindo num raio de aproximadamente $10 \mathrm{~cm}$ na extremidade inferior, em contato com o solo, para proteger contra a incidência de radiação solar direta (Groot \& King, 1992; Gutiérrez et al., 1994; Marin, 2003). Na Figura 6 é 
mostrada uma seqüência de fotos que ilustra a montagem dos sensores sobre o caule das plantas.

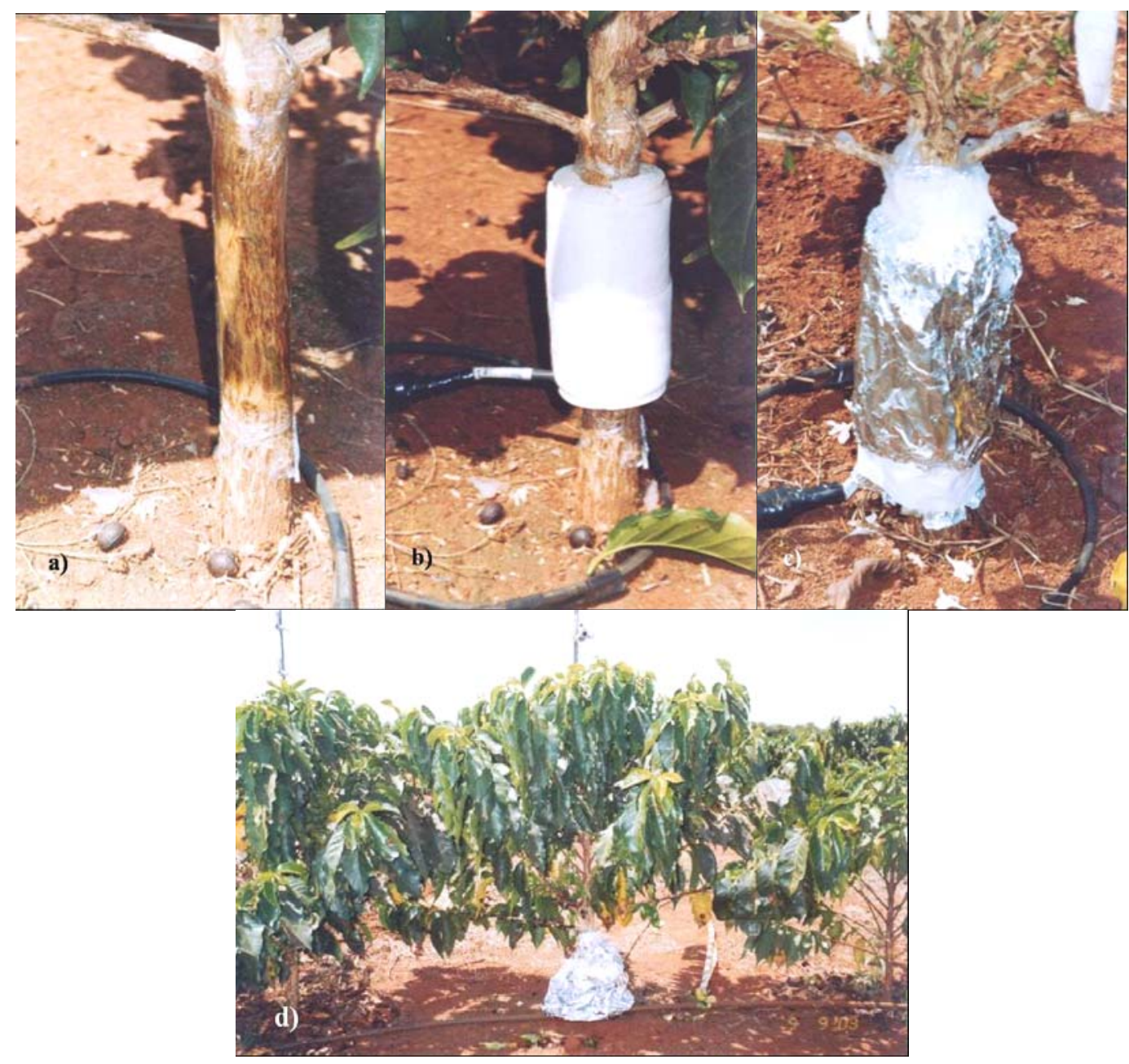

Figura 6 - Seqüência de fotos mostrando as etapas de instalação dos sensores de fluxo de seiva: caule com a pasta condutora térmica e o filme de PVC (a); sensor instalado (b); sistema envolvido pelo papel alumínio, como isolante térmico e radiativo (c) e; isolante radiativo adicional em forma de cone (d)

As plantas escolhidas para se determinar $F S$ tinham um desenvolvimento acima da média do cafezal em 2002, devido ao tamanho dos sensores disponíveis. Em 2003 foi possível selecionar plantas mais representativas da lavoura, dentro de um raio de $10 \mathrm{~m}$ 
em torno do sistema de aquisição de dados. Na seleção dessas plantas, procurou-se por aquelas com o segmento de caule uniforme, para garantir um bom contato sensor - caule (Weibel \& De Vos, 1994).

Em geral, todas as plantas utilizadas nas medidas de $F S$ começaram a apresentar indícios de definhamento cerca de 45 dias após a primeira instalação dos sensores, morrendo posteriormente, provavelmente por causa do impedimento das trocas gasosas no tecido envolto pela pasta e pelo filme plástico, associado ao aquecimento e algum possível efeito tóxico (Wiltshire et al., 1995). Assim, para evitar um raleamento do cafezal em torno do local onde estavam instalados os mastros micrometeorológicos e os lisímetros, não foram feitas medidas de $F S$ em maio - julho de 2003 e nas plantas dos próprios lisímetros.

\subsection{Armazenamento e processamento dos dados}

Os sinais de saída dos sensores de fluxo de seiva, das células de carga, dos termopares, dos anemômetros, do saldo radiômetro e das placas de fluxo de calor no solo foram tomadas a cada $5 \mathrm{~s}$ e suas médias calculadas pelo sistema de aquisição de dados CR7 (Campbell Scientific Inc., Logan, EUA) a cada 15 min, e armazenadas em fase com as medidas na estação meteorológica.

\subsection{Determinação da evapotranspiração da cultura e de referência}

Para os cálculos de $L E$ e $H$ por métodos micrometeorológicos, trabalhou-se com intervalos de $30 \mathrm{~min}$ para suavização da variabilidade dos elementos meteorológicos, especialmente da velocidade do vento (Monteith \& Unswort, 1990). Os gradientes de vento, de temperatura e de pressão de vapor $[\partial(u, \theta, e) / \partial z]$ foram considerados equivalentes às diferenças finitas $\left[\Delta\left(\theta, T_{u}, u\right) / \Delta z\right]$ (Pereira, 1998), embora a instalação dos equipamentos não tenha seguido uma disposição logarítmica (Stearns, 1970; Pereira, 1998). Para o MA, testou-se a aproximação $\partial(u, \theta, e) / \partial z \approx \overline{\Delta(u, \theta, e) / \Delta z}=$ $\Delta(u, \theta, e) /\left[\left(z_{i} \cdot z_{i-1}\right)^{0,5} \cdot \ln \left(z_{i} / z_{i-1}\right)\right]($ Pereira, 1998). 
A evapotranspiração da cultura $(E T c)$ foi determinada a partir dos fluxos calculados com o MA e o MRB. Para tal, foram utilizados os gradientes de velocidade do vento, de temperatura e de umidade do ar obtidos em M1 e M2. Seguindo Pereira (1998), a partir das Equações 3 a 9 e partindo-se da hipótese de similaridade, estabeleceu-se a relação $L E / \tau$ e $H / \tau$, sendo $\tau$ o transporte de momento para a superfície, resultando nas Equações 22 e 23:

$$
\begin{aligned}
& L E_{M A}=-\rho \cdot L \cdot k^{2} \cdot \frac{0,622}{P} \cdot\left(\overline{z_{u}}-d\right)^{2} \cdot \frac{\Delta u}{\Delta z_{u}} \cdot \frac{\Delta e}{\Delta z_{p}} \cdot F \\
& H_{M A}=-\rho \cdot c p \cdot k^{2} \cdot\left(\overline{z_{u}}-d\right)^{2} \cdot \frac{\Delta u}{\Delta z_{u}} \cdot \frac{\Delta \theta}{\Delta z_{p}} \cdot F
\end{aligned}
$$

em que $L E_{M A}$ e $H_{M A}$ são, respectivamente, os fluxos de calor latente e sensível determinados pelo MA; $P$ é a pressão atmosférica em $\mathrm{kPa} ; \overline{z_{u}}$ é a altura média geométrica $\left[\overline{z_{u}}=\left(z_{u, i} \cdot z_{u, i-1}\right)^{0,5}\right]$ referente aos níveis $i$ de velocidade do vento consideradas; $\Delta e$ é a diferença de pressão de vapor entre o nível superior e inferior; $\rho$ é a densidade do ar úmido $\left\{\rho=\left[M a .\left(P-e_{\text {médio }}\right)+M w . e_{\text {médio }}\right] /\left(R . \theta_{\text {média }}\right)\right\}$, sendo $M a$ a massa molecular do ar seco, $M w$ a massa molecular da água, $e_{m e ́ d i o}$ a pressão de vapor do ar média dos níveis considerados, $R$ a constante universal dos gases ideais $\left(8,3143 \mathrm{~J} \cdot \mathrm{mol}^{-1} \cdot \mathrm{K}^{-1}\right)$ e $\theta_{\text {médio }}$ a temperatura potencial média dos níveis considerados no perfil, com $\theta=T_{s}-\Gamma(\Gamma$ é o gradiente adiabático seco, $\left.-0,0098{ }^{\circ} \mathrm{C} . \mathrm{m}^{-1}\right) ; F$ é o fator de correção de estabilidade, o qual é função empírica de $R i$.

Para condições de instabilidade atmosférica $(-0,01>R i>-1)$, tem-se (Dyer \& Hicks, 1970):

$$
\phi_{m}^{2}=\phi_{h}=\phi_{w}=(1-16 \cdot R i)^{-0,5}
$$

e, sendo $K_{h} / K_{m}=K_{w} / K_{m}=\phi_{m} / \phi_{h}=\phi_{m} / \phi_{w}$, tem-se:

$$
F=\frac{K_{h}}{K_{m}} \cdot \phi_{m}{ }^{-2}=\frac{K_{w}}{K_{m}} \cdot \phi_{m}{ }^{-2}=(1-16 \cdot R i)^{0,75}
$$

Na estabilidade atmosférica $(1>R i>0,01)$, tem-se (Webb, 1970):

$$
\phi_{m}=\phi_{h}=\phi_{w}=(1-5,2 . R i)^{-1} ; K_{h} / K_{m}=K_{w} / K_{m}=\phi_{m} / \phi_{h}=\phi_{m} / \phi_{w}=1 \mathrm{e},
$$




$$
F=\frac{K_{h}}{K_{m}} \cdot \phi_{m}{ }^{-2}=\frac{K_{w}}{K_{m}} \cdot \phi_{m}{ }^{-2}=(1-5,2 \cdot R i)^{2}
$$

A Equação 26 é indeterminada quando $R i \rightarrow 0,1923$ e Webb (1970) discute que esse valor encontra-se em uma provável transição para ausência total de turbulência. Portanto, para $R i \geq 0,19, F$ foi considerado igual a $(1-5,2.0,19)^{2}=1,4 \cdot 10^{-5}$. Quando a atmosfera foi neutra $(|R i| \leq 0,01), F=1$.

$R i$ foi calculado de acordo com a Equação 28:

$$
R i=\frac{g \cdot \frac{\Delta \theta}{\Delta z_{p}}}{\theta_{\text {média. }}\left(\frac{\Delta u}{\Delta z_{u}}\right)^{2}}
$$

em que $g$ é a aceleração da gravidade $\left(9,8 \mathrm{~m} . \mathrm{s}^{-2}\right), \theta_{\text {média }}$ é a temperatura potencial média (em $\mathrm{K})$ e $\Delta \theta$ é a diferença entre as temperaturas potenciais dos níveis considerados.

O valor de $d$ foi determinado a partir do perfil de vento por um método iterativo, sendo aquele que correspondeu ao mínimo erro no ajuste entre $u_{z}$ e $\ln (z-d)$ (Pereira, 1998; Righi et al., 2003). Como o perfil logarítmico é válido somente em condições de neutralidade atmosférica, o que é relativamente difícil de se obter a campo e as medidas de $T_{s}$ e $T_{u}$ foram feitas em níveis diferentes de $u$, assumiu-se procedimento semelhante ao de Villa Nova (1973). Quando a atmosfera se apresenta mais próxima da neutralidade, o ajuste entre $u_{z}$ e $\ln (z)$ é maior, o qual foi avaliado pelo coeficiente de determinação $\mathrm{R}^{2}$. Portanto, considerou-se os valores médios de $d$ calculados quando $\mathrm{R}^{2}$ para a relação entre a velocidade do vento e $\ln (z)$ foi maior ou igual a 0,99 e $|R i| \leq 0,06$, após aqueles acima de $h+\sigma_{h}$ (sendo $\sigma_{h}$ o desvio padrão da altura média dos cafeeiros amostrados), e menores do que zero terem sido desconsiderados, por não terem significado físico. Um limite superior inicial igual ao nível inferior considerado foi imposto nas iterações, por não existir logaritmo de valor nulo ou negativo, que seriam obtidos quando $d \geq z$.

A pressão de vapor no ar foi determinada a partir dos dados de temperatura potencial do ar e de bulbo úmido:

$$
e=e s_{u}-A_{p} \cdot P \cdot\left(\theta-T_{u}\right)
$$


em que $A_{p}$ é o coeficiente psicrométrico, considerado igual a $6,60 \cdot 10^{-4} \cdot{ }^{\circ} \mathrm{C}^{-1}$. Este valor de $A_{p}$ é um pouco maior do máximo termodinâmico, mas foi assim escolhido para contemplar parte do efeito do acúmulo de poeira sobre o bulbo úmido (Bindon, 1965; Fevrot, 1977; Fan, 1987; Visscher, 1995; Simões-Moreira, 1999).

A determinação de $L E$ e $H$ pelo MRB foi realizada utilizando-se as Equações 10 a 13, aproximadas na forma:

$$
\begin{aligned}
& L E_{M R B}=\frac{R n-G}{1+\beta} \\
& H_{M R B}=\frac{(R n-G) \cdot \beta}{1+\beta} \text { para } \beta \neq-1 \\
& \beta=\left(\frac{s+\gamma}{\gamma} \cdot \frac{\Delta T_{u}}{\Delta \theta}-1\right)^{-1}
\end{aligned}
$$

em que $s$ é a tangente à curva de saturação de vapor do ar $\left(s=\Delta e s_{u} / \Delta T_{u}\right), \gamma$ é o coeficiente psicrométrico $[\gamma=c p \cdot P /(0,622 . L)], \Delta e s_{u}$ é a diferença de pressão de saturação entre níveis adjacentes em função de $T_{u}$ e $L=2,497 \cdot 10^{6}-2,370.10^{3}$. $\theta_{\text {média }}$ é o calor latente de evaporação $\left(\mathrm{J}^{\mathrm{kg}}{ }^{-1}\right)$.

Os valores de $L E_{M R B}$ foram considerados válidos somente quando as situações abaixo foram satisfeitas (Perez et al., 1999):

$$
\frac{\Delta e}{L E_{M R B}}=\frac{\Delta e+\gamma \cdot \Delta \theta}{R n-G}<0
$$

$\mathrm{e}$

$$
\beta \leq(-1-|\partial \beta|)
$$

ou

$$
\beta \geq(-1+|\partial \beta|),
$$

sendo $\partial \beta$ o erro absoluto em $\beta$ calculado conforme a Equação 34:

$$
\partial \beta=\frac{\partial \Delta e-\gamma \cdot \partial \Delta T_{s}}{\Delta e}
$$

$\partial \Delta e$ foi calculado a partir de $\partial e / \partial T_{u}$ e $\partial e / \partial T_{s}$, considerando-se a soma de todos os erros: 


$$
\partial \Delta e=\left(\frac{4098 \cdot e e_{u, z_{i}}}{\left(237,3+T_{u, z_{i}}\right)^{2}}+A \cdot P+\left|-\frac{4098 \cdot e s_{u, z_{i-1}}}{\left(237,3+T_{u, z_{i-1}}\right)^{2}}-A \cdot P\right|\right) \cdot \partial T_{u}+(|-A \cdot P|+A \cdot P) \cdot \partial T_{s}
$$

em que os subscritos $z_{i}$ referem-se ao nível considerado. Os valores de $\partial T_{s}$ e $\partial T_{u}$ foram considerados equivalentes ao desvio padrão médio de uma seqüência de 4 dias de medidas realizadas ao término do experimento, com os psicrômetros instalados num mesmo nível, em laboratório com ar acondicionado. Desta maneira, como os erros podem ocorrer em sentidos opostos, considerou-se um valor fixo para os mesmos, sendo que $\partial \Delta T_{s}=2 . \partial T_{s}$ e $\partial \Delta T_{u}=2 . \partial T_{u}$. Conforme Fuchs \& Tanner (1970), o erro repassado para $\gamma$ é desprezível, sendo desconsiderado neste estudo.

Nos períodos em que a metodologia de Perez et al. (1999) mostrou incoerência nos valores resultantes de $L E_{M R B}$, interpolaram-se os valores obtidos nas medidas anterior e posterior, desde que não tenha ocorrido um período contínuo superior a $2 \mathrm{~h}$ de dados incoerentes. Normalmente, ocorreram problemas à noite e, principalmente, no início e final do dia, quando ocorre a inversão dos sinais de $R n$. Como se objetivou trabalhar na escala diária, $L E_{M R B}$ e $L E_{M A}$ foram integrados somente no período diurno. Quando houve incoerência nos fluxos calculados no início da manhã e final da tarde, considerou-se o primeiro (5:30 h de outubro de 2002 a março de 2003 e 6:00 h de maio a setembro de 2003) e o último (19:00 h de outubro de 2002 a março de 2003 e 18:30 h de maio a setembro de 2003) valores iguais a zero e fez-se interpolação linear com o valor calculado mais próximo nos momentos com valores incoerentes. Os dias descartados no MRB foram também descartados no MA. Os valores de ETc $\left(\mathrm{mm}^{\mathrm{dia}}{ }^{-1}\right)$ foram obtidos dividindo-se $L E\left(\mathrm{MJ} . \mathrm{m}^{-2} \cdot\right.$ dia $\left.^{-1}\right)$ pelo calor latente de evaporação $L\left(\mathrm{MJ}_{\mathrm{kg}}{ }^{-1}\right)$ médio para o período do dia considerado.

Para o cálculo da evapotranspiração referente aos renques de cafeeiros, foram consideradas tanto as medidas lisimétricas como as de $F S$. A transpiração dos cafeeiros foi considerada equivalente à média dos valores de $F S$ integrados ao longo de 24 horas nas duas plantas amostradas concomitantemente, normalizados pela área foliar de cada uma $\left[F S_{m}=(F S 1+F S 2) / 2\right]$. A evaporação do solo nos lisímetros $(E s)$ foi obtida 
subtraindo-se a transpiração da planta do lisímetro $\left(F S_{m} \cdot A F_{L}\right.$, sendo $A F_{L}$ a área foliar da planta instalada no lisímetro, resultando em kg.planta $\left.{ }^{-1} \cdot \mathrm{dia}^{-1}\right)$ das medidas lisimétricas $\left(E s=\right.$ kg.lisímetro $\left.{ }^{-1} \cdot \operatorname{dia}^{-1}\right)$. Assim, obteve-se a evapotranspiração lisimétrica ( $E L$; mm.dia ${ }^{-1}$ ) considerada representativa do cafezal, ponderando-se $E s$ para a superfície de solo disponível para cada planta sob o renque, com a relação $E L=\left[\left(E s / A_{l}\right) \cdot A_{\text {renque }}\right] / A+T$, sendo $A_{l}$ a área da superfície do lisímetro $\left(0,6362 \mathrm{~m}^{2}\right), A_{\text {renque }}$ a área de solo disponível para cada planta sob o renque $\left(0,9.0,9=0,81 \mathrm{~m}^{2}\right), A$ a superfície de solo total disponível para cada planta $\left(3,5.0,9=3,15 \mathrm{~m}^{2}\right)$ e $T$ a transpiração média do cafezal normalizada para a área disponível para cada planta, em mm.dia ${ }^{-1}\left[T=F S_{m} \cdot I A F_{\text {cafezal }} ; I A F_{\text {cafezal }}=\right.$ $A F / A$, sendo $A F$ a área foliar média dos cafeeiros].

Nos dias com determinações concomitantes de $E L$ e $T$, calcularam-se os valores de $T / E L$ para os períodos de 2002, fevereiro - março e agosto - setembro de 2003, os quais foram utilizados para obter a evapotranspiração basal da cultura. Primeiramente considerou-se a evapotranspiração do renque normalizada pela área disponível para cada planta, de acordo com a Equação 36:

$$
E T_{\text {renque }}{ }^{\prime}=E L . A \cdot\left\{\left(\frac{T}{E L}\right) \cdot \frac{I A F_{\text {cafezal }}}{A F}+\left[1-\left(\frac{T}{E L}\right)\right] \cdot \frac{1}{A}\right\}
$$

Finalmente, conforme proposto por Marin et al. (2001b), foi ponderado $E L$ e $T$ pela área disponível para cada planta na faixa de solo ocupado pelo renque, conforme a Equação 37:

$$
E T_{\text {renque }}=E L . A .\left\{\left(\frac{T}{E L}\right) \cdot \frac{I A F_{\text {renque }}}{A F}+\left[1-\left(\frac{T}{E L}\right)\right] \frac{1}{A_{\text {renque }}}\right\}
$$

sendo $I A F_{\text {renque }}=A F / A_{\text {renque }}$. Em maio - julho de 2003, quando não foram feitas medidas de $F S$, considerou-se o valor médio de $T / E L$ de agosto - setembro de 2003, visto as características ambientais semelhantes entre os dois períodos.

Como os valores da evapotranspiração da cobertura ETc são referentes à superfície total do cafezal, esse tipo de análise possibilita uma avaliação da fração da evapotranspiração total que é oriunda do renque, quando feitas comparações utilizandose a área superficial total $\left(E T_{\text {renque }} / E T c\right)$ e, também, da proporção da evapotranspiração em uma unidade de área do renque em relação à média do cafezal $\left(E T_{\text {renque }}\right.$ /ETc). 
A evapotranspiração de referência ETo $\left(\mathrm{mm} \cdot \mathrm{dia}^{-1}\right)$ foi determinada a partir dos dados da estação meteorológica automática do Departamento de Ciências Exatas ESALQ/USP, localizada a aproximadamente $200 \mathrm{~m}$ ao norte dos mastros do cafezal. O cálculo foi realizado pelo método de Penman-Monteith (Equação 38), conforme proposto pelo boletim FAO 56 (Allen et al., 1998):

$$
\text { ETo }=\frac{0,408 . s \cdot(R n-G)+\gamma \cdot \frac{900}{T_{a}+273} \cdot u 2 \cdot(e s-e a)}{s+\gamma \cdot(1+0,34 \cdot u 2)}
$$

em que $T_{a}$ é a temperatura média diária, $u 2$ é a velocidade média diária do vento a $2 \mathrm{~m}$ de altura do solo, es - ea é o déficit médio diário de pressão de saturação de vapor no ar e $s$ é a tangente a curva de pressão de saturação de vapor no ar. Nessa Equação, $R n$ tem as unidades de MJ.m ${ }^{-2} \cdot$ dia $^{-1}$. A placa de fluxo de calor no solo na estação meteorológica não funcionou durante o período experimental e foi considerada equivalente $0 \mathrm{MJ}^{-2} \cdot \mathrm{dia}^{-1}$, pois, conforme Allen et al. (1998), sob gramado e na escala diária, $G$ pode ser ignorado. Os valores de es, ea e $s$ foram calculadas conforme as Equações 39-41:

$$
\begin{aligned}
& e s=0,6108 \cdot 10^{\left(\frac{7,5 \cdot T_{a}}{237,3+T_{a}}\right)} \\
& e a=\frac{U R}{100} \cdot e s \\
& s=\frac{4098 \cdot e s}{\left(237,3+T_{a}\right)^{2}}
\end{aligned}
$$

em que $U R$ é a umidade relativa do ar média diária (\%).

Os valores de $K c$, o qual é referido como coeficiente "global" de cultura por estar ligado, neste caso, a uma cobertura heterogênea e com períodos com superfície de solo seca, diferindo do seu conceito original (Allen et al., 1998), foram determinados a partir dos cálculos de ETc e ETo:

$$
K c=\frac{E T c}{E T o}
$$

Embora Allen et al. (1998) definam somente $K c$ e $K c b$, sendo este "a evapotranspiração da cultura dividida pela evapotranspiração de referência quando a superfície do solo está seca, mas com a transpiração numa taxa potencial, ou seja, a água 
não é limitante para a transpiração", para a finalidade de irrigação em uma cultura em estágios iniciais de desenvolvimento em grandes espaçamentos, como nesse caso, é interessante o conhecimento do coeficiente de evapotranspiração do renque, o qual contempla também a evaporação do solo entre e sob as plantas, sendo determinado conforme a Equação 43:

$$
K c_{\text {renque }}=\frac{E T_{\text {renque }}}{E T o},
$$

Sendo assim, o coeficiente de evapotranspiração da entrelinha $\left(K_{e-l}\right)$ pode ser obtido pela Equação 44:

$$
K_{e-l}=K c-K c_{\text {renque }} \text {. }
$$

Conhecendo-se $K c_{\text {renque }}$, pode-se obter um valor de $K c b$ aproximado, pela relação $K c b=K c_{\text {renque. }}(T / E L)$.

Algumas análises foram feitas utilizando-se ETo calculada pelo método do tanque Classe A, conforme a Equação 45:

$$
E T o=K_{p a n} . E C A
$$

em que $K_{\text {pan }}$ é o coeficiente de tanque Classe A, calculado de acordo com a Equação 46 (Pereira et al., 1997):

$$
K_{p a n}=0,482+0,024 \cdot \ln (B)-0,000376 \cdot u 2+0,0045 \cdot U R
$$

em que $B$ é a "bordadura" em torno do tanque Classe A, adotada como $10 \mathrm{~m}$ (Villa Nova et al., 2002).

Em 2002 e fevereiro - março de 2003 os valores da direção do vento foram obtidos pela média linear dos valores pontuais, não sendo corretamente representativos da direção vetorial observada no intervalo de 15 min. Em abril de 2003 o programa no sistema de aquisição de dados foi corrigido, permitindo seu uso na análise dos dados. 


\section{RESULTADOS E DISCUSSÃO}

\subsection{Caracterização das condições ambientais durante o experimento}

O extrato do balanço hídrico normal para Piracicaba (Figura 7) calculado em base mensal pelo modelo de Thornthwaite \& Mather (1955), considerando uma capacidade de água no solo $(C A D)$ de $50 \mathrm{~mm}$, escolhida por melhor se adequar ao pequeno sistema radicular dos cafeeiros, mostra que em termos climatológicos ocorre excedente hídrico no período de outubro a março e deficiência no restante do ano, a qual é máxima em agosto e setembro.

A Figura 8a mostra a evolução da evapotranspiração potencial $(E T P)$ e da evapotranspiração real $(E T R)$, obtidas a partir do balanço hídrico seqüencial qüinqüidial $(C A D=50 \mathrm{~mm})$ e da precipitação, durante o período de setembro de 2002 a setembro de 2003. Nota-se que a partir do quarto qüinqüídio de novembro de 2002 (Nov4) até o primeiro qüinqüídio de fevereiro de 2003 (Fev1) ocorreram poucos eventos em que ETR foi menor do que ETP, o que caracterizaria deficiência hídrica. Isso se deveu aos freqüentes eventos de precipitação e relativamente elevados, característicos das condições normais locais (Figura 7). Sendo assim, do quarto qüinqüídio de novembro de 2002 até o primeiro de fevereiro, predominou o excedente ou a reposição hídrica, com pequenos períodos de deficiência (Figura 8b). Do primeiro qüinqüídio de setembro ao quinto qüinqüídio de outubro de 2002 ocorreu deficiência acentuada, sendo que outubro pode ser caracterizado como atípico em termos de média histórica. Os elevados valores de ETP equivalentes a mais de $5 \mathrm{~mm} \cdot \mathrm{dia}^{-1}$ observados nos qüinqüídios Out1 a Out4 podem ser considerados superestimativos em comparação com ETo média para o mesmo período $\left(4 \mathrm{~mm} \cdot \mathrm{dia}^{-1}\right)$, os quais ocorreram em função do método de Thornthwaite \& 
Mather (1945) levar em consideração somente $T a$ nos cálculos de ETP, a qual variou entre 26,5 e $28,0^{\circ} \mathrm{C}$ nesse período. No mesmo período em 2003, os valores de ETo e ETP foram menores e mais próximos entre si $\left(E T P=2,8 \mathrm{~mm} \cdot \mathrm{dia}^{-1} ; E T o=2,5 \mathrm{~mm} \cdot \mathrm{dia}^{-1}\right)$. A deficiência ocorrida a partir de abril de 2003, acentuada em julho, agosto e setembro, é típica da região.

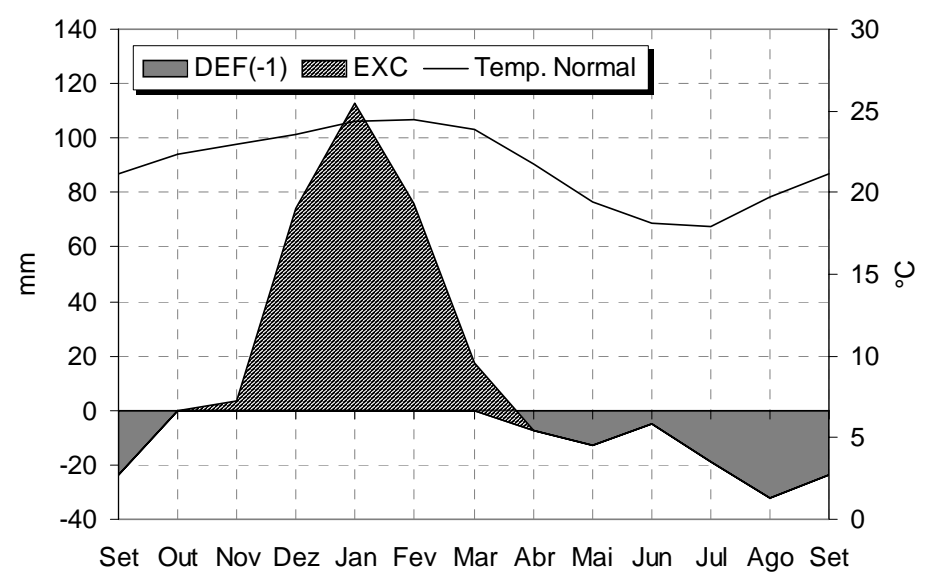

Figura 7 - Extrato do balanço hídrico mensal normal (1961 - 1990) para Piracicaba, SP, considerando-se a capacidade de água disponível no solo de $50 \mathrm{~mm}$ e a temperatura normal

Neste trabalho, embora outubro de 2002 e fevereiro de 2003 tenham sido períodos com deficiência hídrica, as campanhas de coleta de dados de outubro dezembro de 2002 e de fevereiro - março de 2003 são referidas no texto como períodos úmidos, enquanto que as de maio - julho e de agosto - setembro de 2003 são referidas como períodos secos. Nos momentos oportunos são feitas ressalvas quanto à fuga das condições normais locais, como as condições secas em outubro de 2002 e fevereiro de 2003.

No local do estudo, existe maior disponibilidade de energia no período úmido (Figura 9a-d), resultando em elevados valores de temperatura do ar e de ETP, os quais são diminuídos no período com escassez de chuvas. No entanto, apesar da menor disponibilidade de energia no período seco, os valores elevados do déficit de pressão de 

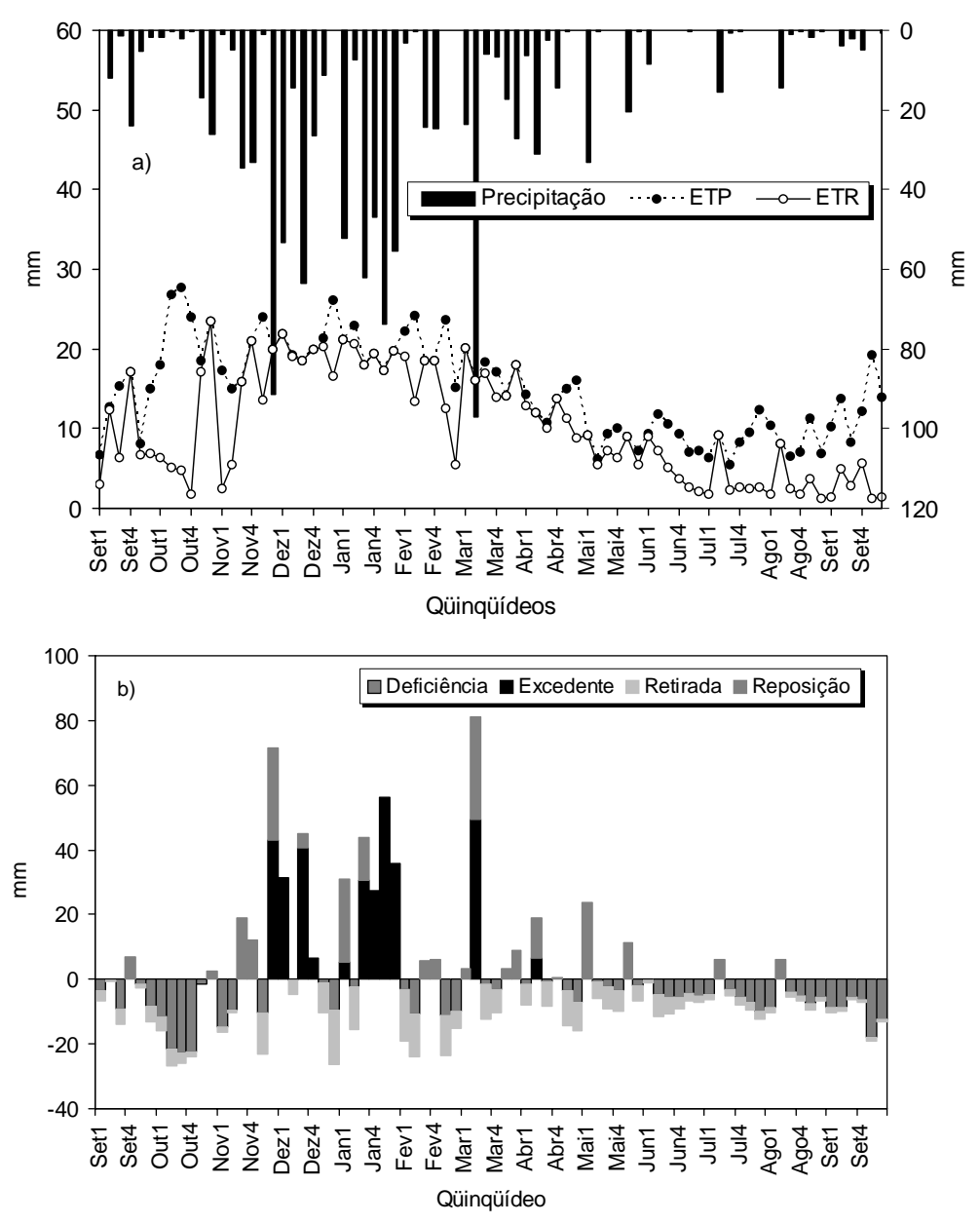

2002

2003

Figura 8 - Balanço hídrico seqüencial qüinqüidial: Evapotranspiração potencial $(E T P)$, evapotranspiração real $(E T R)$ e precipitação acumulada nos respectivos qüinqüídios (a) e deficiência, excedente, retirada e reposição de água no solo (b) ao longo do período experimental ( $\operatorname{Jan} 1=1^{\circ}$ qüinqüídio de janeiro, Jan2 $=2^{\circ}$ qüinqüídio de janeiro, $\left.\ldots\right)$

saturação de vapor no ar $(D)$ (Figura 9a-d), principalmente no período diurno, exercem uma compensação no cômputo da evapotranspiração em culturas irrigadas. No período de maio - julho de 2003 (Figura 9c) ocorreram os menores valores de $R n$ e, apesar da 
baixa altura pluviométrica, os valores de $D$ se mantiveram num patamar relativamente baixo, com a média diária normalmente abaixo de $1,0 \mathrm{kPa}$, se comparado a agosto setembro de 2003, quando ocorreu maior variação, com valores médios diários superiores a 1,5 $\mathrm{kPa}$, com a média máxima de 2,14 $\mathrm{kPa}$. Mesmo no período úmido, houve maior oscilação dos valores diários de $D$, sendo observados em alguns dias valores de 1,5 $\mathrm{kPa}$, enquanto que em maio - julho o máximo valor médio diário foi de $1,25 \mathrm{kPa}$.

Os valores obtidos durante o período diurno com menor umidade relativa (entre 13:30 h e 15:30 h) servem para caracterizar os extremos ocorridos durante o experimento, sendo que as médias de cada período foram de, respectivamente, $1,4 \mathrm{kPa}$, $1,6 \mathrm{kPa}$ e 1,9 kPa em novembro - dezembro de 2002, fevereiro - março e maio - julho de 2003 , com respectivos valores máximos no período de $3,4 \mathrm{kPa}, 3,3 \mathrm{kPa}$ e $3,4 \mathrm{kPa}$, enquanto que em outubro de 2002 e agosto - setembro de 2003 os respectivos valores médios foram de $3,0 \mathrm{kPa}$ e de 2,12 $\mathrm{kPa}$ e máximos de 4,9 $\mathrm{kPa}$ e 4,2 $\mathrm{kPa}$, demonstrando que no final do inverno e início da primavera, quando as chuvas não haviam iniciado e a energia incidente encontrava-se em crescente, a demanda hídrica atmosférica foi consideravelmente alta.

O período de fevereiro - março de 2003 foi relativamente atípico quanto às condições de precipitação normalmente verificadas em Piracicaba, sendo observado cerca de $100 \mathrm{~mm}$ de chuva a menos que o normal no mês de fevereiro. Em maio - julho, apesar da falta de chuvas (somente cerca de $90 \mathrm{~mm}$ ), os valores de $D$ relativamente baixos ocorreram em função da menor disponibilidade de energia e por tratar-se de uma época que pode ser considerada de transição do período com chuvas freqüentes para o seco, existindo ainda uma evapotranspiração relativamente elevada pela retirada da água armazenada dos horizontes inferiores de solo pela cobertura vegetal ainda ativa. Como se percebe na Figura 9c, a partir do dia 182, referente a 01/07/03, há uma elevação expressiva de $R n$ e $D$, vindo a ocorrer os máximos valores de $D$ em agosto - setembro, com condições bastante secas. 

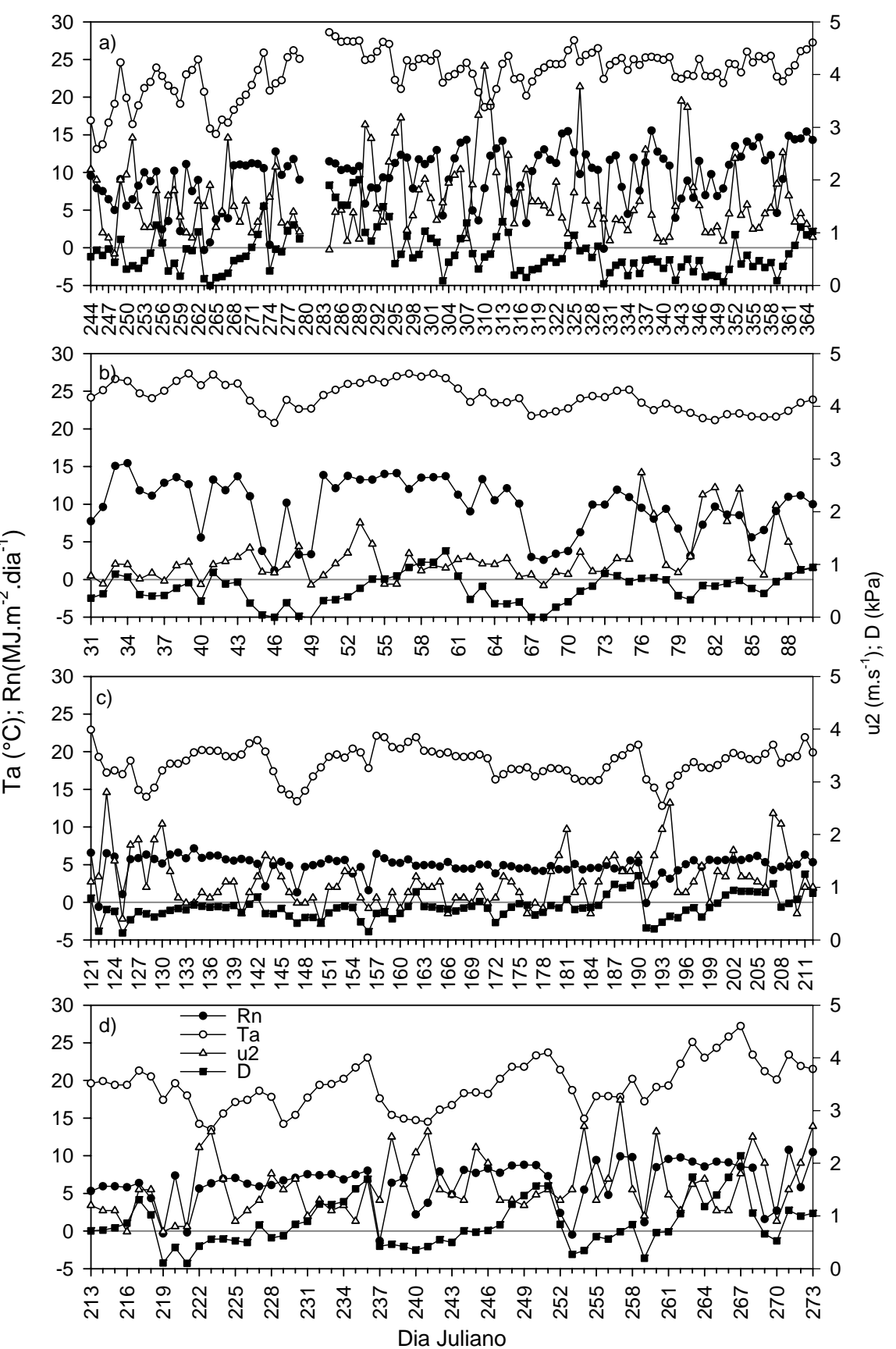

Figura 9 - Evolução dos valores médios diários do déficit de pressão de saturação de vapor no $\operatorname{ar}(D)$, da temperatura do $\operatorname{ar}(T a)$, da velocidade do vento a $2 \mathrm{~m}$ do solo $(u 2)$ e do saldo de radiação acumulada diária $(R n)$ obtidos na estação meteorológica: setembro a dezembro de 2002 (a); janeiro a março de 2003 (b); maio a julho de 2003 (c) e; agosto a setembro de 2003 (d) 


\subsection{Biometria dos cafeeiros}

A Figura 10 mostra a evolução de algumas variáveis biométricas a partir de 50 a 55 plantas amostradas em função do número de dias após o transplante (NDT), sendo 15/10/01 o dia zero. Tanto o diâmetro médio das copas $\left(D_{c}\right)$, como a altura $(h)$ e a área foliar média das folhas $\left(A F_{f}\right)$, teve uma evolução linear ao longo do tempo, porém, o número médio de folhas por planta $(N F)$, teve um ajuste mais significativo com uma função logarítmica (Figura 10a). No entanto, a área foliar média das plantas $(A F)$ teve crescimento linear com o tempo, existindo uma compensação entre as evoluções logarítmicas de $N F$ e lineares de $A F_{f}$ (Figura 10b).

Uma análise individual foi feita para as duas plantas lisimétricas (Figura 10b), onde se nota que a área foliar da planta do lisímetro $2\left(A F_{L 2}\right)$ teve um desenvolvimento razoavelmente semelhante à média do cafezal, enquanto que a planta do lisímetro 1 $\left(A F_{L 1}\right)$ apresentou restrições quanto ao seu crescimento. Isso foi observado visualmente, pelas folhas da planta em $L 1$ menores e em significativo menor número do que em $L 2$, além de sua coloração amarelada em grande parte do estudo. Possivelmente tenha ocorrido algum dano ao sistema radicular no transplante para o lisímetro, visto que a condução foi a mesma daquelas do campo e a drenagem funcionou satisfatoriamente ao longo do experimento.

Como foram feitas determinações biométricas somente em setembro e dezembro de 2002 e fevereiro e setembro de 2003, as funções mostradas na Figura 10 foram utilizadas para estimar as variáveis de crescimento no período de maio - julho de 2003 e em meados de outubro de 2002, além de $D_{c}$ e $h$ para dezembro de 2002, quando estas medidas não foram feitas. A determinação de $A F_{L 1}$ foi feita interpolando-se os valores determinados linearmente em função de $N D T$, pois não houve uma função de ajuste para os valores medidos.

$\mathrm{Na}$ Tabela 2 são apresentados os valores biométricos das plantas em cada período experimental. Nota-se a expressiva evolução de $A F$, que em novembro de 2002 era de $0,33 \mathrm{~m}^{2}$ e até setembro de 2003 aumentou cerca de 6 vezes, tendo alcançado um valor de 2,09 $\mathrm{m}^{2}$. 

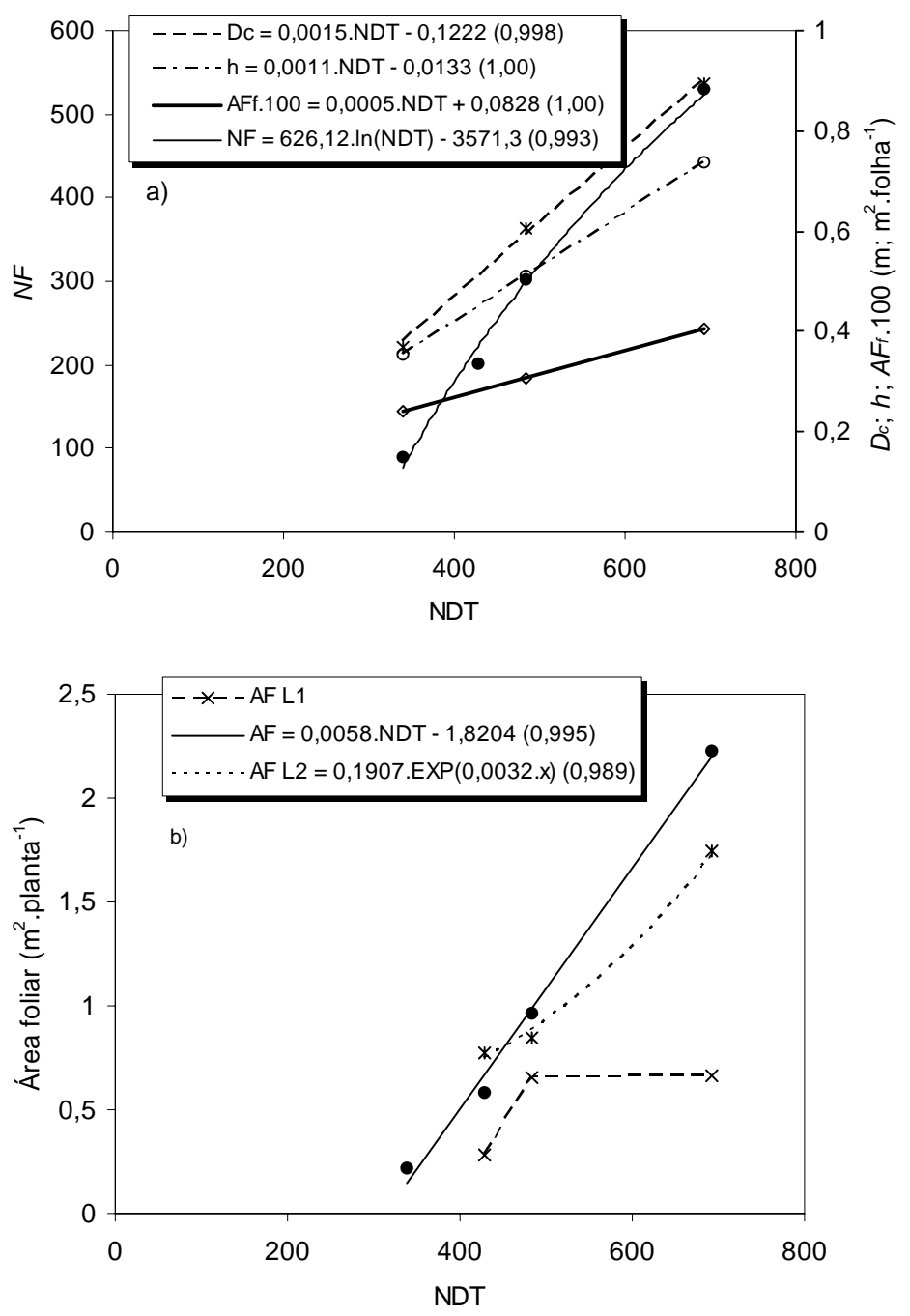

Figura 10 - Evolução biométrica média dos cafeeiros com o número de dias após o transplante $(N D T)$ : diâmetro das copas $\left(D_{c}\right)$, altura $(h)$, área foliar média individual de cada folha $\left(A F_{f}\right)$ (multiplicada por 100 para facilitar a visualização na escala do eixo) e o número de folhas $(N F)$ (a); área foliar média por planta $(A F)$ e das plantas dos lisímetros $1\left(A F_{L 1}\right)$ e $2\left(A F_{L 2}\right)$ (b)

Apesar dos cuidados desde o transplante, que foi realizado separando-se as mudas em classes de acordo com o seu vigor para ter-se um estabelecimento homogêneo das plantas, foi observado um número relativamente grande de falhas no cafezal, embora 
realizada uma reposição de plantas cerca de 8 meses após o transplante, tendo sido notada uma heterogeneidade elevada no crescimento das mesmas. Tomando-se como referência $h$, para as determinações aleatórias de fevereiro e setembro de 2003, o coeficiente de variação (CV) ficou em torno de $24 \%$, com desvios padrões entre $0,14 \mathrm{~m}$ e $0,18 \mathrm{~m}$ para respectivos $h=0,53 \mathrm{~m}$ e $h=0,74 \mathrm{~m}$. Quando considerado $D_{c}$ e $N F$, a variabilidade foi ainda maior, sendo seus valores de CV, respectivamente, de $40 \%$ e de 65\%. O período entre maio e setembro de 2003 foi muito seco, chegando a ter amplitudes térmicas diárias superiores a $20{ }^{\circ} \mathrm{C}$, que associadas com uma provável fase fisiológica de repouso natural da cultura, resultou no amarelecimento e queda de folhas dos cafeeiros no final do período experimental. Como essa queda foi acentuada após o dia 09/09/03, data final das determinações biométricas, $A F$ pode ser considerada representativa até essa última data.

Tabela 2. Diâmetro de copa $\left(D_{c}\right)$, altura das plantas $(h)$, número de folhas $(N F)$ e área foliar $(A F)$ do cafezal utilizados como referência para cada período

\begin{tabular}{|c|c|c|c|c|}
\hline Período & $D_{c}$ & $h$ & $N F$ & $A F$ \\
\hline & \multicolumn{2}{|c|}{$\mathrm{m}$} & & $\mathrm{m}^{2}$ \\
\hline $04 / 10 / 02-10 / 11 / 02$ & 0,43 & 0,39 & 131 & 0,33 \\
\hline $11 / 11 / 02-17 / 12 / 02$ & 0,49 & 0,44 & 195 & 0,53 \\
\hline $31 / 01 / 03-23 / 03 / 03$ & 0,62 & 0,53 & 317 & 1,00 \\
\hline $27 / 05 / 03-22 / 07 / 03$ & 0,80 & 0,66 & 450 & 1,66 \\
\hline $20 / 08 / 03-18 / 09 / 03$ & 0,91 & 0,74 & 519 & 2,09 \\
\hline
\end{tabular}

\subsection{Evapotranspiração do cafezal}

\subsubsection{Efeito das condições de "bordadura"}

Antes de entrar na análise propriamente dita dos fluxos verticais de calor sensível $(H)$ e latente $(L E)$ do cafezal, é necessário verificar quais níveis de medida ficaram dentro da camada atmosférica em equilíbrio com a superfície e se as condições 
de "bordadura" da área foram suficientes para evitar a advecção de calor sensível, como garantia da igualdade entre os coeficientes de transporte para calor sensível $K_{h}$ e calor latente $K_{w}$.

Partindo-se das dimensões da área e aplicando-se a Equação 2, considerando-se que a "bordadura" na direção predominante do vento (sudeste) era de $170 \mathrm{~m}$ no local onde foi instalado o mastro M1 (eventos na direção norte tiveram uma freqüência muito baixa, podendo ser desconsiderados nessa análise) e tendo-se como a menor altura da rugosidade da superfície $\left(z_{o}\right)$ aquela observada na campanha de 2002, cujo valor foi de $0,01 \mathrm{~m}$, a altura da camada da atmosfera em equilíbrio com a superfície foi de cerca de $2,42 \mathrm{~m}$. Adicionando-se o valor do deslocamento do plano zero $d \approx 0,29 \mathrm{~m}$, resulta em $\delta$ $\approx 2,71 \mathrm{~m}$. Esta foi a situação de menor $\delta$ para essa "bordadura", pois com o crescimento dos cafeeiros, ocorreu aumento tanto de $d$ quanto de $z_{o}$, sendo que os máximos valores foram observados nas medidas de maio - julho de 2003 , com $d \approx 0,39 \mathrm{~m}, z_{o} \approx 0,03 \mathrm{~m} \mathrm{e}$, conseqüentemente, $\delta \approx 3,41 \mathrm{~m}$.

As menores "bordaduras" para M1 ocorreram quando o vento soprou transversalmente à área, sendo que, considerando-se a quase ausência de ventos de oeste, a menor "bordadura" $(\approx 60 \mathrm{~m})$ para as medidas micrometeorológicas pode ser considerada a referente à direção leste (entre $60^{\circ}$ e $80^{\circ}$ ) (ver Figura 1), sendo que os mesmos cálculos resultaram em $\delta \approx 1,34 \mathrm{~m}$ em 2002 e $\delta \approx 1,70 \mathrm{~m}$ em 2003. Isso significa que as medidas foram feitas dentro de $\delta$ até o nível 3 em 2002 e até o nível 4 para as medidas de temperatura em 2003 (Tabela 1) quando o vento soprou nas direções aproximadamente paralelas à área (Figura 1) e, quando o vento tinha direção transversal, apenas os níveis 1 e 2 ficaram dentro da camada superficial em equilíbrio. Na campanha de maio - julho de 2003, as medidas de $u_{4}$ também ficaram dentro de $\delta$ quando com a maior "bordadura". Se usado o critério de Heilman et al. (1989), de que uma relação $\delta: x$ de 1:20 seria suficiente em condições de atmosfera instável para a determinação da razão de Bowen, as quais predominam durante o período diurno, e com fluxo no sentido de uma superfície mais rugosa para uma mais lisa (algodão - gramado), no caso em questão resulta em $\delta$ entre $3,3 \mathrm{~m}$ e $8,9 \mathrm{~m}$, de acordo com a direção do vento, condição que pode 
ser até conservadora na direção predominante do vento, visto que não houve uma mudança tão intensa de rugosidade, indicando que todas as medidas de temperatura, até o nível 4, e de vento, até o nível 3, teriam sido feitas dentro da camada atmosférica em equilíbrio com a superfície.

De qualquer forma, é importante analisar os perfis das propriedades medidas, a fim de verificar se houve advecção horizontal ou, caso ela tenha ocorrido, de se ter uma noção de sua grandeza e dos efeitos indesejados sobre as estimativas dos fluxos. Seguindo Verma et al. (1978), os perfis de temperatura e umidade são similares se a razão $(\partial \theta / \partial z) /(\partial e / \partial z)$ for constante ao longo da camada atmosférica amostrada, o que tende a não ocorrer sob advecção de calor sensível. A Figura 11 apresenta a relação entre as razões $\left(\theta_{4}-\theta_{1}\right) /\left(\theta_{3}-\theta_{1}\right)$ e $\left(e_{4}-e_{1}\right) /\left(e_{3}-e_{1}\right)$ para os dias com gradientes que podem ser considerados fisicamente adequados às estimativas pelo MRB de acordo com os critérios de Perez et al. (1999) nos diferentes períodos analisados, sendo que o número subscrito indica o nível de medida. Considerou-se somente o período diurno entre 9:00 h e 16:00 h e sem chuva. Esse intervalo foi selecionado por representar o período diário com maiores taxas de fluxo evapotranspiratório e para evitar um excessivo efeito dos erros nas medidas quando próximo dos momentos diários de inversão dos perfis (Fuchs \& Tanner, 1970; Angus \& Watts, 1984; Perez et al., 1999).

Durante os períodos úmidos, referentes a outubro - dezembro de 2002 e fevereiro - março de 2003, a dispersão dos dados foi comparativamente pequena em torno da linha 1:1, em relação àquela dos períodos secos de coleta de dados, de maio a setembro de 2003 (Figura 11). Isso significa que o efeito das condições das áreas circundantes ao cafezal foi maior no período seco, com evidências da ocorrência de advecção. Nessa análise, tomando-se como referência os gradientes entre os níveis 3 e 1, os casos com leve advecção de calor sensível produzem gradientes de temperatura menores entre os níveis 4 e 1, caracterizados pelos pontos localizados abaixo da linha 1:1. No caso de condições de forte advecção, ocorre inversão dos perfis de temperatura do ar, a qual foi observada com baixa freqüência ao longo do experimento, mas está presente em parte dos pontos acima da linha 1:1. 


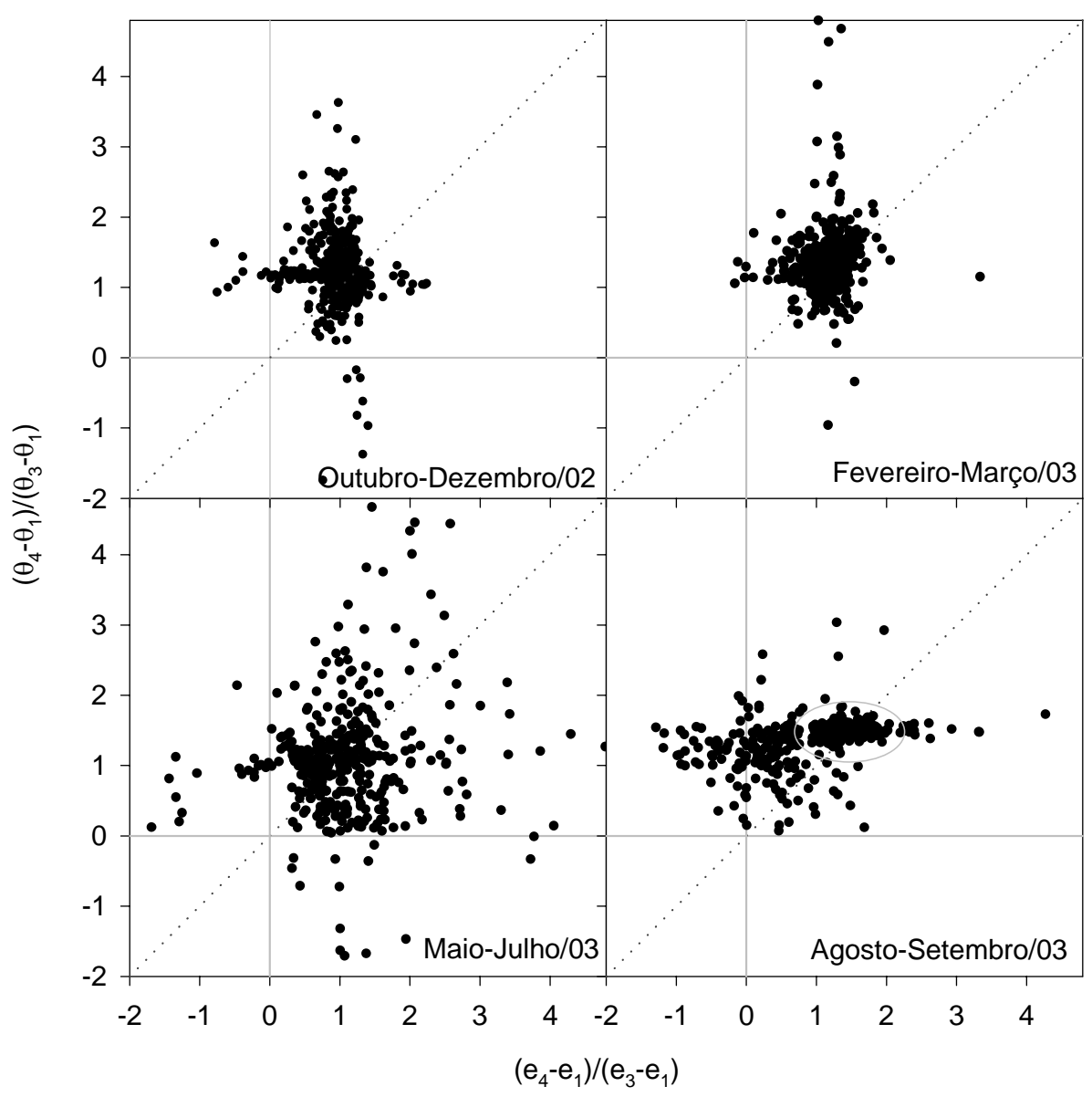

Figura 11 - Relação entre a razão dos gradientes de temperatura $(\theta)$ e pressão de vapor no ar (e) considerando-se os níveis 4 - 1 e 3 - 1, nos períodos de 4/10/02 a 17/12/02 (a), 31/01/03 a 23/03/03 (b), 17/05/03 a 22/07/03 (c) e 20/08/03 a 18/09/03 (d). Foram considerados somente os dados obtidos entre 9:00 h e 16:00 h, na ausência de chuva e "utilizáveis" seguindo os critérios de Perez et al. (1999)

Nesses períodos úmidos, a dispersão observada deveu-se principalmente aos erros nas medidas de temperatura pelos psicrômetros, o que é exemplificado numa condição extrema para os dias 16 e 21 de fevereiro de 2003 (Figura 12), considerando-se erros nas medidas de temperatura de bulbo seco $\partial T=0,02{ }^{\circ} \mathrm{C}$ e um erro médio nas diferenças de pressão de saturação de vapor $(\partial \Delta e)$ entre os psicrômetros de $0,04 \mathrm{kPa}$, 
obtido a partir de $\partial T_{u}=0,06{ }^{\circ} \mathrm{C}$ (Equação 38); a qualidade dos dados é discutida no item 4.3.3. O caso 1 considera os dados medidos como verdadeiros, enquanto que o caso 2 considera $\left(\Delta \theta_{4-1}+2 . \partial T\right) /\left(\Delta \theta_{3-1}-2 . \partial T\right)$ e $\left(\Delta e_{4-1}-\partial \Delta e\right) /\left(\Delta e_{3-1}+\partial \Delta e\right)$ e o caso 3 considera o sinal dos erros contrários. Nota-se o significativo efeito desses erros sobre a dispersão dos dados, principalmente no caso 2, o que leva à necessidade de se adotar intervalos de valores em torno da linha 1:1 como representativos de condições não advectivas. Para facilitar a análise, conforme proposto por Verma et al. (1978), pode-se considerar um índice de similaridade $I=1$ para condição de não-advecção, que é obtido pela divisão dos valores do eixo y por aqueles do eixo x da Figura 11. Admitindo-se que o erro nas medidas pode levar a uma variação de $I$ de $\pm 0,3$, uma proporção de $65 \%$ dos dados ficaram entre 0,7 e 1,3 no período úmido (Figura 11), desconsiderando-se os valores negativos provenientes de condições de inversão dos perfis, que corresponderam a cerca de $4 \%$ dos dados.

A partir da elevada dispersão e da alta concentração de pontos sob a linha 1:1, procedeu-se uma análise com a direção do vento nos períodos secos. Como os ventos fluindo sobre o cafezal a partir do pupunhal e seringal foram pouco freqüentes, foram considerados como eventos com menor "bordadura" somente as situações em que o mesmo teve direções entre $40^{\circ}$ e $100^{\circ}$. Nessas condições, observou-se $41 \%$ e $26 \%$ das medidas para os respectivos períodos de maio - julho e agosto - setembro de 2003, com $31 \%$ e $20 \%$ dos valores de $I$ abaixo de 0,7 . Ao mesmo tempo, a proporção de valores entre 0,7 e 1,3 foi de $30 \%$ na primeira e $20 \%$ na segunda campanha do período seco. Apesar do ambiente estar em condições altamente secas até 19/10/02, numa análise separada dos dados nesse período obteve-se $0,7<I<1,3$ em 73\% dos casos, demonstrando que com os ventos predominantes de sudeste (Pereira et al., 2002a), a "bordadura" de $\approx 170$ m reduziu suficientemente o efeito do aporte lateral de energia.

O efeito da direção do vento é ilustrado na Figura 13, onde são mostradas as relações dos gradientes considerando-se somente o vento fluindo das direções dentro (Figura 13a) e fora (Figura 13b) dos limites de $40^{\circ}$ a $100^{\circ}$ no período de maio - julho de 2003. Observa-se na Figura 13 b que ocorre uma tendência dos pontos de dados ficarem 


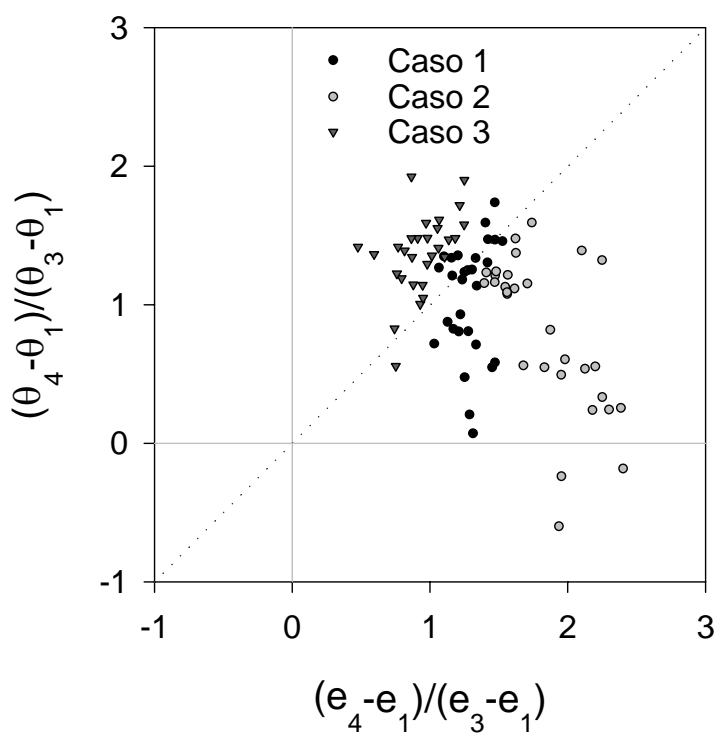

Figura 12 - Relação entre a razão dos gradientes de temperatura $(\theta)$ e de pressão de vapor no ar (e) considerando-se os níveis $4-1$ e 3 - 1, com dados entre 9:00 h e 16:00 h, sem chuva e "utilizáveis" seguindo os critérios de Perez et al. (1999). O caso 1 considera as medidas como verdadeiras; o caso 2 considera $\left(\Delta \theta_{4-1}+2 . \partial T\right) /\left(\Delta \theta_{3-1}-2 . \partial T\right)$ e $\left(\Delta e_{4-1}-\partial \Delta e\right) /\left(\Delta e_{3-1}-\partial \Delta e\right)$ e; o caso 3, o mesmo que o 2, porém com os sinais dos erros invertidos. $\partial T$ e $\partial \Delta e$ são os erros de medida, considerados, respectivamente, iguais a 0,02 ${ }^{\circ} \mathrm{C}$ e $0,02 \mathrm{kPa}$

em torno da linha 1:1, enquanto que na Figura 13a, a grande maioria ficou abaixo da mesma, indicando uma situação mais crítica.

A situação observada em agosto - setembro de 2003 é mais complexa, sendo que de 27 a 29 de agosto, de 3 a 10 e em 13 de setembro foram utilizados os dados do mastro M2 pelas medidas em M1 serem inadequadas pelos critérios de Perez et al. (1999), devido aos gradientes estarem na faixa dos erros dos sensores ou existirem inversões incoerentes, como, por exemplo, do perfil de umidade quando toda região estava seca. Até o dia 01/09/03 as entrelinhas localizadas entre o cafezal adulto e os mastros micrometeorológicos estavam com o solo removido e sem cobertura vegetal, 
enquanto que o restante da área estava sob condição normal de manejo. Provavelmente, a elevada dispersão observada nesse período se deve, em parte, à heterogeneidade horizontal (Cellier \& Brunet, 1992; De Bruin et al., 1999), pois, devido às diferentes fontes de calor e vapor na superfície, os perfis de temperatura e umidade tomam forma diferente ao longo da camada atmosférica próxima da superfície (McNaughton \& Laubach, 1998; De Bruin et al., 1999).

Apesar do provado efeito advectivo sobre as medidas durante o período seco, pode-se inferir que grande parte da dispersão dos dados é conseqüência dos erros dos sensores e problemas de manutenção, associados aos pequenos gradientes de umidade naturais no período (Angus \& Watts, 1984; Fuchs \& Tanner, 1971). A partir das anotações de campo, notou-se que nos dias 27 e 30 de agosto e 3 e 10 de setembro de 2003 foram feitas as substituições das gazes dos bulbos úmidos, coincidindo com a transição de períodos com medidas coerentes e incoerentes em M1. Portanto, evidenciase o efeito da manutenção dos sensores, constituindo-se em grande dificuldade para a obtenção de medidas psicrométricas com boa qualidade no período seco. Em M2 esses problemas ficaram destacados entre 22 e 27 de agosto, voltando a produzir medidas ruins após a substituição das gazes no dia 12/09/03.

Selecionando-se somente os dados referentes ao período entre 02/09 e 18/09/03 obtidos em M2, quando toda área encontrava-se sem vegetação intercalar, notou-se que a maioria dos pontos de dados ficou mais próxima da linha 1:1 (pontos destacados na Figura 11). Uma hipótese para explicar essa melhora nos dados seria o aumento temporário da evaporação devido à exposição de horizontes inferiores do solo pelo seu revolvimento em cerca de metade da área, repercutindo em um aumento dos gradientes de umidade com relativa diminuição dos erros de medida da temperatura de bulbo úmido (no item 4.3.3 é dada atenção especial à qualidade dos dados medidos), mas esse efeito parece ter sido desprezível, pois o mesmo não foi observado nas medidas de M1, que tiveram que ser descartadas. Vale destacar que em agosto - setembro de 2003 as velocidades do vento foram em média $30 \%$ maiores do que em maio - julho, sendo que neste período houve baixa freqüência de valores de $u_{3}$ acima de $2 \mathrm{~m} . \mathrm{s}^{-1}$. Portanto, podese aventar que parte da dispersão dos dados foi devida a advecção de calor causada pelas 
elevadas velocidades do vento na última campanha e, principalmente, pelos erros de medida associados aos pequenos gradientes verticais de umidade.

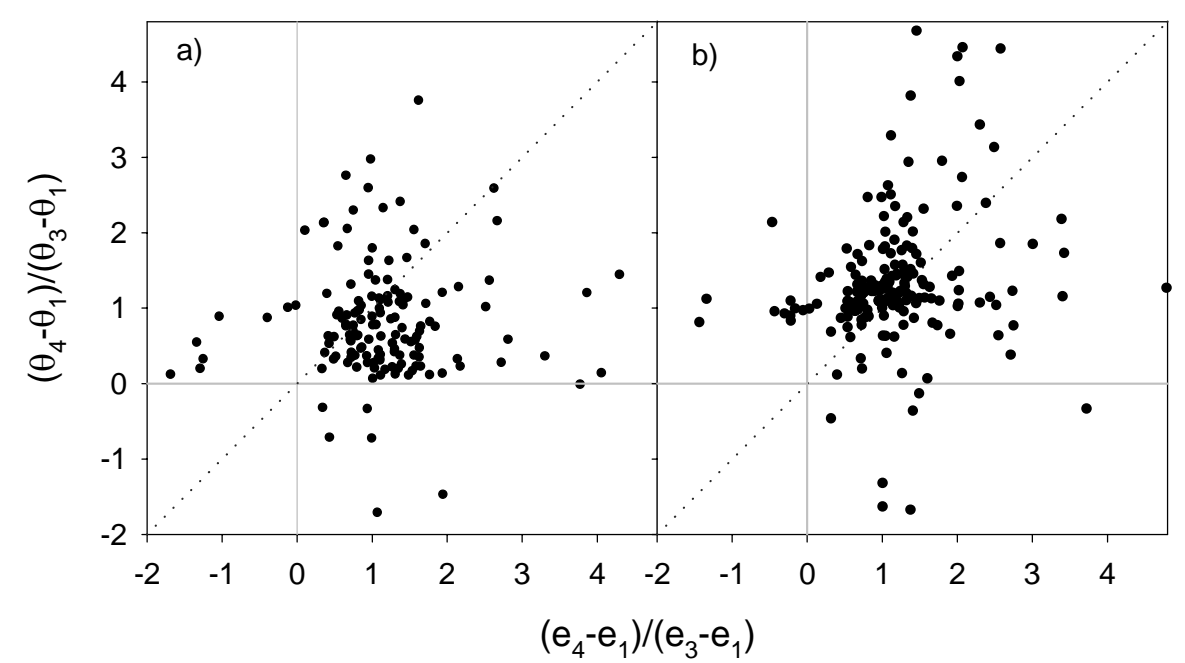

Figura 13 - Relação entre a razão dos gradientes de temperatura $(\theta)$ e da pressão de vapor no ar (e) considerando-se os níveis $4-1$ e $3-1$, no período de 17/05/03 a 22/07/03, referentes aos momentos com direção do vento dentro (a) e fora (b) dos limites de $40^{\circ}$ a $100^{\circ}$. Foram considerados somente os dados obtidos entre 9:00 h e 16:00 h, na ausência de chuva e "utilizáveis" seguindo critérios de Perez et al. (1999)

A partir dessa análise, percebe-se que no período úmido pode-se considerar $K_{h} / K_{w}=1$, mas no período seco, a ocorrência de advecção e a maior heterogeneidade horizontal tornaram a igualdade entre $K_{h}$ e $K_{w}$ questionável. Entretanto, não é possível saber em que grau se está incorrendo em erros ao considerar-se $K_{h} / K_{w}=1$, pois não foram feitas medidas dos fluxos energéticos para aferição das estimativas. De qualquer forma, desconsiderando-se os casos em que houve inversão dos perfis de temperatura e, como a análise foi feita utilizando-se os níveis 3 e 4 como superiores (os quais variaram entre 1,96 m e 2,95 m de altura em relação ao solo, distanciados entre si cerca de 0,9 m), ao se utilizar os níveis 3 e 1, que podem ser considerados dentro de uma camada da atmosfera mais equilibrada com a superfície, os cálculos dos fluxos no período seco 
considerando-se a igualdade $K_{w}=K_{h}$ não devem incorrer em grandes erros, como verificado por McNaughton \& Laubach (1998).

Assim, assumiu-se $z_{p, 3}$ como nível superior de medida de temperatura e umidade mais adequado aos cálculos dos fluxos energéticos, sendo desconsiderados os dados dos dias com observação de mais do que $2 \mathrm{~h}$ com inversão do gradiente de temperatura $(\beta<0)$ em períodos com $R n-G>0 \mathrm{~W} \cdot \mathrm{m}^{-2}$, entre 9:00 h e 16:00 h. Os critérios de Perez et al. (1999) mostraram-se bastante interessantes na seleção dos dados "utilizáveis" em função dos erros de medida, por excluir grande parte dos casos em que os gradientes de umidade e temperatura foram próximos de zero. Portanto, grande parte das condições características de adveção de calor sensível $[-0,2<\beta<0,1$, segundo McNaughton \& Laubach (1998)] foram excluídas da análise.

\subsubsection{Determinação do deslocamento do plano zero (d) e da altura de rugosidade da superficie $\left(\mathrm{z}_{\mathrm{o}}\right)$}

A partir da relação entre a velocidade do vento $u$ e $\ln \left(z_{u}-d\right)$, sendo $z_{u}$ a altura de medida de $u$, o valor de $d$ foi atribuído de forma iterativa até resultar no menor erro no ajuste, cujo valor determinado normalmente constava de quatro casas decimais com unidades em metros, ou seja, com resolução maior do que aquela das medidas de altura $(0,01 \mathrm{~m})$. Foram utilizadas médias da velocidade do vento de $30 \mathrm{~min}$ em $30 \mathrm{~min}$, intervalo de tempo mínimo recomendado por Monteith \& Unsworth (1990) para este tipo de estudo.

Como descrito em Material e Métodos, as determinações foram feitas a partir dos perfis em que a relação $\ln \left(z_{u}\right)$ versus $u$ tinha um coeficiente de determinação $\mathrm{R}^{2}$ igual ou superior a 0,99 e a estabilidade atmosférica encontrava-se razoavelmente próxima da neutralidade $(|R i| \leq 0,06)$. Os casos com $u_{2}<1,5 \mathrm{~m} . \mathrm{s}^{-1}$ foram desconsiderados, por terem sido observadas distorções nos perfis de vento, visto que a velocidade de partida dos anemômetros é de $0,447 \mathrm{~m} . \mathrm{s}^{-1}$ para os modelos 014A e de $0,2811 \mathrm{~m} \cdot \mathrm{s}^{-1}$ para o 034B-L. Para uma cultura de algodão, McInnes et al. (1991) utilizaram critério semelhante, considerando somente os valores acima de $1 \mathrm{~m} \cdot \mathrm{s}^{-1}$ a $0,4 \mathrm{~m}$ do topo de leiras de solo 
espaçadas $1 \mathrm{~m}$. Somente os valores dentro do intervalo $0 \leq d \leq\left(h+\sigma_{h}\right)$ foram considerados válidos para a análise, sendo $\sigma_{h}$ o desvio padrão de $h$. Nos casos em que o nível $z_{u}$ inferior nas análises foi menor do que $\left(h+\sigma_{h}\right)$, o limite imposto foi $\left(z_{u}-0,01\right)$ $\mathrm{m}$, para evitar erros devido a inexistência de logaritmo de zero ou de valor negativo $(z-$ $d \leq 0$ ). As situações com $d<z_{o}$ também foram desconsideradas.

Antes de analisar os valores de $d$ e $z_{o}$, é necessário verificar se as medidas foram feitas dentro da subcamada atmosférica inercial ou da rugosa. Garratt (1980) verificou que a altura da transição $(z *)$ entre essas duas subcamadas (quantificada a partir de $d$ ) sobre uma floresta heterogênea de savanas apresentou valores entre 3,2.h e 7,5.h, em dois mastros em locais com heterogeneidades diferentes. Quando relacionado $z *$ com um parâmetro de heterogeneidade da floresta $\varphi$, considerado igual à raiz quadrada da área superficial disponível para cada planta, foi encontrada uma relação de $z *=3,0 . \varphi$ para ambos locais. Cellier \& Brunet (1992) encontraram uma relação semelhante sobre uma cobertura de milho $(z * \approx 4,2 . \varphi)$, considerando $\varphi$ igual ao espaçamento entre linhas, devido à configuração de plantio.

Utilizando-se a concentração de rugosidade $\lambda$ como parâmetro de comparação, definido como a área frontal do elemento de rugosidade (aqui considerada proporcional à metade da área de um disco de diâmetro igual a $D_{c}$ ) por unidade de área horizontal ocupada por planta, obteve-se $0,04 \leq \lambda \leq 0,11$, que se aproximou mais da condição de Garratt (1980), $\lambda=0,03$ e $\lambda=0,20$, enquanto que Cellier $\&$ Brunet (1992) obtiveram $\lambda=$ 1,70. Sendo assim, adotando-se $z * / \varphi=3,0$ (Garrat, 1980) e $\varphi=(0,9.3,5)^{0,5}=1,78 \mathrm{~m}$, tem-se para o cafezal em questão $z * \approx 5,0 \mathrm{~m}$.

Em análise realizada a partir de correções para $K_{h, w}$ na subcamada rugosa propostas por Cellier \& Brunet (1992) $\left(\gamma_{h, w}=K_{h, w} * / K_{h, w}=z * /(z-d)\right.$; para $\left.z-d<z_{*}\right)$, verificou-se que $\gamma_{h, w}$ teria um valor de aproximadamente 20 em $z-d=0,5 . h$ considerando-se $z *=5,0 \mathrm{~m}$. Este valor é demasiadamente elevado, conforme revisado e verificado por Cellier \& Brunet (1992) e por Mölder et al. (1999), cujo valor de $\gamma_{h, w}$ determinado em $(z-d) / h \approx 0,5$ varia de 1,5 a 3,0. Desta maneira, tomando-se $\gamma_{h, w}=2,5$ determinado sobre savana com $\lambda=0,03$ e $\lambda=0,20$, conforme revisado por Cellier \& 
Brunet (1992), é provável que $z *+d$ tenha variado entre aproximadamente $0,8 \mathrm{~m}$ em 2002 e 1,3 m em agosto - setembro de 2003, valores próximos dos citados por Raupach et al. (1996), Wieringa (1993) e Finnigan (2000), de que a altura da subcamada de rugosidade varia entre $2 . h$ e $3 . h$. Isso significa que as medidas em $u_{1}$ e $u_{2}$ podem ter sido influenciadas pela otimização da turbulência nas proximidades da superfície, devido $z_{u, 1}$ $<z_{*}+d$ e $z_{u, 2}$ estar próximo de $z_{*}+d$, embora existam evidências experimentais de que $z *$ para momento é menor do que para calor (Thom et al., 1975; Garratt, 1978, 1980; Raupach et al., 1980; Raupach \& Legg, 1984; Cellier \& Brunet, 1992; Mölder et al., 1999).

Logicamente, essa análise é uma aproximação, pois não foram encontrados na literatura estudos desse tipo sobre coberturas compostas de renques distanciados algumas vezes sua altura e a "bordadura" limitada torna questionável a determinação de $z_{*}$. Nas condições experimentais do cafezal, em que existiu incidência de vento praticamente em direção paralela aos renques $\left(\approx 170^{\circ}\right)$, provavelmente $z *$ tenha um valor menor devido à diminuída interação com as copas das plantas.

Sendo assim, fez-se uma comparação entre os valores de $d$ determinados a partir dos níveis $1-4$ e $1-5$ e aqueles do nível $2-5$. Nessa análise, foram inicialmente utilizados os dados de maio - julho de 2003, a partir de quando pôde-se contar com medidas confiáveis da direção do vento e durante o período foram invertidos os anemômetros dos níveis 1 e 5 (situação 1) e, posteriormente, dos níveis 2 e 1 (situação 2), ficando, então, o modelo 034B-L no nível 1. Essas trocas foram feitas para verificar se existiam diferenças nos perfis devidas aos anemômetros, principalmente por serem de modelos com velocidade de partida deferentes, as quais não foram percebidas quando $u_{2}$ $\geq 1,5 \mathrm{~m} \cdot \mathrm{s}^{-1}$.

Considerando-se os níveis $2-5$ na determinação de $d$, na situação 1 , quando o 034B-L estava no nível 2, obteve-se $d=0,45 \mathrm{~m}$ e, na situação $2, d=0,35 \mathrm{~m}$. Observando-se a distribuição dos valores de $u_{3}$, tomados como referência, e de $d$ com a direção do vento, verificou-se que na situação 1 ocorreu predominância de ventos em direções praticamente transversais e diagonais aos renques de cafeeiros (Figura 14a), enquanto que na situação 2 ocorreu maior distribuição dos dados na direção do vento e 
com velocidades maiores mais freqüentes (respectivamente, os casos com $u_{3}>3,0 \mathrm{~m} . \mathrm{s}^{-1}$ corresponderam a 53\% na situação 1 e 70\% na situação 2) (Figura 14b). Nas Figuras 14 e 15 , percebe-se uma tendência dos menores valores de $d$ concentrarem-se nas direções entre aproximadamente $120^{\circ}$ e $200^{\circ}$, devido a um provável efeito associado da maior velocidade do vento observada quando em direções paralelas aos renques.

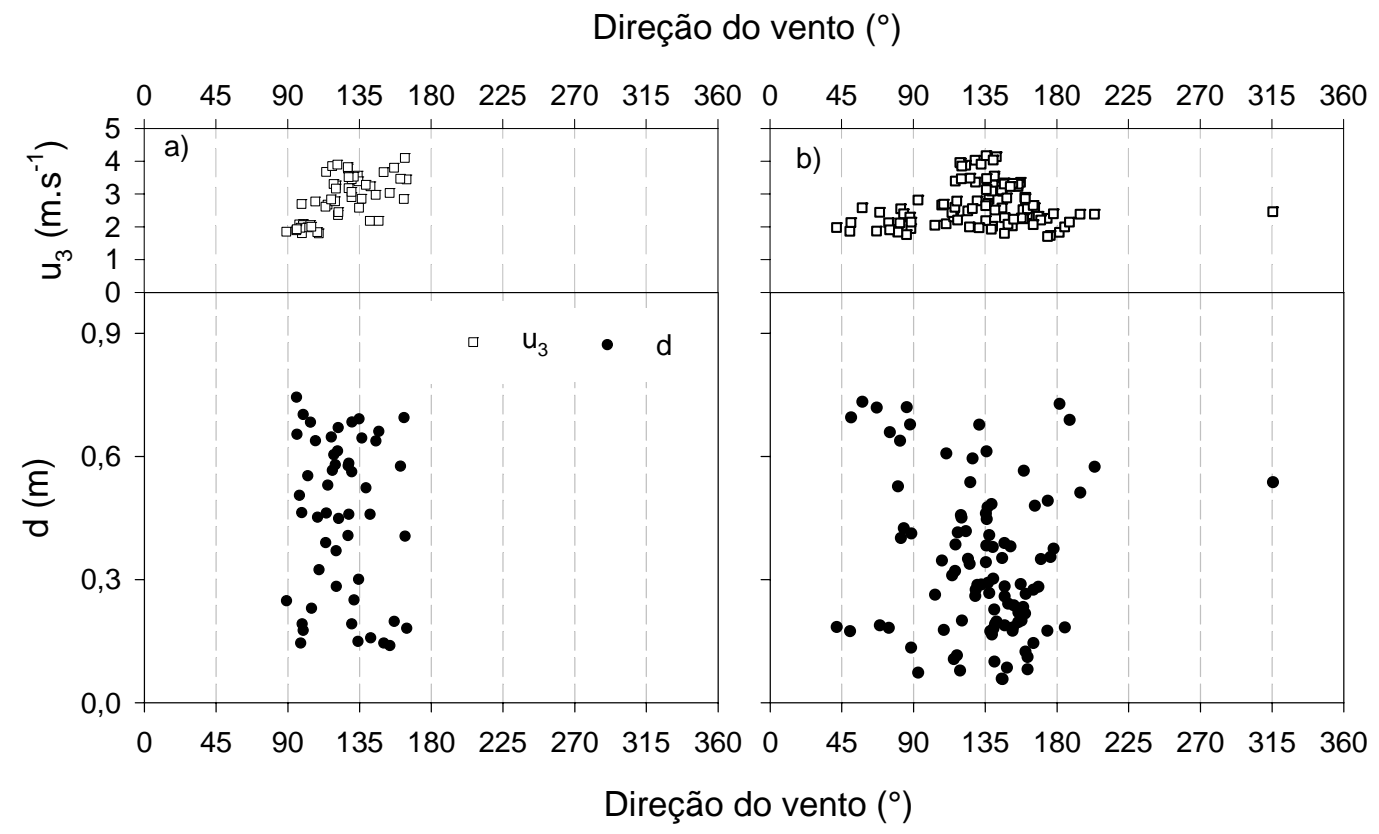

Figura 14 - Distribuição dos valores de velocidade do vento no nível $3\left(u_{3}\right)$ e do deslocamento do plano zero $(d)$, determinado para os níveis $2-5$, de acordo com a direção do vento, antes da inversão dos anemômetros entre os níveis 1 e 2 (a) e após a inversão (b)

Quando posicionados transversalmente ao fluxo de ar, os renques atuam como obstáculos relativamente rígidos pela estrutura arbórea dos cafeeiros, exercendo maior resistência ao fluxo e causando um aumento do nível efetivo de absorção de momento. Ao mesmo tempo, a baixa velocidade do vento, que exerce menor encurvamento dos elementos de rugosidade na superfície, diminui o aporte de momento no dossel (Munro \& Oke, 1973; Shaw \& Pereira, 1982; McInnes et al., 1991; Pereira, 1998; Righi et al., 2003). Portanto, dentro dos critérios utilizados as diferenças entre os valores de $d$ entre 
as situações 1 e 2 não devem ter sido causadas pelas diferenças entre os modelos dos anemômetros.

As estimativas dos valores de $d$ foram de fato influenciadas pelas medidas nas proximidades da superfície. Quando foram considerados os níveis $1-4$ e $1-5$, os valores médios de $d$ foram, respectivamente, iguais a $0,29 \mathrm{~m} \mathrm{e} 0,27 \mathrm{~m}$, enquanto que com os níveis 2 - 5 (o nível 2 estava entre $0,50 \mathrm{~m}$ e 0,70 m acima do nível 1), o valor médio obtido foi de $0,39 \mathrm{~m}$. Fazendo-se a mesma análise com os dados de fevereiro março do mesmo ano e em 2002, houve uma subestimativa de aproximadamente $0,15 \mathrm{~m}$ nos valores determinados nos níveis 1 - 4 e 1 - 5 em comparação com aquele determinado em 2 - 5. Em maio - julho e agosto - setembro de 2003 essa subestimativa foi menor, provavelmente em conseqüência da aproximação relativa entre os níveis inferiores $\left[\left(z_{u, 2}-z_{u, 1}\right) /(h-d)=4,8\right.$ em 2002; $\left(z_{u, 2}-z_{u, 1}\right) /(h-d)=2,3$ em agosto setembro de 2003] e da possibilidade dos valores de $u_{2}$ estarem sendo obtidos dentro da subcamada rugosa $\left(z *+d \approx 1,30 \mathrm{~m} ; z_{u, 2}=1,52 \mathrm{~m}\right)$, com valores de $d$ considerando-se o nível $z_{u, 1}$ aproximadamente $0,10 \mathrm{~m}$ menores daquele obtido com os níveis 2 - 5. Esses resultados concordam com aqueles de Garrat (1980) e com o comentário de Raupach et al. (1980), de que existem muitos resultados na literatura em que $d$ foi subestimado quando determinado a partir das informações do perfil de vento na subcamada rugosa.

Assim, considerando-se que $z_{u, 2}$ foi maior ou pelo menos mais próximo de $z_{*}+$ $d$, todas as análises seguintes foram feitas com os dados dos níveis $2-5$. O nível 5, embora completamente fora da camada atmosférica ajustada com a superfície, mas ainda dentro da camada limite interna (Equação 2), foi levado em consideração para adicionarse um quarto ponto nas análises, a fim de se ter maior confiança nos cálculos dos mínimos erros na determinação de $d$ e $z_{o}$.

A Tabela 3 apresenta os valores de $d, z_{o}$, velocidade característica da superfície $u$ * e o número de dados "utilizáveis" nos períodos estudados, separados pelas condições de cobertura da entrelinha e da disposição dos anemômetros em M1. Inicialmente, é possível notar um aumento dos valores de $d$ com o desenvolvimento da cultura de 2002 até fevereiro - março de 2003, com posterior estabilização, variando de 0,29 m a 0,39 m considerando-se todos os dados, enquanto que $z_{\mathrm{o}}$ ficou entre $0,009 \mathrm{~m} \mathrm{e} 0,030 \mathrm{~m}$. 
A cobertura da entrelinha não teve efeito claro sobre $d$, fato provavelmente relacionado com a estrutura arbórea mais rígida dos renques de cafeeiros, os quais conferiram os principais elementos de rugosidade na área. Ao contrário de $d, z_{\mathrm{o}}$ tendeu a aumentar com a cobertura da entrelinha (Tabela 3), a qual era composta por herbáceas mais flexíveis e suscetíveis à agitação pelo vento, sendo sua interação com a atmosfera maior quando $h_{e-l}$ era elevada, conforme discutido por Munro \& Oke (1973), Shaw \& Pereira (1982) e Pereira (1998). Os valores de $z_{\mathrm{o}}$ tenderam a aumentar até o período de maio - julho de 2003, sendo que em agosto - setembro do mesmo ano, quando $h_{e-l}$ era praticamente zero, eles foram semelhantes aos de 2002.

Como pode ser notado nas Figuras 14 e 15, existiu um efeito associado das baixas velocidades do vento nas direções transversais aos renques, com predominância de valores de $d$ mais elevados nessas situações, pois tanto para a transversalidade do vento aos renques, como para as menores velocidades, seria esperado aumento de $d$ (Munro \& Oke, 1973; McInnes et al., 1991; Pereira, 1998; Righi et al., 2003). Uma análise de regressão entre a velocidade do vento medida a 2,0 $\mathrm{m}$ de altura na estação meteorológica e no nível $u_{3}$ mostrou não existir efeito da direção do fluxo sobre as medidas no cafezal. Portanto, as menores velocidades do vento nas direções do quadrante leste provavelmente devam-se às condições meteorológicas de meso e macroescala. Quanto a $z_{o}$, a análise é ainda mais complexa, visto que em baixos valores de $u_{3}$, $z_{\mathrm{o}}$ tenderia a valores menores pela agitação diminuída da cobertura, ao mesmo tempo que o efeito transversal aos renques resultaria na elevação de $z_{\mathrm{o}}$ (Munro \& Oke, 1973; Shaw \& Pereira, 1982; McInnes et al., 1991; Pereira, 1998; Righi et al., 2003).

Procedeu-se, então, uma análise separando-se os dados conforme faixas de direção do vento em intervalos de $60^{\circ} \mathrm{em}$ torno do paralelismo, da diagonalidade e da perpendicularidade aos renques, evidenciando-se um efeito negativo tanto de $u_{3}$ quanto de $u^{*}$ sobre $d$, em todos os casos, embora com grande dispersão dos dados, confirmando observações feitas por McInnes et al. (1991) e Righi et al. (2003). Porém, $z_{\mathrm{o}}$ apresentou relação somente $\operatorname{com} u^{*}$, a qual foi positiva, parecendo ser conseqüência do efeito compensatório existente com $d$ (Munro \& Oke, 1973; Jacobs \& Van Boxel, 1988; McInnes et al., 1991; Pereira, 1998). 
Direção do vento $\left(^{\circ}\right)$
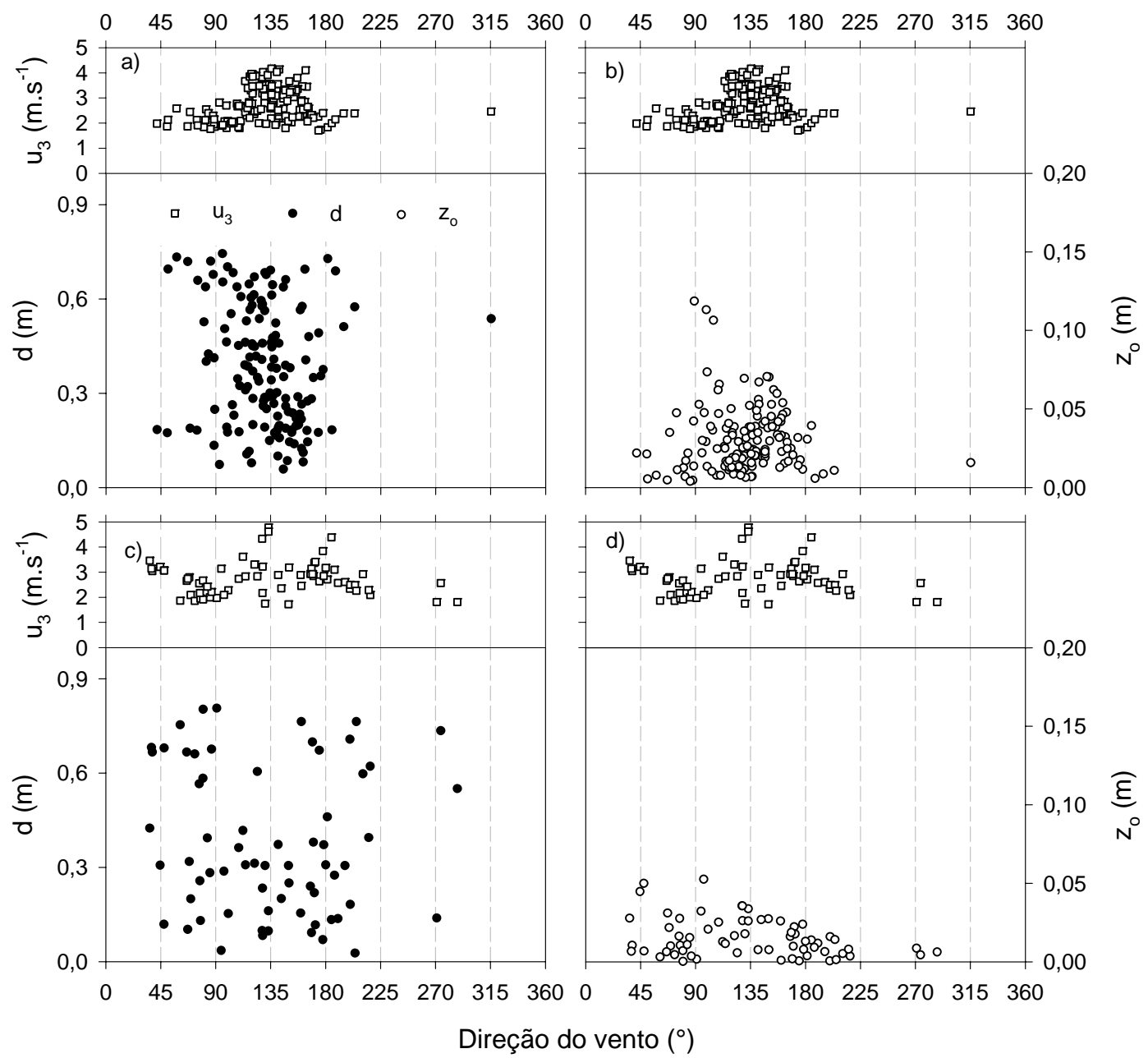

Figura 15 - Distribuição dos valores "utilizáveis" do deslocamento do plano zero $(d)(a$; c) e da altura de rugosidade $\left(z_{o}\right)(\mathrm{b} ; \mathrm{d})$ nos períodos de maio - julho $(\mathrm{a} ; \mathrm{b})$ e agosto - setembro (c; d) de 2003

Na Tabela 4 são apresentados os valores médios de $d$ e $z_{o}$ para as faixas de direção do vento de $0^{\circ}-30^{\circ}, 30^{\circ}-60^{\circ}$ e $60^{\circ}-90^{\circ}$, sendo $0^{\circ}$ e $90^{\circ}$ referentes ao paralelismo e à perpendicularidade da direção do vento aos renques. Os valores de $d$ foram mais elevados quando o fluxo foi perpendicular ou diagonal, enquanto que $z_{o}$ foi menor na diagonalidade, possivelmente por algum efeito de canalização do fluxo rente aos 
Tabela 3. Valores do deslocamento do plano zero $(d)$, da altura de rugosidade $\left(z_{o}\right)$, de seus respectivos desvio-padrão $\left(\sigma d\right.$ e $\left.\sigma z_{o}\right)$, da velocidade característica do escoamento $\left(u^{*}\right)$ e do número de dados considerados $(N d)$, para os períodos mensais, diferentes alturas da cobertura da entrelinha $\left(h_{e-l}\right)$ e para todos os dados, nos respectivos períodos de coleta de dados. O anemômetro modelo 034B-L estava instalado no nível 2 na situação 1 e no nível 1 na situação 2

\begin{tabular}{|c|c|c|c|c|c|c|}
\hline Período / condição & $d$ & $z_{o}$ & $\sigma d$ & $\sigma z_{o}$ & $u^{*}$ & $N d$ \\
\hline & \multicolumn{4}{|c|}{$\mathrm{m}$} & $\mathrm{m} \cdot \mathrm{s}^{-1}$ & \\
\hline & \multicolumn{4}{|c|}{ outubro - dezembro de 2002} & & \\
\hline $04 / 10-31 / 10 / 02$ & 0,27 & 0,009 & 0,1372 & 0,0129 & 0,26 & 58 \\
\hline $01 / 11-30 / 11 / 02$ & 0,27 & 0,008 & 0,1538 & 0,0083 & 0,28 & 83 \\
\hline $01 / 12-17 / 12 / 02$ & 0,32 & 0,011 & 0,1550 & 0,0073 & 0,31 & 71 \\
\hline$h_{e-l}(0,2-0,5 \mathrm{~m})$ & 0,29 & 0,005 & 0,1586 & 0,0037 & 0,27 & 54 \\
\hline$h_{e-l}(0,5-0,7 \mathrm{~m})$ & 0,30 & 0,011 & 0,1544 & 0,0087 & 0,31 & 102 \\
\hline Todos os dados & 0,29 & 0,009 & 0,1509 & 0,0096 & 0,28 & 212 \\
\hline \multicolumn{7}{|c|}{ fevereiro - março de 2003} \\
\hline$h_{e-l}(0,2-0,35 \mathrm{~m})$ & 0,36 & 0,021 & 0,1422 & 0,0142 & 0,27 & 22 \\
\hline$h_{e-l}(0,35-0,65 \mathrm{~m})$ & 0,35 & 0,026 & 0,1797 & 0,0160 & 0,27 & 32 \\
\hline$h_{e-l}(0,2 \mathrm{~m})$ & 0,40 & 0,015 & 0,1733 & 0,0091 & 0,28 & 47 \\
\hline Todos os dados & 0,38 & 0,020 & 0,1693 & 0,0132 & 0,27 & 111 \\
\hline \multicolumn{7}{|c|}{ maio - julho de 2003} \\
\hline Situação 1 & 0,45 & 0,038 & 0,1918 & 0,0327 & 0,28 & 51 \\
\hline Situação 2 & 0,35 & 0,026 & 0,1872 & 0,0147 & 0,25 & 105 \\
\hline Todos os dados & 0,39 & 0,030 & 0,1929 & 0,0229 & 0,26 & 155 \\
\hline \multicolumn{7}{|c|}{ agosto - setembro de 2003} \\
\hline 1/2 área gradeada & 0,38 & 0,012 & 0,2387 & 0,0095 & 0,21 & 35 \\
\hline Toda área gradeada & 0,37 & 0,019 & 0,2315 & 0,0139 & 0,25 & 31 \\
\hline Todos os dados & 0,38 & 0,015 & 0,2335 & 0,0122 & 0,23 & 66 \\
\hline
\end{tabular}


Tabela 4. Valores médios do deslocamento do plano zero $(d)$, do comprimento de rugosidade da superfície $\left(z_{o}\right)$, da velocidade característica da superfície $\left(u^{*}\right)$ e da velocidade média do vento no nível de referência $3\left(u_{3}\right)$ em faixas de direção do vento variando de $0^{\circ}$ a $30^{\circ}$, de 30 a $60^{\circ}$ e $60^{\circ}$ a $90^{\circ}$, sendo que $0^{\circ}$ equivale ao paralelismo e $90^{\circ}$ equivale a transversalidade da direção do vento em relação aos renques

\begin{tabular}{|c|c|c|c|c|}
\hline Direção do vento & $d$ & $z_{o}$ & $u_{3}$ & $u^{*}$ \\
\hline & \multicolumn{2}{|c|}{$\mathrm{m}$} & \multicolumn{2}{|c|}{$\mathrm{m} \cdot \mathrm{s}^{-1}$} \\
\hline \multicolumn{5}{|c|}{ maio - julho de 2003} \\
\hline $0^{\circ}-30^{\circ}$ & 0,33 & 0,032 & 2,9 & 0,28 \\
\hline $30^{\circ}-60^{\circ}$ & 0,42 & 0,025 & 2,9 & 0,27 \\
\hline $60^{\circ}-90^{\circ}$ & 0,45 & 0,031 & 2,1 & 0,21 \\
\hline \multicolumn{5}{|c|}{ agosto - setembro de 2003} \\
\hline $0^{\circ}-30^{\circ}$ & 0,30 & 0,018 & 3,0 & 0,26 \\
\hline $30^{\circ}-60^{\circ}$ & 0,39 & 0,014 & 2,6 & 0,23 \\
\hline $60^{\circ}-90^{\circ}$ & 0,43 & 0,017 & 2,3 & 0,20 \\
\hline
\end{tabular}

renques, numa faixa de solo praticamente nu, e interagindo menos com a cobertura da entrelinha e os próprios cafeeiros. No entanto, na Figura $15 \mathrm{~b}$ nota-se que existe tendência de elevação de $z_{o}$ em torno das direções de $100^{\circ}$ e $150^{\circ}$, as quais não são referentes exatamente à transversalidade ou ao paralelismo, respectivamente, mas devese ressaltar que no quadrante sudoeste da área existia um certo grau de curvatura dos renques para oeste, o que deve ter distorcido um pouco o efeito da direção do vento sobre os parâmetros de rugosidade. A grande diferença nos valores de $z_{o}$ entre maio julho e agosto - setembro de 2003 deve estar relacionada aos maiores valores de $u_{3}$ e a praticamente ausente cobertura da entrelinha no último período. Em julho, havia cerca de $70 \%$ de cobertura verde na entrelinha, enquanto que no final de agosto, havia somente 20 a $30 \%$ no lado oeste e praticamente $0 \%$ no lado leste do mastro M1 até o dia 03/09/03, quando foi eliminado o restante da cobertura da entrelinha. 
Fica evidenciado, portanto, que o fluxo transversal aos renques resulta no aumento de $d$ e o fluxo diagonal reduz $z_{o}$, enquanto que a velocidade do vento tende a diminuir $d$ e, embora não tão evidente, a aumentar $z_{o}$ nessas condições de cultivo. No entanto, em termos práticos é inviável levar em consideração o efeito dessas variáveis sobre esses parâmetros aerodinâmicos, por não serem bem entendidas fisicamente e, portanto, não existirem relações bem claras (Campbell \& Norman, 1998).

Uma forma adequada de representação de $d$ e $z_{o}$ referentes a uma cobertura, é normalizando-os em relação à altura dos elementos de rugosidade principais, nesse caso, dos cafeeiros. Na Tabela 5 são apresentadas essas relações juntamente com a altura média das plantas no período, cujos valores de $d$ e $z_{o}$ são referentes aos obtidos com todos os dados "utilizáveis". Verifica-se que os valores de $d / h$ ficaram dentro do intervalo entre 0,5 e 0,90 comumente encontrado na literatura até o período de maio julho de 2003 (Thom et al., 1975; Shaw \& Pereira, 1982; Monteith \& Unsworth, 1990; Sentelhas et al., 1993; Santos \& André, 1993; Pereira et al., 2003), sendo que nos períodos úmidos $(04 / 10$ - 17/12/02 e 31/01 - 23/03/03) se aproximaram do valor de $d / h$ $=0,76$ encontrado por Thom (1971) e dos valores entre 0,64 e 0,90 utilizados em florestas e savanas (Garrat, 1978; Thom et al., 1975; Rosemberg et al., 1983; Kustas et al., 1989a; Campbell \& Norman, 1998; Mölder et al., 1999). Especialmente no período úmido, essas relações ficaram bem próximas daquela obtida por Kustas et al. (1989b) sobre um algodoal com cobertura incompleta, $d / h \approx 0,65$, considerando $h$ a altura dos algodoeiros e das leiras em que eram cultivados. No entanto, nos períodos seguintes, essas relações tenderam a diminuir pelo aumento de $h$ e pela estabilização de $d$ entre $0,38 \mathrm{~m}$ e $0,39 \mathrm{~m}$. Wieringa (1993) estabelece que os valores de $d / h$ determinados com $z_{u}$ inferior do perfil menor do que $z *$ são confiáveis somente quando ficarem entre 0,6 e 0,8, adicionando que valores menores do que 0,6 devem ser considerados somente em superfícies não homogêneas, como é o caso do cafezal.

Não foi possível a formulação de uma explicação clara para a queda dos valores de $d / h$ a partir de fevereiro - março de 2003 , mas não pode ter como única causa a tomada de medidas na subcamada rugosa e, possivelmente, estão relacionados com a estrutura dos cafeeiros. Em setembro de 2002, a altura média das copas era equivalente a 
0,44.h, enquanto que um ano depois essa relação era de $0,76 . h$. Portanto, numa cobertura em que o espaçamento entre os renques variou aproximadamente entre 8.h e 4.h, o aporte de momento deve ocorrer em níveis inferiores das copas das plantas, visto que não houve qualquer selamento superficial. Em cafeeiros novos, a maior concentração de material - folhas e ramos - tende a níveis inferiores da copa, cuja relação da altura da sua base com $h$ diminuiu de 0,60 para 0,24 ao longo do experimento, o que explicaria a redução de $d / h$, de acordo com os resultados de Shaw \& Pereira (1982). O aumento da relação $d / h$ de outubro - dezembro de 2002 a fevereiro - março de 2003 deve ter ocorrido pelo aumento de $D_{c}$ e o respectivo preenchimento dos espaços vazios no renque de $50 \%$ para $70 \%$, diminuindo significativamente a sua porosidade e elevando o nível médio de dreno de momento.

Conclusões a respeito dos valores de $z_{o}$ são mais difíceis de serem obtidas. $\mathrm{Na}$ Tabela 5 percebe-se uma grande variação de $z_{o} / h$ nos períodos estudados, devido sua maior sensibilidade às condições de cobertura da entrelinha (Tabela 3) além do efeito da direção e velocidade do vento. A explicação para isso pode ser a maior agitação dessas plantas causada pelo vento, pois são mais flexíveis do que o cafeeiro. A título de comparação, pode-se calcular o índice de área da planta $P A I$ (área acumulada de todos os elementos - folhas e ramos - da planta dividido por $A$ ), aqui aproximado pelo $I A F_{\text {cafezal, }}$ e obtém-se da Figura 5 de Shaw \& Pereira (1982) $z_{o} / h$ variando entre aproximadamente 0,06 e 0,12 , sendo maiores do que aqueles obtidos no cafezal, mas deve-se ressaltar que as condições adotadas na simulação desses autores foram consideravelmente diferentes daquelas do caso presente. No entanto, a relação de Lettau (1969), $z_{o} / h=0,5 . \lambda$, sendo o coeficiente 0,5 referente ao coeficiente de arraste médio de obstáculos, que, segundo Wieringa (1993), é válida para baixos $\lambda$, produziu valores muito próximos daqueles obtidos no cafezal $(0,03$ em outubro - dezembro de 2002 e fevereiro - março de 2003, 0,04 em maio julho e 0,05 em agosto - setembro de 2003), demonstrando que as determinações a partir dos perfis de vento podem ser consideradas coerentes.

Os valores médios da velocidade característica do escoamento $u^{*}$ variaram 
Tabela 5. Relação do deslocamento do plano zero $(d)$ e da altura da rugosidade $\left(z_{o}\right)$ com a altura média dos cafeeiros $(h)$, nos períodos experimentais considerados, utilizando-se todos os dados "utilizáveis"

\begin{tabular}{cccc}
\hline Período & $d / h$ & $z_{\delta} / h$ & $h$ \\
\hline & & & $\mathrm{m}$ \\
\cline { 4 - 4 } $04 / 10-17 / 12 / 02$ & 0,69 & 0,021 & 0,42 \\
$31 / 01-23 / 03 / 03$ & 0,72 & 0,038 & 0,53 \\
$27 / 05-21 / 07 / 03$ & 0,59 & 0,045 & 0,66 \\
$20 / 08-18 / 09 / 03$ & 0,51 & 0,020 & 0,74 \\
\hline
\end{tabular}

entre $0,21 \mathrm{~m} \cdot \mathrm{s}^{-1}$ e $0,31 \mathrm{~m} \cdot \mathrm{s}^{-1}$. Embora seja esta variável dependente das condições de rugosidade da superfície, a análise dos valores médios não é esclarecedora, pois ela é diretamente proporcional à velocidade do vento (Equação 7) e não existem valores medidos. Porém, com seus valores determinados pontualmente, é possível verificar se os valores de $d$ e $z_{o}$ médios de cada período são coerentes quando se têm condições atmosféricas próximas da neutralidade. Na Figura 16 é mostrada a relação entre as estimativas pela Equação 3 a partir dos valores médios de $d$ e $z_{o}$ de cada período com os valores medidos de $u_{3}$, as quais mostraram uma tendência próxima de 1,0 e um razoável ajuste, quantificado pelo coeficiente de determinação $\mathrm{R}^{2}$. Somente em agosto - setembro de 2003 o coeficiente linear da equação de regressão foi significativo a $1 \%$ de probabilidade $\left(\mathrm{y}=1,25 . \mathrm{x}-0,79 ; \mathrm{R}^{2}=0,82\right)$, devido à tendência de subestimativa de $u_{3}$ quando abaixo de $2,5 \mathrm{~m} \cdot \mathrm{s}^{-1}$. De qualquer maneira, apesar dos valores relativamente elevados do desvio-padrão das médias $\left(\sigma d ; \sigma z_{0}\right)$ observados na Tabela 3, provavelmente em conseqüência dos erros de medida pelos sensores (Francey \& Garrat, 1981; De Bruin \& Moore, 1985), os valores médios de $d$ e $z_{o}$ podem ser considerados representativos da cobertura e realmente devem ter sofrido pouco ou nem um efeito das medidas próximas da superfície quando utilizados os níveis $2-5$.

Apesar da grande dificuldade em determinar os parâmetros aerodinâmicos de cultivos em renques com alta heterogeneidade, com o efeito da estrutura dos cafeeiros e a contribuição das condições de cobertura das entrelinhas importantes, diante da 


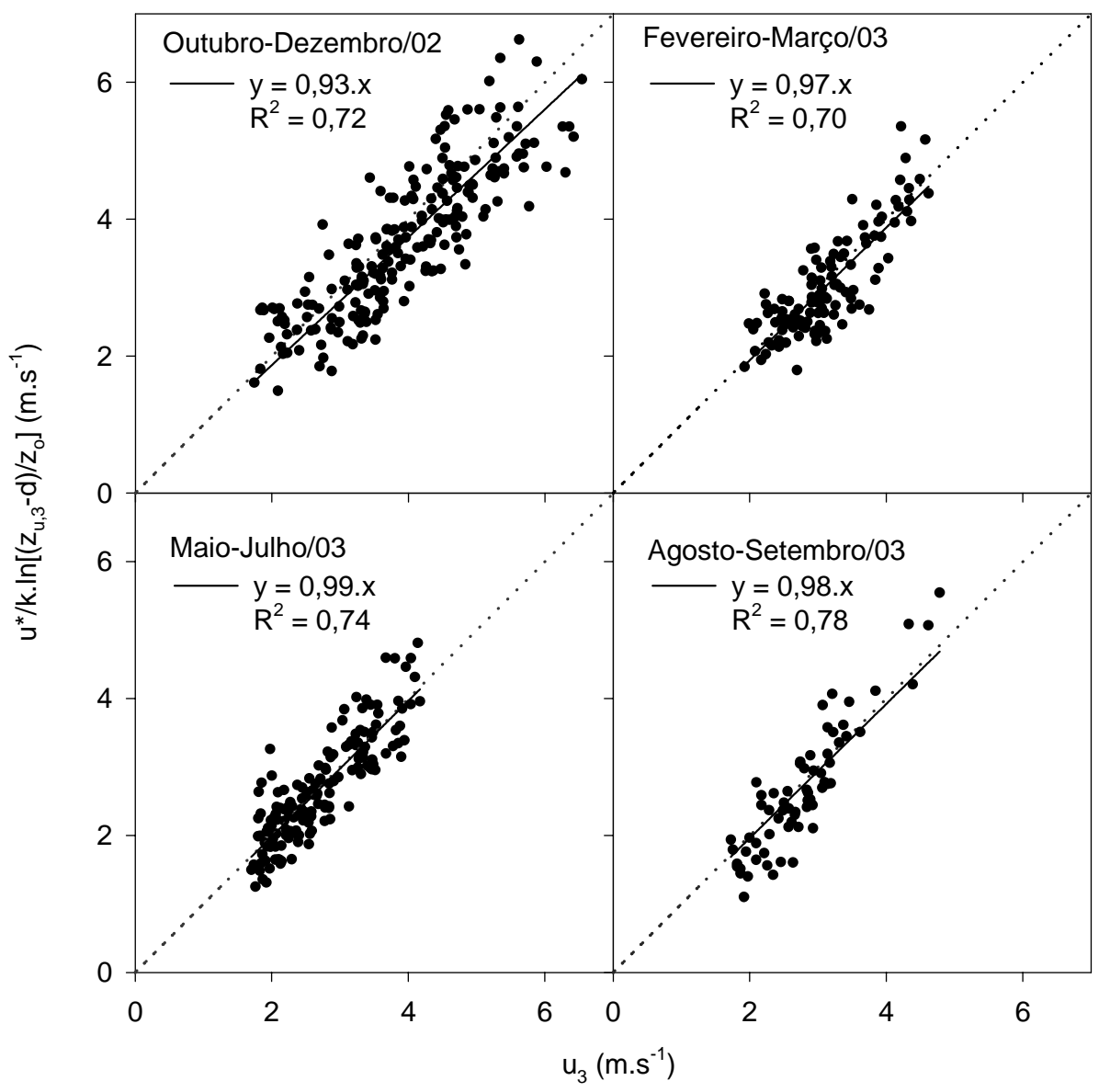

Figura 16 - Relação entre a velocidade do vento estimada no nível $z_{u, 3}$ pela Equação 7 a partir dos valores da velocidade característica da cobertura $\left(u^{*}\right)$, dos valores médios do deslocamento do plano zero $(d)$ e do comprimento de rugosidade $\left(z_{\mathrm{o}}\right)$ com os valores medidos $\left(u_{3}\right)$. $k$ é a constante de von Karman, considerada igual a 0,41 . Foram consideradas as condições com o módulo do número de Richardson $(|R i|)$ menor ou igual a $0,06, \mathrm{R}^{2} \geq 0,99$ no ajuste entre $u$ e $\ln (z)$ e $u_{2} \geq 1,5 \mathrm{~m} \cdot \mathrm{s}^{-1}$

razoável aproximação com o que se pode inferir das proposições de Lettau (1969) e Shaw \& Pereira (1982) e das boas estimativas de $u_{3}$ observadas na Figura 16, concluiuse ser válido trabalhar com os valores observados, utilizando-se as médias de cada 
período, por serem coerentes e representarem as condições ocorridas ao longo do experimento, como a variação da cobertura da entrelinha.

\subsubsection{Análise da qualidade dos dados dos gradientes de temperatura e umidade}

Inicialmente, fez-se uma análise dos níveis de medida mais adequados para os cálculos. De acordo com análise feita no item 4.3.1, $z_{p, 3}$ foi assumido como o nível superior mais adequado a ser considerado sem sofrer demasiado efeito das condições das áreas contornantes. Posteriormente às medidas, verificou-se que, em média, $z_{p, 1}$ estava abaixo de $d$ cerca de $0,05 \mathrm{~m}$ em 2002 e $0,12 \mathrm{~m}$ entre os dias 31/01/03 e 13/03/03 (Tabelas 1 e 3). Este fato torna questionável a representatividade das medidas feitas em $z_{p, 1}$, as quais foram tomadas abaixo do nível médio de trocas (Thom, 1971).

Outro quesito levado em conta foi o tamanho do gradiente a ser medido e as diferenças entre os psicrômetros. Conforme analisado por Fuchs \& Tanner (1970), Angus \& Watts (1984) e Perez et al. (1990), quanto menores forem os gradientes, os erros nas medidas tomam peso relativo maior. Como os gradientes tendem a diminuir com a altura, pela mistura turbulenta na atmosfera, e a aproximação dos níveis dos sensores torna menores as diferenças a serem medidas, o número de dias "utilizáveis" considerando-se $z_{p, 2}$ como nível inferior foi menor 35\% em 2002 e aproximadamente $44 \%$ (entre 4 e 2) e $53 \%$ (entre 3 e 2) em fevereiro - março de 2003, comparativamente às mesmas determinações feitas para os níveis 3 e 1 e 4 e 1 .

Análises de regressão mostraram que entre os dias 31/01/03 e 13/03/03, quando $z_{p, 1}-d \approx-0,12 \mathrm{~m}$ representou a situação mais crítica, ocorreu uma tendência de subestimativa de $1 \%$ a $4 \%$ nas determinações do fluxo de calor latente pelo MRB tendo como nível inferior $z_{p, 1}$, em relação às estimativas feitas acima de $z_{p, 2}$. Em contrapartida, em 2002, quando $z_{p, 1}-d \approx-0,05 \mathrm{~m}$, a mesma análise mostrou subestimativas entre $6 \% \mathrm{e}$ 10\%. As diferenças em 2002 parecem estar relacionadas com os erros psicrométricos, visto que as relações entre os valores de $L E_{M R B}$ calculados entre os níveis 2 e 1,3 e 1, 4 e

1, e 5 e 1 tenderam a ter diferenças menores do que $4 \%$ e com um ajuste elevado $\left(R^{2} \geq\right.$ 0,96) (Figura 17a-b), enquanto que entre os níveis 3 e 2 e 4 e 2, o ajuste foi 
consideravelmente inferior $\left(\mathrm{R}^{2}=0,81\right)$, embora com diferenças médias de somente $2 \%$. Portanto, considerando-se que na situação potencialmente mais crítica observada entre 31/01/03 e 13/03/03 (Tabela 1) houve pequena diferença entre as estimativas de $L E_{M R B}$ tendo-se como níveis inferiores $z_{p, 1}$ e $z_{p, 2}$, mais o fato de se ter maior número de dias "utilizáveis" quando considerado $z_{p, 1}$, optou-se por trabalhar com os níveis 1,3 e 4 .

Nas Figuras 17 e 18, verifica-se que na relação entre as estimativas dos fluxos entre os diferentes níveis, os pontos de dados ficaram muito próximos da linha 1:1 no período úmido, existindo uma excelente relação entre as estimativas de $L E_{M R B}$ (Figuras $17 \mathrm{a}$ e 17b), enquanto que no período seco houve maior dispersão dos dados a ponto de resultarem em baixos coeficientes de determinação $\mathrm{R}^{2}$ (Figuras 17c e 17d). Essa dispersão pode ser atribuída aos casos em que houve diferença nos perfis por advecção de calor sensível e aos erros sistemáticos devido a diferenças psicrométricas associadas aos pequenos gradientes de umidade observados no período seco. A excelente relação entre as estimativas entre os níveis 3 e 1 e 4 e 1 demonstram que no período úmido as medidas em $z_{p, 4}$ ficaram dentro da camada atmosférica em equilíbrio com a superfície, fato que não pôde ser observado no período seco, confirmando análise feita no item 4.3.1 e corroborando com Heilman et al. (1989).

Com relação a $H_{M R B}$, em todos os casos foi observada maior dispersão, existindo tendência de superestimativa no nível superior durante o período úmido. A análise de erro de acordo com metodologia de Perez et al. (1999) para os dias 11/02/03 $\left(H \approx 3 \mathrm{MJ} \cdot \mathrm{m}^{-2} \cdot \mathrm{dia}^{-1}\right)$ e 23/03/03 $\left(H \approx 7 \mathrm{MJ} \cdot \mathrm{m}^{-2} \cdot \operatorname{dia}^{-1}\right)$, mostrou que as diferenças encontradas corresponderam ao erro esperado nas estimativas, as quais foram maiores em dias mais secos (maiores valores de $\beta$ ).

Tanto para as estimativas de $L E_{M R B}$ quanto de $H_{M R B}$, outra provável causa da elevada dispersão dos dados no período seco foi a heterogeneidade espacial, conseqüente da existência de faixas com e sem cobertura verde, além de se ter uma fonte de vapor mais concentrada no renque de cafeeiro (Cellier \& Brunet, 1992; De Bruin et al., 1999). É possível que essa condição de heterogeneidade superficial tenha sido agravada pelo fato de se realizar irrigações subseqüentes por quadrantes, resultando em áreas com diferentes condições de umidade da superfície do solo sob os gotejadores. 
A partir das observações e da discussão das Figuras 17 e 18, nota-se a necessidade de se ter equipamentos nos diferentes níveis com respostas iguais às condições ambientais para não haver distorção nos perfis. Fuchs \& Tanner (1970), Spittlehouse \& Black (1979; 1980), Redford et al. (1980), Munro (1980), McCaughey \& Brintnell (1984), Aston (1985) e Heilman et al. (1989) contornaram as diferenças entre os diferentes conjuntos psicrométricos através da inversão periódica dos níveis de

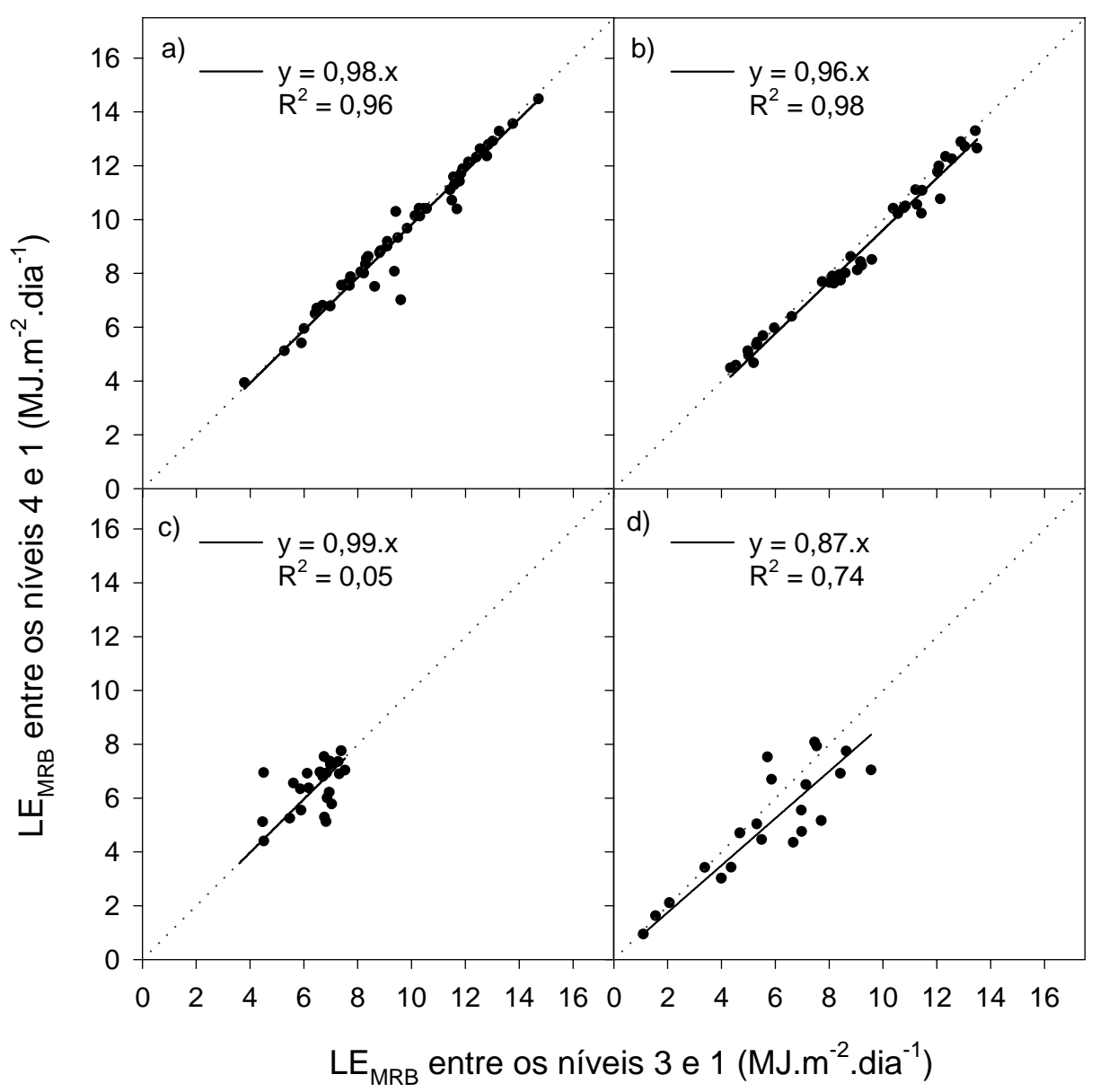

Figura 17 - Relação entre os fluxos de calor latente determinados pelo método do balanço de energia - razão de Bowen $\left(L E_{M R B}\right)$ entre os níveis 4 e 1 e 3 e 1 , para os períodos: outubro - dezembro de 2002 (a); fevereiro - março (b), maio - julho (c) e agosto - setembro (a partir dos mastros M1 e M2) (d) de 2003 


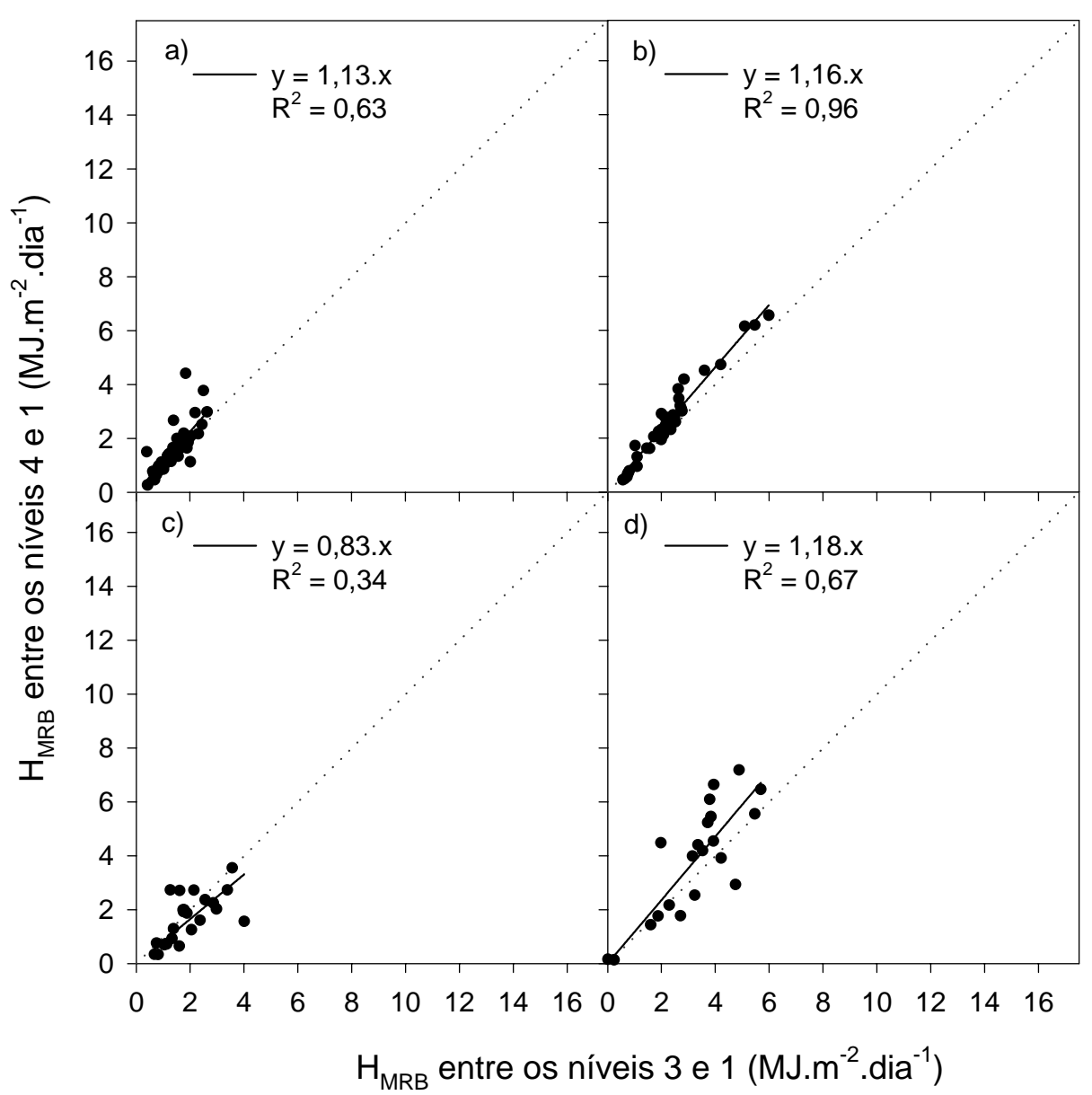

Figura 18 - Relação entre os fluxos de calor sensível determinados pelo método do balanço de energia - razão de Bowen $\left(H_{M R B}\right)$ entre os níveis 4 e 1 , e 3 e 1 , para os períodos: outubro - dezembro de 2002 (a); fevereiro - março (b), maio - julho (c) e agosto - setembro (a partir de M1 e M2) (d) de 2003

instalação dos equipamentos, enquanto que Rosemberg \& Brown (1974) testaram o desempenho dos aparelhos pela sua periódica disposição num mesmo nível, assumindo condições horizontalmente homogêneas, permitindo a correção das diferenças estruturais dos equipamentos. Esses procedimentos não foram feitos no experimento de campo, pois resultariam em uma montagem demasiadamente complicada do mastro micrometeorológico. 
No entanto, em uma série de medidas comparativas entre os psicrômetros feitas em laboratório ao final do experimento, mantendo-os sob as mesmas condições atmosféricas, obteve-se um desvio padrão médio entre eles de $\partial T_{s}=0,02{ }^{\circ} \mathrm{C}$ para as medidas de temperatura do ar e de $\partial T_{u}=0,06{ }^{\circ} \mathrm{C}$ para as medidas de temperatura de bulbo úmido. Nas observações feitas em laboratório, ficaram claras leves diferenças nas tendências entre as temperaturas de bulbo úmido após a substituição das gazes, provavelmente em função de alguma diferença na geometria final dos bulbos molhados. Especialmente no período seco, esse tipo de problema influenciou as medidas de campo, como discutido no item 4.3.1. Uma forma de contornar esses problemas é aumentar a distância vertical entre os sensores e, assim, obter uma diluição dos erros nos cálculos, conforme discutido por Aston (1985) e verificado por Spittlehouse \& Black (1980) e Unland et al. (1996). Daí a opção em se considerar as medidas nos níveis 1, 3 e 4 nas análises aqui realizadas, e não no nível 2.

Na Figura 19 são mostrados alguns exemplos de perfis observados durante o experimento, evidenciando-se um aumento dos gradientes de temperatura e umidade com a falta de chuvas no período úmido, como observado nos perfis dos dias 20/02/03, dois dias após uma chuva, e 01/03/03, 15 dias sem chuva. Não é bem claro porque isso aconteceu, mas parece estar relacionado com as condições de umidade atmosféricas e as fontes relativamente atuantes de vapor dos renques de cafeeiros irrigados e da cobertura relativamente densa da entrelinha (próxima de 90\% com solo coberto e com 0,30 m a 0,40 m de altura). Porém, quando toda a região encontrava-se seca (08/07/03), com uma proporção de cobertura verde da entrelinha de 30 a $40 \%$, ocorreram muitos dias com gradientes sensivelmente menores, principalmente entre 10:00 h e 18:00 h, enquanto que no dia 20/02/03 os gradientes mantiveram-se estáveis ao longo do dia e sem grandes distorções do perfil de umidade. Isso aumentou o efeito dos erros sobre as estimativas dos fluxos nos períodos secos, contribuindo para as maiores distorções observadas nas Figuras 19 e 20 (reparar as escalas, as quais não são iguais, para maior clareza dos perfis). De acordo com a análise de Angus \& Watts (1984), a medida que aumenta o valor de $\beta$, a influência dos erros nas medidas torna-se maior, tendendo a comprometer o desempenho do MRB em ambientes secos. 

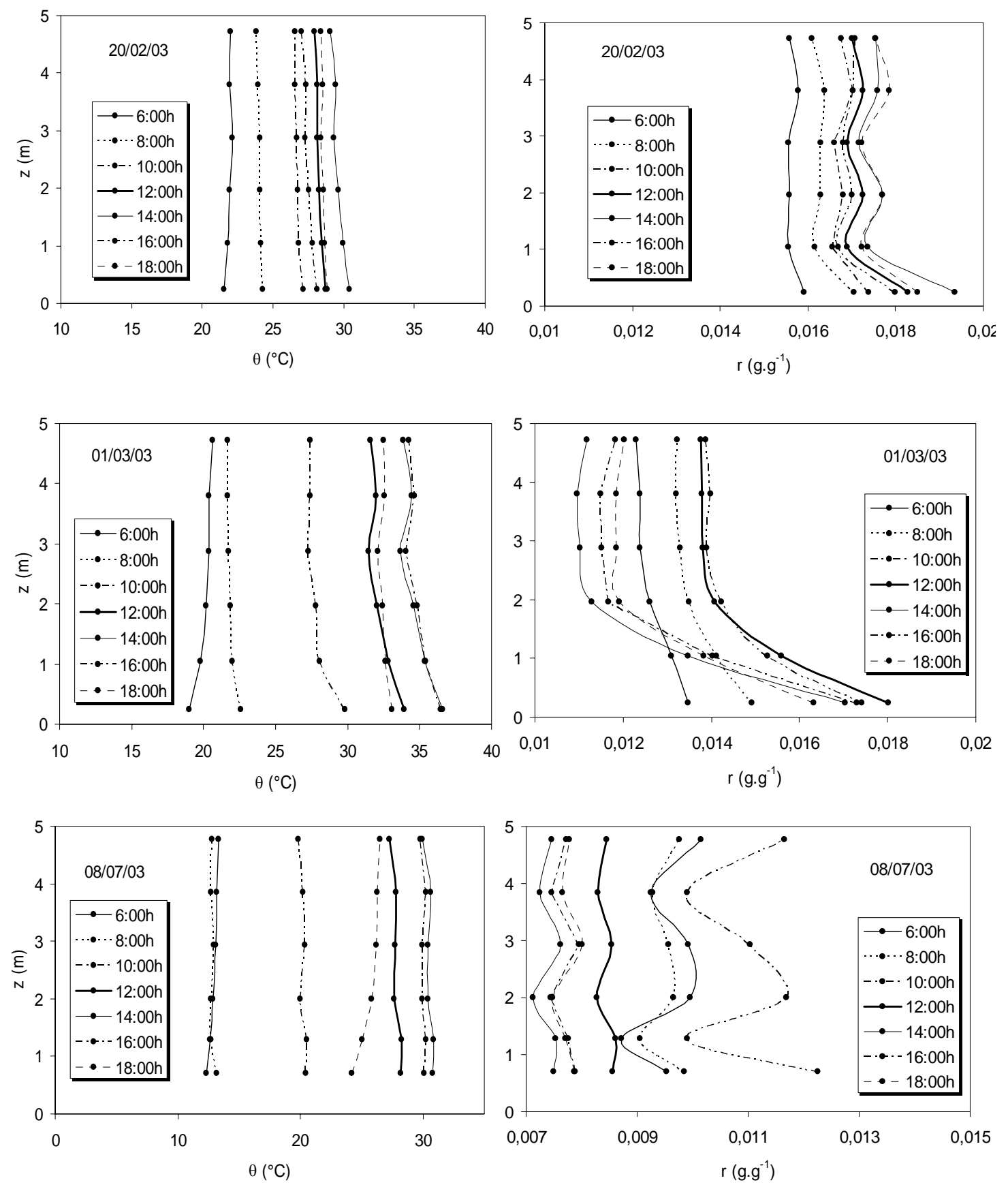

Figura 19 - Perfis da temperatura potencial $(\theta)$ e da razão de mistura $(r=0,622 . e / P)(\mathrm{g}$ de $\mathrm{H}_{2} \mathrm{O} . \mathrm{g}^{-1}$ de ar seco) para um dia úmido (20/02/03), um dia seco no período úmido $(01 / 03 / 03)$ e um dia seco no período seco $(08 / 07 / 03)$ 


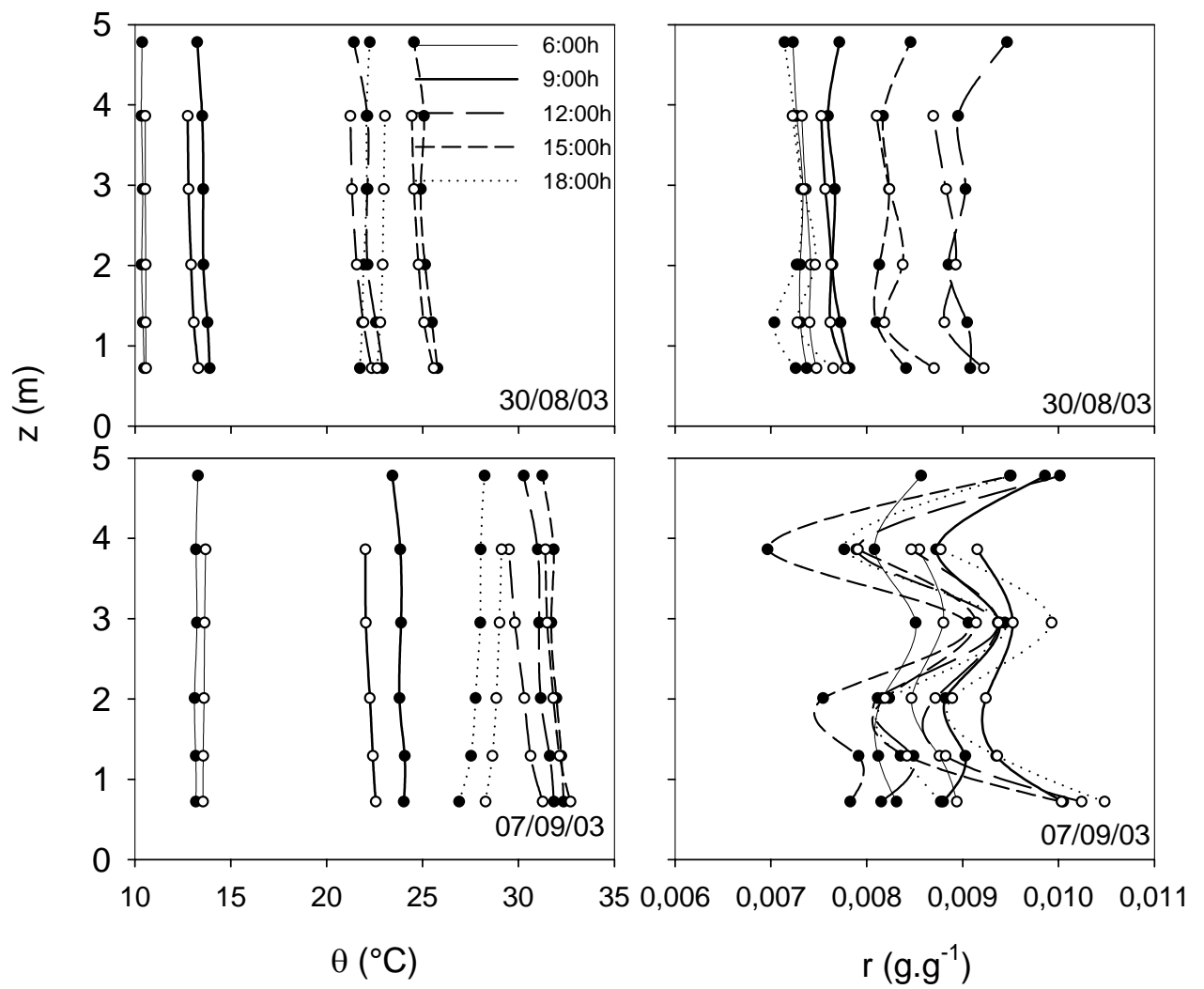

Figura 20 - Perfis de temperatura potencial $(\theta)$ e da razão de mistura $(r=0,622 . e / P)$ a partir das medidas nos mastros M1 (círculos abertos) e M2 (círculos fechados) ao longo dos dias 30/08/03 e 07/09/03

A partir dos perfis do dia 08/07/03 (Figuras 19 e 20), percebe-se a amplitude térmica de cerca de $20^{\circ} \mathrm{C}$, característica de ambientes secos, quando foram registrados valores mínimos de umidade relativa de cerca de 15\%. Mesmo nas medidas de temperatura do ar, que são menos suscetíveis a erros dos conjuntos psicrométricos (Monteith \& Unsworth, 1990), ocorreram algumas distorções dos perfis com a altura, fugindo do que seria teoricamente esperado, ou seja, um perfil quase logarítmico, o que está relacionado também à heterogeneidade da superfície e à advecção de calor sensível.

Ao se comparar os perfis de temperatura e umidade medidos nos mastros M1 e M2, percebe-se que as distorções ocorreram em ambos, mas de forma bastante diferente, 
tanto na grandeza dos valores, como na inversão de gradientes entre os mesmos níveis (Figura 20). Nesse caso, as diferenças psicrométricas podem ser consideradas comprometedoras, pois os pequenos gradientes verticais de temperatura e umidade ficaram muito próximos dos erros instrumentais $\left(\partial \Delta \theta=0,04{ }^{\circ} \mathrm{C}\right.$ e $\partial \Delta e \approx 0,02 \mathrm{kPa}$, equivalendo à diferença de razão de mistura do ar $\left.\partial \Delta r \approx 1,3 \cdot 10^{-4} \mathrm{~g} \cdot \mathrm{g}^{-1}\right)$. Isso fez com que muitos dos 30 dias de coleta de dados tivessem de ser desconsiderados no período de agosto - setembro de 2003 (15 dias em M1 e 6 dias em M2), resultado de fluxos contragradiente e fluxos de vapor no sentido atmosfera-superfície no período diurno, o que não é aceitável pelas fontes de vapor dos arredores serem até mais restritas do que no cafezal irrigado. A qualidade dos dados prejudicou as estimativas também no período de maio julho de 2003, quando 50\% das estimativas diárias foram inadequadas, enquanto que em fevereiro - março de 2003, $80 \%$ dos dias com medidas foram "utilizáveis". A redução das diferenças de pressão de vapor entre os níveis no período seco foi conseqüência, também, da aproximação dos psicrômetros realizada pela elevação dos níveis inferiores devido ao crescimento das plantas.

Numa comparação entre os fluxos determinados pelo MRB em ambos os mastros, duas particularidades ficaram destacadas. A primeira é que dos 29 dias de medida na campanha de agosto - setembro de 2003, pelos critérios utilizados na seleção de dados "utilizáveis", apenas 9 foram comuns aos dois mastros (Figura 21); a segunda é a tendência de superestimar $L E_{M R B}$ e de subestimar $H_{M R B}$ em M2, tomando-se como referência M1 e os níveis 3 e 1. Com exceção dos dias 27/08/03 e 03/09/03, ocorreu um bom ajuste entre $L E_{M R B}$ estimado a partir dos dados dos dois mastros. As diferenças entre os fluxos nos dois locais podem estar ligadas ao fato de que os gradientes de M1 permitiram estimativas "utilizáveis" de 20/08 a 03/09/03, sendo que até o dia 02/09/03 a área encontrava-se com o solo da entrelinha removido no lado leste dos mastros, mas M2 estava instalado mais próximo da área alterada e a $12 \mathrm{~m}$ de M1, significando que os gradientes de temperatura e umidade não representavam as mesmas condições superficiais. Entretanto, após a homogeneização da área, os gradientes de umidade em M1 tornaram-se praticamente nulos, enquanto que M2 continuou a produzir gradientes adequados para as estimativas de fluxo, mas somente até o dia 13/09/03. 
Os psicrômetros instalados no mastro M2 foram construídos de acordo com o desenho de Marin et al. (2001a), estruturalmente idênticos aos instalados em M1, com a única diferença que aqueles de M1 foram pintados externamente com tinta prateada. Como em cada mastro estavam instalados aparelhos do mesmo tipo e tempo de uso, esperava-se alguma diferença nos valores absolutos, mas não nos formatos dos perfis. Apesar da possibilidade do efeito de diferenças de construção e manutenção dos equipamentos, isso não é suficiente para explicar as distorções observadas, o que evidencia a ocorrência de diferenças nos formatos finais dos bulbos úmidos após cada troca das gazes (Visscher et al., 1995).
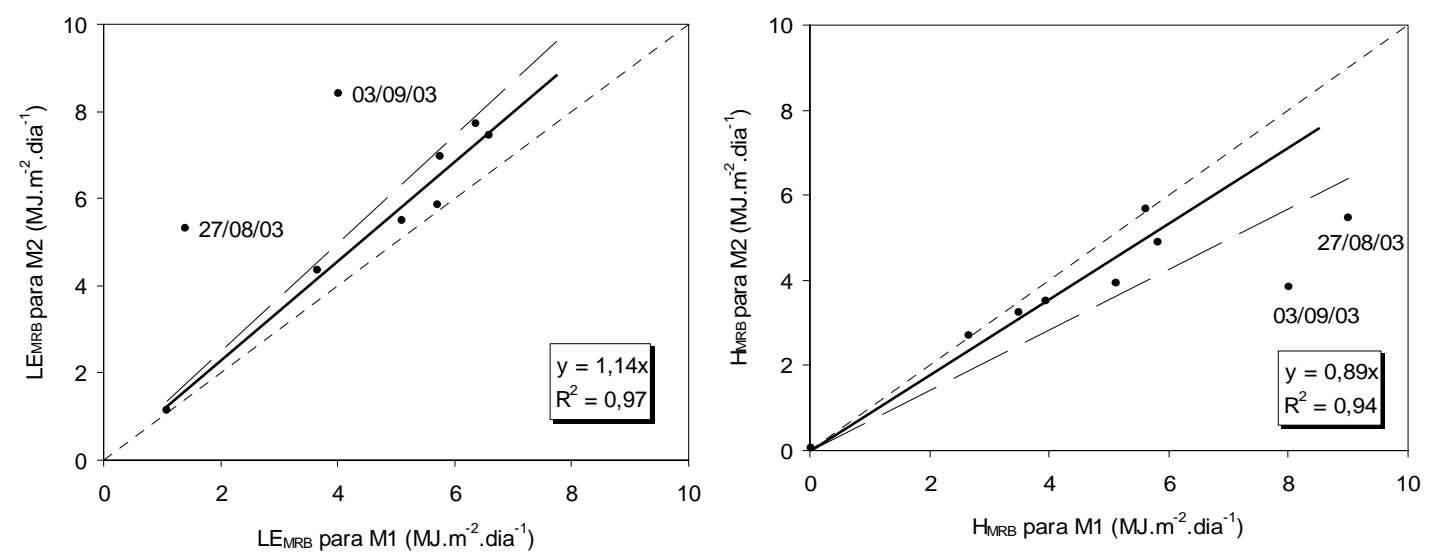

Figura 21 - Relação entre os valores dos fluxos de calor latente $\left(L E_{M R B}\right)$ e sensível $\left(H_{M R B}\right)$ determinados pelo método do balanço de energia - razão de Bowen com os dados dos mastros M1 e M2. A equação da regressão foi obtida desconsiderando-se os dias 27/08/03 e 03/09/03. A linha de tendência tracejada é referente a todos os dados

De qualquer maneira, fica evidente que a diminuição dos gradientes prejudica a performance do MRB e do MA nas estimativas dos fluxos, corroborando com as conclusões de Marin et al. (2001b) e Pereira et al. (2003) e com as análises de erro feitas por Angus \& Watts (1984) e Fuchs \& Tanner (1970). Especialmente nas condições presentes, o fato de que a principal fonte de vapor era representada pela área coberta pelos cafeeiros e com irrigação localizada, ocupando no máximo $25 \%$ do cafezal, levou 
ao estabelecimento de pequenos gradientes, inadequados para as estimavas dos fluxos com a precisão dos equipamentos utilizados. Diante desses problemas observados, do bom ajuste entre os valores de $L E_{M R B}$ nos dois mastros e de existir uma tendência razoavelmente próxima de 1:1, nos dias em que os gradientes medidos em M1 não foram adequados para as estimativas, elas foram feitas com os gradientes medidos em M2, quando estes estiveram disponíveis.

\subsubsection{Comparação entre as estimativas de LE pelo MRB e pelo MA}

As análises a seguir foram feitas considerando-se os níveis de medida $z_{u, 1}, z_{u, 3}$, $z_{p, 1}$ e $z_{p 3}$. Na Figura 22 são mostradas as relações entre as estimativas de $L E$ pelos métodos MRB e MA, verificando-se uma forte dispersão dos dados e valores de $L E_{M A}$ exageradamente elevados, quando comparados com $L E_{M R B}$ e com $(R n-G)$ em parte dos dias. A princípio, essa superestimativa de $L E_{M A}$ é contraditória ao verificado por Thom et al. (1975), Garratt (1978), Raupach et al. (1980); Raupach \& Legg (1984), Cellier \& Brunet (1992) e Mölder et al. (1999), de que o uso das relações válidas para a subcamada inercial resulta em subestimativas de $L E_{M A}$ quando as medidas são feitas na subcamada rugosa, pois nesse caso foram considerados como níveis inferiores $z_{p, 1}$ e $z_{u, 1}$, ambos menores do que $z *$. Em pomar de limoeiro irrigado, Marin (2000) e Pereira et al. (2003) também verificaram superestimativa de $L E_{M A}$ entre algumas alturas de medida, o que foi atribuído principalmente às pequenas velocidades do vento em pequenos $\Delta z$ resultarem em pequenos valores de $(\Delta u / \Delta z)^{2}$ e, conseqüentemente, $|R i|$ e $F$ exageradamente elevados em atmosfera instável. No caso do cafezal, não ficou evidente que a velocidade do vento ou os valores de $R i$ sejam as causas dessas superestimativas.

Na Figura 23 percebe-se que os valores de $L E_{M A}$ normalizados por $R n-G$ ficaram praticamente divididos em dois grupos conforme as diferenças médias de pressão de vapor em módulo, aspecto que já havia sido levantado por Marin (2000). Nessa figura, vê-se que os valores menores do que 1, que podem ser considerados coerentes na ausência de advecção de calor sensível e correspondem aos valores abaixo da linha 1:1 da Figura 22, ocorreram quando o gradiente de pressão de vapor em módulo 


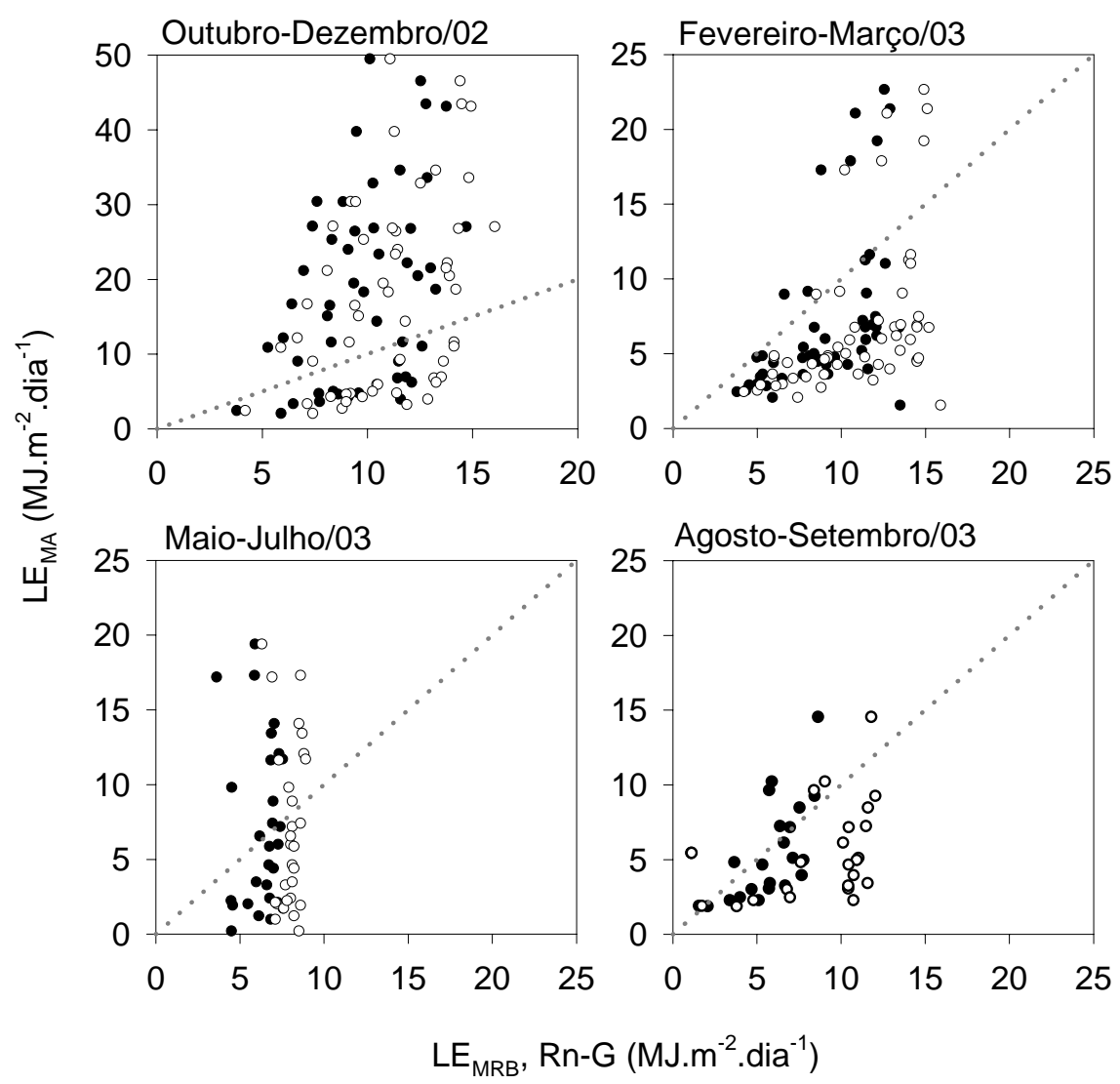

Figura 22 - Relação entre os fluxos de calor latente determinados pelo método aerodinâmico $\left(L E_{M A}\right)$ com aqueles determinados pelo método do balanço de energia - razão de Bowen $\left(L E_{M R B}\right)$ (círculos fechados) e a energia disponível aos fluxos referente ao mesmo período do dia $(R n-G)$ (círculos abertos) para os períodos de setembro - dezembro de 2002, fevereiro - março, maio - julho e agosto - setembro de 2003

entre 9:00 h e 16:00 h foi menor do que um determinado valor para cada período de medida. Nessas condições, ocorreram os casos com subestimativas de $L E_{M A}$ em relação a $L E_{M R B}$ observada na Figura 22, concordando com Thom et al. (1975), Garratt (1978), Raupach et al. (1980), Raupach \& Legg (1984) e Cellier \& Brunet (1992).

Ao se analisar os gradientes verticais de pressão de vapor, notou-se que este foi 


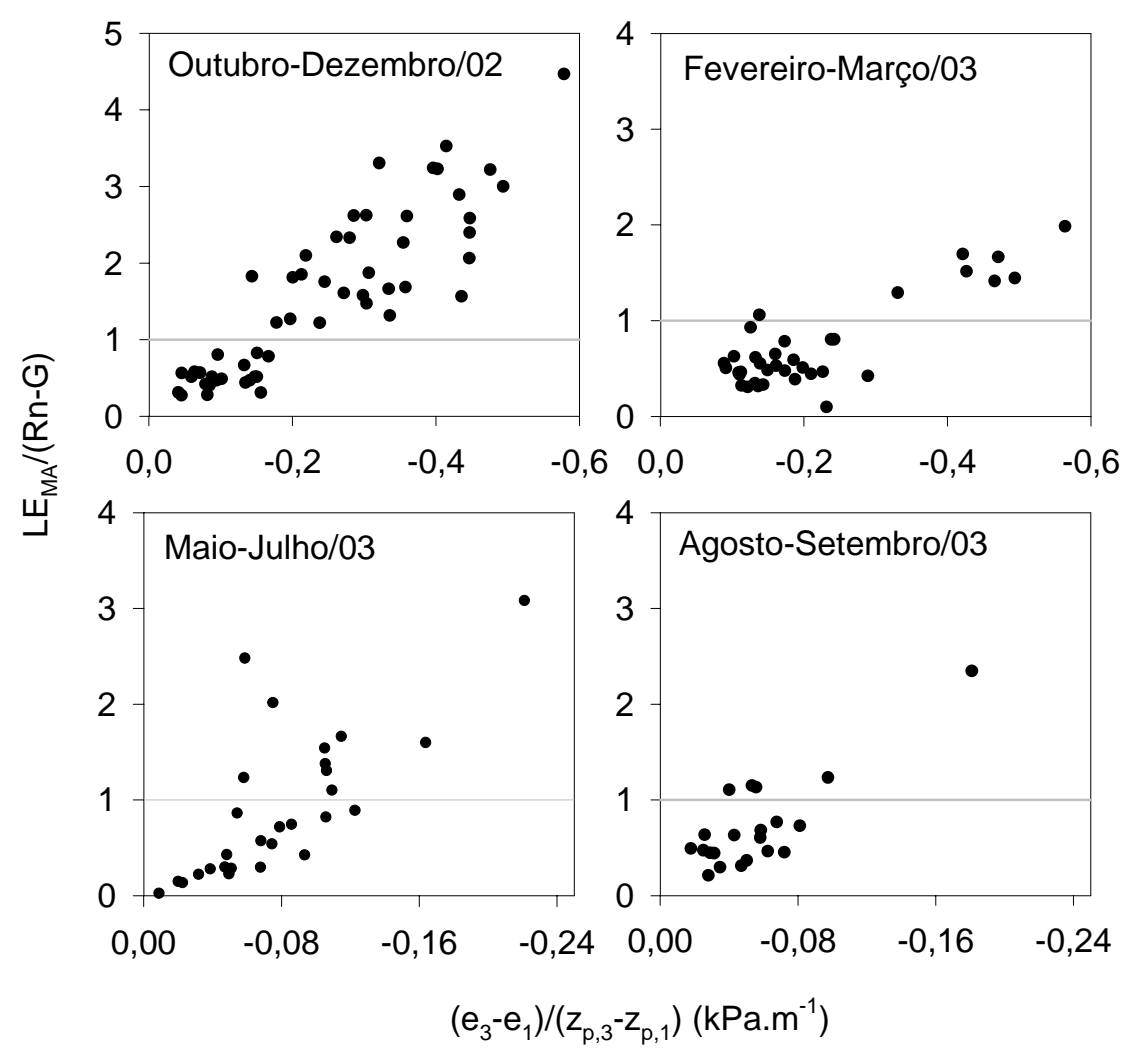

Figura 23 - Relação entre a razão do fluxo de calor latente determinados pelo método aerodinâmico $\left(L E_{M A}\right)$ com a energia disponível $(R n-G)$ e o gradiente médio de pressão de vapor no $\operatorname{ar}\left(e_{3}-e_{1}\right) /\left(z_{p, 3}-z_{p, 1}\right)$ entre 9:00 h e 16:00 h para os períodos de setembro - dezembro de 2002, fevereiro - março, maio - julho e agosto - setembro de 2003

influenciado pelas condições ambientais regionais e, possivelmente, de meso e macroescala. Sua evolução é mostrada na Figura 24, juntamente com os gradientes de temperatura e de vento, e com os eventos de chuva, com os valores de $\theta_{3}$ e os de $R i$ ao longo dos dias de medida, enquanto que na Figura 25 são mostrados os valores diários de $\operatorname{Pr}, L E_{M A} /(R n-G), H_{M A} /(R n-G)$ e as médias diárias entre 9:00 h e 16:00 h de $R i$ e dos gradientes de pressão de vapor, para o período de 2002. Nessas figuras, verifica-se que a medida que se afastou de um evento de chuva (entre os dias $264(20 / 09 / 02)$ e 265 
(21/09/02) choveu $21 \mathrm{~mm}$ e entre $274(30 / 09 / 02)$ e 275 (01/10/02) choveu 3,7 mm), o gradiente de pressão de vapor tendeu a aumentar, enquanto que a partir do dia Juliano 325 (20/11/2002), as chuvas tornaram-se mais significativas e freqüentes, e os gradientes estabilizaram em valores menores do que $1-0,3 \mid \mathrm{kPa} \cdot \mathrm{m}^{-1}$, quando já existia uma condição de umidade regional homogênea. Ao mesmo tempo, não se percebe modificação expressiva nos gradientes de velocidade do vento associados aos elevados gradientes de temperatura e umidade, enquanto que os valores de $L E_{M A} /(R n-G)$ passaram a serem menores do que 1 a partir do dia 325 (20/11/2002) (Figura 25).

Em fevereiro - março de 2003 foi observada uma situação semelhante. Ao longo dos últimos 15 dias de janeiro de 2003, a altura pluviométrica foi de $180 \mathrm{~mm}$ bem distribuídos ao longo do período, que pode ser caracterizado como de elevada umidade. Do dia 31 (31/01/03) até o dia 50 (19/02/03) (Figura 26), apesar dos elevados gradientes de temperatura, ocorreram chuviscos e pequenos eventos de chuva (4 $\mathrm{mm}$ até o dia $42 \mathrm{e}$ $58 \mathrm{~mm}$ até o dia 50) que proporcionaram pequenos gradientes de pressão de vapor. Entre os dias 50 e $62(03 / 03 / 03)$ houve uma secagem progressiva da superfície, com nenhuma ocorrência de chuva, elevando os gradientes de pressão de vapor, até retornar um novo período de chuvas com início no dia 62. Além das condições de umidade superficiais, percebe-se que a evolução dos gradientes de temperatura e pressão de vapor nessas situações aparentemente foi também influenciada pelas condições atmosféricas de meso e/ou macro-escala, como se nota pelos valores elevados de $D$ nesses períodos na Figura 9, além dos elevados gradientes de temperatura mesmo com elevada umidade na superfície.

Os valores de $R i$ apresentaram dependência dos gradientes de temperatura, tendendo a valores mais próximos de zero sob instabilidade atmosférica $(R i<-0,01)$ após um evento de chuva, com $R i \leq-0,5(F \geq 5,2)$ no máximo em $25 \%$ dos casos nos dias com superestimativa de $L E_{M A}$, mas em poucas situações (menos do que $12 \%$ dos valores menores do que zero) observou-se $R i<-1,0$, limite para o qual as correções de estabilidade são válidas (Dyer, 1967, 1974; Dyer \& Hicks, 1970). Portanto, os valores de $R i$ não devem ter sido a causa das estimativas demasiadamente elevadas de $L E_{M A}$, pois mesmo sem aplicar as correções de estabilidade atmosférica $(F=1)$, em 2002 apenas 


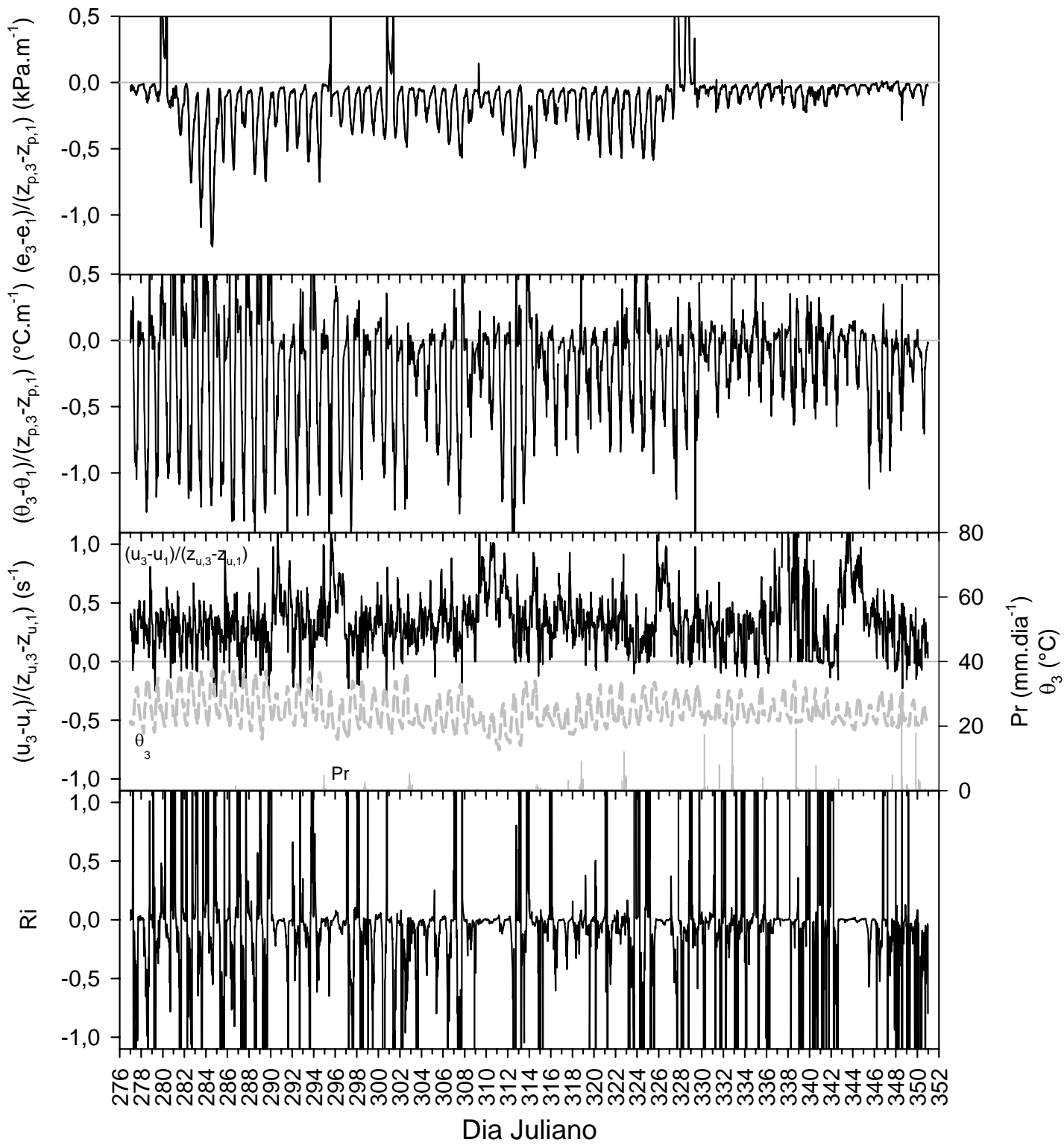

Figura 24 - Variação dos gradientes de pressão de vapor $\left(e_{3}-e_{1}\right) /\left(z_{p, 3}-z_{p, 1}\right)$, de temperatura do ar $\left(\theta_{3}-\theta_{1}\right) /\left(z_{p, 3}-z_{p, 1}\right)$ e de velocidade do vento $\left(u_{3}-\right.$ $\left.u_{1}\right) /\left(z u_{, 3}-z_{u, 1}\right)$ entre os níveis 3 e 1 , juntamente com o número de Richardson $(R i)$, com a precipitação $(P r)$ e com a temperatura potencial medida no nível $3\left(\theta_{3}\right)$, no período de outubro - dezembro de 2002 


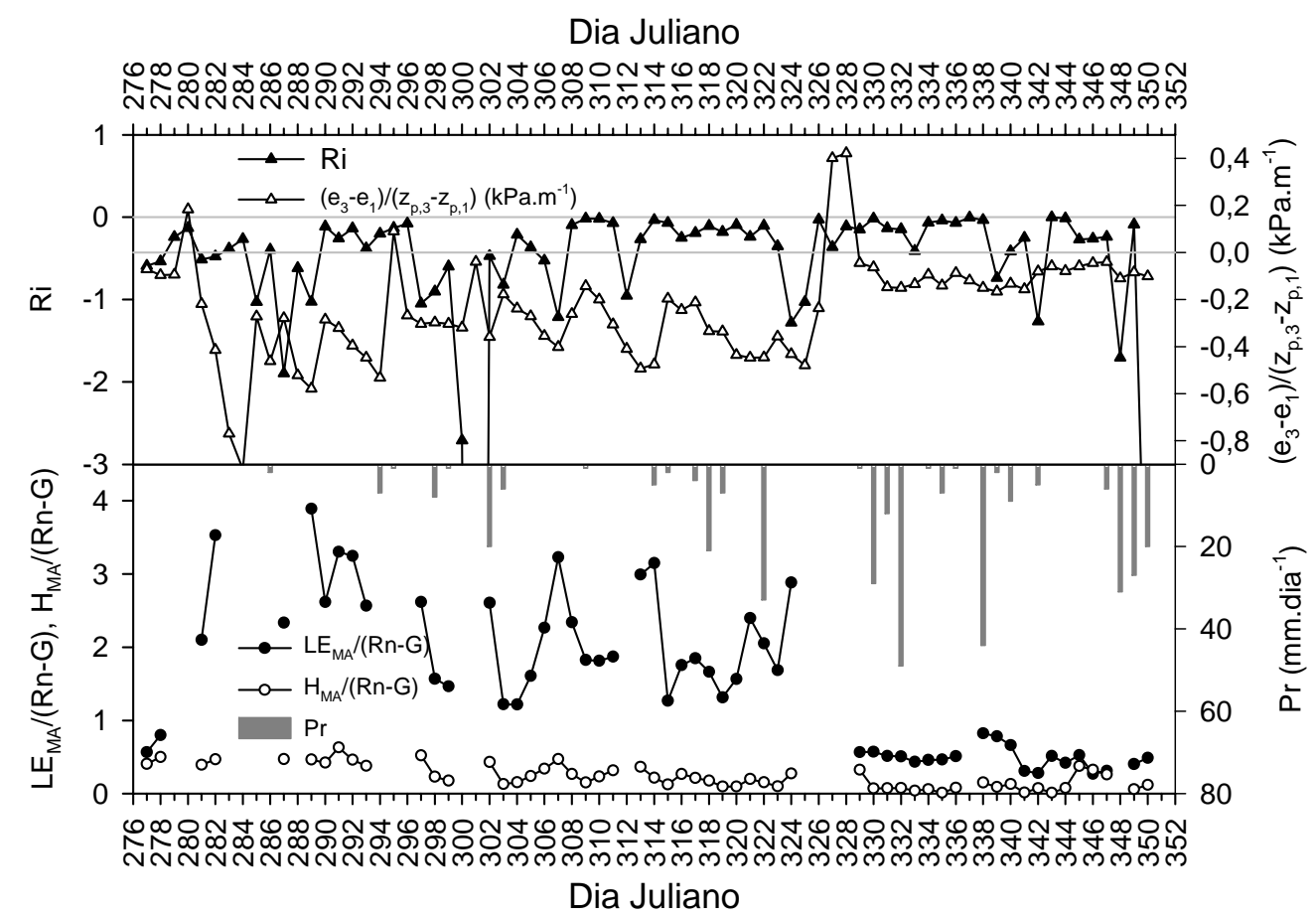

Figura 25 - Evolução diária das razões dos fluxos de calor latente e sensível determinados pelo método aerodinâmico com a energia disponível na superfície, respectivamente, $L E_{M A} /(R n-G)$ e $H_{M A} /(R n-G)$, da precipitação $(P r)$ e dos valores médios entre 9:00 h e 16:00 h do número de Richardson $(R i)$ e do gradiente de pressão de vapor entre os níveis 3 e $1\left(e_{3}-e_{1}\right) /\left(z_{p, 3}-z_{p, 1}\right)$

$36 \%$ dos dias com superestimativa passaram a ter uma relação $L E_{M A} /(R n-G) \leq 1$. Erros nas medidas de temperatura ocorreram, mas diante dos elevados valores dos gradientes, podem ser descartados como única causa da discrepância observada, pois seus erros relativos ficaram diluídos nas medidas.

Parte dos erros pode ter acontecido pela inconsistência do valor de $d$, principalmente pelo efeito sobre ele da velocidade e da direção do vento. Outra possível fonte de erros pode ter sido o fato de $z_{p, l}$ estar instalado num nível próximo ou abaixo de $d$ em parte da coleta dos dados em 2002 e parte do período de fevereiro - março de 2003, mas como existia um elevado espaçamento entre os renques, com o solo 


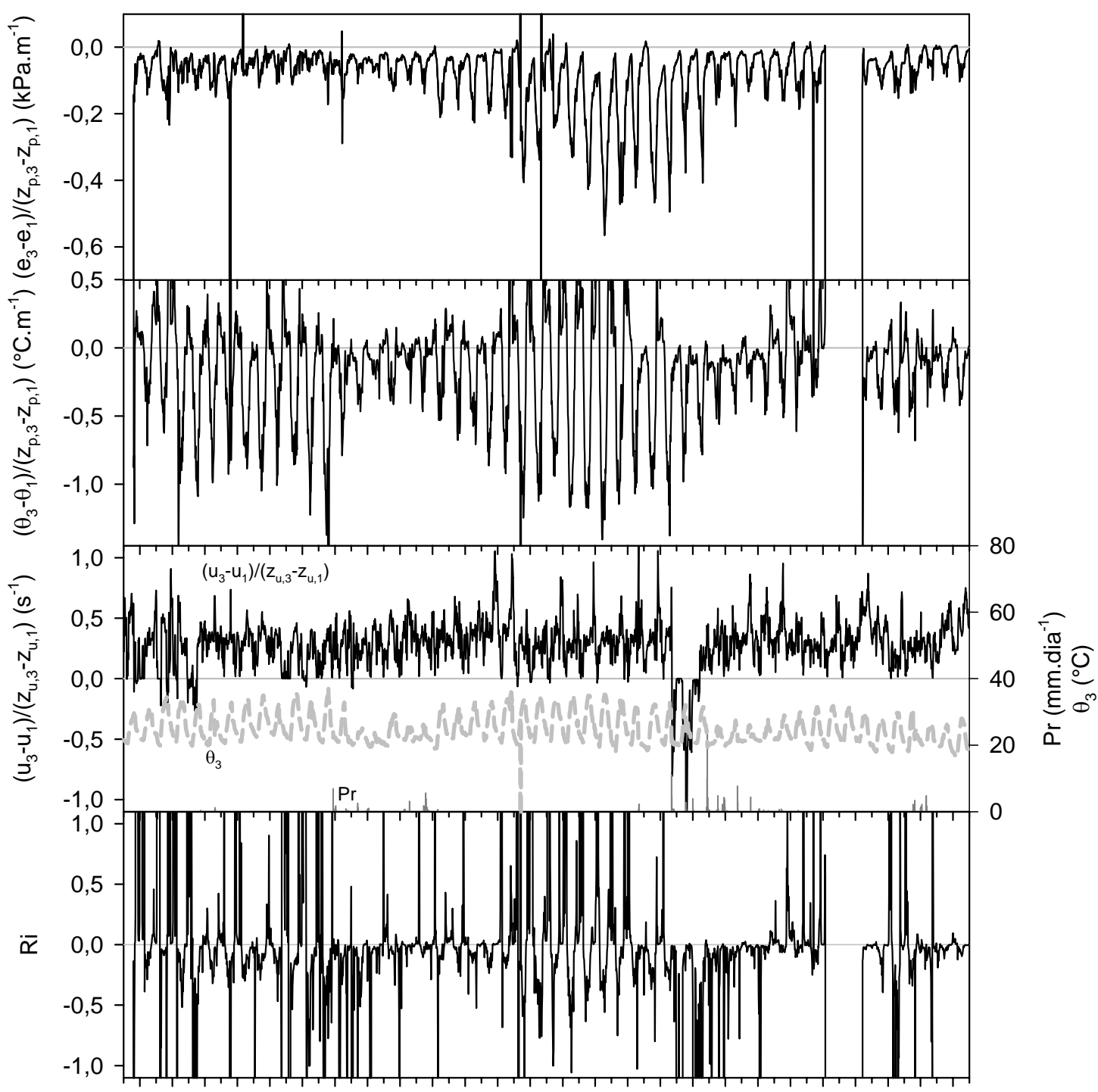

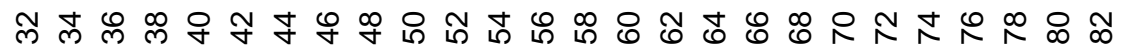

Dia Juliano

Figura 26 - Variação dos gradientes de pressão de vapor $\left(e_{3}-e_{1}\right) /\left(z_{p, 3}-z_{p, 1}\right)$, da temperatura do ar $\left(\theta_{3}-\theta_{1}\right) /\left(z_{p, 3}-z_{p, 1}\right)$ e da velocidade do vento $\left(u_{3}-\right.$ $\left.u_{1}\right) /\left(z_{u, 3}-z_{u, 1}\right)$ entre os níveis 3 e 1 , juntamente com o número de Richardson $(R i)$, a precipitação $(P r)$ e a temperatura potencial medida no nível $3\left(\theta_{3}\right)$, no período de fevereiro - março de 2003 
parcialmente nu num raio de aproximadamente $1,5 \mathrm{~m}$ em torno do mastro e a tomada de ar pelos psicrômetros estava afastada mais de 1,0 $\mathrm{m}$ das copas dos cafeeiros, provavelmente, o ar amostrado em $z_{p, 1}$ tenha sido representativo da cobertura devido à forte mistura pela elevada atividade turbulenta nesta região, além de terem sido observados valores de $L E_{M A}$ esdrúxulos também durante os períodos secos, quando $z_{u, 1} \mathrm{e}$ $z_{p, l}$ estavam instalados acima de $h$. Além disso, as estimativas "utilizáveis" de $L E_{M A}$ entre os níveis $z_{p, 3}$ e $z_{p, 2}$ também apresentaram valores esdrúxulos em períodos com elevado gradiente de umidade. A correção dos gradientes apresentada por Pereira (1998), $\partial(u, \theta, e) / \partial z \approx \overline{\Delta(u, \theta, e) / \Delta z}=\Delta(u, \theta, e) /\left[\left(z_{i \cdot} \cdot z_{i-1}\right)^{0,5} \cdot \ln \left(z_{i} / z_{i-1}\right)\right]$, resultou em um aumento de aproximadamente $20 \%$ nos gradientes de temperatura e de pressão de vapor e 9\% nos gradientes de vento, em relação aos cálculos considerando-se somente o quociente $\Delta(u, \theta, e) / \forall$, agravando as superestimativas nos períodos de secagem da superfície. Portanto, restam somente os coeficientes de transporte turbulento e o valor de $z_{o}$ diferente para transporte de calor, de vapor e de momento (Thom, 1972; Garratt \& Hicks, 1973; Kustas et al., 1989a; Pieri \& Fuchs, 1990) como prováveis causas dessas elevadas discrepâncias.

As funções de estabilidade $\phi$ utilizadas neste trabalho são aquelas propostas por Dyer \& Hicks (1970) e Webb (1970), válidas para superfícies homogêneas e medidas feitas na subcamada inercial, condições que diferem daquelas do cafezal, fazendo com que, possivelmente, a relação $K_{h, w} / K_{m}=\phi_{m} / \phi_{h, w}$ não seja válida no caso presente. Quanto a $K_{w} / K_{m}$, Pruitt et al. (1973) verificaram que essa razão foi $13 \%$ maior do que a unidade nas proximidades da neutralidade atmosférica. As relações desses autores foram testadas no período de 2002, levando a uma pequena redução das superestimativas, mas insignificante diante dos elevados valores verificados.

Outra fonte de erro pode ser a diferença entre $K_{h}$ e $K_{w}$; Verma et al. (1978) e Motha et al. (1979) encontraram valores de $K_{h} / K_{w}$ inferiores a 1 durante parte da manhã, mas que aumentaram a valores acima de 3 durante o período da tarde, quando foi observada inversão dos perfis de temperatura, sob elevada advecção regional. Sob 
advecção local, Bink (1996) encontrou $K_{h}<K_{w}$. De Bruin et al. (1999) e McNaughton \& Laubach (1998) relatam várias situações em que se evidenciou $K_{h} \neq K_{w}$.

McNaughton \& Laubach (1998) mostraram analiticamente, que sob condições advectivas, para valores de $\beta$ positivos ocorre $K_{h}<K_{w}$ e o contrário quando $\beta<0$. Ficou evidente, também, que quando $\beta \rightarrow 0$, a desigualdade tende ao infinito, sendo que na faixa $-0,2<\beta<0,1$, considerada como a faixa característica de condições de advecção, a hipótese da similaridade é gravemente comprometida, embora os erros em uma simulação de $\mathrm{H}$ tenham sido maiores em condições de forte estabilidade atmosférica $(\beta \rightarrow-1)$.

No entanto, de acordo com análise feita no item 4.3.1, o índice de similaridade $I$ entre os gradientes de temperatura e pressão de vapor durante o período úmido entre 9:00 h e 16:00 h pode ser considerado satisfatoriamente próximo de 1, diante das fontes de erro nas medidas. Sendo assim, provavelmente as relações $K_{h, w} / K_{m}$ e, conseqüentemente, as funções $\phi_{h, w, m}$ válidas para a subcamada inercial não são adequadas para as condições superficiais do cafezal, ao mesmo tempo que as relações propostas por Cellier \& Brunet (1992) e Mölder et al. (1999) para corrigir os coeficientes de transporte na subcamada rugosa da atmosfera não são válidas durante períodos de secagem progressiva da superfície, caracterizados por elevados gradientes de pressão de vapor. Fatores como o grande espaçamento entre os renques, o arranjo destes em paralelo, juntamente com faixas de solo nu e de solo coberto pelos cafeeiros e ervas daninhas, caracterizando elevada heterogeneidade horizontal e uma razoável rugosidade aerodinâmica, fazem com que os fluxos turbulentos se comportem de forma diferente do que seria observado na subcamada inercial da atmosfera sobre superfícies homogêneas e, até mesmo, em relação aos tipos de subcamada rugosa estudados na literatura. Outra possibilidade, não estudada nesse caso, é a rugosidade da superfície para trocas de calor e vapor ser menor em relação a momento, conforme discutido por Thom (1972) e Garratt (1973).

Em relação ao MRB, como os perfis de temperatura e pressão de vapor tiveram formatos semelhantes, como visto no item 4.3.1, e a modificação dos coeficientes de transporte pela otimização dos fluxos nas proximidades da superfície tem-se mostrado 
semelhante para calor e vapor (Cellier \& Brunet, 1992; Mölder et al., 1999), provavelmente a relação $K_{h} / K_{\mathrm{w}}$ não tenha sido muito diferente de 1 . De acordo com McNaughton \& Laubach (1998), a determinação de $H$ pelo MRB é usualmente satisfatória dentro das condições verificadas nas aplicações práticas, o que pode ser esperado para $L E_{M R B}$ também, exceto quando na presença de intensa inversão térmica. Além disso, o MRB leva em consideração a energia disponível aos fluxos de calor para a atmosfera, o que limita o efeito das distorções dos perfis, podendo-se inferir que as estimativas de $L E_{M R B}$ estão sujeitas a menores erros e aproximam-se dos valores reais.

\subsubsection{Partição da energia disponível na superfície}

Nas análises a seguir foram utilizadas as estimativas feitas pelo MRB, tendo em vista que este método apresentou melhor desempenho nas condições do estudo. Os fluxos de calor latente e sensível são referidos, deste ponto em diante, somente como $L E$ e $H$.

O valor médio da razão $G / R n$ no período diurno foi de $15 \%$ em $2002,8 \%$ em fevereiro - março e em agosto - setembro e 5\% em maio - julho de 2003. Nota-se, portanto, que quando os valores de $D_{c}$ (Tabela 1) e a cobertura da entrelinha eram relativamente pequenos, $G$ foi mais elevado. Com o aumento da área ocupada pelas copas de cafeeiros e da cobertura na entrelinha, que variava em torno de 80 a $100 \%$ entre seca e verde, a componente $G$ tendeu a diminuir. Em maio - julho de 2003, $G$ teve participação menor no balanço global de energia do que nos outros períodos, provavelmente em conseqüência da cobertura da entrelinha relativamente elevada, composta em mais de $50 \%$ por palhada seca, a qual é mais eficiente como isolante radiativa e térmica. Os baixos valores de $G / R n$ neste período se devem também à maior inclinação dos raios solares e aos conseqüentes menores valores de radiação incidente (Cellier et al., 1996). Sem dúvida, as condições de umidade tiveram efeito sobre a grandeza dos valores de $G / R n$, mas sua análise é complicada, pois seria necessário que as propriedades físicas e térmicas do solo fossem conhecidas e bem determinadas, além de medidas dos gradientes de temperatura e do conteúdo de umidade ao longo do tempo, 
os quais não foram medidos. Provavelmente, a velocidade do vento e $H$ também tenham influenciado os valores de $G$ (Cellier et al., 1996; Massman, 1992).

Desprezando a fotossíntese e algum armazenamento no solo e na biomassa, o restante do saldo de energia radiante disponível $(R n-G)$ é repartido entre $L E$ e $H$ conforme as condições de umidade do solo, sendo maior $L E$ em detrimento de $H$ em condições úmidas, levando a valores de $\beta$ menores (Pereira et al., 1997; Pereira, 1998). Na Figura 27 é mostrada a variação dessas duas componentes do balanço de energia, juntamente com $(R n-G)$, no período entre os dias julianos $50(19 / 02 / 03)$ e 59 (28/02/03), após uma sequência de cerca de 10 dias chuvosos. Nota-se que ao longo deste período, ocorreu um leve aumento dos valores de $\beta=H / L E$, sendo que, considerando-se o ciclo hidrológico, em termos gerais $\beta$ respondeu à sazonalidade local, como visto na Figura 28, com médias entre 9:00 h e 16:00 de 0,14 $( \pm 0,06)$ na campanha de 2002 e de 0,26 $( \pm 0,16)$ na de fevereiro - março, e médias entre 9:00 h e 15:00 h de $0,38( \pm 0,32)$ na de maio - julho e de $0,71( \pm 0,34)$ na de agosto - setembro de 2003 . O valor de $\beta=2,40$ no dia 01/06/03 não foi considerado por ter-se observado valores esdrúxulos ao longo do dia.

Porém, dividindo-se o período de 2002 conforme as condições de precipitação (Figura 28), até o dia 293 (20/10/02), período com elevada deficiência hídrica (Figura 8) e sem chuvas, obteve-se $\beta=0,19$, e de 294 (21/10/02), quando, embora fracas, as chuvas se iniciaram, a $350(16 / 12 / 02)$, obteve-se $\beta=0,13$. Observa-se que, mesmo sob condições secas, o valor médio de $\beta$ antes das chuvas iniciarem foram bem inferiores daqueles obtidos em condições ambientais também secas em 2003 (maio - julho e agosto - setembro). Outro resultado, de certa forma contraditório, ocorreu até o dia 43 (12/02/03) (Figura 28), quando elevados gradientes de temperatura resultaram em valores médios de $\beta=0,50$, mesmo sendo um período com elevada umidade na superfície (ver Figura 26).

Os valores baixos de $\beta$ em outubro de 2002 ocorreram pelos elevados gradientes de pressão de vapor observados no início do experimento, conseqüência provável da cobertura da entrelinha relativamente alta (cerca de $80 \%$ ) e ativa, pelas 


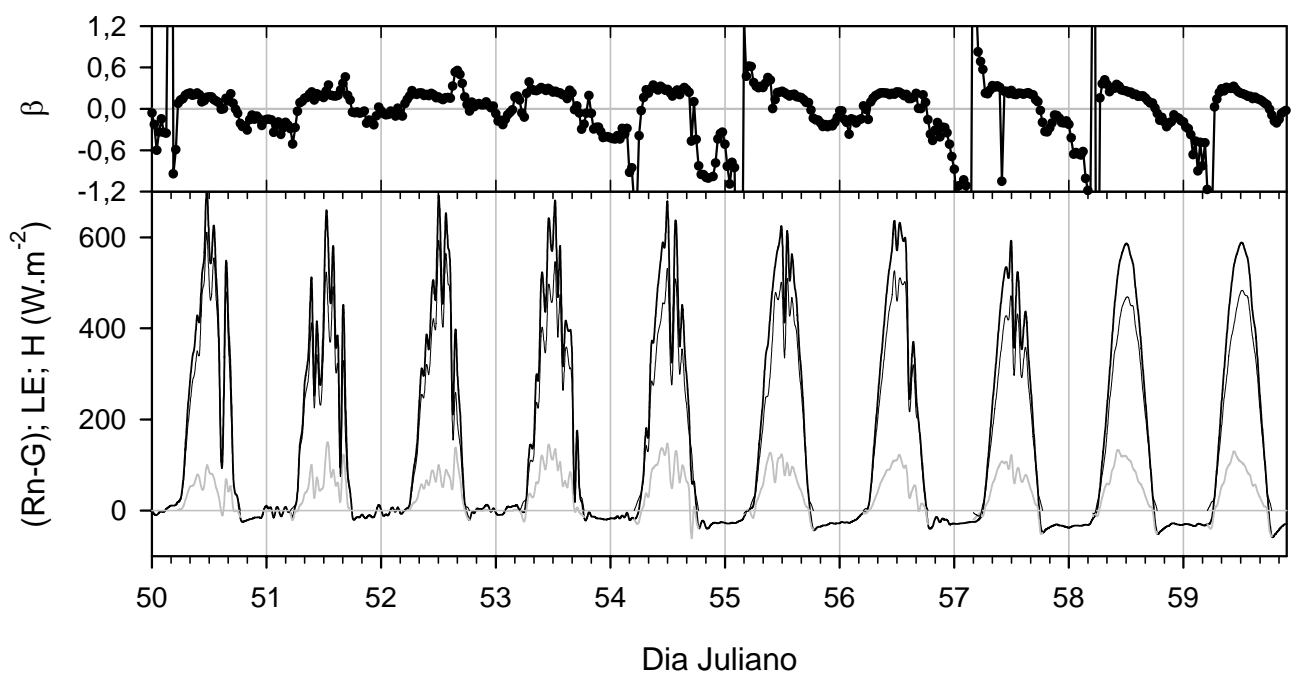

Figura 27 - Variação da energia disponível no ambiente $(R n-G ;-)$ juntamente com as componentes fluxo de calor latente $(L E ; \longrightarrow)$ e calor sensível $(H ; \longrightarrow)$ e a razão $(\beta=H / L E ;-\bullet-)$, no período entre os dias $50(19 / 02 / 03)$ e 59 $(28 / 02 / 03)$. Valores médios de $30 \mathrm{~min}$; cada intervalo no eixo x equivale $\mathrm{a} 4 \mathrm{~h}$

chuvas de $45 \mathrm{~mm}$ entre 07/09 e 21/09/02 terem intensificado o seu crescimento. Outra questão que deve ser levantada nessa comparação é que do dia 145 (24/05/03) até o final do experimento choveu somente $55 \mathrm{~mm}$, caracterizando um período mais seco em relação ao mesmo em $2002(P r=120 \mathrm{~mm})$, sendo que, ainda, entre 16/05 e 22/05/02 choveu $84 \mathrm{~mm}$, indicando uma possível quantidade maior de água disponível no solo em outubro de 2002 do que aquela apresentada na Figura 8b, visto que ETP tendeu a superestimar a evapotranspiração com maior intensidade naquele período (seção 4.1). Em fevereiro de 2003, percebe-se que a parcial secagem da superfície, juntamente com a elevada disponibilidade energética, proporcionaram a formação de gradientes de temperatura elevados, enquanto que a cobertura verde ativa e a relativamente alta umidade na atmosfera (Figura $8 b$ ), devido aos freqüentes, embora pequenos, eventos de chuva, resultaram em gradientes de umidade reduzidos. Ao mesmo tempo, entre os dias $51(20 / 02 / 03)$ e $62(03 / 03 / 03)$, quando houve uma secagem progressiva da 


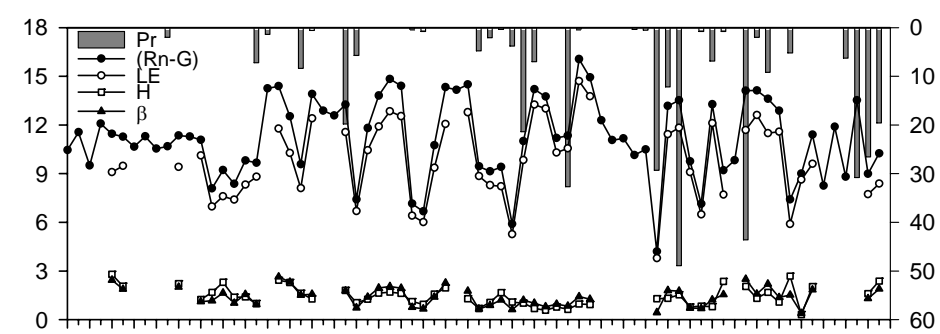

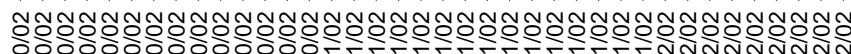

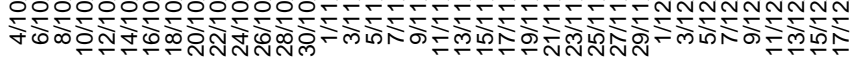

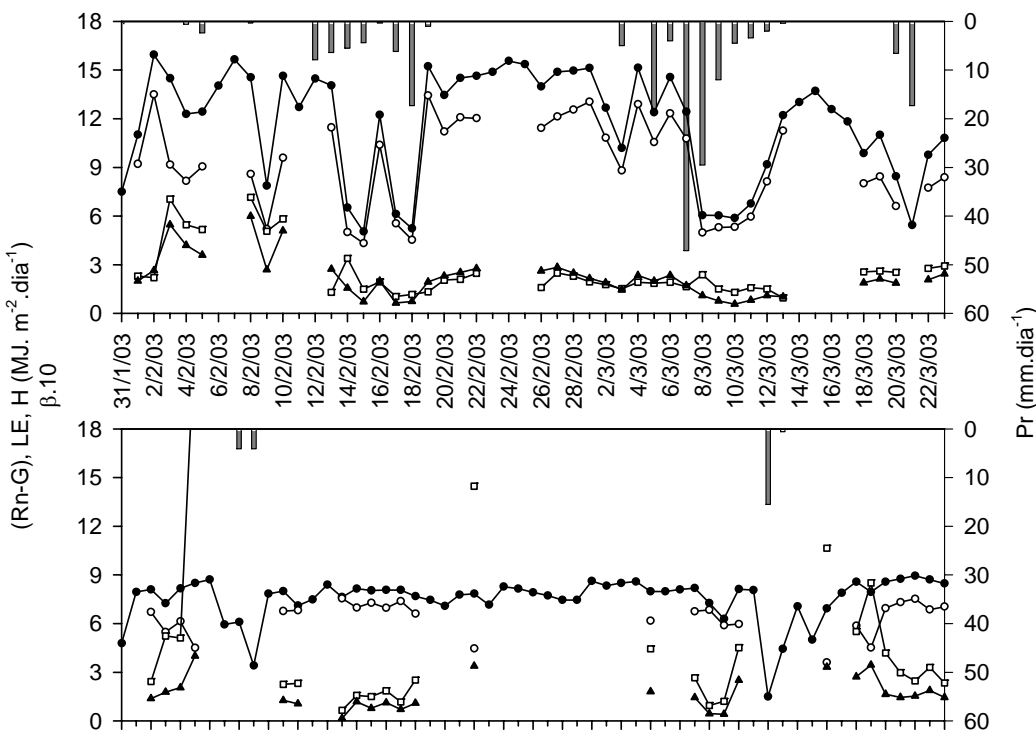

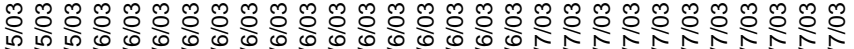

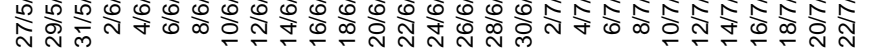

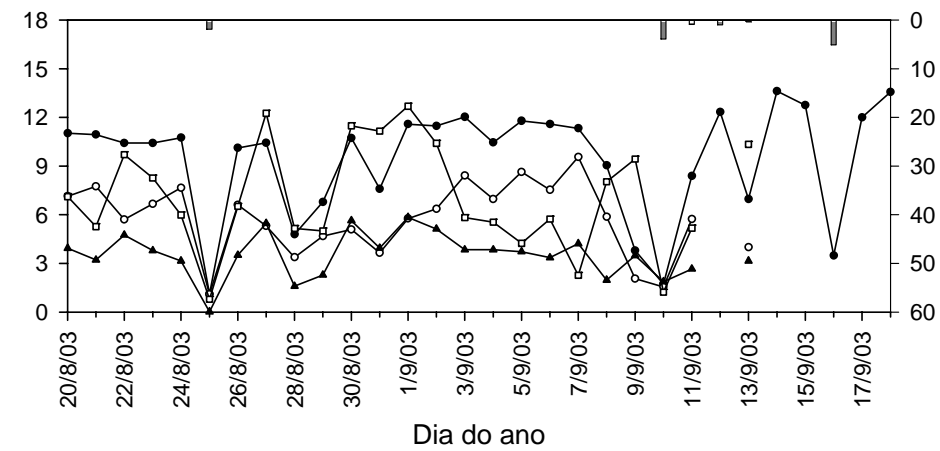

Figura 28 - Variação dos valores diários da energia disponível $(R n-G)$, dos fluxos de calor latente $(L E)$ e sensível $(H)$, da precipitação $(P r)$ e da razão de Bowen $(\beta)$. Os valores de $(R n-G), L E$ e $H$ foram acumulados entre $6: 00 \mathrm{~h}$ e $18: 30 \mathrm{~h}$ em 2002 e fevereiro - março de 2003 e entre 6:00 h e 18:00 h em maio - julho e agosto setembro de 2003. Os valores de $\beta$ são as médias entre 9:00 h e 16:00 h em $2002 \mathrm{e}$ fevereiro - março de 2003 e entre 9:00 h e 15:00 h em maio - julho e agosto setembro de 2003, estão multiplicados por 10 
superfície, os valores de $\beta$ tiveram somente um leve aumento (de 0,19 para 0,25 ), visto que neste período tanto os gradientes de temperatura quanto os de umidade foram elevados. Parece, portanto, ter existido algum efeito de meso ou macro-escala, de modo a explicar os elevados valores de $\beta$ no início do período fevereiro - março de 2003 e os baixos valores sob condições secas em outubro de 2002.

O efeito das condições de precipitação na partição da energia disponível entre $H$ e $L E$ pode ser visualizado na Figura 28. Observando-se a evolução nos períodos estudados, nota-se que no úmido $L E$ correspondeu a mais de $80 \%$ da energia disponível, declinando durante o período seco para 78\% em maio - julho e $64 \%$ em agosto setembro de 2003 (Figura 29). Esses valores são próximos daqueles encontrados por Marin (2000) em pomar de citros na mesma região e por Lopes et al. (2001) num pomar de mangueiras conduzido na região nordeste, ambos irrigados por gotejamento, porém são relativamente maiores comparados aos de Gutiérrez \& Meinzer (1994b) [LE/Rn = $40 \% \rightarrow L E /(R n-G) \approx 53 \%$ ] para um cafezal com $I A F=1,4$ e irrigação por gotejamento, porém com espaçamento de 3,6 $\mathrm{m}$ entre renques e $0,7 \mathrm{~m}$ entre plantas.

Na comparação com os resultados de Gutiérrez \& Meinzer (1994b), é preciso considerar que, no Havaí $\left(21^{\circ} \mathrm{N}\right)$, o período seco coincide com a maior disponibilidade de energia, o que proporciona uma elevada carga radiativa e térmica. Provavelmente, isso leva a uma maior secagem na entrelinha, além da possibilidade da ocorrência de um controle da transpiração mais intenso por parte das plantas, resultando em um peso maior de $H$ na partição da energia, mesmo com valores do índice de área foliar cerca de 2 vezes maior do que o observado em agosto - setembro de 2003 no estudo presente.

Percebe-se que de fevereiro - março $[L E /(R n-G)=81 \%]$ para maio - julho $[L E /(R n-G)=78 \%]$ praticamente não ocorreu diferença na partição de $R n-G$. Ao observar-se a distribuição das chuvas no período de fevereiro - março de 2003, nota-se que o primeiro mês foi relativamente seco, com somente $50 \mathrm{~mm}$ de chuva acumulados entre os dias 12 e 18, resultando em déficit hídrico em grande parte do período, visto que as chuvas em março ficaram concentradas no segundo qüinqüídio (Figura 8). Isso, mais o fato da cobertura da entrelinha ter sido roçada no dia 03/02/03, aumentando a 

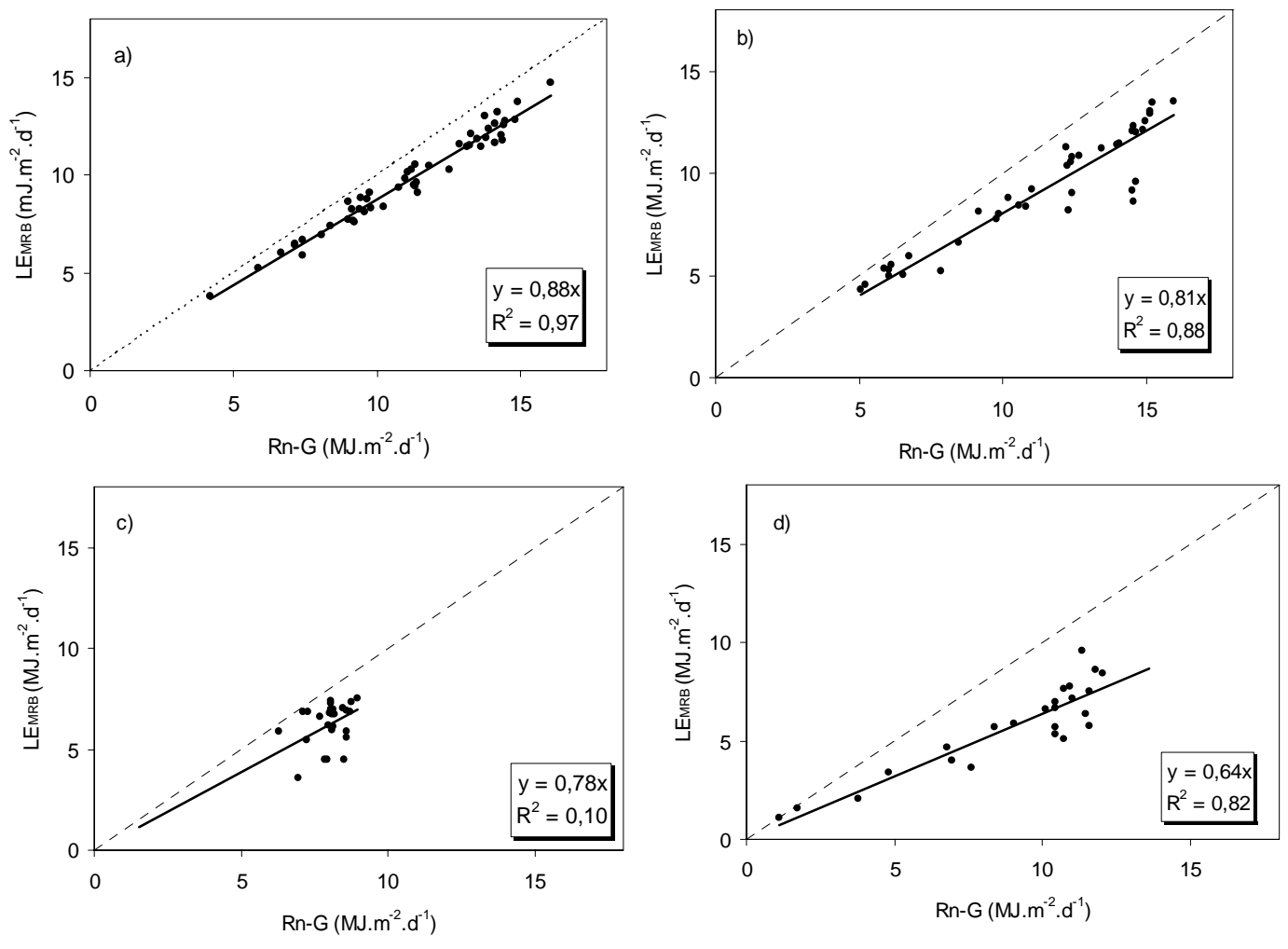

Figura 29 - Relação entre os valores dos fluxos de calor latente $\left(L E_{M R B}\right)$ entre os níveis 3 e 1 e a energia disponível $(R n-G)$ nos períodos de outubro - dezembro de 2002 (a), fevereiro - março (b), maio - julho (c) e agosto - setembro (d) de 2003

exposição da faixa de solo nu próximo aos cafeeiros $(\approx 0,45 \mathrm{~m}$ em cada lado do renque $)$ e reduzindo a evapotranspiração da entrelinha, resultaram no aumento do peso de $H$ na partição da energia. Além disso, nesse período houve um aumento da área foliar dos cafeeiros de $66 \%$ e, durante grande parte de maio - julho de 2003 , cerca de $30 \%$ da faixa de solo irrigada estava coberta por plantas invasoras, resultando em um aumento relativo da utilização de energia para fluxo de vapor. Porém, em agosto - setembro de 2003, ficaram evidentes os efeitos das condições secas e das entrelinhas praticamente desprovidas de cobertura, principalmente quando com o solo revolvido, o que quebrou o continuum de vasos capilares na sua camada superfícial, bloqueando o movimento de ascensão de umidade dos horizontes inferiores. 
Em geral, o peso de $L E$ na partição da energia disponível no cafezal no período úmido foi similar ao de culturas agrícolas conduzidas em cobertura total, sem ou com leve efeito de advecção de calor sensível e em boas condições de disponibilidade hídrica no solo, como em alfafa (Cunha \& Bergamaschi, 1994), milho (Cunha et al., 1996) e crotalária juncea (Hayashi et al., 2002), enquanto que no período seco, a relação $L E /(R n$ - G) foi inferior à observada em cultura com cobertura do solo completa, mesmo quando sem irrigação, como em comparação com um segundo experimento em crotalária juncea de Hayashi et al. (2002). Esses resultados demonstram a importância da alta umidade na superfície do solo e da cobertura da entrelinha na partição da energia disponível em coberturas incompletas.

Na Figura 29 observa-se que no período de maio - julho de 2003 o ajuste dos dados foi baixo $\left(\mathrm{R}^{2}=0,10\right)$ e em alguns dias a relação ficou muito próxima de 1 , o que pode ser conseqüência dos erros de medida associados aos pequenos gradientes de pressão de vapor, e do efeito da advecção em conseqüência da "bordadura" insuficiente, pois esse foi o período com maior freqüência de ventos na direção transversal ao cafezal, como discutido nas seções 4.3.1 a 4.3.3. O baixo valor de $\mathrm{R}^{2}$ ocorreu também pela pequena faixa de variação nos valores de $(R n-G)$ (Figura 7), diminuindo a significância de uma tendência média.

Em função dos erros de medida, fez-se uma análise das incertezas relativas nas estimativas de $L E(\partial L E / L E)$ de acordo com Perez et al. (1999), considerando-se $\partial T_{u}=$ $0,06{ }^{\circ} \mathrm{C}, \partial T_{s}=0,02{ }^{\circ} \mathrm{C} \mathrm{e}$, conforme proposto por Angus \& Watts (1984), $\partial(R n-G) /(R n$ $-G)=0,04$. Na Figura 30 são mostrados os valores médios das incertezas relativas nas estimativas entre 9:00 h e 16:00 h para os dias "utilizáveis", onde se verifica uma estabilidade dos valores próximos a um patamar de 10\% em 2002 e fevereiro - março de 2003, enquanto que no período seco foram demasiadamente elevados, chegando a quase 200\%. Em média, as incertezas relativas foram de 8\% em 2002, 10\% em fevereiro março, 38\% em maio - julho e 34\% em agosto - setembro de 2003.

Como normalmente esses erros relativos são menores no período diurno entre 9:00 h e 16:00 h, sendo neste período do dia quando se observam os maiores valores dos gradientes e dos próprios fluxos (Figura 31), é interessante ter-se uma noção da grandeza 
em valores absolutos e acumulados, os quais foram em média de 0,15 MJ.m ${ }^{-2}$ em 2002, 0,18 MJ.m ${ }^{-2}$ em fevereiro - março, 0,32 MJ.m ${ }^{-2}$ em maio - julho e 0,35 MJ.m ${ }^{-2}$ em agosto - setembro de 2003. Os maiores erros no período seco se devem às causas discutidas no item 4.3.3, como os menores gradientes e os valores de $\beta$ maiores.

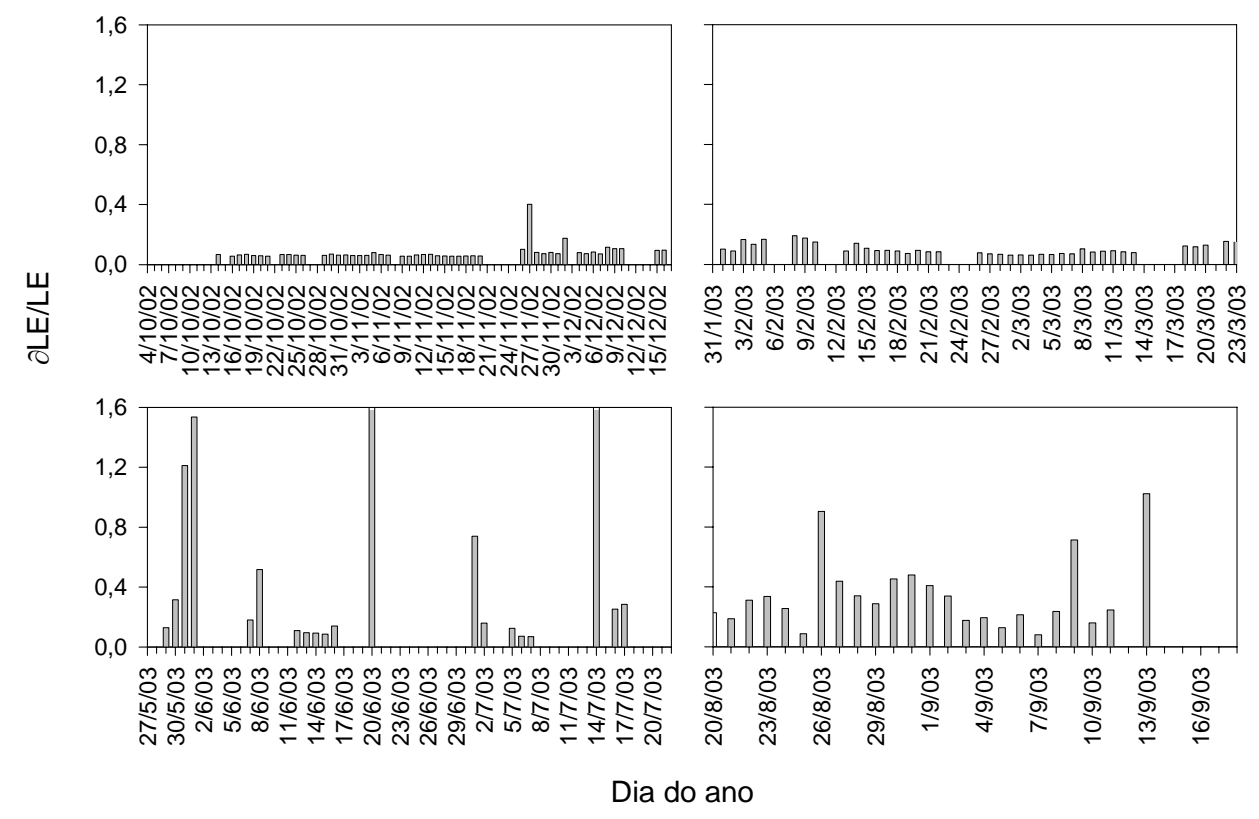

Figura 30 - Valores das incertezas relativas do fluxo de calor latente $(\partial L E / L E)$ médias do período entre 9:00 h e 16:00 h observadas nos dias "utilizáveis"

Embora tenham sido verificados erros relativos elevados, cabe ressaltar que em seus cálculos considerou-se uma situação extrema, resultando nas máximas incertezas possíveis. Isso, logicamente deve ter ocorrido ao longo do experimento, mas não em $100 \%$ dos casos, sendo que os erros realmente ficaram num patamar menor daqueles observados na Figura 30, por não ocorrerem sempre em seu máximo e em muitos casos se anularem (Angus \& Watts, 1984; Perez et al., 1999). Embora seja impossível quantificar com exatidão essa redução, provavelmente esses erros não inviabilizam as estimativas dos fluxos nas condições apresentadas neste trabalho, embora se deva ter certa cautela em utilizá-las no período seco. 


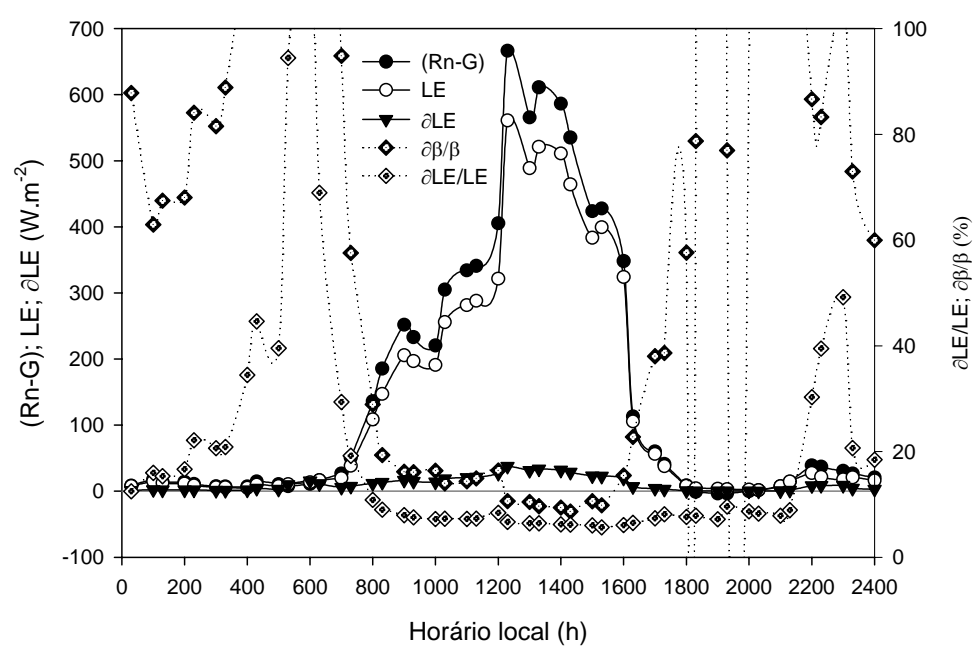

Figura 31 - Evolução ao longo do dia 07/03/03 da energia disponível $(R n-G)$, do fluxo de calor latente $(L E)$ e seus erros relativos $(\partial L E / L E)$ e absolutos $(\partial L E)$ e do erro relativo na razão de Bowen $(\partial \beta / \beta)$

\subsection{Partição da evapotranspiração}

4.4.1 Relações entre fluxo de seiva, evapotranspiração lisimétrica e variáveis ambientais; análise do desempenho dos lisímetros e dos sensores de fluxo de seiva

Na comparação entre os valores diários de $F S$ obtidos concomitantemente com os sensores de fluxo de seiva referidos como FS1 e FS2 e normalizados pela área foliar de cada planta, a tendência sistemática pelo $F S 2$ de superestimativa no período úmido (11\%; modelo SGB16) (Figura 32a) e subestimativa no período seco ( $\approx 29 \%$ em média; modelo SGB25) (Figura 32b) denota um provável desempenho diferenciado entre eles. Tomando-se por base o período de agosto - setembro de 2003, embora tenham existido diferenças na área foliar entre as plantas em que se determinou o fluxo de seiva (as áreas foliares das plantas 1, 2, 3 e 4 eram, respectivamente, de $2,2 \mathrm{~m}^{2}, 3,9 \mathrm{~m}^{2}, 4,4 \mathrm{~m}^{2}$ e 3,1 $\mathrm{m}^{2}$ ), o que possivelmente resultou nas respostas diferenciadas às condições ambientais observadas na Figura 33, observa-se que mesmo com alternância dos tamanhos das 
plantas entre os sensores (as medidas das plantas 1 e 3 foram sempre tomadas pelo sensor 1 e a área foliar da planta 1 era menor que a da 2 e aquela da 3 era maior que a da 4), FS2 tendeu sistematicamente a valores menores do que FS1.

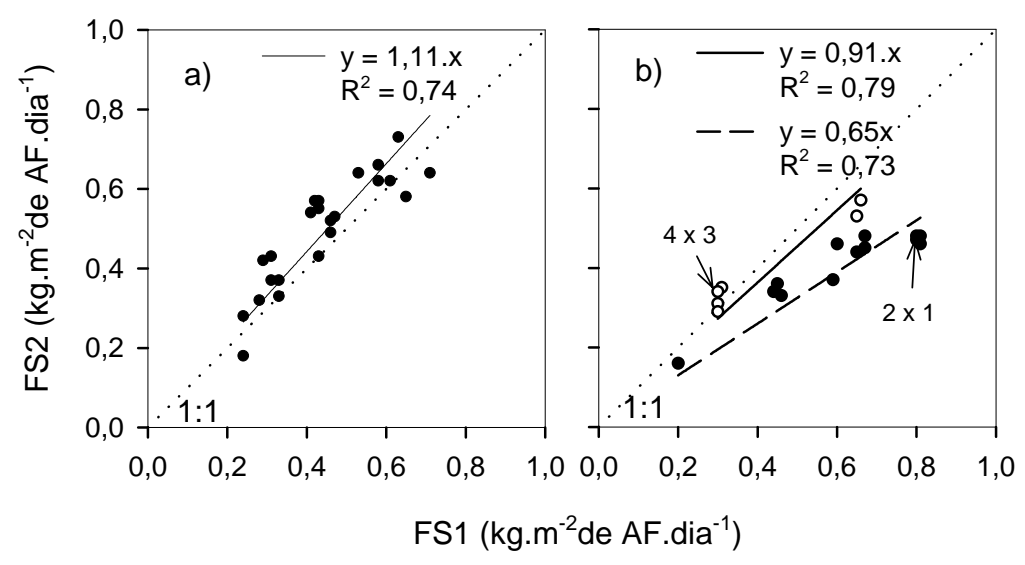

Figura 32 - Relação entre os valores diários do fluxo de seiva $(F S)$ normalizados pela área foliar e determinados concomitantemente em duas plantas em $2002 \mathrm{e}$ fevereiro - março de 2003 com sensores SGB16 (a) e agosto - setembro de 2003 com sensores SGB25 (b). As relações entre FS2 e FS1 foram obtidas entre as plantas 1 e 2,3 e 4 e 5 e 6 , sendo $F S 2$ referente às plantas 2,4 e 6 e FS1 às plantas 1,3 e 5

Inicialmente, buscou-se explicar essas diferenças por algum problema de operacionalização, mas durante as medidas tentou-se manter todas as condições recomendadas pelo manual dos sensores (Van Bavel, 1994), tendo-se observado $T_{\text {sup }}-$ $T_{\text {inf }} \geq 0,30^{\circ} \mathrm{C}$ durante o período diurno e $T_{\text {sup }}-T_{\text {inf }}<8,0^{\circ} \mathrm{C}$ à noite, o que é indicativo de um suprimento adequado de calor ao caule. Entretanto, embora tomados todos os cuidados na instalação, em alguns eventos de chuva ocorreram problemas como entrada de umidade entre o caule e o sensor, bem como nas conexões dos cabos, os quais interferiram na qualidade das medidas. Mas, como esses casos foram classificados de acordo com a intensidade e horário, tendo-se substituído os valores com problemas por outros recalculados com interpolação linear entre as medidas anterior e posterior, 
quando perduraram por menos do que 2 horas ou em períodos máximos de 4 h à noite, tendo sido descartados alguns dias completos, tais problemas não devem ter sido a causa das diferenças entre $F S 1$ e $F S 2$, até porque elas seriam aleatórias e não levariam às tendências sistemáticas observadas na Figura 32.

O desempenho do MBC em cafeeiros já foi estudado quando de seu emprego no campo, em ambiente protegido e em vaso. Gutiérrez et al. (1994), trabalhando em cafeeiros com caules de diâmetro de $19 \mathrm{~mm}$ e de $25 \mathrm{~mm}$, verificaram que na escala diária os erros de medida de $F S$ em relação às de transpiração foram inferiores a $10 \%$, o que não está de acordo com Marin et al. (2003b), que verificaram cerca de 25\% de superestimativa pelo MBC em comparação à transpiração de uma planta de cafeeiro com caule de diâmetro de $10 \mathrm{~mm}$, não encontrando causas evidentes desse mau desempenho, até porque trabalharam com uma única planta. Para mudas de laranjeira, esses mesmos autores verificaram que os diferentes sensores utilizados ( $5 \mathrm{~mm}, 19 \mathrm{~mm}$ e $25 \mathrm{~mm}$ ) não tiveram desempenho idêntico, sendo que a relação entre o fluxo de seiva e a transpiração variou entre 1,0 e 1,3 .

Os resultados quanto ao desempenho do MBC têm sido contraditórios quando se comparam os valores do fluxo de seiva determinados sem levar em consideração o termo armazenamento na equação do balanço de calor com aqueles determinados pelo balanço completo ou com a transpiração medida gravimetricamente. Embora a maioria dos trabalhos encontrados na literatura ateste um bom desempenho do MBC (Baker \& Van Bavel, 1987; Weibel \& De Vos, 1994; Grime et al., 1995a, 1995b; Grime \& Sinclair, 1999; Gutiérrez et al., 1994; Righi et al. ${ }^{2}$ ), outros mostram erros relativamente grandes (Weibel \& De Vos, 1994; Marin et al., 2003; Righi et al. ${ }^{1}$ ). Como se trata de um método em certo grau empírico, é difícil eliminar fontes aleatórias de erros ligadas, principalmente, à instalação do sensor. No presente estudo, podem ter ocorrido problemas em algumas medidas em conseqüência de danos às plantas causadas em instalações anteriores dos sensores, como se observou na seqüência de medidas realizada

${ }^{1}$ RIGHI, E. Z.; RIBEIRO, R. V.; MARIN, F. R.; ANGELOCCI, L. R.; OLIVEIRA, R. F.; MACHADO, E. C. (ESALQ/USP) Estimative of sap flow in potted-plants by heat balance technique: I. methodological and practical aspects. (Em elaboração). 
entre 11/03 e 17/03/03, quando os valores de $F S$ ficaram bem abaixo daqueles observados em dias anteriores com níveis comparáveis de $R n$ e $D$, sendo que as mesmas plantas haviam sido amostradas cerca de 20 dias antes.

Embora os métodos térmicos não possam ser considerados como referência, são ferramentas utilíssimas nos estudos de relações hídricas e os resultados mostrados na Figura 32 indicam que em grande parte dos dias ocorreram medidas de boa qualidade, com diferenças sistemáticas de $11 \%$ no período úmido e de $9 \%$ quando amostradas as plantas 3 e 4 no período de agosto - setembro de 2003, enquanto que a diferença de $35 \%$ entre as plantas 1 e 2 é apreciável e sugere cuidado na adoção dos valores de FS. Apesar disso, a utilização dos valores médios das duas plantas amostradas simultaneamente pode ser considerada aceitável no estudo da partição da evapotranspiração do cafezal em suas componentes, incluindo a transpiração dos cafeeiros. É evidente que o uso de somente duas plantas nessas medidas está longe de ser o ideal e pode ser questionado, mas deve-se considerar que a pequena disponibilidade de sensores e os problemas causados nas plantas pelos mesmos, que resultaram na morte "a posteriori” da realização dessas medidas, impediram que um número maior de cafeeiros fosse amostrado.

Em relação aos lisímetros, ao longo do dia foi observada uma forte flutuação das medidas, conseqüente da carga de momento pelo vento (Figura 34), fato já conhecidos na literatura (Allen et al., 1991; Backer et al., 1991; Wright, 1991; Bergamaschi et al., 1997; Santiago, 2002). Em virtude do comprometido desenvolvimento da planta do lisímetro $L 1$, todas as análises foram feitas tendo como referência somente o lisímetro $L 2$. Novamente, fica questionável a representatividade dessas medidas para o cafezal como um todo, mas diante dos recursos limitados, o experimento foi montado com somente dois lisímetros de tamanho suficiente para conduzir uma planta em cada um. De qualquer maneira, ele quantifica a magnitude da evapotranspiração representativa da faixa onde se encontra o renque dos cafeeiros.

Nessa análise, os dias chuvosos e/ou com irrigação durante o período diurno foram descartados. No descarte da água de drenagem armazenada nos reservatórios foi observada uma histerese nas células de carga que resultou em um prolongamento de sua 
resposta nos sinais de saída de até uma hora, sendo os dias de sua realização também descartados.

As Figuras 33 e 34 mostram as relações entre o fluxo de seiva dos cafeeiros e as variáveis ambientais $R n$ e $D$, onde se nota que $F S$ acompanhou positivamente as variações de $R n$, ao mesmo tempo em que se percebe um significativo efeito de $D$, principalmente no período seco. Na Figura 34, nota-se uma defasagem de FS em relação a $R n$, a qual é detalhada na Figura 33 em duas seqüências de dias secos em agosto e setembro de 2003. Essa defasagem foi conseqüência dos valores diários máximos de $D$ terem ocorrido posteriormente ao pico de máxima incidência de radiação solar (Figura $34)$.

Na Figura 33 fica evidenciada a ocorrência de regulação da perda de água pelas plantas em conseqüência dos elevados valores de $D$, principalmente no período seco. Nas duas seqüências apresentadas nessa figura, quando $D$ foi maior do que aproximadamente 1,0 $\mathrm{kPa}$, os valores de $F S$ estabilizaram e até diminuíram, principalmente nas plantas 2, 3 e 4, que tinham maior área foliar, demonstrando que os cafeeiros sofreram algum grau de déficit hídrico temporário ao longo do dia pela dificuldade do sistema radicular suprir água em taxas adequadas para atender às altas demandas atmosféricas. Evidentemente, as plantas maiores exigiram mais dos próprios sistemas radicular e hidráulico para atender suficientemente a quantidade de água transpirada nas folhas (Barros et al., 1995; Carr, 1995; Angelocci, 2002). No período úmido, apesar da maior disponibilidade de energia, devido ao menor déficit de saturação do ar, o qual foi poucas vezes maior do que $2,5 \mathrm{kPa}$, e à pequena área foliar dos cafeeiros, foram observados poucos dias com evidências de déficit hídrico nas plantas.

Embora os cafeeiros tenham sua origem em sub-bosques úmidos (Ascanio Evanoff, 1994; Carr, 2001), onde são expostos a baixas irradiâncias e baixos déficits de saturação do ar, eles têm uma alta capacidade de adaptação fisiológica a essas condições de cultivo, como verificado por Da Matta et al. (1993) e Marin et al. (2003a, 2005), devido seu eficiente controle da perda d'água através do fechamento estomático, de modo a evitar excessiva desidratação de seus tecidos. Ao final do experimento as plantas deflagraram uma reduzida atividade fisiológica, notada pelo amarelecimento e queda de 

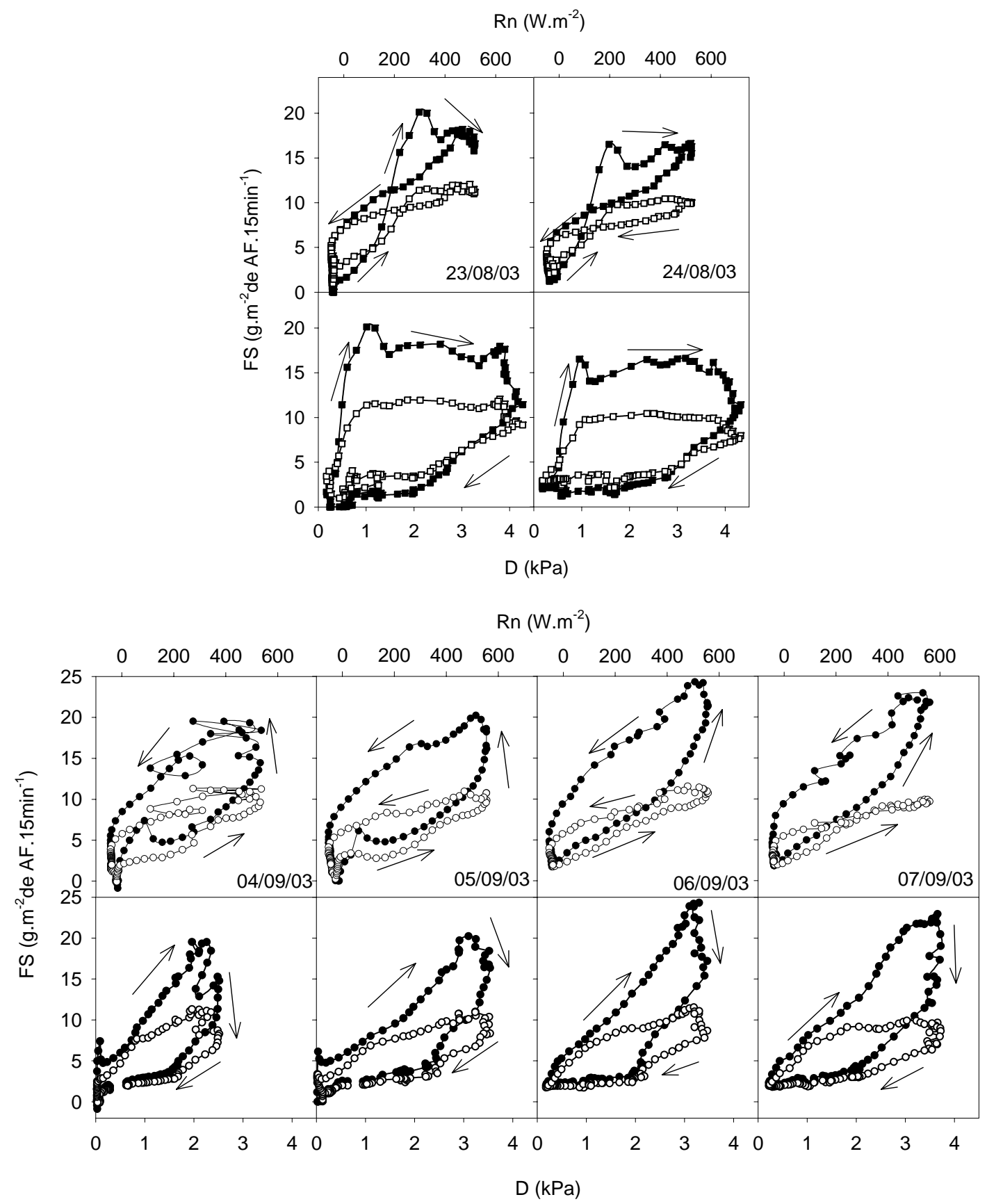

Figura 33 - Evolução do fluxo de seiva normalizado pela área foliar $(F S)$ nas plantas 1 $(\bullet), 2(\circ), 3(\bullet)$ e 4(口) em função do saldo de radiação $(R n)$ e do déficit de saturação do ar no nível $3(D)$. As setas indicam a evolução temporal das medidas 
uma parcela das folhas dos cafeeiros e, conforme discutido por Angelocci (2002), os valores baixos de temperatura (menores de $15{ }^{\circ} \mathrm{C}$ ) podem ter prejudicado a expansão radicular e a própria absorção de água, principalmente nas camadas superficiais do solo, onde se concentram as raízes absorventes (Bull, 1963; Ascanio Evanoff, 1994; Carr, 2001). De qualquer maneira, esse é um período de repouso para os cafeeiros, imposto talvez pelas condições fisiológicas ditadas pelo ciclo de desenvolvimento da cultura.

$\mathrm{Na}$ Figura 34, nota-se que durante o período úmido os valores de $F S$ normalizados pela área de solo disponível para cada planta $\left(A=3,15 \mathrm{~m}^{2}\right)$ ficaram muito próximos de zero durante a noite, enquanto que no período seco foram observados valores que ficaram entre 0,6 e 4,0 g. $\mathrm{m}^{-2} \cdot 15 \mathrm{~min}^{-1}$. Esses valores de fluxo de seiva noturnos podem ter sido causados, em parte, por erros nas estimativas dos coeficientes de dissipação radial de calor $(K r)$ no MBC. Porém, foi observado $F S$ noturno durante todo o período seco e as medidas lisimétricas também apontaram evapotranspiração à noite, embora neste caso exista uma considerável contribuição por parte da evaporação do solo (Figura 32). Righi et al. ${ }^{1}$ verificaram uma transpiração correspondente à cerca de $13 \mathrm{~g} . \mathrm{m}^{-2} \cdot \mathrm{h}^{-1}$ com um analisador de gás ao infravermelho (IRGA), considerando a mesma base de cálculo da Figura 34 e $A F=2,0 \mathrm{~m}^{2}$, em uma série de medidas realizadas no mesmo cafezal entre 5:30 h e 5:40 h (11/09/04), com temperatura do ar e $D$, respectivamente, de $\approx 19^{\circ} \mathrm{Ce} \approx 0,66 \mathrm{kPa}$, demonstrando que as plantas de café realmente transpiraram a noite.

Comparando-se a evolução de $F S$ e $E L$, também normalizado por $A$, percebe-se uma redução gradativa da evapotranspiração medida pelo lisímetro em relação a uma evolução praticamente estável dos valores do fluxo de seiva para quatro dias de níveis semelhantes de $R n$. Essa diferença ocorreu pelo lisímetro contemplar a evaporação direta do solo, principalmente no período úmido, quando toda a superfície do monolito contido pelo tanque lisimétrico permaneceu com alta umidade. A seqüência de dias apresentada na Figura 34 é posterior a uma irrigação realizada na noite do dia $245(02 / 09 / 03)$ para

\footnotetext{
${ }^{1}$ RIGHI, E. Z.; RIBEIRO, R. V.; MARIN, F. R.; ANGELOCCI, L. R.; OLIVEIRA, R. F.; MACHADO, E. C. (ESALQ/USP) Estimative of sap flow in potted-plants by heat balance technique: I. methodological and practical aspects. (Em elaboração).
} 

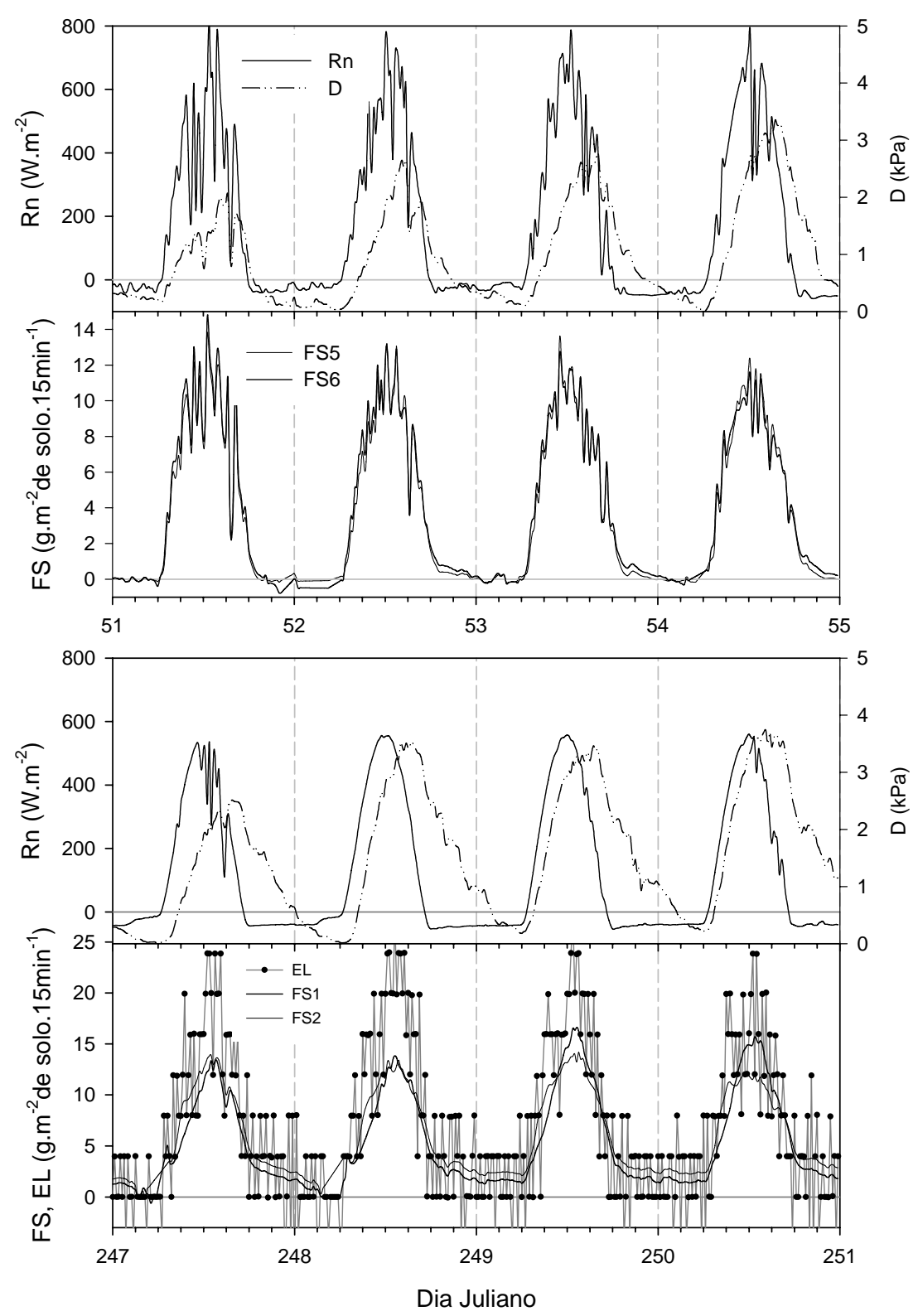

Figura 34 - Evolução do saldo de radiação $(R n)$, do déficit de pressão de saturação de vapor no ar $(D)$ e das determinações do fluxo de seiva $(F S)$ nas plantas 5 $\left(A F=2,5 \mathrm{~m}^{2}\right)$ e $6\left(A F=2,0 \mathrm{~m}^{2}\right)$ entre os dias julianos $51(20 / 02 / 03)$ e 54 $(24 / 02 / 03)$ e nas plantas $1\left(A F=2,2 \mathrm{~m}^{2}\right)$ e $2\left(A F=3,9 \mathrm{~m}^{2}\right)$, juntamente com a variação de peso lisimétrico $(E L)\left(A F=1,7 \mathrm{~m}^{2}\right)$ entre os dias julianos 247 $(04 / 09 / 03)$ e $251(08 / 09 / 03)$. Os valores de $F S$ e $E L$ foram normalizados pela área de solo disponível para cada planta $\left(3,15 \mathrm{~m}^{2}\right)$. No eixo $\mathrm{x}$ a subdivisão indica um período de 3 horas 
$246(03 / 09 / 03)$, por isso $E L$ foi maior nos primeiros três dias, quando a evaporação do solo ocorria em taxas próximas da potencial pela superfície do mesmo sob os gotejadores estar bastante úmida, enquanto que com a secagem da mesma, a evaporação passou a depender das propriedades físicas do solo, ocorrendo em taxas menores na segunda fase do processo evaporativo (Ritchie, 1972).

\subsubsection{Componentes da evapotranspiração do cafezal}

Na Figura 35 é mostrada a evolução dos valores diários de $T, E L, R n, T / E L$ e $P r$ durante as campanhas de coleta de dados, onde se nota a forte influência das condições de umidade da superfície do solo sobre $E L$. Enquanto $T$ tendeu a se manter num patamar estável para níveis semelhantes de $R n, E L$ normalmente diminuiu à medida que se afastou de um evento de chuva ou irrigação (indicada por uma seta), levando a um aumento gradativo de $T / E L$.

Sazonalmente pode ser observado o crescimento da razão média $T / E L$, a qual variou de $10 \%(\mathrm{CV}=31 \%)$ em 2002 e $17 \%(\mathrm{CV}=32 \%)$ em fevereiro - março para $45 \%$ $(\mathrm{CV}=21 \%)$ em agosto - setembro de 2003. Durante o período úmido, praticamente toda a superfície do solo no lisímetro e, conseqüentemente, na faixa referente ao renque, permaneceu com umidade elevada, permitindo que a evaporação ocorresse a taxas próximas da potencial (Ritchie, 1972), fazendo com que a transpiração dos cafeeiros compusesse uma pequena fração da evapotranspiração do renque. No entanto, no período seco, a superfície do solo suficientemente úmida para permitir evaporação em taxas potenciais ficou restrita a um bulbo sob os gotejadores do sistema de irrigação, que variou entre $0,30 \mathrm{~m}$ e $0,60 \mathrm{~m}$ de diâmetro.

Concomitantemente à secagem progressiva da superfície de solo, ocorreu um aumento de $A F$ e $D_{c}$, que, além de aumentar a quantidade de água transpirada, resultou no crescimento da área sombreada pela copa dos cafeeiros (Tabela 2), diminuindo a carga energética incidente diretamente sobre o solo nos renques, de acordo com observações feitas por Ritchie \& Burnett (1971) e Yunusa et al. (1993a, b). Enquanto os valores da transpiração nos dias de medida de $F S$ em 2002 variaram entre 0,20 L.planta ${ }^{-1} \cdot$ dia $^{-1} \mathrm{e}$ 
0,40 L.planta ${ }^{-1} \cdot \operatorname{dia}^{-1}\left(A F \approx 0,58 \mathrm{~m}^{2}\right.$ entre 4 e 9/12/02), em fevereiro - março de 2003, variaram entre 0,21 L.planta ${ }^{-1} \cdot \operatorname{dia}^{-1}$ e 0,67 L.planta ${ }^{-1} \cdot \operatorname{dia}^{-1}\left(A F=1,00 \mathrm{~m}^{2}\right)$, com um aumento médio de 42\% (0,31 L.planta ${ }^{-1} \cdot \operatorname{dia}^{-1}$ para 0,44 L.planta $\left.{ }^{-1} \cdot \operatorname{dia}^{-1}\right)$. Apesar da evidência de déficit hídrico interno nas plantas em agosto - setembro de 2003 (seção 4.4.1), os elevados valores de $D$ levaram a um aumento médio de $120 \%$ (0,97 L.planta ${ }^{1} \cdot \mathrm{dia}^{-1}$, com mínimo de 0,34 L.planta ${ }^{-1} \cdot \operatorname{dia}^{-1}$ e máximo de 1,35 L.planta $\left.{ }^{-1} \cdot \operatorname{dia}^{-1}\right)$ em relação a fevereiro - março, correspondendo ao acréscimo em $A F(110 \%)$. Esses fatores explicam o aumento da relação $T / E L$ para cerca de $45 \%$ em agosto - setembro de 2003.

Esses resultados mostram que tanto o crescimento dos cafeeiros quanto a umidade na superfície do solo influenciaram a magnitude relativa da evapotranspiração dos renques em relação àquela da superfície total. No período úmido, a razão média $E T_{\text {renque }} / E T c$ foi de $22( \pm 7) \%$, enquanto que no período seco, a razão aumentou para cerca de $30( \pm 11)$ em maio - julho e $33( \pm 4) \%$ em agosto - setembro de 2003 (Figura 36). Isso significa que cada unidade de área de solo nos renques perdeu água a taxas inferiores à média do cafezal no período úmido ( $\left.E T_{\text {renque" }} / E T c \approx 85 \%\right)$, enquanto que no período seco $E T_{\text {renque }}$ " foi superior à média $\left(E T_{\text {renque }}\right.$ " $\left./ E T c \approx 120 \%\right)$.

Seguindo a sugestão de Marin et al. (2001b), a transpiração ou, nesse caso, a evapotranspiração do solo sob os renques, pode ser considerada proporcional à área de solo sombreada pela copa quando o sol se encontra no zênite local, de modo a se conhecer a grandeza de quanto cada unidade de área efetivamente ocupada pela planta evapotranspirou em relação à média do cafezal. Sendo assim, os valores recalculados de $E T_{\text {renque }}$ " $/ E T c$ foram de aproximadamente $107 \%$ no período úmido, de $150 \%$ em maio julho e de $162 \%$ em agosto - setembro de 2003.

O aumento de $E T_{\text {renque }} / E T c$ no período seco é decorrente do aumento de $A F \mathrm{e}$ da diminuição relativa de ETc causada pela secagem da superfície da entrelinha. Os valores de $E T_{\text {renque }} / E T c$ são baixos, comparativamente a $T / E T c=0,91$ no período seco e $T / E T c=0,67$ no período úmido obtidos em um cafezal adulto por Marin (2003), cultivado ao lado daquele deste estudo. Quando os cafeeiros são pequenos, a quantidade de água transpirada é reduzida, enquanto que a entrelinha é submetida a uma elevada 

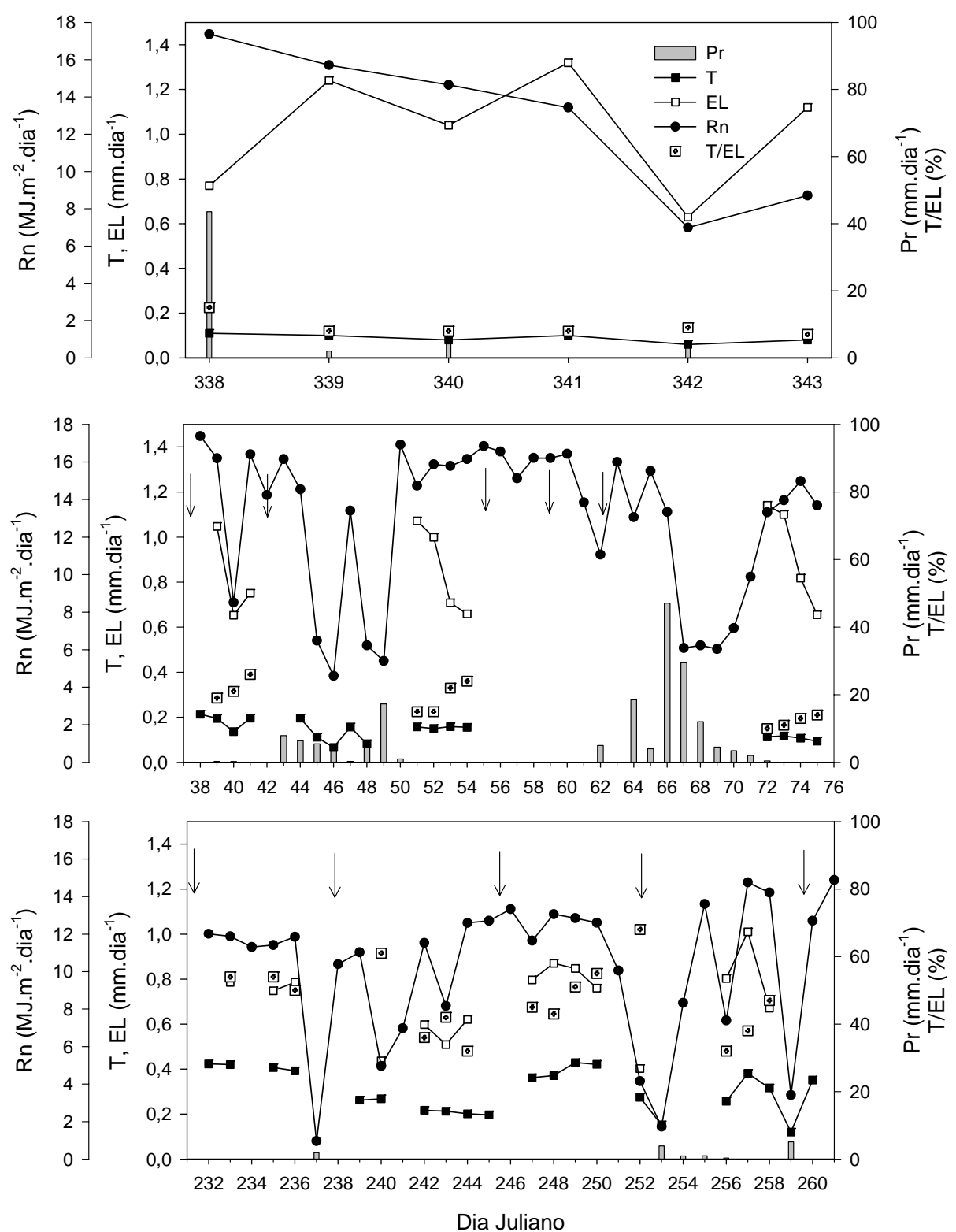

Figura 35 - Variação diária da transpiração da planta $(T)$ e da evapotranspiração no lisímetro $2(E L)$ e sua razão porcentual, juntamente com a precipitação $(P r)$ e o saldo de radiação $(R n)$ acumulado no período de 24 horas. As setas indicam os eventos de irrigação nos lisímetros. O gráfico superior refere-se à 2002 , os demais a 2003 


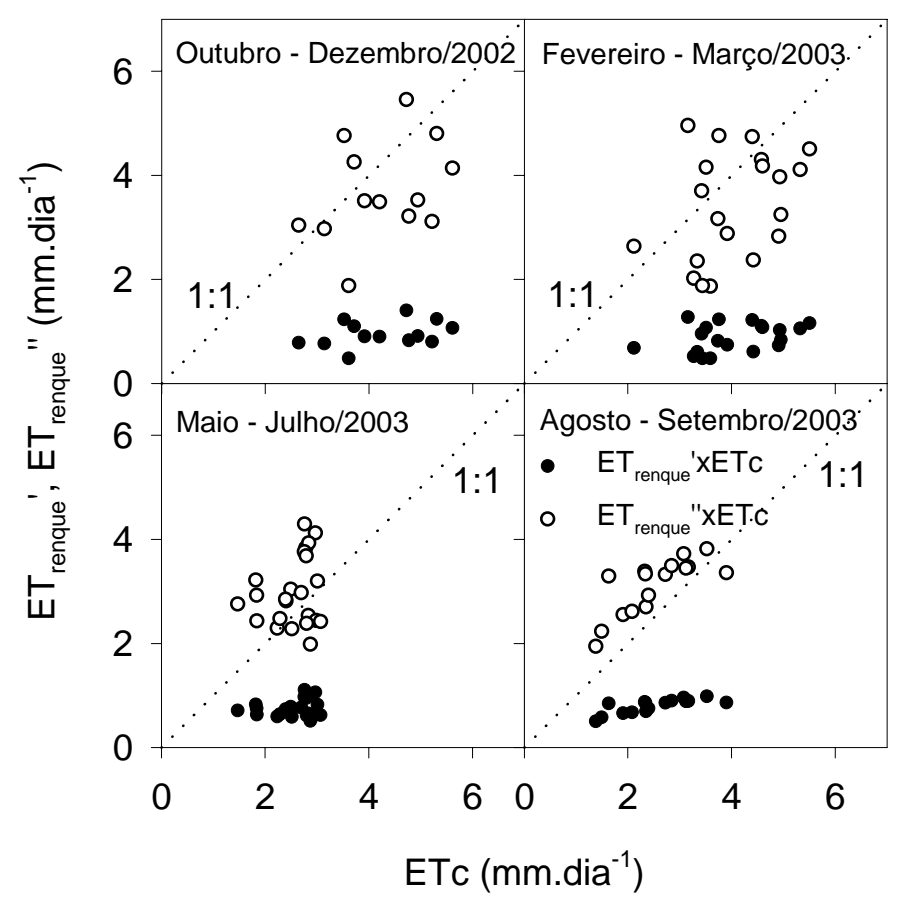

Figura 36 - Relação entre a evapotranspiração do renque normalizado pela área total disponível para cada cafeeiro $\left(E T_{\text {renque }}\right)$ e pela área do renque disponível para cada cafeeiro $\left(E T_{\text {renque }}\right)\left(0,81 \mathrm{~m}^{2}\right)$ e a evapotranspiração da cultura $(E T c)$

insolação, aumentando sua contribuição para ETc. Além disso, com base na discussão de Marin et al. (2005), pode-se inferir que ocorre maior acoplamento da superfície e da vegetação da entrelinha com a atmosfera, aumentando sua evapotranspiração enquanto os cafeeiros são de porte pequeno.Embora sob condições altamente secas ocorridas de maio a setembro de 2003, a entrelinha contribuiu com aproximadamente $70 \%$ da evapotranspiração da cobertura, ou seja, somente $30 \%$ de ETc foi decorrente de um volume de solo que pode ser considerado realmente explorado pelos cafeeiros. A evapotranspiração média da entrelinha, calculada como a diferença entre $E T c$ e $E T_{\text {renque }}$,

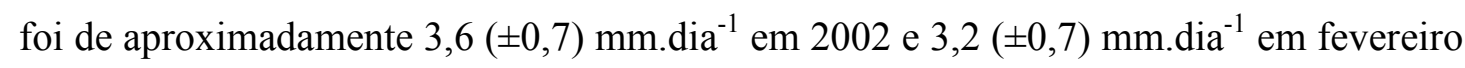
- março de 2003, e de 1,8 $( \pm 0,6)$ mm.dia ${ }^{-1}$ no período seco.

A evapotranspiração média diária obtida com os cinco minilisímetros instalados na entrelinha $\left(E T_{e-l}\right)$ foi de aproximadamente $1,4 \mathrm{~mm} \cdot \mathrm{dia}^{-1}\left( \pm 0,2 \mathrm{~mm} \cdot \mathrm{minilisímetro}^{-1}\right)$ ao 
longo de 10 dias após um evento de chuva de $16 \mathrm{~mm}$, precedido por um longo período seco, sendo que o valor médio obtido por diferença entre $E T c$ e $E T_{\text {renque }}$ para o mesmo período foi de $1,9( \pm 0,6) \mathrm{mm} \cdot \mathrm{dia}^{-1}$. Quando em condições extremamente secas e afastadas de eventos de chuva, as medidas de $E T_{e-l}$ foram menores do que $0,5( \pm 0,3)$ mm.dia ${ }^{-1}$, sendo demasiadamente inferiores aos valores obtidos como resíduo dos valores da evapotranspiração "global" da cobertura e do renque. Essas diferenças podem ser atribuídas a erros nas estimavas de ETc, como discutido no item 4.3.5, de EL, devido à grande variabilidade observada nas medidas lisimétricas pontuais causadas pelo aporte de momento e das próprias medidas nos minilisímetros que, apesar dos cuidados, foram influenciadas pela pesagem de terra impregnada nas hastes de ferro utilizadas como base para os minitanques e, até mesmo, de resolução do multímetro utilizado para tais medidas.

No entanto, esses erros não devem ter sido suficientemente altos para explicar os baixos valores obtidos nos minilisímetros, de forma que o problema mais grave parece ter sido a quebra do "continuum" poroso no solo dos minitanques, bloqueando a ascensão capilar da água dos horizontes mais profundos e reduzindo o aporte de vapor para a atmosfera a partir do monolito amostrado. Essa restrição pôde ser notada pela vegetação dos minilisímetros estar totalmente seca no final do experimento, enquanto que a entrelinha permaneceu com uma parcela relativamente elevada de cobertura verde ao longo de todo período seco, contribuindo na evapotranspiração do cafezal. De qualquer maneira, nos dez dias seguintes a uma chuva pôde-se notar que existiu coerência nos valores obtidos como resíduo entre a evapotranspiração total da cultura e a do renque, a despeito das aproximações e considerações adotadas no cálculo de sua proporção. Devido aos problemas observados nas medidas dos minilisímetros, seus valores não foram utilizados nas análises.

\subsubsection{Coeficientes de cultura}

Os valores médios do coeficiente "global" de cultura $(K c)$, coeficiente de evapotranspiração do renque ( $\left.K c_{\text {renque }}\right)$ e coeficiente basal de cultura $(K c b)$, de $E T c$, de 
ETo e de $I A F$ nos respectivos períodos estudados são apresentados na Tabela 6, sendo que a Figura 37 apresenta a evolução de $K c, K c_{\text {renque }}$ e $\operatorname{Pr}$ ao longo das quatro campanhas de coleta de dados. Os valores médios dos coeficientes de cultura $K c$ foram inicialmente calculados considerando-se todos os dias "utilizáveis" pelos critérios de Perez et al. (1999), variando entre 1,16 e 1,45 no período úmido e entre 0,91 e 1,36 no período seco.

Valores como 1,45 e 1,36, principalmente este último observado no período seco, são demasiadamente elevados em relação ao que seria esperado pelo porte da cultura, cobertura da entrelinha e pelos valores encontrados na literatura para cafezal adulto (Allen et al., 1998; Villa Nova et al., 2002; Marin et al., 2005). Observando-se a Figura 37, nota-se que ocorreram picos nos valores de $K c$ variando entre 1,5 e 3,0, que foram dependentes da intensidade e do horário de ocorrência dos eventos de chuva. Normalmente, esses casos corresponderam aos dias com ocorrência de eventos de chuva antes de 16:00 h, o que, devido à grande proporção de solo exposto e sob elevada umidade, em muitos casos com poças d'água, propiciou evaporação a taxas potenciais referentes a uma superfície de água livre (Ritchie, 1972; Tanner \& Jury, 1976) e não representativas de uma condição normal de cultivo.

Devido a esse fato, procedeu-se análise somente dos dados sem esse tipo de influência, o que resultou em valores de $K c$ variando entre 1,04 e 1,30 no período úmido, os quais são maiores que os valores entre 0,76 e 0,85 (respectivamente, para $I A F=1,08$ e $I A F=0,58$; período úmido) a $0,90(I A F=0,26$; período seco) observados por Villa Nova et al. (2002) num cafezal com irrigação por aspersão total, com a de referência obtida a partir da evaporação do tanque classe A. Considerando-se os valores de ETo calculados pelo método do tanque classe A no presente estudo, os valores de $K c$ no período úmido ficaram entre aproximadamente 0,80 e 1,00, demonstrando relativamente boa concordância entre os dois experimentos e indicando as dificuldades de comparação de valores de $K c$ entre trabalhos em que os métodos de estimativa de ETo são diferentes e com o valor de ETc sendo condicionada pelo método de determinação e pela distribuição da cobertura no terreno.

No período seco, além das maiores incertezas de ETc (seção 4.3.5) e da seleção com base nos eventos de chuva, foi necessário fazer-se uma análise mais detalhada dos 


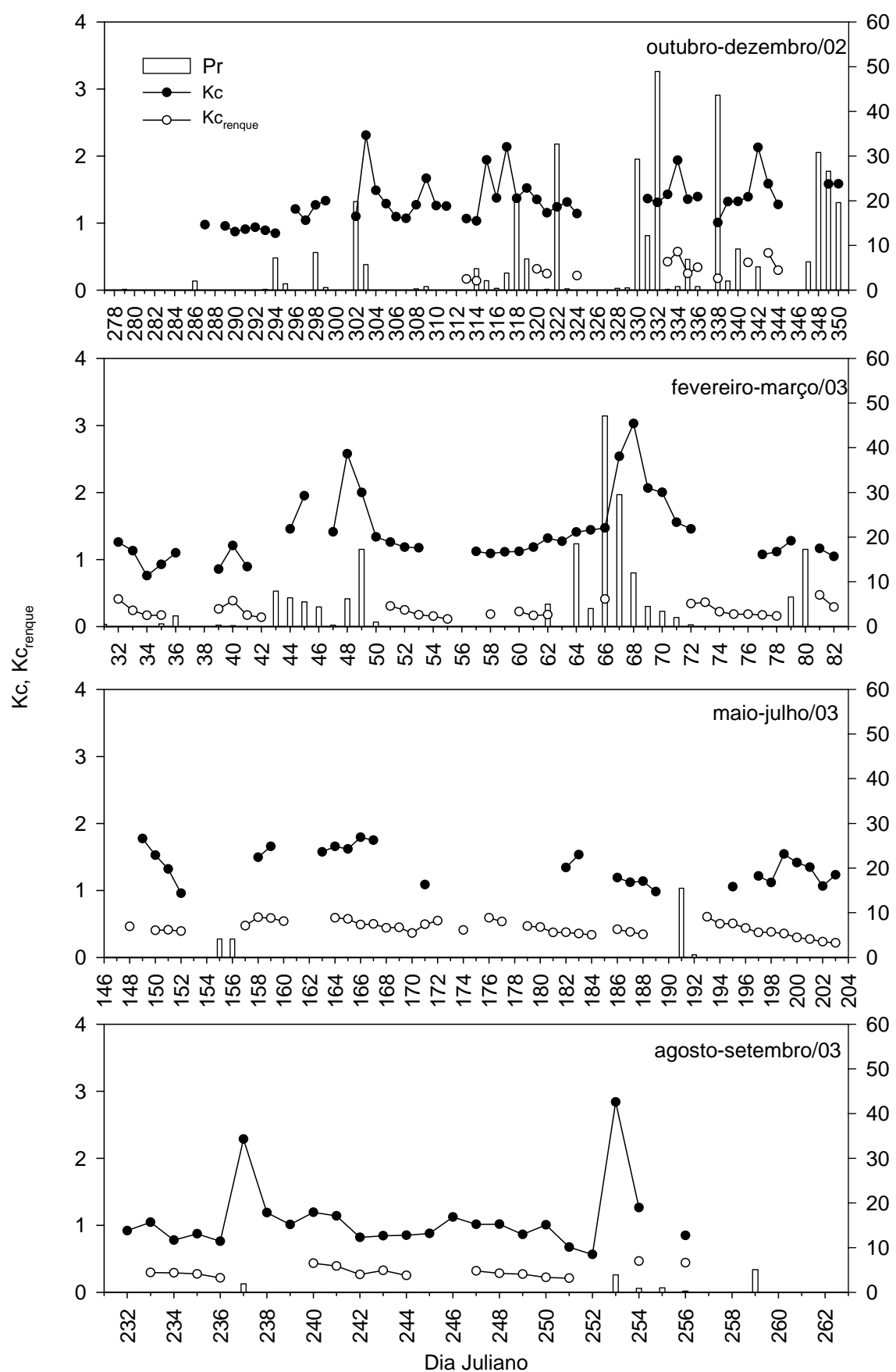

Figura 37 - Flutuação dos valores do coeficiente de cultura $(K c)$, coeficiente de evapotranspiração do renque ( $\left.K c_{\text {renque }}\right)$ e da precipitação $(P r)$, nos períodos de $04 / 10 / 03$ a $16 / 12 / 02$, de $31 / 01 / 03$ a $23 / 03 / 03$, de $27 / 05 / 03$ a $22 / 07 / 03$ e de $20 / 08 / 03$ a $18 / 09 / 03$ 
Tabela 6. Valores médios por período da evapotranspiração do cafezal $(E T c)$, do renque $\left(E T_{\text {renque }}\right)$ e de referência $(E T o)$, em mm.dia ${ }^{-1}$, dos coeficientes de cultura $(K c)$, de evapotranspiração do renque de cafeeiros $\left(K c_{\text {renque }}\right)$ e basal $[K c b=$ $\left.K c_{\text {renque. }}(T / E L)\right]$, juntamente com o índice de área foliar médio do cafezal $\left(I A F_{\text {cafezal }}\right)$ nos respectivos períodos. Os valores entre parênteses são referentes ao desvio padrão

\begin{tabular}{lccccccc}
\hline \multicolumn{1}{c}{ Período } & $I A F_{\text {cafezal }}$ & $E T o$ & $E T c$ & $E T_{\text {renque }}$ & $K c$ & $K c_{\text {renque }}$ & $K c b$ \\
\hline Out/02 & 0,098 & $3,67^{*}$ & $3,77^{*}$ & - & $1,04( \pm 0,19)^{*}$ & - & - \\
Nov/02 & & 3,51 & 3,86 & - & 1,16 & - & - \\
& 0,146 & $3,60^{*}$ & $4,45^{*}$ & $0,91^{*}$ & $1,27( \pm 0,20)^{*}$ & $0,30( \pm 0,20)^{*}$ & 0,03 \\
Dez/02 & & 3,28 & 4,12 & 0,91 & 1,37 & 0,30 & \\
& 0,194 & $3,51^{*}$ & $4,41^{*}$ & $0,98^{*}$ & $1,30( \pm 0,20)^{*}$ & $0,34( \pm 0,20)^{*}$ & 0,03 \\
Média/02 & & 2,91 & 3,98 & 1,00 & 1,45 & 0,34 & \\
& & $3,70^{*}$ & $4,26^{*}$ & $0,98^{*}$ & $1,18( \pm 0,19)^{*}$ & $0,31( \pm 0,19)^{*}$ & 0,03 \\
Fev-Mar/03 & 0,316 & $3,81^{*}$ & $4,25^{*}$ & $0,82^{*}$ & $1,13( \pm 0,16)^{*}$ & $0,22( \pm 0,09)^{*}$ & 0,04 \\
& & 3,07 & 3,74 & 0,84 & 1,40 & 0,18 & \\
Mai-Ju1/03 & 0,527 & $2,25^{* *}$ & $2,51^{* *}$ & $0,78^{* *}$ & $1,11( \pm 0,09)^{* *}$ & $0,43( \pm 0,11)^{* *}$ & 0,20 \\
& & 1,91 & 2,56 & 0,77 & 1,36 & 0,44 & \\
& & & & & $1,40 *$ & $0,39 *$ & \\
Ago-Set/03 & 0,663 & $2,92^{* *}$ & $2,55^{* *}$ & $0,80^{* *}$ & $0,86( \pm 0,10)^{* *}$ & $0,28( \pm 0,04)^{* *}$ & 0,13 \\
& & 2,84 & 2,56 & 0,79 & 0,91 & 0,29 & \\
\hline
\end{tabular}

*Seleção pelos eventos de chuva.

**Seleção pelos eventos de chuva e de advecção.

dados. Tomando-se o período de 27/05/03 a 22/07/03, nota-se na Tabela 6 que, mesmo desconsiderando-se a influência dos eventos de chuva, obteve-se valor de $K c=1,40$, que pode ser considerado elevado para uma superfície seca e com a cobertura da entrelinha sem receber irrigação. Diante disso, buscou-se por outras explicações para esses elevados valores de $K c$, como erros nas determinações de ETo (erros de medida das variáveis utilizadas no seu cálculo, inconsistência entre as determinações pelos métodos utilizados), os quais não se comprovaram, bem como efeito da cobertura da entrelinha, que não ficou claro e, finalmente, efeito de advecção. Na Figura 38 pode-se notar que 
conforme aumentou a freqüência relativa $(F r)$ de casos com vento soprando na direção transversal aos renques (menor "bordadura") entre 9:00 h e 16:00 h, os valores de $K c$ tenderam a aumentar, principalmente no período de maio - julho de 2003. Na mesma figura, percebe-se que para valores de $F r \leq 4 / 15=0,27$ nesse período, os valores de $K c$ ficaram entre 0,98 e 1,23, com a média igual a 1,11, sendo mais próxima dos resultados prévios obtidos na literatura (Villa Nova et al., 2002; Allen et al., 1998). Provavelmente tenha existido efeito da advecção de calor também quando o vento soprou em direções referentes às maiores "bordaduras", mas ele deve ter sido pequeno (ver seção 4.3.1), visto que não houve tendência de aumento de $K c$ com a velocidade do vento, a qual teve valores relativamente baixos durante esse período.

No período agosto - setembro de 2003, tão ou mais seco e com menor disponibilidade hídrica na parte não irrigada do solo, como se pode inferir do balanço hídrico seqüencial (Figura 8), que mostra a deficiência hídrica acentuada nesses dois meses, os valores de $K c$ diminuíram em relação a maio - julho. Por outro lado, verificase pela Figura 38 que em agosto - setembro a relação entre $K c$ e $F r$ mostra-se menos consistente, o que, embora não elimine a possibilidade do efeito advectivo ter ocorrido, mostra a necessidade de se considerar outros fatores atuando nos valores de $K c$.

Deve-se considerar que no final de agosto a altura da vegetação intercalar havia diminuído bastante (Figura 1b) e que ocorreram problemas de manejo que elevaram a heterogeneidade da cobertura vegetal da área, pois metade dela estava com solo nu e a outra metade tinha vegetação com menor altura do que em maio - julho (que, por sua vez, tinha 55\% a 70\% dessa vegetação em estado seco), sendo que no dia 245 (02/09/03) houve gradagem do restante da área. Esses aspectos talvez expliquem, em parte, o padrão de variação de $K c$ no último período de análise (Figura 37), no qual se verifica que, com exceção dos dias 237 (25/08/03) e 253 (10/09/03) (de ocorrência de chuvas pouco intensas), a oscilação dos valores é pequena. Os valores mais elevados que ocorreram nos dias $238(26 / 08 / 03)$ a 239 (27/08/03) podem ter sido conseqüência de um leve aumento da umidade da superfície da cobertura, havendo, ainda, condições de advecção, embora menos acentuada. 
Nos dias 240 (28/08/03) e 241 (29/08/03), a área do cafezal e as adjacentes já estavam bem secas, tendo ocorrido velocidades elevadas do vento (respectivamente, média de 3,0 m.s e 3,7 m.s ${ }^{-1}$ no período entre 9:00 h e 16:00 h) que podem ter contribuído para o aporte de energia advectiva. A elevação de $K c$ no dia 246 (03/09/03) é difícil de ser explicada; uma hipótese é essa elevação estar dentro da faixa de erro das determinações, outra é que, tendo havido o revolvimento do solo no dia anterior, evaporação adicional pode ter ocorrido pela exposição de camadas de solo inferiores e mais úmidas a oeste dos mastros micrometeorológicos, visto que, posteriormente, mesmo sob $F r$ da ordem de 0,67 e velocidades do vento acima de 2,5 m.s ${ }^{-1}$ houve diminuição de $K c$, possivelmente em resposta à secagem dos torrões de solo, à eliminação da cobertura verde e à quebra do continuum capilar que facilitava a chegada da umidade dos horizontes inferiores até a superfície. Portanto, os valores de $K c$ nesse período ficaram comprometidos, sendo necessário muito cuidado na sua utilização como referência devido aos diversos fatores que concorreram no seu estabelecimento.
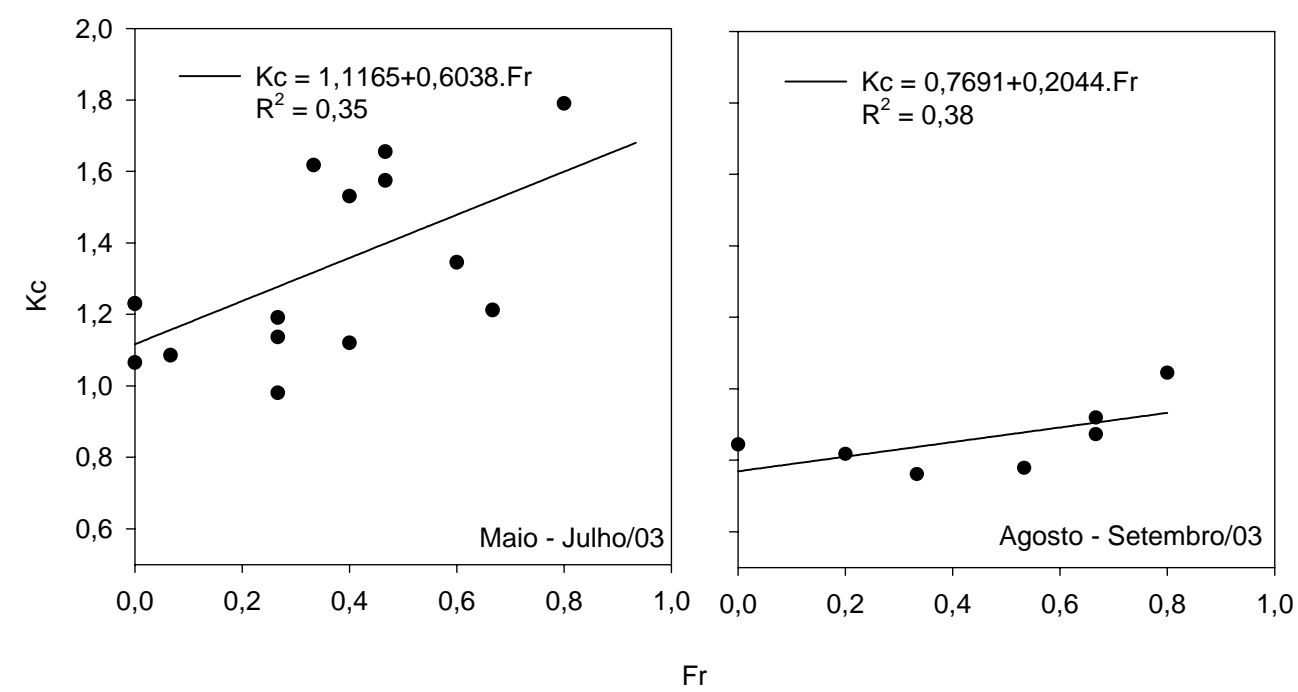

Figura 38 - Relação entre os valores do coeficiente de cultura $(K c)$ e a freqüência relativa de ocorrência de vento transversal aos renques de cafeeiros $(F r)$ entre 9:00 h e 16:00 h nos períodos de maio - julho e agosto - setembro de 2003. Neste último período, foram considerados somente os dias “utilizáveis" entre 20/08 e 01/09/03 
Esses resultados demonstram o grande cuidado que deve ser tomado, tanto na instalação como no manejo do experimento, ou na análise dos dados, quando se tem uma superfície com umidade adequada contornada por áreas secas. Quando as condições regionais de umidade são elevadas, como ocorreu no período úmido, pode ser considerado que não existe efeito advectivo de calor sensível sobre a área de interesse, tornando os valores de $K c$ mais confiáveis.

Comparados aos valores de $K c$ entre 0,51 e 0,59 obtidos por Gutiérrez \& Meinzer (1994b) para um cafezal (cultivar catuaí amarelo) com espaçamento de 3,6 m x $0,7 \mathrm{~m}$ e irrigado por gotejamento no período seco, porém, com $I A F=1,4$, aqueles obtidos no presente trabalho são relativamente elevados. Logicamente, os valores de $K c$ são influenciados pela variedade, pelo manejo, pelo tipo de solo e distribuição radicular e pela cobertura da entrelinha, mas provavelmente as micrometeorológicas sejam as mais importantes diferenças causais. Marin et al. (2005), em análise dos valores de $K c$ por eles obtidos no mesmo local deste estudo e aqueles do Havaí $\left(\approx 21^{\circ} \mathrm{N}\right)$ em cafezais adultos, evidenciaram que as condições microclimáticas dos dois locais levam a um maior acoplamento entre o dossel dos cafeeiros e a atmosfera, favorecendo a transpiração ter uma elevada relação com $D$, como observado na evolução de $F S$ ao longo do dia (Figura 33 e 34), podendo levar ao controle estomático da transpiração. Portanto, considerando-se que no Havaí o período seco coincide com a maior disponibilidade de energia, sendo que Gutiérrez \& Meinzer (1994b) obtiveram ETo variando entre 4,06 mm.dia ${ }^{-1}$ e 7,42 mm.dia ${ }^{-1}$, é provável que exista um controle estomático mais intenso por parte das plantas sobre a transpiração, inclusive daquelas da entrelinha, levando aos valores reduzidos de $K c$ e à maior participação do fluxo de calor sensível na partição do saldo de radiação (seção 4.3.5).

Os valores de $K c$ tenderam a aumentar ao longo de todo o período do estudo em 2002, em parte em resposta ao aumento de $I A F_{\text {cafezal }}(\mathrm{d} K c / \mathrm{d} I A F=4,34)$ e da cobertura da entrelinha $\left(\mathrm{d} K c / \mathrm{d} h_{e-l}=0,34 \mathrm{~m}^{-1}\right)$. Em fevereiro - março de 2003, também existiu uma relação positiva de $K c$ com $I A F$ e $h_{e-l}\left(\mathrm{~d} K c / \mathrm{d} I A F=2,27 ; \mathrm{d} K c / \mathrm{d} h_{e-l}=0,90 \mathrm{~m}^{-1}\right)$. No entanto, observando-se a Figura 37, percebe-se que os valores de $K c$ foram influenciados 
principalmente pela umidade do solo, como pode ser observado em fevereiro - março de 2003 pela queda de $K c$ após o dia 50 (19/02/03), tendendo novamente a aumentar com as chuvas a partir de $62(03 / 03 / 03)$, embora durante esse período tenha havido aumento de $h_{e-l}$ e $I A F$ (Figura 1). Apenas como exemplo da importância desta variável, no início de outubro de 2002, antes do início das chuvas, obteve-se $K c=0,93$, próximo daquele observado em agosto - setembro de 2003 (Tabela 6). Utilizando-se todos os dados, menos aqueles de agosto - setembro de 2003, ficou notável o efeito de $h_{\text {el }}$ sobre $K c$ $\left(\mathrm{d} K c / \mathrm{d} h_{e-l}=0,53 \mathrm{~m}^{-1}\right)$, enquanto que na relação com $I A F$ não houve tendência. Isso demonstra a importância da entrelinha na evapotranspiração de coberturas descontínuas e confirma que durante o período seco essas plantas realmente buscaram umidade em camadas inferiores de solo mais úmidas, existindo ainda a possibilidade de existir fluxo lateral da água da irrigação. O efeito de $I A F$ quando utilizados todos os dados ficou mascarado pela grande variação da umidade do solo e da própria cobertura da entrelinha. No período seco, como se têm poucos valores de $K c$ com evidências da não influência de chuvas ou de advecção, não foi possível a realização deste tipo de análise separadamente.

Os valores de $K c_{\text {renque }}$, mantiveram-se relativamente pouco variáveis ao longo do experimento (Tabela 6). Ficou destacada sua diminuição na seqüência de dias após uma chuva ou irrigação, devido ao efeito da secagem progressiva da superfície úmida do solo sob renque (Figura 37). A relativamente baixa variação sazonal observada é decorrente do aumento da área foliar das plantas e da concomitante diminuição da contribuição da evaporação do solo conforme o experimento avançou no período seco. $\mathrm{O}$ aumento de 0,22 de fevereiro - março para 0,43 em maio - julho de 2003 provavelmente foi decorrente do aumento da transpiração em conseqüência do acréscimo de área foliar $\left(1,00 \mathrm{~m}^{2}\right.$ para $\left.1,66 \mathrm{~m}^{2}\right)$ associado às condições comparáveis de umidade superficial do solo sob os renques nos dois períodos, pois em fevereiro e março foi necessário o acionamento da irrigação. A posterior diminuição de $K c_{\text {renque }}$ do período maio - julho para agosto - setembro de 2003, embora sob condições de umidade semelhantes e aumento da área foliar média dos cafeeiros de 1,66 $\mathrm{m}^{2}$ para 2,09 $\mathrm{m}^{2}$, deve estar relacionada à redução de $K c b$ de 0,20 para 0,13 , provavelmente devido à baixa atividade 
fisiológica dos cafeeiros e aos altos valores de $D$, que forçaram os mesmos a controlar a transpiração com maior intensidade em agosto - setembro de 2003 (Figuras 7, 33, 34). É provável que o controle estomático em maio - julho não tenha sido tão intenso pelos valores de $D$ terem sido menores nesse período (seção 4.1), compensando parcialmente a consideração de $T / E L$ obtida em agosto - setembro, quando $A F$ foi maior. No período úmido, $K c b$ teve pouca variação, oscilando entre 0,03 e 0,04 .

Tomando-se por base o período de agosto - setembro de 2003, quando $I A F$ do cafezal foi de 0,663 , o valor de $K c b=0,13$ pode ser considerado relativamente alto em comparação com os valores entre 0,14 e 0,17 obtidos a partir de $T$ e ETo apresentados na Tabela 2 de Gutiérrez \& Meinzer (1994) num cafezal com irrigação por gotejamento e $I A F=1,4$, pois, conforme discutido acima, as condições microclimáticas no Havaí possivelmente levam ao controle estomático da transpiração mais intenso por parte dos cafeeiros. Em comparação com os valores determinados por Villa Nova et al. (2002) ( $K c b$ entre 0,092 e 0,375 para $I A F$ variando entre 0,23 e 1,08), determinados pelo balanço hídrico no solo e com irrigação por aspersão total, os valores deste estudo são inferiores.

Villa Nova et al. (2002) consideraram que a depleção no armazenamento de água no volume de solo de controle sob a copa dos cafeeiros foi devida somente à transpiração. Essa consideração é válida para plantas adultas que bloqueiam a incidência de radiação direta sobre o solo e levam a um desacoplamento desta com a atmosfera, significando que, devido aos baixos $I A F$, na comparação dos resultados obtidos neste estudo e por Villa Nova et al. (2002) deve-se considerar $K c_{\text {renque }}$ o qual quantifica também a evaporação do solo sob renques. Embora em períodos com condições de umidade diferentes, os valores podem ser considerados razoavelmente próximos, observando-se consistência dos valores de $K c_{\text {renque }}$ nas fases iniciais de crescimento dos cafeeiros no local de estudo.

Esses resultados mostram que a evapotranspiração da entrelinha nas condições deste estudo foi uma componente altamente significativa de ETc, mesmo no período seco e com um sistema de irrigação localizado, sendo que o coeficiente de 
evapotranspiração da entrelinha $\left(K_{e-l}\right)$ manteve-se em torno de 0,95 no período úmido, caindo para aproximadamente 0,63 no período seco.

O uso dos valores de $K c, K c_{\text {renque }}$ (ou $K c b$ ) para fins práticos deve respeitar a situação de umidade e cobertura do solo na entrelinha e o sistema de irrigação, além dos parâmetros biométricos dos cafeeiros e da exposição do solo sob os renques. Relacionar tais variáveis com $K c$ é de ordem prática complicada, pois seria necessário estabelecer curvas de resposta em função dos dados da cobertura da entrelinha e da umidade do solo para diferentes faixas de $I A F_{\text {cafezal }}$. Além das dificuldades práticas inerentes a essa metodologia, a falta de uma relação significativa e constante entre essas variáveis, como observado nesse trabalho, inviabilizam tal procedimento.

Portanto, o usuário deve ter cautela e bom senso ao utilizar os coeficientes obtidos neste estudo, de modo a reduzir os erros em considerar um valor médio representativo de condições específicas da superfície vegetada. A discussão acima e aquela referente à flutuação de $K c$ mostram o cuidado que se deve ter na interpretação dos seus valores quando se trabalha com coberturas vegetais descontínuas, com grande heterogeneidade quanto às fontes dos fluxos de calor e de vapor. Deve-se entender que, nesse caso, o conceito de coeficiente "global" de cultura foge do seu sentido original, ligado à evapotraspiração de uma cultura formando uma cobertura homogênena e sob condições hídricas ideais.

Embora tenham sido identificados problemas de advecção no período seco, os valores de $K c$ e $K c_{\text {renque }}$ determinados até julho de 2003 podem ser considerados passíveis de utilização para fins práticos, desde que em condições de plantio, de manejo e de $I A F$ semelhantes às do cafezal estudado, enquanto que aqueles obtidos em agosto setembro de 2003 devem ser adotados com cautela. 


\section{CONCLUSÕES}

O parâmetro "deslocamento do plano zero" normalizado pela altura da cultura mostrou um aumento inicial, com um posterior decréscimo teoricamente inconsistente com o aumento da altura dos cafeeiros, além de uma grande variação do comprimento de rugosidade, a qual dependeu das condições de cobertura das entrelinhas, da direção e velocidade do vento, sendo que ficou evidenciado o efeito dessas últimas duas variáveis também sobre o deslocamento do plano zero.

Devido à alta heterogeneidade da cobertura vegetal e às medidas feitas próximas da superfície, o método aerodinâmico mostrou um fraco desempenho na determinação dos fluxos energéticos superficiais, sendo que em períodos de secagem progressiva do solo ocorreram erros grosseiros. O método do balanço de energia - razão de Bowen apresentou desempenho satisfatório, sendo que a similaridade razoavelmente boa entre os perfis de temperatura e pressão de vapor tornou seus resultados confiáveis.

Os pequenos gradientes de pressão de vapor e os erros de medida dos sensores dos psicrômetros compuseram a maior dificuldade na determinação dos fluxos de calor latente e sensível durante o período seco, destacando a necessidade de uso de equipamentos com desempenho similar.

Durante o período úmido, a partição da energia em fluxo de calor latente equivaleu a mais de $80 \%$ da energia radiante disponível à superfície, havendo diminuição durante o período seco para somente $64 \%$.

A evapotranspiração da faixa de $0,9 \mathrm{~m}$ de largura sob os renques de cafeeiros foi equivalente a $22 \%$ no período úmido e $30 \%$ a $33 \%$ no período seco da evapotranspiração total. Os valores do coeficiente "global" de cultura foram mais elevados em novembro $(1,27)$ e dezembro $(1,30)$ de 2002, período com chuvas 
freqüentes. Nos outros períodos, o coeficiente "global" de cultura variou entre 1,11 em maio - julho e 1,13 em fevereiro - março de 2003. Menores valores foram observados sob as condições mais secas, sendo de 1,04 em outubro de 2002 e de 0,86 em agosto setembro de 2003, sendo este valor comprometido por problemas de condução da área.

O "coeficiente de evapotranspiração dos renques" apresentou baixa variabilidade sazonal, com os valores ficando normalmente entre 0,22 e 0,30, com exceção do período de maio - julho de 2003 , cujo valor foi de 0,43 . O coeficiente basal de cultura variou entre aproximadamente 0,03 no início do experimento até $0,20 \mathrm{em}$ maio - julho, decaindo, posteriormente, para 0,13 em função da estagnação fisiológica dos cafeeiros. 


\section{REFERÊNCIAS BIBLIOGRÁFICAS}

ALLEN, R.G.; FISHER, D.K. Direct load-cell based weighing lysimeter system. In: ALLEN, R.G.; HOWELL, T.A.; PRUITT, W.O.; WALTER, I.A.; JENSEN, M.E. Lysimeters for evapotranspiration and environmental measurements. New York: American Society of Civil Engineers, 1991. p.114-124.

ALLEN, R.G.; PRUITT, W.O.; JENSEN, M.E. Environmental requirements of lysimeters. In: ALLEN, R.G.; HOWELL, T.A.; PRUITT, W.O.; WALTER, I.A.; JENSEN, M.E. Lysimeters for evapotranspiration and environmental measurements. New York: American Society of Civil Engineers, 1991. p.170-181.

ALLEN, R.G.; PEREIRA, L.S.; RAES, D.; SMITH, M. Crop evapotranspiration: guidelines for computing crop water requirements. Rome: FAO, 1998. 300p. (FAO Irrigation and Drainage Paper, 56).

ALLEN, S.J.; GRIME, V.L. Measurements of transpiration from savannah shrubs using sap flow gauges. Agricultural and Forest Meteorology, v.75, p.23-41, 1995.

ALLEN, S.J.; BRENNER, A.J.; GRACE, J. A low-cost psychrometer for field measurements of atmospheric humidity. Plant, Cell and environment, v.17, p.219$225,1994$.

ANGELOCCI, L.R. Métodos e técnicas de estudo das relações água-plantaatmosfera. Piracicaba: ESALQ, 2001. 172p.

ANGELOCCI, L.R. Água na planta e trocas gasosas/energéticas com a atmosfera. Piracicaba: O autor, 2002. 268p.

ANGUS, D.E.; WATTS, P.J. Evapotranspiration - how good is the Bowen ratio method? Agricultural and Water Management, v.8, p.133-150, 1984. 
ASCANIO EVANOFF, C.E. Biologia del café. Caracas: Universidad Central de Venezuela, 1994. 308p.

ASTON, A.R. The effect of vertical separation of psychrometers on the determination of Bowen ratios over a young eucalypt forest. Agricultural and Forest Meteorology, v.35, p.299-307, 1985.

AZEVEDO, P.V.; SILVA, B.B., SILVA, V.P.R. Water requeriments of irrigate mango orchards in northeast Brazil. Agricultural and Water Management, v.58, p.241254, 2003.

BAKER, J.M.; NIEBER, J.L. An analysis of the steady-state heat balance method for measuring sap flow in plants. Agricultural and Forest Meteorology, v.48, p.93109, 1989.

BAKER, J.M.; VAN BAVEL, C.H.M. Measurement of mass flow of water in the stems of herbaceous plants. Plant, Cell and Environment, v.10, p.777-782, 1987.

BACKER, L.W.; ROUMIEUX, S.M.; WERY, B.J. Electronic lysimeter for hydrologic studies. In: ALLEN, R.G.; HOWELL, T.A.; PRUITT, W.O.; WALTER, I.A.; JENSEN, M.E. Lysimeters for evapotranspiration and environmental measurements. New York: American Society of Civil Engineers, 1991. p.70-78.

BARROS, R.S.; MAESTRI, M.; RENA, A.B. Coffee crop ecology. Tropical Ecology, v.36, n.1, p.1-19, 1995.

BARROS, R.S.; MOTA, J.W.S.; DA MATTA, F.M.; MAESTRI, M. Decline of vegetative growth in Coffea arabica L. in relation to leaf temperature, water potential and stomatal conductance. Field Crops Research, v.54, p.65-72, 1997.

BERGAMASCHI, H.; ROSA, L.M.G.; SANTOS, A.O.; BERGONCI, J.I. Automação de um lisímetro de pesagem através de estação meteorológica, a campo. In: CONGRESSO BRASILEIRO DE AGROMETEOROLOGIA, 10., Piracicaba, 1997. Anais. Piracicaba: FEALQ, 1997. p.222-224.

BINDON, H.H. A critical review of tables and charts use in psychrometry. In: WEXLER, A. Humidity and moisture. New York: Reinhold, 1965. v.1, p.3-15. 
BINK, N.J. The ratio of eddy diffusivities for heat and water vapour under conditions of local advection. Physics and Chemistry of the Earth, v.21, n.3, p.119-122, 1996.

BLAD, B.L.; ROSEMBERG, N.J. Lysimetric calibration of the Bowen ratio-energy balance method for evapotranspiration in the Central Great Plains. Journal of Applied Meteorology, v.13, p.227-236, 1974.

BRAKKE, T.W.; VERMA, S.B; ROSEMBERG, N.J. Local and regional components of sensible heat advection. Journal of Applied meteorology, v.17, p.955-963, 1978.

BRUNINI, O.; ANGELOCCI, L.R. Resistência ao fluxo de água no sistema solo-planta e recuperação do potencial da água na folha após estresse hídrico em mudas de cafeeiro. Revista Brasileira de Fisiologia Vegetal, v.10, n.1, p.45-50, 1998.

BRUTSAERT, W. Evaporation into the atmosphere: theory, history and applications. Dordrecht: D. Reidel Publ., 1984. 299p.

BULL, R.A. Studies on the effect of mulch and irrigation on root and stem development in Coffea arabica L. 1. Changes in the root system induced by mulching and irrigation. Turrialba, v.13, n.2, p. 96-115, 1963.

BUSINGER, J.A.; WINGAARD, J.C; ISUMI, Y.; BRADLEY, E.F. Flux profile relationships in the atmospheric surface layer. Journal of the Atmospheric Sciences, v.28, p.181-189, 1971.

CAMARGO, A.P. Florescimento e frutificação de café arábica nas diferentes regiões (cafeeiras) do Brasil. Pesquisa Agropecuária Brasileira, v.20, n.7, p.831-839, 1985.

CAMARGO, A.P.; PEREIRA, A.R. Agrometeorology of coffee crop. Geneva: WMO, 1994. 53p. (Bulletin, 58).

CAMPBELL, G.S.; NORMAN, J.M. An introduction to environmental biophysics. 2.ed. New York: Springer-Verlag, 1998. 286p.

CARR, M.K.V. The water relations and irrigation requirements of coffee. Experimental Agriculture, v.37, p.1-36, 2001.

CELLIER, P.; BRUNET, Y. Flux-gradient relationships above tall plant canopies. Agricultural and Forest Meteorology, v.38, p.93-117, 1992. 
CELliER, P.; RICHARD, G.; ROBIN, P. Partition of sensible heat fluxes into bares soil and atmosphere. Agricultural and Forest Meteorology, v.82, p.245-265,1996.

CĚRMAK, J.; DELM, M.; PENKA, M. A new method of sap flow rate determination in trees. Biologia Plantarum, v.18, p.105-110, 1973.

COELHO FILHO, M.A. Determinação da transpiração máxima em um pomar jovem de lima ácida 'tahiti' (Citrus latifólia Tan.) e sua relação com a evapotranspiração de referência, Piracicaba, 2002. 91p. Tese (Doutorado) - Escola Superior de Agricultura “Luiz de Queiroz”, Universidade de São Paulo.

CUNHA, G.B.; BERGAMASCHI, H. Balanço de energia em alfafa. Revista Brasileira de Agrometeorologia, v.2, p.9-16, 1994.

CUNHA, G.R.; BERGAMASCHI, H.; BERLATO, M.A.; MATZENAUER, R. Balanço de energia em cultura de milho. Revista Brasileira de Agrometeorologia, v.4, n.1, p.1-14, 1996.

CUNHA, A.R. da; ESCOBEDO, J.F.; KLOSOWSKI, E.S. Balanço de energia em pimentão sob cultivo protegido e a campo. Revista Brasileira de Agrometeorologia, v.9, n.2, p.159-167, 2001.

DA MATTA, F.M.; MAESTRI, M.; BARROS, R.S.; REGAZZI, A.J. Water relations of coffee leaves (Coffea arábica and C. canephora) in response to drought. Journal of Horticultural Science, v.68, n.5, p.741-746, 1993.

DAAMEN, C.C.; SIMMONDS, L.P.; SIVAKUMAR, M.V.K. The impact of sparse millet crops on evaporation from soil in semi-arid Niger. Agricultural and Water Management, v.27, p.225-242, 1995.

DAAMEN, C.C.; SIMMONDS, L.P.; WALLACE, J.S.; LARYEA, K.B.; SIVAKUMAR, M.V.K. Use of microlysimeters to measure evaporation from sandy soils. Agricultural and Forest Meteorological, v.65, p.159-173, 1993.

DE BRUIN, H.A.R.; MOORE, C.J. Zero-plane displacement and roughness length for tall vegetation, derived from a simple mass conservation hypothesis. BoundaryLayer Meteorology, v.31, p.39-49, 1985. 
DE BRUIN, H.A.R.; VAN DEN HURK, B.J.J.M.; KROON, L.J.M. On the temperature-humidity correlation and similarity. Boundary-Layer Meteorology, v.93, p.453-468, 1999.

DRINMAN, J.E.; MENZEL, C.M. Temperature affects vegetative growth and flowering of coffee (Coffea arabica L.). Journal of Horticultural Science, v.70, n.1, p.25-34, 1995.

DUGAS, W.A.; FRITSCHEN, L.J.; GAY, L.W.; HELD, A.A.; MATHIAS, A.D.; REICOSKY, D.C.; STEDUTO, P.; STEINER, J.L. Bowen ratio, eddy correlation, and portable chamber measurements of sensible and latent heat flux over irrigated spring wheat. Agricultural and Forest Meteorology, v.56, p.1-20, 1991.

DUNIN, F.X.; NULSEN, R.A.; BAXTER, I.N.; GREENWOOD, E.A.N. Evaporation from a lupin crop: a comparison of methods. Agricultural and Forest Meteorology, v.46, p.297-311, 1989.

DYER, A.J. The turbulent transport of heat and water vapour in an unstable atmosphere. Quarterly Journal of the Royal Meteorological Society, v.93, p.501508, 1967.

DYER, A.J. A review of flux-profile relationships. Boundary-Layer Meteorology, v.7, p.363-372, 1974.

DYER, A.J.; HICKS, B.B. Flux-gradients relationships in the constant flux layer. Quarterly Journal of the Royal Meteorological Society, v.96, p.715-721, 1970.

FAN, J. Determination of the psychrometer coefficient A of the WMO Reference Psychrometer by comparison with a standard gravimetric hygrometer. Journal of Atmospheric and Oceanic Technology, v.4, p.239-244, 1987.

FEVROT, C.H. Mesure de l'humidité relative de l'air a l'aide d'un psychromètre. Measures Regulátion Automatisme, p.55-61, Maio 1977.

FINNIGAN, J. Turbulence in plant canopies. Annual Review of Fluid Mechanics, v.32, p.519-571, 2000.

FRANCEY, R.J.; GARRATT, R.J. Interpretation of flux-profile observations at ITCE (1976). Journal of Applied Meteorology, v.20, n.6, p.618-603, 1981. 
FRANCO, C.M.; INFORZATO, R. Quantidade de água transpirada pelo cafeeiro cultivado ao sol. Bragantia, v.10, n.9, p.247-257, 1950.

FRANCO, C.M.; INFORZATO, R. Quantidade de água transpirada pelo cafeeiro sombreado e pelo ingazeiro. Bragantia, v.11, n.4/6, p.121-125, 1951.

FUCHS, M.; TANNER, C.B. Error analysis of Bowen ratios measured by differential psychrometry. Agricultural Meteorology, v.7, p.329-334, 1970.

GARRATT, J.R. Flux profile above tall vegetation. Quarterly Journal of the Royal Meteorological Society, v.104, p.199-211, 1978.

GARRATT, J.R. Surface influence upon vertical profiles in the atmospheric nearsurface layer. Quarterly Journal of the Royal Meteorological Society, v.106, p.803-819, 1980.

GARRATT, J.R.; HICKS, B.B. Momentum, heat and water vapour transfer to and from natural and artificial surfaces. Quarterly Journal of the Royal Meteorological Society, v.99, p.680-687, 1973.

GARRIZ, P.I.; VICUÑA, R.S. Variaciones anuales em el crecimiento vegetativo y la arquitectura del canopeo de Coffea arabica L. cv. Caturra Rojo. Agronomia Tropical, v.36, n.4/6, p.33-45, 1986.

GERVASIO, E.S.; LIMA, L.A. Efeito de diferentes lâminas de água no desenvolvimento do cafeeiro (Coffea arabica L.) em fase inicial de formação da lavoura. Revista Brasileira de Engenharia Agrícola e Ambiental, v.2, n.1, p.68$74,1998$.

GRANIER, A. Une nouvelle méthode pour la mesure du flux de sève brute dans le tronc des arbres. Annales des Sciences Forestieres, v.42, p.193-200, 1985.

GREBET, P. Precision lysimeter in France. In: ALLEN, R.G.; HOWELL, T.A.; PRUITT, W.O.; WALTER, I.A.; JENSEN, M.E. Lysimeters for evapotranspiration and environmental measurements. New York: American Society of Civil Engineers, 1991. p.105-117. 
GREBET, P.; CUENCA, R.H. Hystory of lysimeter design of environmental disturbances. In: ALLEN, R.G.; HOWELL, T.A.; PRUITT, W.O.; WALTER, I.A.; JENSEN, M.E. Lysimeters for evapotranspiration and environmental measurements. New York: American Society of Civil Engineers, 1991. p.10-18.

GRIME, V.L.; SINCLAIR, F.L. Sources of error in stem heat balance sap flow measurements. Agricultural and Forest Meteorology, v.94, p.103-121, 1999.

GRIME, V.L.; MORISON, J.I.L.; SIMMONDS, L.P. Including the heat storage term in sap flow measurements with the stem heat balance method. Agricultural and Forest Meteorology, v.74, p.1-25, 1995a.

GRIME, V.L.; MORISON, J.I.L.; SIMMONDS, L.P. Sap flow measurements from stem heat balances: a comparison of constant with variable power methods. Agricultural and Forest Meteorology, v.74, p.27-40, 1995b.

GROOT, A.; KING, K.M. Measurement of sap flow by the heat balance method: numerical analisys and application to coniferous seedlings. Agricultural and Forest Meteorology, v.59, p.289-308, 1992.

GUTIÉRREZ, M.V.; MEINZER, F.C. Energy balance and latent Fiat flux partitioning in coffee hedgerows at different stages of canopy development. Agricultural and Forest Meteorology, v.68, p.173-186, 1994a.

GUTIÉRREZ, M.V.; MEINZER, F.C. Estimating water use and irrigation requirements of coffee in Hawaii. Journal of American Society for Horticultural Science, v.119, n.3, p.652-657, 1994 b.

GUTIÉRREZ, M.V.; HARRINGTON, R.; MEINZER, F.C.; FOWNES, J.H. The effect of environmentally induced stem temperature gradients on transpiration estimates from the heat balance method in two tropical woody species. Tree Physiology, v.14, p.179-190, 1994.

HAM, J.M.; HEILMAN, J.L. Dynamics of a heat balance stem flow gauge during high flow. Agronomy Journal, v.82, p.147-152, 1990.

HAM, J.M.; HEILMAN, J.L.; LASCANO, R.J. Determination of soil water evaporation and transpiration from energy balance and stem flow measurements. Agricultural and Forest Meteorology, v.52, p.287-301, 1990. 
HATFIELD, J.L. Aerodynamic properties of partial canopies. Agricultural and Forest Meteorology, v.46, p.15-22, 1989.

HAYASHI, M.M.S.; CAMPELO JÚNIOR, J.H.; PRIANTE Fl., N.; NOGUEIRA, J.S.; VOURLITTIS, G.L. Balanço de energia da Crotalaria juncea L. no período seco e no período úmido do ano em condições de cerrado. Revista Brasileira de Agrometeorologia, v.10, n.2, p.197-205, 2002.

HEIKINHEIMO, M.; KANGAS, M.; TOURULA, T.; VENÄLÄINEN, A.; TATTARI, S. Momentum and heat fluxes over lakes Tämnaren and Råksjö determined by the bulk-aerodynamic and eddy-correlation methods. Agricultural and Forest Meteorology, v.98-99, p.521-534, 1999.

HEILMAN, J.L.; BRITTIN, C.L.; NEALE, C.M.U. Fetch requeriments for Bowen ratio measurements of latent and sensible heat fluxes. Agricultural and Forest Meteorology, v.44, p.261-273, 1989.

HOWELL, T.A.; SCHNEIDER, A.D.; JENSEN, M.E. History of lysimeter design and use for evapotranspiration measurements. In: ALLEN, R.G.; HOWELL, T.A.; PRUITT, W.O.; WALTER, I.A.; JENSEN, M.E. Lysimeters for evapotranspiration and environmental measurements. New York: American Society of Civil Engineers, 1991. p.1-9.

INMAN-BAMBER, N.G.; McGLYNCHEI, M.G. Crop coefficients and water-use estimates for sugarcane based on long-term Bowen ratio energy balance measurements. Field Crops Research, v.83, p.125-138, 2003.

ISHIDA, T.; CAMPBELL, G.S.; CALISSENDORFF, C. Improved heat balance method for determining sap flow rate. Agricultural and Forest Meteorology, v.56, p.35-48, 1991.

JACOBS, A.F.G.; VAN BOXEL, J.H. Changes of the displacement height and roughness length of maize during a growing season. Agricultural and Forest Meteorology, v.42, p.53-62, 1988.

KASHYAP, P.S.; PANDA, R.K. Evaluation of evapotranspiratio estimation methods and development of crop-coefficients for potato crop in a sub-humid region. Agricultural and Water Management, v.50, p.9-25, 2001. 
KJELGAARD, J.F; STOCKLE, C.O.; BLACK, R.A.; CAMPBELL, G.S. Measuring sap flow with the heat balance approach using constant and variable heat inputs. Agricultural and Forest Meteorology, v.85, p.239-250, 1997.

KUSTAS, W.P.; CHOUDHURY, B.J.; KUNKEL, K.E.; GAY, L.W. Estimate of the aerodynamic roughness parameters over an incomplete canopy cover of cotton. Agricultural and Forest Meteorology, v.46, p.91-105, 1989a.

KUSTAS, W.P.; CHOUDHURY, B.J.; MORAN, M.S.; REGINATO, R.J.; JACKSON, R.D.; GAY, L.W.; WEAVER, H.L. Determination of sensible heat flux over sparse canopy using thermal infrared data. Agricultural and Forest Meteorology, v.44, p.197-216, 1989b.

LANG, A.R.G. Measurement of evapotranspiration in the presence of advection, by means of a modified energy balance procedure. Agricultural Meteorology, v.12, p.75-81, 1973.

LETTAU, H. Note on aerodynamic roughness-parameter estimation on the basis of roughness-element description. Journal of Applied Meteorology, v.8, p.828-832, 1969.

LEWIS, J.M. The story behind the Bowen ratio. Bulletin of the American Meteorological Society, v.76, n.12, p.2433-2443, 1995.

LIU, C.; ZHANG, X.; ZHANG, Y. Determination of daily evaporation and evapotranspiration of winter wheat and maize by large-scale weighing lysimeter and micro-lysimeter. Agricultural and Forest Meteorology, v.111, p.10-120, 2002.

LO, A.K.; McBEAN, G.A. On the relative errors in methods of flux calculations. Journal of Applied Meteorology, v.17, n.11, p.1704-1711, 1978.

LOPES, P.M.O.; SILVA, B.B. da; AZEVEDO, P.V. de; SILVA, V.P.R. de; TEIXEIRA, A.H.C.; SOARES, J.M.; SOBRINHO, J.E. Balanço de energia num pomar de mangueiras irrigado. Revista Brasileira de Agrometeorologia, v.9, n.1, p.1-8, 2001.

MAGALHÃES, A.C.; ANGELOCCI, L.R. Sudden alterations in water balance associated with flower bud opening in coffee plants. Journal of Horticultural Science, v.51, p. 419-423, 1976. 
MALEK, E.; BINGHAM, G.E. Comparison of the Bowen ratio-energy balance and the water balance methods for the measurement of evapotranspiration. Journal of Hydrology, v.146, p.209-220, 1993.

MALEK, E. Night-time evapotranspiration vs. daytime and $24 \mathrm{~h}$ evapotranspiration. Journal of Hydrology, v.138, p.119-129, 1992.

MALEK, E. Rapid changes of the surface soil heat flux and its effects on the estimation of evapotranspiration. Journal of Hydrology, v.142, p.89-97, 1993.

MARIN, F.R. Evapotranspiração, Transpiração e Balanço de Energia em Pomar de Lima Ácida “Tahiti”. Piracicaba, 2000. 74p. Dissertação (Mestrado) - Escola Superior de Agricultura “Luiz de Queiroz”, Universidade de São Paulo.

MARIN, F.R. Evapotranspiração e transpiração maxima em cafezal adensado. Piracicaba, 2003. 118p. Tese (Doutorado) - Escola Superior de Agricultura "Luiz de Queiroz”, Universidade de São Paulo.

MARIN, F.R.; ANGELOCCI, L.R.; PEREIRA, A.R.; VILLA NOVA, N.A.; SENTELHAS, P.C. Sap flow and evapotranspiration in an irrigated citrus orchard. Revista Brasileira de Agrometeorologia, v.9, n.2, p.219-226, $2001 \mathrm{~b}$.

MARIN, F.R.; ANGELOCCI, L.R; RIGHI, E.Z.; SENTELHAS, P.C. Evapotranspiration and irrigation requirements of a coffee plantation in Southern Brazil. Experimental Agriculture, v.41, n.2, 2005. /No prelo/

MARIN, F.R.; ANGELOCCI, L.R.; COELHO FILHO, M.A.; VILLA NOVA, N.A. Construção e avaliação de psicrômetro aspirado de termopar. Scientia Agrícola, V.58, n.4, p.839-844, 2001a.

MARIN, F.R.; RIBEIRO, R.V.; ANGELOCCI, L.R.; OLIVEIRA, F.R. de Avaliação do método do balanço de calor para medida da transpiração de mudas de laranjeira e cafeeiro. In: CONGRESSO BRASILEIRO DE AGROMETEOROLOGIA, 13, Santa Maria, 2003. Anais. Santa Maria: UNIFRA, SBA, UFSM, 2003b. p.79-80.

MARIN, F.R.; SANTIAGO, A.V.; RIGHI, E.Z.; SENTELHAS, P.C.; ANGELOCCI, L.R.; MAGGIOTTO, S.R.; PEZZOPANE, J.M. Solar radiation interception and its relation with transpiration in different coffee canopy layers. Revista Brasileira de Agrometeorologia, v.11, n.1, p.1-6, 2003a. 
MARSHAL, D.C. Measurement of sap flow in conifers by heat transport. Plant Physiology, v.33, p.385-396, 1958.

MARTIN, E.C.; OLIVEIRA, A.S.; FOLTA, A.D.; PEGElOW, E.J.; SLACK, D.C. Development and testing of a small weighable lysimeter system to assess water use by shallow-rooted crops. Transactions of the ASAE, v.44, n.1, p.71-78, 2001.

MASSMAN, W.J. Correcting errors associated with soil heat flux measurements and estimating soil thermals properties from soil temperature and heat flux plate data. Agricultural and Forest Meteorology, v.59, p.249-266, 1992.

McCAUGHEY, J.H.; BRINTNELL, D.M. Evaluation of a Bowen ratio measurement system over forest and clear-cut sites at Ptawawa, Ontario, Journal of Atmospheric and Oceanic Technology, v.1, p.276-282, 1984.

McINNES, K.J.; HEILMAN, J.L.; GESCH, R.W. Momentum roughness and zero-plane displacement of ridge-furrow tilled soil. Agricultural and Forest Meteorology, v.55, p.167-179, 1991.

McNAUGHTON, K.G.; LAUBACH, J. Unsteadiness as a cause of non-equality of eddy diffusivities for heat and vapour at the vase of an advective inversion. BoundaryLayer Meteorology, v.88, p.479-504, 1998.

MÖLDER, M.; GRELLE, A.; LINDROTH, A.; HALLDIN, S. Flux-profile relationships over a boreal forest - roughness sublayer corrections. Agricultural and Forest Meteorology, v.98-99, p.645-658, 1999.

MONTEITH, J.L.; UNSWORTH, M.H. Principles of environmental physics. 2.ed. London: Edward Arnold, 1990. 291p.

MOTHA, R.P.; VERMA, S.B.; ROSEMBER, N.J. Exchange coefficients under sensible heat advection determined by eddy correlation. Agricultural Meteorology, v.20, p.273-280, 1979.

MUNRO, D.S. A portable differential psychrometer system. Journal of Applied Meteorology, v.19, p.206-214, 1980.

MUNRO, D.S.; OKE, T.R. Estimating wind profile parameter for tall dense crops. Agricultural Meteorology, v.11, p.223-228, 1973. 
MUNRO, D.S.; OKE, T.R. Aerodynamic boundary-layer adjustment over a crop in neutral stability. Boundary-Layer Meteorology, v.9, p.53-61, 1975.

NUTMAN, F.J. Studies on the physiology of Coffea arabica L. III. Transpiration rates of whole trees in relation to natural environmental conditions. Annals of Botany, v.1, p.681-693, 1941.

NUTMAN, F.J. Studies on the physiology of Coffea arabica L. I. Photossynthesis of coffee leaves under natural conditions. Annals of Botany, v.1, p.353-367, 1937a.

NUTMAN, F.J. Studies on the physiology of Coffea arabica L. II. Stomatal movements in relation to photosynthesis in natural conditions. Annals of Botany, v.1, p.681693, $1937 b$.

OKE, T.R. Boudary layer climates. 2.ed. London: Routledge, 1987. 435p.

PAULETTO, E.A. Determinação da condutividade hidráulica de solos a partir da curva de retenção de água. Piracicaba, 1986. 133p. Tese (Doutorado). Escola Superior de Agricultura “Luiz de Queiroz", Universidade de São Paulo.

PEREIRA, H.C. Field measurements of water use for irritation control in Kenya coffee. Journal of Agricultural Science, v.49, p.459-467, 1957.

PEREIRA, A.R. Introdução à micrometeorologia. Piracicaba: ESALQ, Departamento de Ciências Exatas, 1998. 70p.

PEREIRA, A.R.; VILLA NOVA, N.A.; SEDIYAMA, G.C. Evapo(transpi)ração. Piracicaba: FEALQ, 1997. 183p.

PEREIRA, A.R.; ANGELOCCI, L.R.; SENTELHAS, P.C. Agrometeorologia: fundamentos e aplicações. Guaíba: Editora Agropecuária, 2002a. 478p.

PEREIRA, A.R.; SANTIAGO, A.S.; MAGGIOTTO, S.R.; FOLEGATTI, M.V. Problemas operacionais com lisímetro de pesagem durante a estação chuvosa e em dias secos com rajadas de vento. Revista Brasileira de Agrometeorologia, v.10, n.1, p.51-56, 2002b.

PEREIRA, A.R.; MARIN, F.R.; ANGELOCCI, L.R.; VILLA NOVA, N.A.; SENTELHAS, P.C. Difficulties with micrometeorological methods to estimate evapotranspiration in a small citrus orchard. Revista Brasileira de Meteorologia, v.18, n.1, p.13-20, 2003. 
PERESSOTI, A.; HAM, J.M. A dual-heater gauge for measuring sap flow with an improved heat-balance method. Agronomy Journal, v.88, p.149-155, 1996.

PEREZ, P.J.; CASTELLVI, F.; IBAÑEZ, M.; ROSELL, J.I. Assessment of reliability of Bowen ratio method for partitioning fluxes. Agricultural and Forest Meteorology, v.97, p.141-150, 1999.

PIERI, P.; FUCHS, M. Comparison of Bowen ratio and aerodynamic estimates of evapotranspiration. Agricultural and Forest Meteorology, v.49, p.243-256, 1990.

ORTEGA-FARIAS, S.O.; CUENCA, R.H.; E.K.M. Daytime variation of sensible heat flux estimated by the bulk aerodynamic method over a grass canopy. Agricultural and Forest Meteorology, v.81, p.131-143, 1996.

PRUEGER, J.H.; HATFIELD, J.L.; AASE, J.K.; PIKUL, Junior J.H. Bowen-ratio comparisons with lysimeter evapotranspiration. Agronomy Journal, v.89, p.730736, 1997.

PRUITT, W.O.; MORGAN, D.L.; LOURENCE, F.J. Momentum and mass transfers in the surface boundary-layer. Quarterly Journal of the Royal Meteorological Society, v.99, p.370-386, 1973.

QIU, G.Y.; MOMII, K.; YANO, T.; LASCANO, R.J. Experimental verification of a mechanistic model to partition evapotranspiration into soil water and plant evaporation. Agricultural and Forest Meteorology, v.93, p.79-93, 1999.

RANA, G.; KATERJI, N. Measurement and estimation of actual evapotranspiration in the field under Mediterranean climate: a review. European Journal of Agronomy, V.13, p.125-153, 2000.

RAUPACH, M.R. Anomalies in flux-gradient relationships. Boudary-Layer Meteorology, v.16, p.467-486, 1979.

RAUPACH, M.R.; LEGG, B.J. The uses and limitations of flux-gradient relationships in micrometeorology. Agricultural and Water Management, v.8, p.119-131, 1984.

RAUPACH, M.R.; FINNIGAN, J.J.; BRUNET, Y. Coherent eddies and turbulence in vegetation canopies: the mixing layer analogy. Boundary-Layer Meteorology, v.22, p.79-90, 1996. 
RAUPACH, M.R.; THOM, A.S.; EDWARDS, I. A wind-tunnel study of turbulent flow close to regularly arrayed rough surfaces. Boundary-Layer Meteorology, v.18, p.373-397, 1980.

REDFORD, T.G.; VERMA, S.B.; ROSENBERG, N.J. Humidity fluctuations over a vegetated surface measured with a Lyman-Alpha hygrometer and a fine-wire thermocouple psychrometer. Journal of Applied Meteorology, v.19, p.860-867, 1980.

RIGHI, E.Z.; MARIN, F.R.; ANGELOCCI, L.R.; CICHOTA, R.; FAVARIN, J.L. Efeito da velocidade do vento no deslocamento do plano zero e no comprimento da rugosidade em cafezal em crescimento. In: CONGRESSO BRASILEIRO DE AGrometeOrologiA, 13., Santa Maria, 2003. Anais. Santa Maria: UNIFRA; SBA; UFSM, 2003. p.177-178.

RITCHIE, J.T. Model for predicting evaporation from a row crop with incomplete cover. Water Resources Research, v.8, n.3, 1972.

RITCHIE, J.T.; BURNETT, E. Dryland evaporative flux in a subhumid climate: II. Plant influences. Agronomy Journal, v.63, p.56-62, 1971.

ROSEMBERG, N.J.; BROWN, K.W. "Self-checking” psychrometer system for gradient and profile determinations near the ground. Agricultural Meteorology, v.13, p.215-226, 1974.

ROSEMBERG, N.J.; BLAD, B.L.; VERMA, S.B. Microclimate: the biological environment. 2.ed. New York: John Wiley, 1983. 495p.

SAKURATANI, T. A heat balance method for measuring water flux in the stem of intact plants. Journal of Agricultural Meteorology, v.37, p.9-17, 1981.

SAKURATANI, T. Improvement of the probe for measuring water flow rate in intact plants with the stem heat balance method. Journal of Agricultural Meteorology, v.40, p.273-274, 1984. 
SANTIAGO, A.V. Evapotranspiração de referência medida por lisímetro de pesagem e estimada por Penman-Monteith (FAO-56), nas escalas mensal e decendial. Piracicaba, 2002. 51p. Dissertação (Mestrado) - Escola Superior de Agricultura “Luiz de Queiroz”, Universidade de São Paulo.

SANTINATO, R.; FERNANDES, A.L. Avanços na tecnologia da irrigação na cultura do café. In: SIMPÓSIO DE PESQUISAS DOS CAFÉS DO BRASIL, 1., Poços de Caldas, 2000. Anais. Poços de Caldas: EMBRAPA, 2000. p.355-373

SANTOS, R.Z. dos; ANDRÉ, R. Relações energéticas e aerodinâmicas em uma cultura de feijão. Revista Brasileira de Agrometeorologia, v.1, p.11-18, 1993.

SENOCK, R.S.; HAM, J.M. Heat balance sap flow gauge for small diameter stems. Plant, Cell and Environment, v.16, p.593-601, 1993.

SENTELHAS, P.C.; PEDRO JÚNIOR, M.J.; MARTINS, F.P. Características aerodinâmicas da videira conduzida em espaldeira. Revista Brasileira de Agrometeorologia, v.1, n.1, p.25-30, 1993.

SHAW, R.H.; PEREIRA, A.R. Aerodynamic roughness of a plant canopy: a numerical experiment. Agricultural Meteorology, v.26, p.51-65, 1982.

SILANS, A.P. de; MONTENY, B.A.; LHOMME, J.P. The correction of soil heat flux measurements to derive an accurate surface energy balance by the Bowen ratio method. Journal of Hydrology, v.188-189, p.453-465, 1997.

SILVA, B.B.da; MOURA, M.S. da; AZEVEDO, P.V. de; SOARES, J.M. Medidas de transpiração de um pomar de goiabeiras pelo método do balanço de calor caulinar. Revista Brasileira de Agrometeorologia, v.10, n.1, p.19-27, 2002.

SILVA, B.B. da; SLACK, D.C.; KILBY, M.W.; HLA, A.K. Measurements of water requeriments of table grapes in Arizona (USA). Revista Brasileira de Agrometeorologia, v.8, n.2, p.175-183, 2000.

SIMÕES-MOREIRA, J.R. A thermodynamic formulation of the psychrometer constant. Measurement Science \& Technology, v.10, p.302-311, 1999.

SLAVIK, B. Methods of studying plant water relations. Berlin: Springer-Verlag, 1974. 449p. 
SMITH, D.M.; ALLEN, S.J. Measurements of sap flow in plant stems. Journal of Experimental Botany, v.47, n.305, p.1833-1844, 1996.

SOTO, F.; MORALES, D. Influencia de diferents condiciones climáticas sobre el crecimiento de posturas de cafetos. Cultivos Tropicales, v.14, n.2/3, p.46-51, 1993.

SOTO, F.; MORALES, D. Relación de la temperature del aire, la humedad relative y la radiación global com el crecimiento de plântulas de cafeto. Cultivos Tropicales, v.17, n.3, p.41-44, 1996.

SPITTLEHOUSE, D.L.; BLACK, T.A. Determination of forest evapotranspiration using Bowen ratio and eddy correlation measurements. Journal of Applied Meteorology, v.18, 647-653, 1979.

SPITTLEHOUSE, D.L.; BLACK, T.A. Evaluation of Bowen ratio/energy balance method for determining forest evapotranspiration. Atmosphere Ocean, v.18, 98$116,1980$.

STEARNS, C.R. Conversion of profile difference quotients to true gradients at the geometric mean height in the suface layer. Boundary-Layer Meteorology, v.1, p.146-154, 1970.

STEINBERG, S.; VAN BAVEL, C.H.M.; McFARLAND, M.J. A gauge to measure mass flow rate of sap in stems and trunks of woody plants. Journal of the American Society for Horticultural Sciency, v.114, n.3, p.466-472, 1989.

STULL, R.B. An introduction to boundary-layer meteorology. Dordrecht: Kluwer Academic, 1994. 665p.

SWANSON, R.H.; WHITFIELD, D.W.A. A numerical analysis of heat pulse velocity: theory and practice. Journal of Experimental Botany, v.32, p.231-239, 1981.

TANNER, C.B.; JURY, W.A. Estimating evaporation and transpiration from a row crop incomplete cover. Agronomy Journal, v.68, p.239-243, 1976.

TEIXEIRA, A.H.C.; AZEVEDO, P.V. de; SILVA, B.B. da; SOARES, J.M. Balanço de energia na cultura da videira, cv. "Itália". Revista Brasileira de Agrometeorologia, v.5, n.2, p.137-141, 1997. 
TEIXEIRA, A.H.C.; BASSOI, L.H.; da COSTA, W.P.L.E.B.; MOURA, J.A.; da SILVA, E.E.G. Consumo hídrico da bananeira no Vale do São Francisco estimado pelo método da razão de Bowen. Revista Brasileira de Agrometeorologia, v. 10, n. 1, p.45-50, 2002.

THOM, A.S. Momentum absorption by vegetation. Quarterly Journal of the Royal Meteorological Society, v.97, p.414-428, 1971.

THOM, A.S. Momentum, mass and heat exchange of vegetation. Quarterly Journal of the Royal Meterological Society, v.98, p.124-134, 1972.

THOM, A.S.; STEWART, J.B.; OLIVER, H.R.; GASH, J.H.C. Comparison of aerodynamic and energy budget estimates of fluxes over a pine forest. Quarterly Journal of the Royal Meteorological Society, v.101, p.93-105, 1975.

THORNTHWAITE, C.W.; MATHER, R.J. The water balance. New Gersey: Laboratory of Climatology, 1955. 104p. (Publication in Climatology, 8).

TODD, R.W.; EVETT, S.R.; HOWELL, T.A. The Bowen ratio-energy balance method for estimating latent heat flux of irrigated alfalfa evaluated in a semi-arid, advective environment. Agricultural and Forest Meteorology, v.103, p.335-348, 2000.

TYAGI, N.K.; SHARMA, D.K.; LUTHRA, S.K. Determination of evapotranspiration and crop coefficients of rice and sunflower with lysimeter. Agricultural and Water Management, v.45, p.41-54, 2000.

UNLAND, H.E.; HOUSER, P.R.; SHUTTLEWORTH, W.J.; YANG, Z. Surface flux measurement and modeling at a semi-arid Sonoran Desert site, Agricultural and Forest Meteorology, v.82, p.119-153, 1996.

VALANCOGNE, C.; NASR, Z. Measuring sap flow in the stem of small trees by a heat balance method. HortScience, v.24, n.2, p.383-385, 1989.

VAN BAVEL, M.G. Flow 32 ${ }^{\text {tm }}$ installation and operation manual version 2.11 software, Houston: Dynamax, 1994. 184p.

VERMA, S.B.; ROSEMBERG, N.J.; BLAD, B.L. Turbulent exchange coefficients for sensible heat and water vapor under advective conditions. Journal of Applied Meteorology, v.17, p.330-338, 1978. 
VIEIRA, D. Gotejamento: nova perspectiva para a cafeicultura. A Granja, Porto Alegre, ago. 1979, p.38-42.

VILLA NOVA, N.A. Estudos sobre o balanço de energia em cultura de arroz. Piracicaba, 1973. 89p. Tese (Livre-Docência) - Escola Superior de Agricultura “Luiz de Queiroz”, Universidade de São Paulo.

VILLA NOVA, N.A.; FAVARIN, J.L.; ANGELOCCI, L.R.; DOURADO NETO, D. Estimativa do coeficiente de cultura do cafeeiro em função de variáveis climatológicas e fitotécnicas. Bragantia, v.61, n.1, p.81-88, 2002.

VISSCHER, G.J.W. Standard psychrometers: a matter of (p)references. Measurement Science \& Technology, v.6, p.1451-1461, 1995.

VOGT, R.; JAEGER, L. Evaporation from a pine forest - using the aerodynamic method and Bowen ratio method. Agricultural and Forest Meteorology, v.50, p.39-54, 1990.

WALLIS, J.A.N. Water use by irrigated Arabica coffee in Kenya. Journal of Agricultural Science, v.60, n.381, p.381-388, 1962.

WEBB, E.K. Profile relationships: the log-linear range, and extension to strong stability. Quarterly Journal of the Royal Meteorological Society, v.96, p.67-90, 1970.

WEIBEL, F.P.; DE VOS, J.A. Transpiration measurements on apple trees with an improved stem heat balance method. Plant and Soil, v.106, p.203-219, 1994.

WIERINGA, J. Representative roughness parameters for homogeneous terrain. Boundary-Layer Meteorology, v.63, p.323-363, 1993.

WILTSHIRE, J.J.J.; WRIGHT, C.J.; COLLS, J.J.; UNSWORTH, M.H. Effects of heat balance stem-flow gauges and associated silicone compound on ash trees. Agricultural and Forest Meteorology, v.73, p.135-142, 1995.

WRIGHT, J.L. Using weighing lysimeters to develop evapotranspiration crop coefficients. In: ALLEN, R.G.; HOWELL, T.A.; PRUITT, W.O.; WALTER, I.A.; JENSEN, M.E. Lysimeters for evapotranspiration and environmental measurements. New York: American Society of Civil Engineers, 1991. p.191-199. 
YUNUSA, I.A.M.; SEDGLEY, R.H.; BELFORD, R.K.; TENNANT, D. Dynamics of water use in a dry Mediterranean environment: I. Soil evaporation little affected by presence of plant canopy. Agricultural and Water Management, v.24, p.205-224, 1993a.

YUNUSA, I.A.M.; SEDGLEY, R.H.; TENNANT, D.; BELFORD, R.K. Dynamics of water use in a dry Mediterranean environment: II. A test of four evaporation moels using microlusimetry under spring wheat. Agricultural and Water Management, v.24, p.225-238, 1993 b. 